\title{
Abastecimento Alimentar
}

Redes Alternativas e Mercados Institucionais
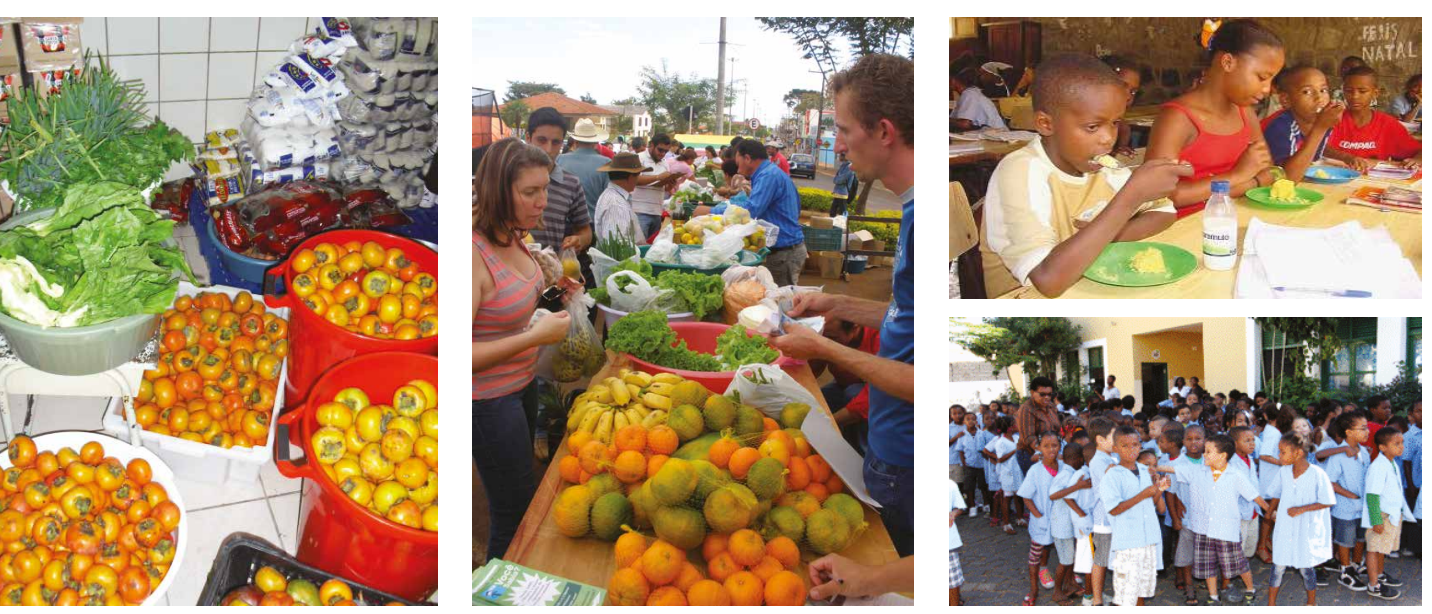

ORGANIZADORES

Julian Perez-Cassarino

Rozane Marcia Triches

Jose Giacomo Baccarin

Carla Rosane Paz Arruda Teo

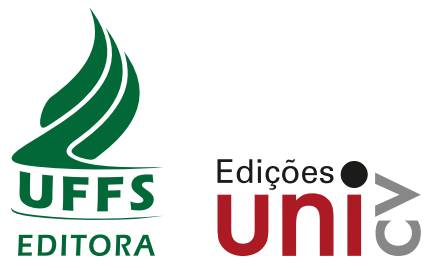



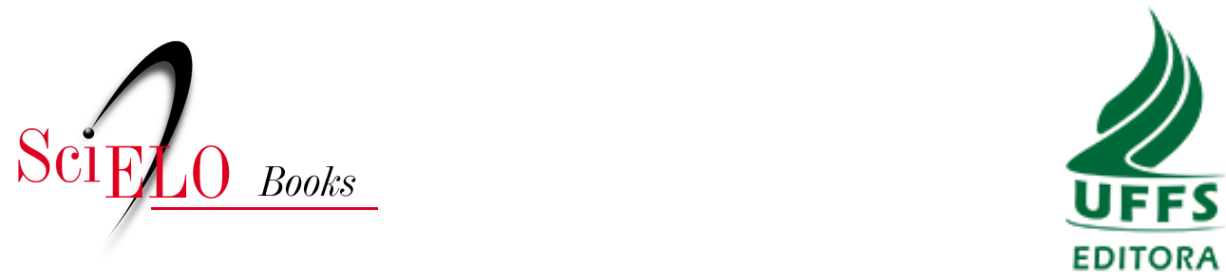

\title{
Abastecimento alimentar redes alternativas e mercados institucionais
}

\author{
Alberto Gómez Perazzoli \\ Inés Gazzano \\ Analía Cartelle \\ Federico Bizzozero \\ (orgs.)
}

\section{SciELO Books / SciELO Livros / SciELO Libros}

PEREZ-CASSARINO, J., TRICHES, R.M., BACCARIN, J.G., and TEO, C.R.P.A., eds. Abastecimento alimentar: redes alternativas e mercados institucionais [online]. Chapecó: Editora UFFS; Praia, Cabo Verde: UNICV, 2018,322 p. ISBN: 978-85-64905-72-6.

https://doi.org/10.7476/9788564905726.

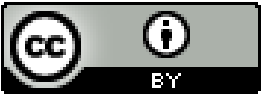

All the contents of this work, except where otherwise noted, is licensed under a Creative Commons Attribution 4.0 International license.

Todo o conteúdo deste trabalho, exceto quando houver ressalva, é publicado sob a licença Creative Commons Atribição 4.0. 


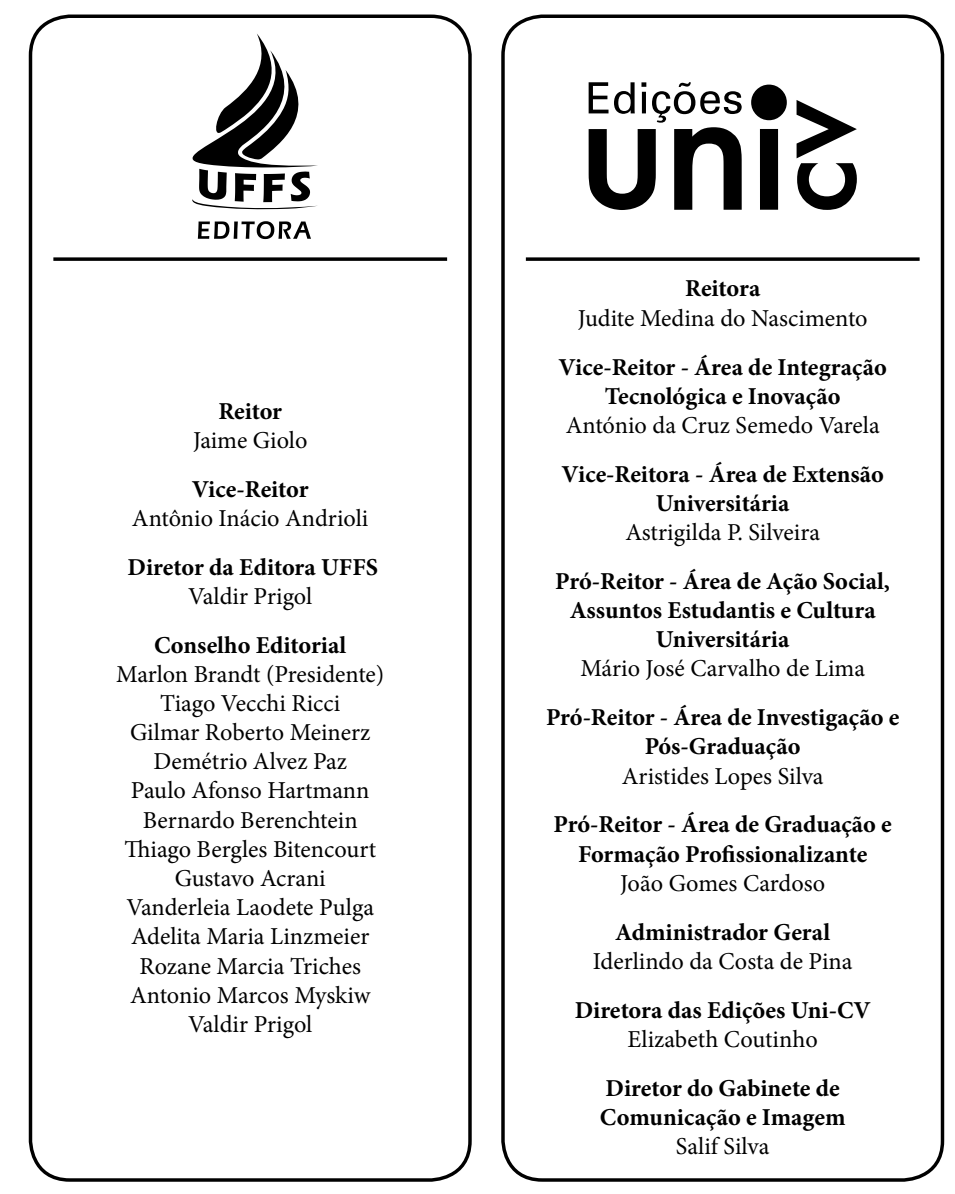

\section{Editora UFFS}

Av. Fernando Machado, $108 \mathrm{E}$

Centro, Chapecó, SC - Brasil

Caixa Postal 181 - CEP 89802-112

Telefone: (49) 2049-3100

CNPJ 11.234.780/0001-50

\section{Edições Uni-CV}

Praça Dr. António Lereno, s/n

Caixa Postal 379-C Praia,

Santiago - Cabo Verde

Tel. (+238) 3340 441; Fax: (+238) 2612660

edicoes@adm.unicv.edu.cv - www.unicv.edu.cv 
TÍTULO Abastecimento Alimentar:

Redes Alternativas e Mercados Institucionais

ORGANIZADORES Julian Perez-Cassarino; Rozane Marcia Triches; Jose Giacomo Baccarin; Carla Rosane Paz Arruda Teo

REVISÃO Marlei Maria Diedrich

PROJETO GRÁFICO Mariah Carraro Smaniotto

CAPA \& DIAGRAMAÇÃO Edson Carvalho | GCI - Gabinete de Comunicação e Imagem da Uni-CV

IMPRESSÃO Gráfica Editora Palloti

TIRAGEM 1000 exemplares

FORMATOS Impresso, ePub, mobi e PDF

COORDENAÇÃO Elizabeth Coutinho, Direção dos Serviços de Documentação e

EDITORIAL Edições da Uni-CV e Fabiane Sulsbach, Chefe do Serviço Especial de Publicações Editoriais da UFFS

COPYRIGHT (C) Universidade de Cabo Verde, Universidade Federal da Fronteira Sul, organizadores e autores dos artigos

Acordo de cooperação para coedição de obra 01/2018 Editora UFFS e Edições Uni-CV

PRAIA, AGOSTO DE 2018

A118 Abastecimento alimentar e mercados institucionais. / Org. Julian Perez-Cassarino ... [et al]. -- Chapecó: Ed. UFFS; Praia, Cabo Verde: UNICV, 2018. - 322 p.: il.

Acordo de cooperação para coedição de obra Editora UFFS e Edições Uni-CV.

ISBN (Editora UFFS): 978-85-64905-71-9 (e-book).

ISBN: 978-85-64905-72-6 (e-pub)

ISBN: 978-85-64905-70-2 (mobi)

ISBN: 978-85-64905-73-3 (impresso)

ISBN (Edições Uni-CV) Impresso: 978-989-8707-47-5

Eletrónico: 78-989-8707-48-2 (Edições Uni-CV)

1. Agricultura familiar - Brasil. 2. Sistemas alimentares sustentáveis. 3. Abastecimento de alimentos. 4. Alimentação escolar - Brasil. 5. Agroecologia - Brasil. 6. Agroecologia - Uruguai 7. Produção de Alimentos - Modelos alternativos - Cabo Verde. 8. Abastecimento de alimentos. I. PerezCassarino, Julian. II. Universidade Federal da Fronteira Sul. III. Universidade do Cabo Verde.

CDD 338.19

630.2745

Ficha catalográfica elaborada pela

Divisão de Bibliotecas - UFFS

Nelcy T. da Rosa Kegler CRB - 14/1311 


\section{Sumário}

\section{PREFÁCIO}

Nilson Maciel de Paula

\section{APRESENTAÇÃO}

Os organizadores.

\section{PARTE 1 - O ABASTECIMENTO NA PERSPECTIVA DE SISTEMAS ALIMENTARES SUSTENTÁVEIS}

Por uma nova ciência para a promoção de sistemas alimentares sustentáveis

Cecilia Rocha

Análise da transição ecológica de sistemas agrialimentares territoriais: ensinamentos de uma comparação franco-brasileira

Claire Lamine; Giles Maréchal; Moacir Darolt.

Equipamentos públicos de Abastecimento Alimentar no Brasil:

trajetória e desafios

Walter Belik; Altivo R. A de Almeida Cunha

\section{PARTE 2 - MERCADOS INSTITUCIONAIS}

Aquisição de produtos da agricultura familiar para a alimentação escolar nos estados de São Paulo, Paraná, Santa Catarina e Rio Grande do Sul Rozane Marcia Triches; José Giacomo Baccarin; Carla Rosane Paz Arruda Teo;

Dificuldades e recursos de superação mobilizados por atores sociais na aquisição de produtos da agricultura familiar para a alimentação escolar nos estados de São Paulo, Paraná, Santa Catarina e Rio Grande do Sul Rozane Marcia Triches; Jose Giacomo Baccarin; Oscar Agustín Torres Figueredo; Aline Luiza Führ; Márcia Pozzagnol Mossmann; Denise Boito Pereira da Silva; Dienifer Heckler; 
Agricultura e mercados institucionais em Cabo Verde: avaliação e seguimento do programa-piloto "compras locais"

Vladmir Antero Delgado Silves Ferreira; Elsa Barbosa Simões

Compras institucionales: estado del arte del proceso uruguayo

Adriana Machado; Alejandro Pizzolon; Jorge Vaz Tourem.

Programa Nacional de Alimentação Escolar e o atendimento à cultura alimentar em municípios do Paraná

Carmine Marcon Piano; Camila Elizandra Rossi.

Grau de processamento dos gêneros alimentícios solicitados aos agricultores familiares para a alimentação escolar e a adequação das chamadas públicas: um estudo realizado nos estados de São Paulo, Santa Catarina e Paraná Cassiani Gotâma Tasca; Suélen Regina Lothermann

Programa de Aquisição de Alimentos e diversificação: possibilidades para a recampesinização e suas limitações estruturais

André A. Michelato Ghizelini.

Os (des)caminhos do Programa de Aquisição de Alimentos na região semiárida: novas governanças, antigas armadilhas

Cimone Rozendo

Compra institucional de alimentos: uma estratégia para impulsionar sistemas alimentares saudáveis e sustentáveis

Panmela Soares; Rafaela Karen Fabri; Suellen Secchi Martinelli; Vitória Uliana Bianchini;

Suzi Barletto Cavalli.

\section{PARTE 3 - FORMAS ALTERNATIVAS DE ABASTECIMENTO}

Grupos de consumo responsável no Brasil: aproximando consumidores e produtores em redes agroecológicas e solidárias

Juliana Gonçalves; Thais Mascarenhas

Rede Ecovida de Agroecologia: origens, princípios

e sua concepção de comercialização

Julian Perez-Cassarino; Laércio Meirelles

Comercialización y agroecología en Uruguay

Alberto Gómez Perazzoli; Inés Gazzano; Analía Cartelle; Federico Bizzozero 
Este livro é dedicado à Fabia Sowa Koziel, agricultora ecologista e geógrafa que dedicou sua vida à luta por um planeta mais justo e sustentável. 


\section{PREFÁCIO}

\section{Nilson Maciel de Paula}

Mais do que um fato momentâneo, a crise alimentar do início do milênio, que levou mais de um bilhão de pessoas à condição de fome e subnutrição, revelou a essência da ordem alimentar global contemporânea. Como expressão de uma tendência em curso desde o início da década de 1970, aquela conjuntura de instabilidades explicitou mais claramente os traços estruturais de um sistema alimentar formado sob a égide das grandes corporações e regulado por uma intensa liberalização dos mercados. Tendo por referência a noção de regime alimentar corporativo financeiro, formulada por Phillip McMichael em suas valiosas interpretações sobre o regime alimentar atual, a alimentação se tornou um campo de sinergia entre capitais situados na indústria processadora, no sistema financeiro, pela conversão de alimentos em derivativos, e no sistema energético pelo uso de alimentos para obtenção de biocombustíveis. Mais ainda, não apenas a comercialização do alimento se dá na interface entre esses sistemas, mas o próprio capital se metamorfoseia assumindo posições em todas as frentes. Ou seja, empresas financeiras investem no comércio de alimentos e compra de terras, assim como empresas agroindustriais se envolvem em operações financeiras e investem na produção de biocombustível. Em suma, os capitais comercial, agroindustrial e financeiro se fundem na simbiose entre sistemas originalmente distintos, na qual os alimentos, convertidos em commodities, são consumidos ou processados de acordo com as expectativas de lucro e com as exigências impostas pelo processo de acumulação. Mais do que de abastecerem o mercado mundial de alimentos, o agronegócio e agricultura de alta escala, estão conectados àquela simbiose e, portanto, sujeitos às suas vicissitudes.

Por outro lado, paralelamente à ampla capilaridade de uma estrutura industrial e varejista oligopolizada, conectando espaços produtivos a um mercado global 
e estimulando o consumo de alimentos processados, um estado de insegurança alimentar se propaga mundialmente, tanto em regiões pobres quanto no interior de sociedades afluentes do mundo desenvolvido. Apesar da redução do número de famintos e subnutridos nos anos recentes, ainda é considerável o contingente populacional sem o acesso adequado aos alimentos, em termos quantitativos e qualitativos. A deterioração das condições de abastecimento alimentar passou a ocorrer tanto do ponto de vista da redução do poder de compra e insuficiência de oferta, quanto pela maior ingestão de produtos industrializados, cujo efeito mais dramático se manifesta no número de pessoas obesas ou com sobrepeso, o qual, tendo já dobrado entre 1980 e 2014, deve atingir mais 2,7 bilhões de pessoas em 2025, um terço da população mundial, segundo informa a World Obesity Federation. Tal fenômeno é mais preocupante quando detectado em países do continente africano, onde o número de crianças com idade inferior a cinco anos com sobrepeso ou obesas correspondem a quase um terço de um total mundial de 41 milhões, tendo aumentado em aproximadamente 50\% desde 2000, segundo dados da Unicef. Impulsionada por variação positiva na renda de determinados segmentos sociais, essa tendência tem sido acompanhada por deficiências nutricionais que comprometem o crescimento, as quais estão associadas à substituição de alimentos naturais de origem local por produtos processados. Mais ainda, numa replicação do que ocorre mundialmente, essa alteração não pode ser explicada sem levarmos em conta o contato da população africana com os grandes supermercados globalizados, linha de frente da difusão de novos produtos que facilmente se tornam objeto de desejo dos consumidores, oriundos de uma indústria processadora também globalizada. Portanto, subnutrição deixa de ser apenas um sintoma de escassez e passa a ser consequência também do excesso e da alteração do padrão de consumo.

Num plano mais geral, os sinais incontestáveis de insegurança alimentar são reverberações da essência do capitalismo neoliberal, no qual o papel regulador do Estado foi substituído pelo autocontrole do mercado, sob os falsos pretextos da eficiência e da capacidade de promover crescimento. Na realidade, as consequências do empobrecimento do trabalho e do desmonte de mecanismos de proteção social como alavancas competitivas nos mercados globais repercutiram diretamente na precarização das condições de vida, paralela à maior concentração de renda e riqueza. Se por um lado, as oito pessoas mais ricas do planeta detêm riqueza equivalente à da metade da população mundial, por outro mais de $70 \%$ 
vivem desprovidos dos serviços básicos de proteção social. Diante desse quadro, governos nacionais são intencionalmente fragilizados através de ajustes estruturais para reduzir o Estado ao mínimo, ao mesmo tempo em que se rendem à falaciosa superioridade da lógica do mercado. Assim, não se trata mais de uma oposição entre Estado e mercado, como visões maniqueístas sugerem, mas de uma unicidade entre os dois, na qual o primeiro se coloca a serviço do segundo.

Nesse contexto, preocupações com segurança alimentar e nutricional passaram a exigir políticas de governos capturados pela falácia da eficiência dos mercados, a compor documentos de organismos multilaterais, e até mesmo a atrair o interesse de grandes corporações orientadas pela questionável necessidade de aumento de oferta. $\mathrm{O}$ entendimento de que o combate à fome requer maior produção preserva as bases da ordem alimentar, abrindo novas oportunidades para o grande capital encrustado numa espécie de reedição da revolução verde e validando uma governança formada pela liberalização dos mercados como vasos comunicantes entre situações de excesso e de escassez. Encobre-se assim a entropia desse sistema e suas contradições estruturais, através de uma agenda hegemônica orientada pela superficial relação entre oferta e demanda e pelo estímulo à propagação de tecnologias de alto rendimento, inclusive, nas áreas rurais mais vulneráveis. A inocuidade daquele receituário é observada nos discursos oficiais e de organizações, de baixa repercussão prática, amparados apenas por ações filantrópicas embutidas em programas de ajuda alimentar, incapazes de alterar o quadro de dependência de muitos países e de atingir os reais determinantes do agravamento da insegurança alimentar. Entretanto, ir além de soluções tópicas e panaceias elusivas envolve ampliar o campo de observação para além da alimentação, para o que é preciso entender que a fome está diretamente associada ao aprofundamento das desigualdades sociais e aumento da pobreza. $\mathrm{Ou}$ seja, os processos de distribuição de renda e riqueza estão na raiz dos problemas alimentares, tanto no que diz respeito ao limitado acesso quanto ao maior interesse pelos produtos processados, cujos atrativos, enaltecidos pelas estratégias de publicidade, estão no baixo preço, na facilidade de consumo, na aparência e no imponderável apelo de modernidade. Os efeitos nutricionais são negligenciados ou camuflados, contribuindo para o distanciamento do alimento de sua condição natural e de sua importância para o ser humano.

A partir dessas observações, entende-se que a insegurança alimentar não se constitui uma falha de mercado ou um desajuste temporário do sistema, passível 
de correção a partir de sua própria dinâmica. Ou seja, a questão alimentar, como caracterizada anteriormente, está na própria essência do sistema alimentar, cuja solução exige o rompimento de paradigmas e transformações estruturais capazes de reorientar as tendências em curso e um confronto aos interesses dominantes. Dessa forma, não é possível esperar dos agentes hegemônicos mudanças que coloquem o sistema em sintonia com a segurança alimentar e nutricional. O desafio ao status quo tem sido feito, na realidade, por movimentos sociais engajados na construção de uma agenda contra-hegemônica de contestação, de formulação de políticas e de iniciativas locais para o fortalecimento das comunidades para controle de seus recursos, recuperação de tecnologias e práticas autóctones agroecológicas, e formação de redes locais de abastecimento. Esse é o caminho rumo à noção de soberania alimentar, formulada pela Via Campesina, cuja atuação tem dado visibilidade global à necessidade de resgatar o sentido da alimentação como direito humano e de reativar campanhas pela reforma agrária como condição para fortalecer a agricultura familiar camponesa de forma, a alterar a correlação de forças no interior do sistema alimentar e proporcionar maior dinamismo às comunidades locais frente aos grandes mercados. Entretanto, o aprofundamento das mazelas sociais no contexto do capitalismo neoliberal nos leva à conclusão de que soluções para o paroxismo da insegurança alimentar só serão bem sucedidas na medida em que o caminho rumo a uma sociedade mais justa e igualitária tenha sido efetivamente trilhado.

Simultaneamente, cabe aos estudiosos da questão alimentar e representantes dos movimentos sociais não apenas identificar criticamente os determinantes da insegurança alimentar e as estratégias de usurpação, pelos agentes dominantes, de bandeiras e proposições alternativas. Mais do que isso é preciso desvendar perspectivas que emergem da sociedade civil e de instituições envolvidas na construção de uma via alternativa que se materialize numa agenda sólida de segurança alimentar desafiadora e capaz de mitigar os efeitos nocivos da ordem alimentar atual. A organização deste livro é uma iniciativa de grande relevância nessa perspectiva, por colocar o tema do abastecimento alimentar sob uma ótica que difere das abordagens convencionais voltadas para a organização dos mercados, posição dos agentes comerciais, e para a conexão mercantil entre produtores e consumidores. Ou seja, não se trata de uma discussão sobre as possibilidades de disciplinar ou dar maior eficiência à estrutura atacadista e varejista, mas sobre estratégias e políticas formuladas para atender as populações mais vulneráveis 
através de redes alternativas, com base nas quais é possível passar ao largo da centralidade dos mercados estruturados sob o comando das grandes corporações.

Este trabalho contém uma sequência de temas articulados de forma bastante coerente cujo ponto de partida é uma avaliação da evolução do sistema alimentar, com ênfase em sua frágil sustentabilidade. Tendo em vista os processos de deterioração ambiental combinada com a propagação da fome e precarização das relações de trabalho, os desafios para a construção de um sistema alimentar sustentável se multiplicam, demandando uma visão capaz de reunir os diferentes campos disciplinares para radiografar a anatomia das estruturas de poder e traçar perspectivas de mudança. Tal discussão implica a construção de um novo campo de referência, no qual estão contemplados o engajamento da sociedade civil, a viabilização de sistemas produtivos agroecológicos com destaque para o sistema de certificação através da Rede Ecovia, e ação dos governos nacional e locais por meio de políticas públicas de abastecimento e de organização de mercados institucionais. As experiências de Cabo Verde, França e Uruguai, tratadas em diferentes capítulos, permitem uma avaliação comparativa entre países de temas relacionados às políticas governamentais de abastecimento e às iniciativas da sociedade civil e comunidades rurais para organizar circuitos alternativos de comercialização.

Do ponto de vista da avaliação de políticas públicas de abastecimento, tanto o Programa Nacional de Alimentação Escolar como o Programa de Aquisição de Alimentos são amplamente discutidos em vários capítulos, com destaque para os impactos positivos na agricultura familiar e junto aos consumidores carentes urbanos e crianças em idade escolar. Tal discussão, cobrindo vários estados brasileiros, embora não ignore as falhas e as fragilidades de tais programas, os trata como estratégicos para uma agenda contra hegemônica, através dos quais uma dieta natural e saudável é possível, baseada em produtos obtidos localmente. Com isso, torna-se possível não apenas fortalecer a agricultura familiar e práticas agroecológicas, mas também circuitos curtos daí derivados, além de valorizar referências culinárias baseadas em produtos locais. Novamente, as análises sobre políticas similares implementadas em Cabo Verde e no Uruguai trazem elementos que contribuem para a avaliação dos rumos tomados por aqueles programas no Brasil e a possibilidade de corrigi-los.

Mais do que expor o alcance das políticas públicas e mostrar as deficiências existentes nas estruturas de abastecimento, as análises aqui reunidas explicitam o 
protagonismo de atores sociais e suas organizações na construção de um caminho alternativo ao dos grandes mercados, entre a produção de alimentos, social e ecologicamente sustentável, e a sociedade consumidora, excluída daqueles. E mais, o resgate de cardápios e hábitos tradicionais, na esteira de uma valorização de sistemas alimentares locais, constitui uma ferramenta importante para uma reflexão que contribua para um estado inclusivo e amplo de segurança alimentar e nutricional. Portanto, a diversidade de temas discutidos complementa de forma plena e adequada o texto de apresentação e os capítulos que abrem essa rica discussão que mostra as contradições do sistema agroalimentar global e as alternativas possíveis para sua transformação. 


\section{APRESENTAÇÃO}

A partir dos quatro últimos séculos, mais intensamente nos últimos 100 anos, a alimentação e a agricultura passaram a ser organizadas em escala mundial. A especialização da produção agrícola estendida entre continentes abriu um vasto espaço entre o local onde as pessoas vivem e a origem dos produtos que consomem, entre o trabalho que realizam e os objetos que utilizam. Segundo Friedmann (1993), as relações entre as pessoas e entre as pessoas e o seu território tornam-se organizadas em uma escala para além da observação direta, o que para a autora foi um divisor de águas na história humana.

Central nesta reflexão é a percepção de que as mudanças demográficas, sociais, econômicas e políticas que se deram concomitantemente foram acompanhadas por uma tendência ascendente de deslocamento entre a produção de alimentos e o seu consumo. Se em uma sociedade tradicional e culturalmente mais fechada esse processo é estritamente localizado, em uma sociedade moderna e contemporânea já não há delimitação de espaço nem de tempo. Os alimentos tornam-se mercadorias e, como tais, são tratados, buscando a sua durabilidade, sua desterritorialização, apropriando-se do seu caráter "natural" e substituindo-os. A técnica e a ciência a favor da industrialização da natureza e dos modelos econômicos e políticos tornam-se interventoras, mediadoras, e compõem vários elos que distanciam o consumidor daquilo que consome, o produtor daquilo que produz, transformando-os - consumidores e produtores - num sistema abstrato e com mútuo desconhecimento. Esse distanciamento não ocorreu sem prejuízos para ambas as partes e para a natureza.

Já em 1993, Friedmann frisava que a localização e a sazonalidade constituiriam uma solução promissora e pontuava dois movimentos importantes na desestabilização do sistema alimentar dominante: um baseado em consumidores cidadãos urbanos interessados em promover produções sustentáveis, diversificadas e locais; outro, baseado no empobrecimento e na marginalidade impostos 
por turbulentas mudanças nos mercados e nos imperativos de exportação que faziam as pessoas despossuídas agirem com criatividade e energia na busca de suas próprias soluções.

Relativo ao primeiro movimento, um novo ator, até então desconsiderado, tem sido o foco dos interesses. Para Goodman (2002; 2004) e Goodman e DuPuis (2002), o consumidor parece estar com o poder na condução das indústrias e dos varejos de alimentos e, portanto, a sua relação com a produção passa a ser preponderante. A preocupação em relação ao consumo nos estudos agroalimentares toma corpo e passa a reconhecer-se o alimento como muito mais que apenas uma mercadoria como outra qualquer.

Seja pelo fato de ser uma reação aos riscos atribuídos às questões de saúde e estética e instabilidade quanto às prescrições dietéticas, seja uma reação aos medos alimentares ou, ainda, uma preocupação quanto às questões ecológicas, parece ocorrer uma desconfiança por parte do consumidor no que não conhece ou uma inabilidade para entender ou avaliar os riscos. Portanto, a revisão dos conceitos de qualidade alimentar, o retorno ou resistência das tradições e a busca do reconhecimento do que se consome e de quem produz configuram uma tendência de releitura dos processos dominantes e do encurtamento da cadeia de abastecimento alimentar.

No que diz respeito ao segundo movimento citado por Friedmann (1993), Van Der Ploeg et al. (2000) relacionam a emergência de um novo modelo de desenvolvimento rural com a resposta ao "squeeze"1 promovido pela modernização da agricultura. Para esses autores, nos anos 1990, começa-se a sentir muito fortemente os custos dessa modernização no que tange às despesas monetárias associadas com o crescimento da necessidade de recursos externos e com tecnologias novas e mais caras, além dos custos de transação e de energia intrínsecos às regulamentações e investimentos obrigatórios. Esse aumento dos custos da produção inviabilizaria a atividade por não compensar os preços de venda, demandando estratégias criativas e inovadoras para diminuir os gastos e otimizar os ganhos.

Nesse sentido, os agricultores buscariam maior autonomia a partir da redefinição de relações e interações com os espaços sociais e o ambiente institucional, buscando formas diversificadas de reação e inovação (WISKERKE; VAN DER

1 Segundo os autores citados, squeeze se refere ao ganho cada vez menor sobre a produção agrícola pelos agricultores, ficando a maior parte dos lucros para as empresas à jusante e à montante. 
PLOEG, 2004). Amin e Cohendet (2004) remetem os processos de inovação e desenvolvimento tecnológico à imersão (embeddedness) em contextos sociais, e a invenção e a criatividade como sendo frutos de um intenso processo de interação e troca de experiências a partir de situações práticas e contingentes. Esses processos seriam, em última instância, soluções criativas e inovadoras que os agricultores utilizariam para enfrentar problemas complexos. Exemplo disso seriam as estratégias de venda direta ao consumidor de produtos "diferenciados", resultando na agregação de valor ao produto e diminuição dos custos de produção e transação comparativamente ao seu alinhamento às cadeias longas de abastecimento.

A junção desses movimentos seria o reflexo de uma pressão material sofrida por diferentes grupos de atores que, em face da incerteza e da adversidade, tentam alguma coisa diferente para sobreviverem ou para "melhor viverem", o que coloca o desafio sobre como desenvolver políticas e regulações que possam assistir seu desenvolvimento.

Em termos regulatórios, aponta Marsden (2003), verifica-se que a evolução para um novo sistema alternativo alimentar não é uma contradição binária entre industrial e alternativo, mas, sim, um sistema convencional de políticas lutando contra si próprio como tentativa de acomodar mais demandas externas e políticas. Para Friedmann (1993), embora a regulação nacional esteja em crise com o regime que sustenta, as nações ainda são o lócus das decisões políticas que estruturam as relações agroalimentares. Porém, sua autonomia é desafiada pelo capital transnacional e pelas instituições e ideologias que promovem a desregulação e o distanciamento do Estado. Para Bonanno (1994), o Estado passa a ter uma ação convergente, mas contraditória. Se por um lado ele protege os interesses da burguesia transnacional, por outro, ele também tenta defender os interesses das classes subordinadas. Então, ambas postulariam a manutenção do Estado, mas motivadas por diferentes e antagônicas razões.

Diante desses três processos ou grupos de atores que se constituem por consumidores, produtores e Estado, é que a cadeia alimentar passa a ser reavaliada. No Reino Unido, a Comissão Política Governamental do Futuro da Agricultura e dos Alimentos encoraja a noção de reconexão da cadeia alimentar como a reconexão dos agricultores com a indústria de alimentos, com o mercado e com o meio rural, e dos consumidores com o que eles consomem e como esse alimento é produzido (CURRY REPORT, 2002 apud ILBERY et al., 2005). Nesse 
contexto, o processo de reaproximação, implicando o reconhecimento da ruptura e da desconexão na cadeia alimentar, apoia a ideia da sobrevivência agrícola e da restauração da confiança na produção de alimentos pelo consumidor, mediante cadeias curtas de abastecimento pautadas em novas concepções e construções de qualidade - "quality turn" (GOODMAN, 2003).

Isso tem resultado em uma maior complexidade dos processos de produção e consumo de alimentos e as interconexões entre eles. Para Slee e Kirwan (2008), intrínseca a esta complexidade está a construção e a mediação de valores ligados à combinação dos processos de "consumption" e "quality turns". Esses assim chamados "turns" ou revisão/revalorização de certos aspectos da qualidade dos alimentos e do papel do consumidor, reconhecem o impacto das novas dinâmicas no desenvolvimento de cadeias alimentares particulares. Essas dinâmicas incluem a crescente importância da localização da produção como forma de valorizar localmente ativos específicos; a necessidade de reconhecer a "natureza" nos processos de produção de alimentos, em vez de simplesmente vê-la como um ônus a ser superado; as preocupações dos consumidores sobre determinados aspectos da cadeia de abastecimento alimentar, com construções de valor cada vez mais complexas; e o reconhecimento da contribuição da agricultura e seu aspecto multifuncional para o desenvolvimento rural.

É mediante essa complexidade que alguns autores (VAN DER PLOEG et al., 2000; MARSDEN et al., 2000; MARSDEN, 2003) vêm defendendo a mudança paradigmática da modernização agrícola para a do desenvolvimento rural, que substituiria teórica, prática e politicamente o anterior. Além dos "turns" do consumo e da qualidade, outra motivação para esse processo estaria nas estratégias, nas práticas, nas identidades, nas políticas, nas instituições e nas novas redes incorporadas ao rural. As cadeias de abastecimento alimentar projetam-se como dimensões-chave nos novos padrões emergentes de desenvolvimento rural. Para Marsden et al. (2000), entender a criação, a operação e o desenvolvimento dessas novas cadeias é significativamente importante para abordar esses aspectos referentes ao novo paradigma.

Por sua vez, para poder caracterizar uma cadeia curta como existente, segundo Marsden (2003), ela teria de ter a habilidade de engendrar alguma forma de conexão entre o consumidor e o produtor. Não necessariamente ela estaria relacionada ao tempo e à distância percorrida, mas ao fato de o produto chegar ao consumidor embebido de informação, dando-lhe condições de fazer conexões 
e associações com um mínimo de dados sobre o lugar e o espaço onde foi produzido, os valores e as pessoas envolvidas e os métodos empregados. Opera-se com o princípio de que quanto mais "imerso" em um sistema de valores e práticas específicas um produto venha a ser, mais escasso ele é no mercado pela distinção de suas qualidades e proveniência.

A natureza dessas ações enfatiza o engajamento de comunidades e de iniciativas locais que chamam a atenção para o componente social da ação econômica e da construção de novos mercados. Dessa forma, pontua-se que analisar a formação dos mercados pelo viés estritamente econômico é incorrer no erro de uma análise simplista. Teóricos sociais, como Polanyi (1980) e Granovetter (1985), argumentam que os processos sociais são mediadores das operações de mercado, e que valores, regras, laços e inter-relações são importantes na definição das transações econômicas. O local passa a ser uma categoria importante na análise, por ser delimitado e caracterizado por ambientes sociais e culturais, com específicos significados, práticas e valores, diferentemente da escala global. Assim, as cadeias localizadas teriam o papel de conexão social, em que a confiança e a reciprocidade demarcariam essas relações (HINRICHS, 2000).

Nesse incentivo às novas relações, em que se passa a considerar não somente a competitividade e o livre comércio, mas também as questões sociais e de sustentabilidade, o Estado teria o poder de intervenção e regulação. Dessa forma, as compras públicas de alimentos para programas governamentais seriam exemplo de incentivo à outra forma de desenvolvimento, o que Morgan (2006) classificaria como democracia ecológica de um "Green State".

Ao localizar as compras públicas, encurtando a cadeia alimentar, a intervenção estatal seria uma resposta aos problemas relativos aos pequenos agricultores e aos consumidores, pondo ênfase na sustentabilidade e na saúde pública.

Resumidamente, o novo paradigma de desenvolvimento rural corresponderia a um modelo mais endógeno, territorializado e ecologicamente enraizado; as redes agroalimentares alternativas seriam inovações precursoras dessa mudança paradigmática. Essas redes alternativas seriam caracterizadas por relações de consumo e produção diferenciadas, em mecanismos institucionais de governança rural e em seu potencial de fortalecer o desenvolvimento econômico rural.

É na esteira dessas reflexões e com a pretensão de enfatizar essas formas alternativas de abastecimento que este livro foi organizado. Ele foi produto de pesquisas realizadas sobre esta temática pelos organizadores e autores que $o$ 
compõem ${ }^{2}$. Divide-se em três seções. A primeira trata de introduzir as discussões sobre a sustentabilidade do sistema alimentar, as formas alternativas de abastecimento e as políticas brasileiras para o setor. A segunda dedica-se aos mercados institucionais, principalmente o caso do Programa Nacional de Alimentação Escolar e do Programa de Aquisição de Alimentos e experiências nesse sentido em Cabo Verde e Uruguai. A terceira parte, que encerra a obra, traz experiências brasileiras e uruguaias de redes alternativas de abastecimento alimentar.

No primeiro capítulo, Cecilia Rocha inicia a obra enfatizando a sustentabilidade dos sistemas alimentares, apontando para as inflexões do atual sistema dominante e a importância de como fazer para promover mudanças. No centro de suas atenções estão os atores sociais, o Estado e a própria Ciência, elementos-chave nesta intenção.

O segundo capítulo da primeira seção, escrito por Claire Lamine, Iles Marechal e Moacir Roberto Darolt, traz uma análise retrospectiva e também atual das dinâmicas do sistema agroalimentar, considerando as experiências sobre circuitos curtos de comercialização do Brasil e da França.

Encerrando esta seção, Walter Belik e Altivo Almeida Cunha tecem um histórico das políticas públicas relativas ao abastecimento no Brasil, considerando as transformações recentes e suas adaptações a partir dos momentos geracionais dos mercados.

Abrindo a segunda seção desta obra, dois capítulos foram elaborados, tendo em vista as pesquisas realizadas em conjunto nos estados de São Paulo, Paraná, Santa Catarina e Rio Grande do Sul sobre as compras do Programa Nacional de Alimentação Escolar (PNAE) de agricultores familiares. O primeiro capítulo, de autoria de Rozane Marcia Triches, José Giacomo Baccarin, Carla Rosane Paz Arruda Teo e Vanessa Ramos Kirsten, traz uma abordagem quantitativa sobre o alcance do Artigo 14 da Lei 11.947/2009 dos municípios e estados. O segundo

2 Esta obra é resultado das pesquisas, dos estudos e das parcerias realizadas no âmbito do Projeto "Agricultura familiar, abastecimento e mercados institucionais: conexões entre Brasil, Cabo Verde e Uruguai na promoção da segurança alimentar e nutricional”, aprovado na chamada CNPq 82/2013. Do projeto resultou a criação do Núcleo de Estudos Avançados em Soberania e Segurança Alimentar e Nutricional “Karu Porã” ou a boa alimentação, em Guarani, sendo que esta publicação agrega as pesquisas e reflexões realizadas no âmbito do NEA-SSAN “Karu Porã” e de seus parceiros como forma de aprofundar o debate em torno da questão do abastecimento alimentar como um elemento-chave para o desenho dos sistemas agroalimentares. Outro projeto que também financiou as pesquisas realizadas em São Paulo, Santa Catarina e Paraná foi o submetido à Chamada MCTI-CNPq/MDS-SAGI No 24/2013 - Desenvolvimento Social, intitulado "Agricultura Familiar sob a Vigência da Lei Federal 11.947/2009: Abrangência e Adequação das Chamadas Públicas, Impactos na Agricultura Local e Preços Recebidos pelos Agricultores Familiares”. 
capítulo aborda as dificuldades e as formas de superação engendrados em alguns municípios destes quatro estados, considerando as entrevistas realizadas com os diversos atores sociais envolvidos - gestores, nutricionistas, conselheiros do Conselho de Alimentação Escolar (CAE), extensionistas rurais e agricultores familiares.

Na sequência, Vladmir Antero Delgado Silves Ferreira e Elsa Barbosa Simões relatam a experiência de Cabo Verde nas compras institucionais de agricultores locais para a alimentação escolar, explanando como estão sendo implantados e implementados os programas-piloto no país.

A experiência uruguaia de compras institucionais também é recente e, nesta obra, é descrita por Adriana Machado, Alejandro Pizzolon e Jorge Vaz Tourem, revelando os caminhos trilhados nesta tentativa, seus percalços, dificuldades e avanços.

Aprofundando as discussões sobre o PNAE no Brasil, o capítulo escrito por Carmine Marcon Piano e Camila Elizandra Rossi busca identificar o respeito à cultura alimentar a partir da análise dos cardápios e das chamadas públicas de municípios paranaenses, observando fragilidades no atendimento a este requisito entre os casos investigados.

Nesse sentido de avaliação da qualidade dos cardápios e alimentos servidos aos escolares, outro capítulo, escrito por Cassiani Gotama Tasca e Suelen Regina Lothermann, identifica o grau de processamento dos gêneros alimentícios solicitados pelas chamadas públicas em municípios dos estados de São Paulo, Paraná e Santa Catarina. As autoras evidenciam que há incongruências entre a demanda e a oferta de produtos, considerando o tipo de alimento que é solicitado aos agricultores familiares.

Além da análise do PNAE, o Programa de Aquisição de Alimentos (PAA) também foi considerado nos próximos três capítulos que se seguem. André A. Michelato Ghizelini inicia as discussões abordando em que medida as compras institucionais relativas ao PAA têm proporcionado condições para que a pequena agricultura possa desenvolver processos de autonomia e menor dependência para os mercados integradores e agroexportadores.

$\mathrm{Na}$ esteira desta abordagem, Cimone Rozendo reflete sobre o caso do PAA na região do semiárido brasileiro, considerando as intervenções que este Programa trouxe e suas influências nas instituições, formas de governança e independência dos agricultores, mas sem deixar de pontuar as armadilhas deste processo.

Por fim, para encerrar a seção de mercados institucionais, Panmela Soares, Rafaela Karen Fabri, Suellen Secchi Martinelli, Vitória Uliana Bianchini e Suzi 
Barletto Cavalli trazem a experiência da modalidade Compra Institucional do PAA para aquisição de produtos da agricultura familiar para os restaurantes populares brasileiros, realizando um diagnóstico revelador sobre as condições atuais.

$\mathrm{Na}$ última seção desta obra, procurou-se trazer outras experiências alternativas de abastecimento. No primeiro capítulo, Juliana Gonçalves e Thais Mascarenhas enfocam o papel do consumo na reorganização destas cadeias de abastecimento alternativas. Para tanto, abordam os circuitos curtos agroalimentares sob a ótica dos grupos de consumo responsável (GCRs) no Brasil e se propõem a discutir a interdependência entre os elos da cadeia de abastecimento de alimentos.

Na sequência, Julian Perez-Cassarino e Laércio Meirelles tratam de descrever a trajetória de uma das principais organizações em âmbito nacional e internacional que representa um modelo alternativo para a produção e comercialização de alimentos - a Rede Ecovida. A proposta é trazer o resultado do processo de sistematização dos documentos e histórico, resgatando as motivações, o ideário e processo de organização desta Rede.

Conclui-se esta parte e esta obra com a experiência do Uruguai com a conformação de redes alternativas de abastecimento, considerando os movimentos, suas dificuldades e formas de atuação para levar a cabo a produção, comercialização e certificação da agricultura orgânica/agroecológica no país.

Espera-se com estes capítulos contribuir para o aprofundamento dos temas que envolvem formas alternativas no abastecimento alimentar que sejam mais justas, mais saudáveis e mais sustentáveis. Nesse sentido, pretende-se evidenciar esta temática para que tanto a academia quanto o Estado e a sociedade possam pensar e efetivar mudanças que promovam sistemas alimentares sustentáveis, com soberania e segurança alimentar e nutricional.

Os organizadores.

\section{REFERÊNCIAS}

BONANNO, A. The locus of polity action in a global setting. In: BONANNO, A. et al. From Columbus to ConAgra: the globalization of agriculture and food. Kansas: University Press of Kansas, 1994. p. 251-264.

AMIN, A; COHENDET, P. Architectures of Knowledge: Firms, Capabilities, and Communities. New York: Oxford, 2004. 
FRIEDMANN, H. After Midas's Feast: alternative food regimes for the future. In: ALLEN, P. Food for the future: conditions and contradictions of sustainability. California: John Wiley e Sons, Inc., 1993. p. 213-233.

GOODMAN, D. Rethinking food production-comsumption: integrative perspectives. Sociologia Ruralis, v. 42, p. 272-277, 2002.

Rural Europe redux? Reflections on alternative agro-food networks and paradigm change. Sociologia Ruralis, v. 44, p. 3-16, 2004.

. The quality 'turn' and alternative food practices: reflections and agenda. Journal of Rural Studies, v. 19, p.1-7, 2003.

GOODMAN, D; DUPUIS, E.M. Knowing food and growing food: beyond the production-consumption debate in the sociology of agriculture. Sociologia Ruralis, v. 42, p. 5-22, 2002.

HINRICHS, C. C. Embeddedness and local food systems: notes on two types of direct agricultural market. Journal of Rural Studies, v.16 p.295-303, 2000.

ILBERY, B. et al. Product, process and place an examination of food marketing and labelling schemes in europe and north america. European Urban and Regional Studies, v.12, p.116-132, 2005.

MARSDEN, T. K. The condition of rural sustainability. Assen: The Netherlands, Van Gorcun, 2003.

.et al. Food supply chain approaches: exploring their role in rural development. Sociologia Ruralis, v.40, p. 424-438, 2000.

MORGAN, K. School Food and public domain: the politics of the public plate. The political quarterly, UK, v.77, p. 379-387, 2006.

POLANYI, K. A grande transformação: as origens de nossa época. Rio de Janeiro: Campus, 1980.

SLEE, B; KIRWAN, J. Hybrid theories for hybrid food chains? In:. WISKERKE J. S. C. et al., Sustaining Food Supply Chains: Grounded perspectives on the dynamics and impact of new modes of food provision, Aldershot: Ashgate Publishers, 2008.

VAN DER PLOEG, J. D. et al. Rural development: from practices and policies towards theory. Sociologia Ruralis, v.40, p.392-408, 2000.

WISKERKE, J. S. C; VAN DER PLOEG, J. D. Seeds of Transition: essays on novelty production, niches and regimes in agriculture. Assen: Royal van Gorcum, 2004. 


\section{PARTE 1 \\ O ABASTECIMENTO NA PERSPECTIVA DE SISTEMAS ALIMENTARES SUSTENTÁVEIS}




\title{
Por uma nova ciência para a promoção de sistemas alimentares sustentáveis
}

\author{
Cecilia Rocha \\ IPES-Food ${ }^{1}$
}

\section{Introdução}

Os sistemas alimentares que herdamos no século XXI apresentam algumas das maiores conquistas da civilização humana. Paradoxalmente, eles também apresentam algumas das maiores ameaças à nossa saúde e à prosperidade contínua. Contrastado com milênios de dietas de subsistência para a maioria da população, os sistemas alimentares de hoje são um sucesso de abundância em muitas partes do mundo. Ao longo dos séculos XIX e XX, grandes avanços na produtividade de culturas agrícolas, processamento de alimentos e capacidade de distribuição levaram a um enorme aumento da disponibilidade de calorias, trazendo dietas mais variadas ao alcance daqueles capazes de pagar por elas. Sistemas alimentares modernos também apresentam resultados impressionantes em termos da segurança dos alimentos. No início do século $\mathrm{XX}$, intoxicação alimentar e contaminação da água eram as principais causas de mortalidade, mesmo em regiões relativamente ricas como a Europa Ocidental. Mais higiene, melhores tecnologias e avanços na medicina, praticamente erradicaram essas patologias nos países mais ricos, e grandes avanços se observam em países com renda média e baixa. No entanto, os sistemas alimentares modernos

\footnotetext{
1 IPES-Food (International Panel of Experts on Sustainable Food Systems) é um grupo internacional composto por cientistas ambientais, economistas, nutricionistas, agrônomos, sociólogos, e membros da sociedade civil e de movimentos sociais. IPES-Food procura contribuir para o debate político sobre a reforma dos sistemas alimentares. Disponível em: <http://www.ipes-food.org/>.
} 
são deficientes em muitos aspectos, e em muitos países e regiões do mundo. $\mathrm{Na}$ verdade, as próprias bases em que esses sistemas foram construídos estão se tornando cada vez mais frágeis.

Mesmo se o único objetivo fosse a erradicação da fome, a perspectiva não é boa. Apesar das reduções na percentagem da população mundial passando fome nas últimas décadas, 795 milhões de pessoas ainda estavam nessa situação em 2015 (FAO, IFAD e WFP, 2015). Expandindo a lente para todos que estão desnutridos, as falhas do presente sistema são muito mais gritantes. Além de fome aguda, dois bilhões de pessoas são afligidas pela "fome oculta" de deficiências em micronutrientes, e mais de 1,9 bilhão são obesas ou estão com sobrepeso (IFPRI, 2016). De fato, um dos maiores paradoxos do nosso tempo é que esta "carga tripla" de desnutrição, fome oculta e obesidade é frequentemente encontrada dentro da mesma região, família ou até mesmo numa mesma pessoa. Doenças não transmissíveis associadas a dietas desequilibradas têm aumentado tão rapidamente que já superaram doenças infecciosas como a causa número um de mortalidade global (IFPRI, 2016).

A perspectiva ambiental é igualmente preocupante. Hoje os sistemas alimentares contribuem entre $19 \%$ e $29 \%$ das emissões globais de gases de efeito estufa (VERMEULEN, et al., 2012). Muitas dessas contribuições vêm da produção de fertilizantes químicos e pesticidas (GILBERT, 2012). Outras vêm do processamento e da venda de alimentos que dependem cada vez mais das embalagens sintéticas e distribuição a grandes distâncias de produtos altamente processados e fora de época aos quais os consumidores se acostumaram (SCHNELL, 2013). Enquanto isso, 70\% de toda a água retirada de aquíferos, rios e lagos é utilizada na agricultura - muitas vezes a taxas insustentáveis (FAO, 2011). O setor agrícola é responsável pela poluição por nitrato, fósforo, pesticidas, outros sedimentos e patógenos no solo e na água (PARRIS, 2011). Além disso, os sistemas agrícolas têm contribuído significativamente para a degradação de solos, bem como a destruição de habitats e perdas de biodiversidade em todo o mundo (SCHERR \& MCNEELY, 2012).

Os sistemas alimentares estão também falhando aos próprios produtores de alimentos. Pequenos agricultores, especialmente mulheres, lutam para emergir acima do nível de subsistência, muitas vezes por falta de acesso ao crédito, insumos externos, suporte técnico e acesso a mercados - ou enfrentam as incertezas da volatilidade dos preços nos mercados globais de commodities. 
A globalização trouxe novas situações em termos de pressões negativas sobre os preços e encargos regulatórios dispendiosos para os agricultores. Como resultado, temos a realidade irônica de pequenos produtores de alimentos comporem cerca de 50\% dos famintos no mundo (WFP, 2015). Empreendimentos agrícolas no norte global podem ser maiores e mais capitalizados, mas também enfrentam elevados riscos e incertezas, e seus rendimentos mostram pouca perspectiva de elevação duradoura. Isso deixa muitos agricultores dependentes de subsídios do governo. Enquanto isso, as condições de trabalho continuam a ser problemáticas em sistemas alimentares, começando pelas circunstâncias precárias enfrentadas por migrantes rurais, à exploração e sub-remuneração dos trabalhadores em matadouros, fábricas de processamento de alimentos, hipermercados e restaurantes. Enquanto agricultura e alimentos geram riqueza para as grandes empresas, um meio de vida digno continua fora do alcance para muitos que trabalham dentro dos sistemas alimentares.

Esses problemas estão profundamente interligados e uma análise holística é necessária. Tal análise assume que os problemas em sistemas alimentares - desde acesso à terra, sobrepeso e obesidade - são componentes de problemas sistêmicos subjacentes à forma como os alimentos são produzidos, processados, distribuídos, e consumidos em todo o mundo. Além disso, os vários componentes dos sistemas alimentares (políticas de comércio exterior e de subsídios agrícolas, por exemplo) evoluíram paralelamente ao longo do tempo, de modo a se reforçarem mutuamente. Isso significa que coligações de interesses evoluíram ao lado deles. Reformas nesses sistemas se tornam difíceis quando grupos de interesse poderosos defendem o status quo. Nesse contexto, o que deve ser mudado se torna menos importante do que identificar como isso pode ser mudado. A ênfase deve ser sobre a economia política dos sistemas alimentares e, particularmente, sobre as relações de poder que funcionam através desses sistemas. Em outras palavras, pontos de pressão para a mudança sistêmica devem ser identificados; são necessárias soluções que abordem o poder diferenciado de vários atores em influenciar tomadas de decisões políticas.

Nos últimos anos, especialmente desde a crise global dos preços dos alimentos de 2007-2008, as comunidades científica e política têm voltado sua atenção para vários problemas nos sistemas globais de alimentos. Iniciativas políticas proliferaram em resposta a essas questões, o que se deu com avaliações científicas e projetos de pesquisa com o objetivo de gerar conhecimento sobre 
esses problemas. No entanto, apesar da mobilização das comunidades políticas e científicas ao redor das várias questões sobre sistemas alimentares, o desafio continua. A tendência é tentar resolver os problemas como peças individuais de um quebra-cabeça e ignorar as relações de poder que desempenham um papel importante na formação desses sistemas. Mais importante: o conhecimento das pessoas e comunidades mais afetadas por problemas nos sistemas alimentares não tem sido devidamente aproveitado para diagnosticar as soluções.

A necessidade, portanto, é produzir uma imagem conjunta, inteira, dos sistemas alimentares e sua economia política, fazendo-o de maneira transdisciplinar, ultrapassando os limites tradicionais da comunidade científica. Temos que aproveitar a oportunidade para a geração de um conhecimento robusto sobre sistemas alimentares em torno de um nexo de ciência, política e prática. Precisamos de uma nova ciência de sistemas alimentares sustentáveis. Este capítulo traça os contornos de um novo quadro analítico para sistemas alimentares sustentáveis (Seção 1). Em seguida, descreve os princípios da ciência transdisciplinar que deve ser aplicada a fim de gerar os tipos de conhecimento que podem apoiar a transição para sistemas alimentares sustentáveis (Seção 2).

\section{Um novo quadro analítico para sistemas alimentares sustentáveis}

O quadro analítico aqui proposto permite uma compreensão de problemas específicos nos sistemas alimentares como componentes de um problema sistêmico mais amplo. Esse quadro pode ajudar a identificar sinergias e pontos de apoio para a implementação de soluções destinadas a reforçar a capacidade de resistência e sustentabilidade dos sistemas alimentares como um todo. Essa lente analítica procura iluminar os seguintes aspectos: i) redes de interações complexas em sistemas alimentares; ii) constelações gerais de políticas capazes de afetar os sistemas alimentares; iii) relações de poder e a economia política dos sistemas alimentares; iv) compreensão holística e de várias escalas da sustentabilidade, como guia para reforma dos sistemas alimentares. 


\section{Redes de interações complexas e de sinergias}

Uma discussão sobre os sistemas alimentares refere-se à rede de atores, processos e interações envolvidos no cultivo, processamento, na distribuição, no consumo e na disposição de alimentos, desde o fornecimento de insumos e extensão rural à embalagem do produto e marketing e à reciclagem de resíduos. Uma lente holística de sistemas alimentares preocupa-se com a forma como esses processos interagem uns com os outros e com o contexto ambiental, social, político e econômico. A lente de sistemas alimentares também traz à luz relações de feedback que se suportam e se equilibram, assim como tensões entre os diferentes componentes e fluxos desses sistemas e suas interações cíclicas e de multiescala. É uma maneira de pensar sobre o mundo que procura identificar as relações lineares e não lineares entre os diferentes componentes do sistema.

\section{Constelações de políticas}

Sistemas alimentares referem-se não só a operações de mercado, mas também à rede de quadros institucionais e reguladores que influenciam esses sistemas. A questão da intervenção do governo (políticas) não deve ser tratada como um conjunto limitado de influências exógenas que podem simplesmente ser ligadas e desligadas com efeitos previsíveis. De uma perspectiva de sistemas alimentares, os tipos de intervenção política vão muito além de armazenagem de grãos ou definição de preços mínimos. Uma série de outros domínios devem ser contabilizados: subsídios para produção agrícola, políticas de comércio e de investimento, normas de saúde e segurança no trabalho, padrões nutricionais, regulamentos de posse da terra, subsídios à energia, regulamentos ambientais, práticas de licitação pública, regulamentos sobre segurança dos alimentos, políticas sociais para fornecer alimentos subsidiados para comunidades carentes, políticas salariais e de direitos dos trabalhadores rurais, e formas de informar e influenciar o comportamento do consumidor. 


\section{Relações de poder e economia política}

Desequilíbrios de poder, muitas vezes decorrentes de desigualdades econômicas, são também um fator-chave na forma como os sistemas alimentares operam. As relações de poder dentro da família ou da comunidade, em particular aquelas decorrentes das diferenças de gênero, podem ser tão cruciais quanto fatores econômicos na determinação da forma que funcionam os sistemas alimentares. A abordagem de direitos humanos transforma a questão do acesso aos alimentos de uma questão puramente técnica, a ser abordada com as ferramentas da economia ou da agronomia, em uma questão política, na qual a justiça social e a não discriminação se tornam centrais.

O poder das grandes empresas privadas é também um fator-chave na dinâmica de sistemas alimentares e tem grande influência na gestão desses sistemas. A concentração econômica no setor agroalimentar nas últimas décadas tem garantido um poder cada vez maior nas mãos de grandes empresas do agronegócio, cujas redes se estendem por vários países e continentes. Análises de sistemas alimentares devem reconhecer as mudanças resultantes no lócus de poder e de tomada de decisão, dos produtores para distribuidores comerciais, e do Estado para as empresas jurídicas, cujo poder dentro da cadeia de abastecimento alimentar e nos acordos intergovernamentais está crescendo (LANG; BARLING, 2012). Quando até 90\% do comércio global de grãos são controlados por quatro empresas do agronegócio, qualquer mudança na política de fornecimento por uma grande empresa pode afetar todo o sistema.

Atores poderosos também podem influenciar a direção da política por outros meios. Nas últimas décadas, o foco da política agrícola e alimentar, e m muitos países, tem sido incentivar produtores de commodities a fornecer seus produtos para as cadeias globais. As empresas multinacionais do agronegócio que têm prosperado sob essas condições também têm desempenhado um papel fundamental na sua manutenção, por exemplo, usando seu crescente poder econômico para influenciar a formulação de políticas comerciais que lhes trazem maiores benefícios (HOLT-GIMÉNEZ E SHATTUCK, 2011). Essas relações de poder são consolidadas por um conjunto de influências exercidas mais indiretamente, por exemplo, por meio de doações de campanhas políticas, ou através do financiamento de projetos de pesquisa, ensino e extensão em universidades (públicas e privadas) que acabam favorecendo e incentivando certos 
tipos de questões e respostas sobre sistemas alimentares em detrimento de outras. Mas empresas do agronegócio não são os únicos atores capazes de exercer essas influências. Nos últimos anos, fundações filantrópicas têm assumido um papel crescente na liderança e no financiamento de uma série de iniciativas, fóruns políticos e pesquisa sobre sistemas alimentares (MCGOEY, 2014).

Esses exemplos ilustram três desafios para a reforma dos sistemas alimentares. Em primeiro lugar, os diferentes componentes dos sistemas alimentares modernos coevoluíram e se reforçam. Fica difícil reformar cada componente individualmente e coletivamente, pois esses interesses entrelaçados e entrincheirados se tornam um poderoso obstáculo à reforma. Por exemplo, as políticas orientadas para a exportação estimulam uma produção em massa dos principais produtos comercializáveis; e os atores principais que dominam o sistema muitas vezes parecem ter ganho a capacidade de bloquear qualquer alternativa emergente.

Um segundo desafio refere-se à análise de sistemas de alimentos em si. Tal análise deveria esclarecer as influências de diversos atores no processo de tomada de decisão. Por conseguinte, essa análise deve ir além de dicotomias simplistas entre os governadores e os governados nos sistemas alimentares ou entre detentores do poder econômico e político. A lente das relações de poder reforça a necessidade de focarmos nossa atenção sobre os sistemas alimentares como um todo e sobre os sistemas políticos e econômicos mais amplos em que estão inseridos, a fim de capturar as teias do poder e da influência que se autorreforçam e criam uma dinâmica sistêmica de bloqueios a mudanças. As avaliações detalhadas das relações de poder, da política de geração de conhecimento e da economia política dos sistemas alimentares, desde o nível nacional ao nível global, devem tomar papel de destaque em nossas análises.

O terceiro desafio refere-se às dificuldades em envolver os atores que atualmente detêm uma posição dominante nos sistemas alimentares. Como lidar com esses atores em nossas análises? Podemos trazê-los para participar desse processo sem arriscar que seu poder acabe definindo os termos e as perguntas em nossos estudos e pesquisas? Como podem as grandes empresas agroindustriais serem envolvidas num processo de se reimaginar um futuro sustentável onde o objetivo de crescimento do lucro de seus acionistas e a eficiência do mercado sejam questionados? Essas perguntas precisam ser feitas, a fim de garantir que o engajamento com atores poderosos se realize de uma forma 
que não perpetue os desequilíbrios de poder e permita que tais atores sejam desafiados de forma crítica e construtiva.

\section{A compreensão holística e de multiescala da sustentabilidade}

Sustentabilidade deve servir como referência para a reforma dos sistemas alimentares, mas deve também ser definida nas escalas e dimensões adequadas. Em primeiro lugar, sustentabilidade não deve ser simplesmente avaliada em termos globais (como a contribuição dos sistemas alimentares para o aquecimento global), mas deve também ser observada em níveis sub-globais (STEFFEN et al., 2015). Por exemplo, os sistemas alimentares coletivamente - em nível mundial - são responsáveis por cerca de um terço do total das emissões de gases com efeito estufa provocadas por ações humanas, mas esse total é composto por várias práticas de produção agrícola, processamento e distribuição de alimentos. É importante medir e compreender esses impactos individualmente e diferenciadamente a fim de se imaginar reformas práticas que atenuem as alterações climáticas. Outros impactos ambientais dos sistemas alimentares devem ser avaliados em diferentes escalas geográficas. Por exemplo, o uso de água doce por sistemas agrícolas afeta grandes bacias hidrográficas em diferentes regiões do mundo, com impactos sobre a sustentabilidade que nem sempre se manifestam globalmente (STEFFEN et al., 2015).

Em segundo lugar, a sustentabilidade dos sistemas alimentares deve ser considerada além das dimensões ambientais. O conceito de "dietas sustentáveis" aponta o caminho para uma definição mais holística. Dietas sustentáveis foram definidas como:

\footnotetext{
dietas com baixos impactos ambientais que contribuem para a segurança alimentar e nutricional e para a vida saudável das gerações presentes e futuras. Dietas sustentáveis protegem e respeitam a biodiversidade e os ecossistemas; são culturalmente aceitáveis, economicamente accessíveis, e nutricionalmente adequadas, seguras, e saudáveis; além de otimizar os recursos naturais e humanos. (FAO, 2010).
}

Muitas dessas dimensões não podem ser objetivamente observadas. O que constitui uma utilização ótima e equitativa dos recursos ou uma oferta alimentar 
culturalmente aceitável exige uma avaliação normativa que deve ser objeto de deliberação. Esse processo muitas vezes também requer uma sustentabilidade política - a legitimidade da governança dos sistemas alimentares e das políticas que os guiam - além das dimensões da sustentabilidade econômica, social e ambiental, como previsto no Relatório Brundtland (BRUNDTLAND, 1987).

\section{Uma nova ciência transdisciplinar de sistemas alimentares sustentáveis}

Se um novo quadro analítico para sistemas alimentares sustentáveis deve ser empregado, como deve ser essa análise? Para que nossa atenção esteja nos sistemas alimentares como um todo e para que a sustentabilidade seja considerada em todos os seus aspectos, as fronteiras que dividem disciplinas científicas devem ser desmontadas. Além disso, se vamos corrigir desequilíbrios de poder, temos que intensificar os esforços para que novos conhecimentos sejam coproduzidos com todos os atores sociais.

De fato, o conhecimento gerado e mantido pelos agricultores, pescadores, extrativistas, trabalhadores da indústria de alimentos, cooperativas, associações de consumidores, movimentos da sociedade civil, populações indígenas e toda uma gama de profissionais é um dos maiores recursos inexplorados na busca para uma melhoria dos sistemas alimentares. O que é necessário não é apenas uma transmissão de conhecimentos de cientistas para os formuladores de políticas, mas sim um fluxo multidirecional de conhecimentos entre os mundos da ciência, da política e da prática, com cada parte deste nexo informado pelos outros dois. Isso significa continuar construindo uma ciência transdisciplinar (JAHN et al., 2012).

Até recentemente, o pressuposto era que o conhecimento científico gerado dentro de disciplinas acadêmicas tinha como objetivo permitir que peritos - claramente distintos de atores sociais - entendessem os problemas vividos por tais atores. As metodologias desenvolvidas eram baseadas na suposição de um mundo físico entendido em termos simplesmente newtonianos, com relações causais fixas e previsíveis. O caminho da pesquisa à política e prática era unidirecional, e os resultados de pesquisas eram considerados universalmente aplicáveis. Essas abordagens, no entanto, estão agora sendo questionadas, e mais 
importância tem sido dada a perspectivas e estudos envolvendo várias disciplinas. Mais importante ainda, muitos cientistas agora percebem a necessidade do trabalho em estreita colaboração com atores sociais e começam a contar com os tipos de conhecimento específicos que tais atores trazem.

Nos domínios da agricultura e do desenvolvimento rural, abordagens pioneiras, como a Avaliação Rural Participativa colocou uma nova ênfase em processamento de dados "no local", por pesquisadores que trabalham em conjunto com aqueles cuja subsistência estavam sendo avaliadas (CHAMBERS, 1994). Enquanto isso, as tentativas de compreender os sistemas socioecológicos complexos e para medir o grau em que atividades humanas podem afetar os ecossistemas desafiaram abordagens científicas tradicionais, estimulando novas formas de colaboração. Insights das Ciências Sociais, por exemplo, sobre normas sociais e motivações complexas de atores individuais e institucionais têm cada vez mais destaque ao lado dos dados biofísicos e químicos na tentativa de traçar caminhos para a sustentabilidade - a partir de agora entendida em termos ecológicos e sociais (ADGER, 2000).

O desafio é aplicar essas abordagens de forma sistemática para a análise de sistemas alimentares sustentáveis a fim de forjar uma nova ciência transdisciplinar de sistemas alimentares sustentáveis que aproveite plenamente a inovação e o conhecimento que emanam do mundo da prática.

\section{Considerações finais}

Apesar do surgimento de novas iniciativas na interface da ciência, política e prática, a fragmentação continua sendo um grande risco. Essa fragmentação divide nosso foco entre diferentes peças e nos impede de ver o quebra-cabeça em sua totalidade. Resistir às forças que nos empurram para um estreitamento da lente analítica e trabalhar para internalizarmos um modo sistêmico, transdisciplinar de análise é necessário. Em particular, precisamos de uma atenção renovada sobre a economia política dos sistemas alimentares. Nosso referencial para uma reforma dos sistemas alimentares deve ser a sustentabilidade, em toda a sua multidimensionalidade.

Abordagens transdisciplinares são uma maneira de ligar diferentes fontes de conhecimento, a fim de melhor reconhecer a complexidade dos sistemas 
socioecológicos. Estas abordagens são particularmente apropriadas em relação aos sistemas alimentares devido à combinação de fatores - naturais, institucionais e regulamentares, e ligados a escolhas individuais e relações socioculturais - que desempenham um papel na formação de tais sistemas. Sistemas socioecológicos exigem que cientistas sociais - economistas, cientistas políticos, geógrafos e sociólogos - colaborem com agrônomos e cientistas biofísicos para fornecer uma descrição adequada aos desafios de hoje. Crucialmente, eles também exigem que cientistas colaborem com os atores sociais na criação de conhecimentos novos. As escolhas e ações desses atores moldam nossos sistemas alimentares.

Os esforços de uma ampla gama de atores serão necessários para transformar conhecimento e evidência em recomendações políticas. E suas vozes serão mais poderosas se forem capazes de falar a mesma linguagem, ancorada em pontos de referência comuns com relação a uma visão sistêmica e multidimensional de sustentabilidade.

\section{REFERÊNCIAS}

ADGER, W. N. Social and ecological resilience: are they related? Progress in human geography, 24(3), 347-364, 2000.

BRUNDTLAND, G. H. Report of the World Commission on environment and development:" our common future.." United Nations, 1987.

CHAMBERS, R. Participatory rural appraisal (PRA): Analysis of experience. World development. 22(9), 1253-1268, 1994.

ERICKSEN, P. J., STEWART, B., DIXON, J., BARLING, D., LORING, P., ANDERSON, M., \& INGRAM, J. The value of a food system approach. security Security and global environmental change, 25-45, 2010.

FAO. Report: International Scientific Symposium, Biodiversity and Sustainable Diets, United Against Hunger, Rome 3-5 November 2010. Available at: <http://www.fao.org/ ag/humannutrition/28506-efe4aed57af34e2dbb8dc578d465df8b.pdf>.

FAO. Why has Africa become a net food importer? Explaining African agricultural and food trade deficits. Rome: FAO, 2011.

FAO, IFAD \& WFP. The State of Food Insecurity in the World 2015. Meeting the 2015 international hunger targets: taking stock of uneven progress. Rome: FAO, 2015.

GILBERT, N. One-third of our greenhouse gas emissions come from agriculture. Nature. 2012. 
HOLT GIMÉNEZ, E., \& SHATTUCK, A. Food crises, food regimes and food movements: rumblings of reform or tides of transformation?. The Journal of peasant studies. 38(1), 109-144, 2011.

IFPRI. Global Nutrition Report 2016. From Promise to Impact: Ending Malnutrition by 2030. Washington, DC: International Food Policy Research Institute, 2011.

JAHN, T., BERGMANN, M., \& KEIL, F.. Transdisciplinarity: Between mainstreaming and marginalization. Ecological Economics, 79, 1-10, 2012.

LANG, T., \& BARLING, D. Food security and food sustainability: reformulating the debate. The Geographical Journal. 178(4), 313-326, 2012.

MCGOEY, L. The philanthropic state: market-state hybrids in the philanthro capitalist turn. Third World Quarterly. 35(1), 109-125, 2014.

PARRIS, K. Impact of agriculture on water pollution in OECD countries: recent trends and future prospects. International Journal of Water Resources Development. 27, 33-52, 2011.

SCHEN, S.J. AND MCNEELY, J. A. Farming with nature: the science and practice of ecoagriculture. Washington, DC: Island Press, 2012.

SCHNELL, S.M. Food miles, local eating, and community supported agriculture: putting local food in its place. Agriculture and Human Values 30, 515-628, 2013.

STEFFEN, W., RICHARDSON, K., ROCKSTRÖM, J., CORNELL, S. E., FETZER, I., BENNETT, E. M. \& SÖRLIN, S. Planetary boundaries: Guiding human development on a changing planet. Science, 2015.

VERMEULEN, S. J., CAMPBELL, B. M., \& INGRAM, J. S. Climate change and food systems. Annual Review of Environment and Resources. 37(1), 195, 2012. 


\section{Análise da transição ecológica de sistemas agrialimentares territoriais: ensinamentos de uma comparação franco-brasileira}

Claire Lamine

Giles Maréchal

Moacir Darolt

\section{Introdução}

Nos últimos vinte anos foram desevolvidas uma série de iniciativas, programas e políticas de segurança alimentar e circuitos curtos de comercialização tanto na França como no Brasil (DAROLT et al., 2013), apesar de contextos muito diferentes em relação à estrutura social da agricultura, questões de acesso à alimentação e à mobilização da sociedade civil. Na França, as políticas nacionais de modernização agrícola, assim como as políticas europeias que tratam desse tema, são originárias dos anos de 1960 e permitiram uma "recuperação" social dos agricultores em relação a outros grupos sociais fazendo com que entrassem "à força" nas cadeias produtivas organizadas, diferente do que acontece no Brasil que apresenta um grande número de agricultores familiares pobres que praticam, sobretudo, a agricultura de subsistência. Por outro lado, na França não se observa atualmente uma articulação forte entre política nacional e ações de acesso à alimentação, à agricultura e às preocupações ambientais.

No Brasil, a realidade social (altos índices de pobreza e maior importância da agricultura familiar) juntamente com a pressão dos movimentos sociais têm conduzido ao desenvolvimento de políticas relevantes a partir da metade dos anos de 1990, favorecendo o acesso à alimentação e beneficiando a agricultura 
familiar, com destaque para os movimentos orgânicos e agroecológicos. $\mathrm{Na}$ França, apesar de especificidades dos sistemas agrialimentares ${ }^{1}$ - fortemente ancorados nos territórios - terem progressivamente desaparecido, a sociedade civil em parceria com redes alimentares alternativas e apoiadas pelas autoridades locais, iniciaram uma relocalização da agricultura e da alimentação a partir dos anos de 1990. Assim, é no âmbito dos territórios rurais e urbanos que são consideradas as iniciativas e políticas, bem como seus efeitos, a fim de analisar os processos de transformação e de transição ecológica dos sistemas agrialimentares visando estudar o processo de ecologização no conjunto das instituições e atores do sistema.

Tanto na literatura científica quanto na ação pública ou militante, diversas noções e abordagens são propostas para analisar as transições dos sistemas agrialimentares, seja em escala territorial ou global. Tomando como base algumas dessas abordagens - "sistemas alimentares"; "regimes alimentares" (food regimes); "transições sustentáveis" (sustainability transitions) - analisam-se as transições com base num enfoque sócio-histórico, sistêmico e pragmático. Assim, este texto pretende analisar a emergência e a evolução ao longo do tempo, tanto de iniciativas passadas quanto de iniciativas atuais que tenham por objetivo o desenvolvimento de práticas ecologicamente corretas (na agricultura, nas agroindústrias, na distribuição e no consumo).

Neste capítulo será mostrado de que forma tais iniciativas podem se complementar e se articular ou até mesmo apresentarem conflitos, favorecendo ou não uma ecologização do conjunto do sistema agrialimentar territorial, ou seja, estudar as relações e interações possíveis. Em seguida, será apresentado como tal enfoque pode ser aplicado aos casos franceses e brasileiros. O pressuposto é que a comparação entre experiências brasileiras e francesas, apesar de diferenças históricas, socioeconômicas e demográficas, é rica em ensinamentos para cada um dos países, ao mesmo tempo em que se complementam, apresentando contribuições significativas para as relações entre ação pública e sociedade civil, bem como para a questão de justiça social e sustentabilidade, cada vez mais debatida no cenário internacional (GOTLLIEB, 2009).

\footnotetext{
1 A noção de "sistema agrialimentar" engloba não somente os atores envolvidos na cadeia de produção, transformação e distribuição (que fazem parte da definição clássica de "sistema agroalimentar"), mas também a assistência técnica e extensão rural (ATER), as políticas públicas, os consumidores e suas práticas, bem como a sociedade civil organizada (LAMINE, 2012).
} 
Essa reflexão foi construída a partir de parcerias de longa data entre os pesquisadores e atores franceses e brasileiros, no âmbito de projetos de cooperação científica ${ }^{2}$ e inter-regional (por exemplo, entre associações de solidariedade internacional e de desenvolvimento local da Bretanha e do Brasil). A pesquisa baseia-se em quatro estudos de caso aprofundados, geralmente inseridos no enfoque da pesquisa-ação de longa duração e tem o objetivo de analisar a diversidade de iniciativas e políticas que tratam dos processos de transição ecológica dos sistemas agrialimentares, considerando o conjunto de instituições e atores envolvidos no sistema e suas inter-relações.

\section{Uma abordagem sistêmica e pragmática dos sistemas agrialimentares territoriais}

$\mathrm{Na}$ literatura internacional e em particular anglo-saxônica os processos de transformação dos sistemas agrialimentares são compreendidos por meio de diversas abordagens teóricas (LAMINE et al., 2015). A teoria dos regimes alimentares (food regimes) foi desenvolvida por autores norte-americanos que tomaram como referência a economia política de inspiração marxista e analisa as transformações do sistema agrialimentar na escala global inserindo-as na história da economia capitalista mundial (FRIEDMANN; McMICHAEL, 1989). Tal teoria caracteriza o regime agroindustrial do pós-guerra por dois princípios fundamentais: o primeiro consiste no distanciamento entre a produção e o consumo, beneficiando as grandes empresas agrícolas e agroalimentares em detrimento aos pequenos agricultores familiares. $\mathrm{O}$ segundo princípio diz respeito à "durabilidade" de produtos agrícolas (no sentido técnico de ser não perecível e durável) por meio da transformação e do processamento ${ }^{3}$. Esses são os fatores que explicam justamente a "não-sustentabilidade" (de acordo com a noção de sustentabilidade ecológica e social) desses regimes alimentares.

2 Projeto CAPES-COFECUB (Agroecologia na França e no Brasil: entre redes científicas, movimentos sociais e políticas públicas, 2011-2014); Convenção de parceria entre o INRA-SAD e o IAPAR estabelecida em 2013; Laboratório international Agriterris envolvendo pesquisadores franceses, brasileiros e argentinos. Agradecemos ainda Terena Peres de Castro pela ajuda na tradução deste texto.

3 O historiador W. Cronon (Nature's metropolis: Chicago and the great west, New York, Norton \& Co., 1991) descreve igualmente os processos de transformação e processamento de produtos agrícolas da mesma forma que a escola regulacionista francesa e a economia das convenções na sua análise sobre a qualidade "industrial". 
Evidentemente os modelos alternativos emergentes se apresentam como formas de resistência a essa globalização da agricultura e suas consequências injustas, contudo pouco influenciam numa transformação estrutural do sistema dominante (BUTTEL, 2006). Em resposta às críticas de insustentabilidade, o modelo industrial se adapta evoluindo para uma dieta alimentar chamada de "regime alimentar ambiental corporativo" (corporate environmental food regime) (CAMPBELL, 2009), basicamente sustentado em sistemas de certificação ambiental privados, visando unicamente a rastreabilidade dos produtos e pouco contribuindo para a sustentabilidade dos modelos de produção, criando novos processos de exclusão.

$\mathrm{Na}$ Europa os autores se baseiam em uma perspectiva, dentre outras existentes, inspirada no pensamento de Giddens (1990), defendendo a ideia de que os atores sociais, notadamente os produtores e consumidores, são sujeitos ativos no processo de transformação imposto pelo modelo de modernização e globalização (PLOEG et al., 2000). Esses autores destacam a emergência de um novo paradigma de desenvolvimento rural "sustentável", baseado na busca de autonomia local e criando o que se designou de "eco-economia" (KITCHEN; MARSDEN, 2009). Juntamente com as noções de "redes cívicas alimentares" (civic food networks), "cidadãos da comida" (food citizens) ou ainda de "democracia alimentar" se destaca o papel crucial da sociedade civil para criar inovações no sistema alimentar.

A partir de trabalhos que abordam as inovações tecnológicas em diferentes setores (energia, indústria), surge ainda uma corrente que trata de "transições sustentáveis" (sustainability transitions), utilizando uma abordagem de análise multiníveis (Multi-Level Perspective). Esse enfoque destaca a maneira como os "nichos" se desenvolvem e influenciam o "regime" dominante, através da qual se desenham diversas "vias de transição" possíveis (GEELS; SCHOT, 2007). O enfoque é centrado na interdependência dos componentes do sistema, entretanto, em comparação com as correntes citadas anteriormentes, aborda de maneira superficial as mudanças de práticas (agrícolas e de consumo), além de ser pouco aplicado em escala territorial.

A partir dos anos de 1990, implanta-se na França um importante campo de trabalho em torno das noções de qualidade, notadamente inspiradas na escola regulacionista e na economia das convenções (ALLAIRE; BOYER, 1995), que teve influência nas correntes precedentes. Assim, é descrito um processo de transição entre um mundo agroindustrial com normas e padrões homogeneizantes e 
procedimentos de qualificação frequentemente sustentados por referenciais tanto relacionados à tradição como também aos territórios locais (particularmente as Denominações de Origem Controlada - DOC). Nesse contexto surgiu uma nova linha de estudos em torno dos "Sistemas Alimentares Localizados" (SIAL), que também se propagou pelo Brasil e outros lugares, desenvolvendo trabalhos relevantes sobre os circuitos curtos e os sistemas alternativos (DINIZ; CERDAN, 2017). Entretanto, os estudos se centraram apenas nas alternativas de circuitos curtos isoladamente, sem analisar o conjunto das iniciativas em termos de mudanças mais ousadas nos sistemas agrialimentares.

No Brasil, os trabalhos concentram-se sobretudo na análise de dois modelos de desenvolvimento rural que têm sido foco das políticas públicas: um modelo do chamado "agronegócio" que prioriza as exportações e cadeias longas baseado em grandes propriedades, na monocultura, no uso intensivo de insumos industriais e pouco uso de mão de obra; e outro modelo da "agricultura familiar", baseado em pequenas propriedades com produção diversificada, uso intensivo de mão de obra familiar e circuitos mais curtos de comercialização (LEÃO, 2013).

Os movimentos sociais brasileiros opostos à intensificação e à agricultura industrial têm sido descritos como tendo um papel importante na fase inicial do desenvolvimento das agriculturas de base ecológica e alternativas de comercialização em circuitos curtos ${ }^{4}$ de comercialização (BRANDENBURG, 2002; DAROLT, 2012). Recentemente as redes alternativas de alimentos, no Brasil e na França, têm destacado as noções de soberania e segurança alimentar ${ }^{5}$, dois conceitos que surgiram em nível internacional no contexto da crise alimentar, com maior destaque a partir de 2008.

Constata-se um recente desenvolvimento de abordagens territoriais de sistemas agrialimentares, impulsionadas pela sociedade civil e por novas formas de governança. Dentro dessa dinâmica, esse trabalho pretende abordar os processos de ecologização dos "sistemas agrialimentares territoriais". Nesse estudo o sistema agrialimentar territorial envolve todos os atores da produção, transformação,

\footnotetext{
4 Os Circuitos Curtos ou Cadeias Curtas (CC) de comercialização são definidos como "um sistema de inter-relações entre atores que estão diretamente engajados na produção, transformação, distribuição e consumo de alimentos" (RENTING et al., 2012). Essa definição traz dois pontos importantes (inter- relações e interdependência) e deixa aberta uma ampla gama de formas de articulação entre produção e consumo.

5 A noção de soberania alimentar envolve o direito de todos à alimentação e à autonomia dos atores sociais em suas estratégias e políticas de apoio à produção, distribuição e consumo, respeitando a diversidade cultural e enfatizando a importância da agricultura familiar e camponesa (PLOEG, 2008).
} 
distribuição e consumo de alimentos num dado território, incluindo não só agricultores e atores econômicos, mas também assistência técnica, extensão rural, pesquisa, políticas públicas, consumidores e sociedade civil organizada.

Essa noção inclui de fato diferentes redes, regulamentos/legislações, modos de coordenação, envolvendo interações entre circuitos curtos e circuitos longos. Esse conceito, que inclui um largo conjunto de atores interessados nas questões agrícolas e alimentares, se aproxima da sugestão de L. Malassis de definir o sistema alimentar como "a maneira pela qual os homens se organizam, no espaço e no tempo, para obter e consumir sua alimentação” (MALASSIS, 1994).

A premissa de análise deste trabalho repousa em duas hipóteses que serão investigadas por meio dos casos franceses e brasileiros: primeiramente, os processos de transformação de um sistema agrialimentar territorial resultam de efeitos advindos de iniciativas e ações variadas que se combinam, muitas vezes apresentando conflitos ou ainda entrando em contradição. Em segundo lugar, um processo de ecologização "justo" para o conjunto do sistema agrialimentar territorial, diz respeito ao desenvolvimento de práticas não somente mais ecológicas, mas também economicamente viáveis e socialmente justas para os diferentes elos do sistema (por exemplo, as iniciativas dos agricultores, o apoio de políticas púbicas, o engajamento do ensino, pesquisa, assistência técnica e extensão rural e de parceiros da indústria), o que pressupõe alguma forma de governança do sistema agrialimentar territorial.

Para demonstrar essas hipóteses, o trabalho faz uma análise retrospectiva e também atual das dinâmicas do sistema agrialimentar. Para tanto, analisam-se as trajetórias de agricultores, de instituições da iniciativa privada e da sociedade civil, as políticas públicas, os modos de gestão em diferentes tipos de iniciativas e projetos, e também os fenômenos de interdependência, emergência e marginalização.

\section{Aplicação aos casos franceses e brasileiros}

Os quatro casos que apresentamos se referem a duas experiências rurais no sudeste da França (Ardeche e Biovallée) e dois casos urbanos (Região Metropolina de Rennes na França e Região Metropolitana de Curitiba no Paraná, Brasil) (Quadro 1). Nesses quatro casos, vamos aplicar um enfoque que mescla uma análise sócio-histórica (estudo da retrospectiva da evolução do sistema 
agrialimentar territorial nas últimas décadas), sistêmica (análise de interdependências e coordenação entre os diversos elos do sistema) e pragmática (análise de visões, argumentos, às vezes controversos, resultando em iniciativas e ações que foram implementadas.

Quadro 1 - Caracterização dos territórios de estudo franceses e brasileiros

\begin{tabular}{|c|c|c|c|}
\hline Territórios & $\begin{array}{l}\text { Superfície e } \\
\text { população }\end{array}$ & $\begin{array}{l}\text { Característica (urbana } \\
\text { / rural) }\end{array}$ & $\begin{array}{l}\text { Tipo de agricultura e de indústria } \\
\text { alimentar }\end{array}$ \\
\hline $\begin{array}{l}\text { França - Sul } \\
\text { Ardeche }\end{array}$ & $\begin{array}{l}160.000 \text { habi- } \\
\text { tantes e cerca } \\
\text { de } 2.500 \mathrm{Km}^{2}\end{array}$ & $\begin{array}{l}\text { Áreas rurais com várias } \\
\text { cidades pequenas; } \\
\text { Forte apelo turístico. }\end{array}$ & $\begin{array}{l}\text { Agricultura diversificada, com predo- } \\
\text { minância de pequenas e médias pro- } \\
\text { priedades e pequenas agroindústrias; } \\
\text { Agricultura Orgânica }(\mathrm{AO})^{\star}=\text { cer- } \\
\text { ca de } 15 \% \text { das propriedades e da área } \\
\text { plantada. }\end{array}$ \\
\hline $\begin{array}{l}\text { França } \\
\text { - Biovallée }\end{array}$ & $\begin{array}{l}54.000 \text { habi- } \\
\text { tantes e cerca } \\
\text { de } 2.200 \mathrm{~km}^{2}\end{array}$ & $\begin{array}{l}\text { Áreas rurais, perto de } \\
\text { cidades de médio porte; } \\
\text { Forte apelo turístico. }\end{array}$ & $\begin{array}{l}\text { Agricultura diversificada com pre- } \\
\text { domínio de pequenas e médias } \\
\text { propriedades; } \\
\text { AO = cerca de } 30 \% \text { das propriedades e } \\
\text { da área plantada. }\end{array}$ \\
\hline $\begin{array}{l}\text { França } \\
\text { - Rennes }\end{array}$ & $\begin{array}{l}426.000 \text { habi- } \\
\text { tantes e cerca } \\
\text { de } 700 \mathrm{~km}^{2}\end{array}$ & $\begin{array}{l}\text { Área urbana composta } \\
\text { de } 3 \text { cinturões verdes } \\
\text { polarizados pela cidade } \\
\text { de Rennes; } \\
\text { Áreas agrícolas entre as } \\
\text { áreas urbanas e no cin- } \\
\text { turão verde. }\end{array}$ & $\begin{array}{l}\text { Pouca diversidade de produção (pre- } \\
\text { domínio de produção leiteira) } \\
\text { Agricultura familiar de médio porte; } \\
\text { AO = cerca de } 7 \% \text { das propriedades e } \\
\text { da área plantada. }\end{array}$ \\
\hline $\begin{array}{l}\text { Brasil } \\
\text { - Criteba }\end{array}$ & $\begin{array}{l}\text { Cerca de } \\
3,5 \text { milhões } \\
\text { habitan- } \\
\text { tes e } 16.000 \\
\mathrm{~km}^{2}(29 \\
\text { municípios) }\end{array}$ & $\begin{array}{l}\text { Área urbana (Curitiba) } \\
\text { com cinturão verde for- } \\
\text { mado por municípios } \\
\text { lindeiros com áreas } \\
\text { rurais; } \\
\text { Turismo Rural emer- } \\
\text { gente nos municípios } \\
\text { lindeiros à Curitiba. }\end{array}$ & $\begin{array}{l}\text { Sistemas diversificados (olericultura } \\
\text { e fruticultura) no primeiro cinturão } \\
\text { lindeiro à Curitiba) com predominân- } \\
\text { cia de agricultura familiar ( } 78 \% \text { das } \\
\text { propriedades); } \\
\text { AO = cerca de } 2 \% \text { das propriedades e } \\
\text { da área plantada. }\end{array}$ \\
\hline
\end{tabular}

Fonte: dados da pesquisa de campo (elaborado pelos autores). 


\section{Os casos do Sul da França (Ardèche e Bivallée)}

Os dois territórios rurais franceses (Ardèche e Vale do rio Drôme - Biovallée) estão localizados na região Rhône-Alpes (Sul da França) (Figura 1). Os dois locais apresentam a particularidade de serem espaços rurais em mutação com uma retomada demográfica depois de 150 anos de abandono. É uma região que possui um ambiente natural exuberante com montanhas, vales verdejantes, vinhedos, lagos, cavernas e parques naturais com densas florestas e com alto apelo turístico. Ademais, está no vale do rio Rhône conhecido pelos vinhos de alta qualidade e referência gastronômica, somado a boas vias de acesso e autoestradas.

Figura 1 - Localização dos territórios da Ardèche, Bivalée e Rennes na França

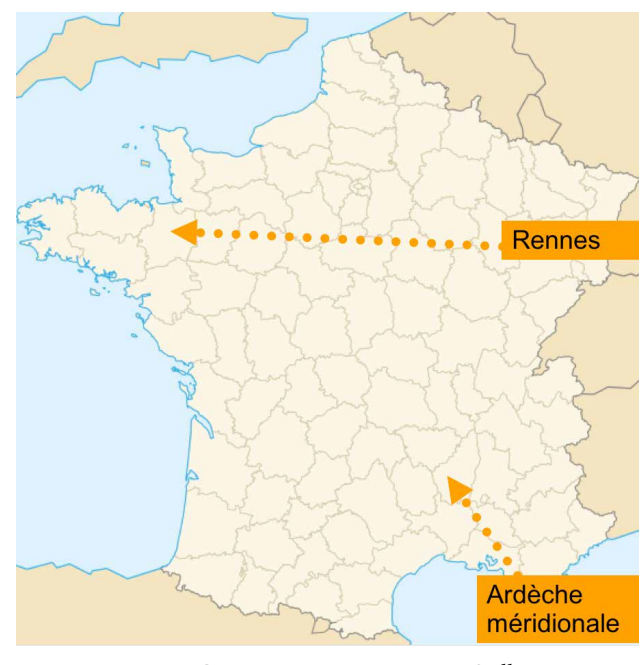

Fonte: Creative commons - Benoit Stella

A produção agropecuária nesses territórios apresenta pontos em comum: diversificação de produtos com alta porcentagem de agricultura orgânica (Quadro 1), forte presença da viticultura em áreas de encosta, pecuária extensiva nas zonas de montanha, culturas de grãos nas planícies e algumas áreas de fruticultura (pêssego, maçã, cereja, ameixa), que tiveram a sua "época dourada", seguido de uma queda nos últimos vinte anos.

No entanto, os dois locais diferenciam-se pelo tipo de dinâmica de seus sistemas agrialimentares territoriais, como veremos. $\mathrm{O}$ caso Ardèche mostra uma profusão de iniciativas da sociedade civil porém pouco conectado com políticas 
públicas, enquanto o caso Biovallée mostra um efeito combinado de ações da sociedade civil com as políticas públicas, somado à mobilização de certos atores agrícolas "convencionais".

Nos anos de 1970 chegaram na Ardèche e no Vale do Drôme os neorurais ${ }^{6}$ que, junto com agricultores tradicionais e habitantes da região, criaram uma diversidade de iniciativas e experiências visando mudar a relação entre a agricultura e os alimentos. Isso vai desde o exemplo de Pierre Rabhi - um dos pioneiros da agroecologia francesa que se instalou na Ardèche no início de 1980 e forneceu os princípios teóricos e práticos para autonomia alimentar das populações - até iniciativas de venda direta como os pontos de venda coletiva (PVC) de agricultores criados na Ardèche em 1997, que permitem maior autonomia dos agricultores e uma forte ligação com os consumidores.

Além disso, formaram-se as $\mathrm{AMAP}^{7}$ que são baseadas em contratos e um engajamento de longo prazo entre agricultores e consumidores, somado às muitas feiras de produtores tradicionais na região. Essas iniciativas vêm se transformando ao longo do tempo: no Diois (no Vale do Drôme) uma cooperativa de consumo existente desde os anos de 1980, gradualmente, vem aumentando a quota de alimentação local através da construção de parcerias duradouras com os produtores locais (BUI, 2015). Paralelamente, uma outra associação de consumidores criada recentemente tem se envolvido com o serviço de refeições coletivas (para empresas, eventos, etc.) interagindo fortemente com atores locais nos municípios e permitindo um protagonismo na transformação do sistema agrialimentar territorial.

Outras iniciativas dizem respeito aos atores "convencionais" do sistema, como é o caso de cooperativas agrícolas que começam a investir na produção orgânica nos dois territórios. No Vale do Drôme, quatro cooperativas agrícolas (viticultura, cerealista, PPAM $^{8}$ e de abastecimento alimentar) fizeram uma parceria desde 1991 para desenvolver a agricultura orgânica, montando um programa de apoio

6 O Neoruralismo é um fenômeno de migração de áreas urbanas para zonas rurais surgido no início dos anos de 1970 na Europa e América do Norte muito ligado à contracultura, em que pessoas voltam ao campo com o objetivo de trabalhar com melhor qualidade de vida e maior contato com a natureza.

7 Associações para Manutenção de uma Agricultura Camponesa ou Familiar - Associations pour le Maintien d’une Agriculture Paysanne (AMAP) que seguem um modelo de iniciativas usualmente lideradas por consumidores em suporte aos agricultores.

8 As Plantas para Perfumes, Aromáticas e Medicinais (PPAM) são particularmente bem representadas na região Rhône-Alpes, com destaque para a lavanda. 
às práticas de produção, assistência técnica e comercialização, atuando com vários elos do sistema agrialimentar. Isso não só permitiu a cooperativa aumentar significativamente sua gama de produtos orgânicos, mas também influenciou na transição de outros agricultores agricultores para o sistema9 (BUI, 2015).

Nota-se que esses atores da cadeia estão tentando fortalecer sua autonomia e valorizar os produtos do território por meio da agregação de valor numa estratégia de "integração territorial vertical". Nesse sentido, a cooperativa cerealista tem trabalhado em parceria com a cooperativa de abastecimento alimentar investindo numa central de produção de sementes a fim de garantir o acesso aos diferentes insumos e também numa fábrica de alimentos orgânicos destinados à pecuária orgânica (incluindo a produção de ovos) assegurando o escoamento da produção e a diversificação de culturas (necessários na produção orgânica).

No sul do território da Ardèche, cooperativas de frutas locais - num contexto de forte queda nos volumes de venda - lançaram a partir da década de 1990 várias iniciativas de diversificação, incluindo o desenvolvimento de frutas orgânicas e, mais recentemente, de hortaliças orgânicas para atender a demanda de um atacadista orgânico em 2008. Para incentivar alguns de seus produtores cooperados (fruticultores) e outros agricultores do território a desenvolver a produção de hortaliças orgânicas, a cooperativa definiu uma estratégia conjunta entre o atacadista e a Secretaria de Agricultura regional, responsável pela assistência técnica e acompanhamento dos produtores.

Apesar da mobilização dos diversos elos do sistema agrialimentar (produção, assistência técnica e comercialização), este projeto mostrou aos produtores os habituais inconvenientes dos circuitos longos como critérios de qualidade padronizados, incerteza de preços e necessidade de grandes volumes de venda (LAMINE, 2012). O fracasso revelou, em contraste com o Vale do Drôme, uma dificuldade comum das cooperativas convencionais na transição para a agricultura orgânica relacionada à falta de assistência técnica e políticas públicas de apoio aos agricultores orgânicos em conversão. Além disso, este caso mostra que é mais difícil evoluir nas práticas de produção e consumo quando o sistema envolve vários intermediários e maior complexidade, comparado, por exemplo,

9 O Conselho da cooperativa cerealista tem gradualmente incluído mais e mais agricultores orgânicos na administração da mesma, eleitos pelos pares, incluindo agricultores convencionais, mostrando um processo de gradual aculturação e um crescente reconhecimento dos orgânicos no mundo agrícola. 
com o caso das AMAP, em que produtores e consumidores evoluem nas suas práticas de produção e consumo num sistema agrialimentar "hiper-simplificado".

Em ambos os territórios, instrumentos de governança foram criados para melhorar a coordenação entre as iniciativas e os elos do sistema agrialimentar. No sul da Ardèche, por exemplo, uma marca coletiva - "Prove a Ardèche" - foi lançada em 1994 por organizações socioprofissionais da agricultura, artesanato e comércio para melhorar a produção local e uma outra estrutura intermediária - "Da Ardèche e da Estação" - foi criada em 2014 para fornecer refeições coletivas à iniciativa privada. Apesar dos avanços evidenciados (Figura 2), ainda não se pode falar que no território da Ardèche há um projeto territorial agrialimentar bem estruturado.

Figura 2 - Esquema do sistema agrialimentar territorial na Ardèche no sul da França

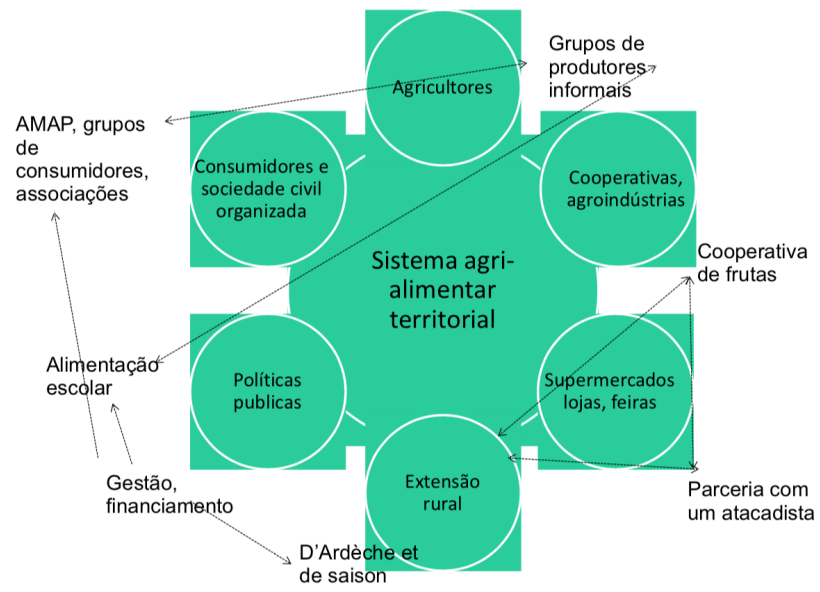

Fonte: dados da pesquisa de campo (elaborado pelos autores).

De maneira pioneira, no Biovallée as autoridades locais vêm discutindo desde 2009 questões relativas ao território, lançando um programa de ação pública para organizar um território-piloto em termos de desenvolvimento sustentável nas áreas de energia, manejo de resíduos, habitação e agricultura, com metas ambiciosas para crescimento da agricultura orgânica e oferta de produtos orgânicos e locais no mercado de refeições coletivas para alimentação escolar 
pública e empresas privadas. No entanto, notou-se que a meta proposta pelas autoridades vai depender muito da evolução das políticas públicas para a região.

Mesmo que o papel das políticas públicas apareça mais forte no território Biovallée, em ambos os casos há uma diversidade de iniciativas que criam uma hibridação, o que permite uma reterritorialização das cadeias, combinando produções especializadas (com exportação de excedentes) e produções diversificadas, as quais buscam reconectar questões agrícolas e alimentares através de modos específicos de coordenação. Essas dinâmicas permitem que, apesar de crises em alguns setores produtivos desses territórios, os sistemas agrialimentares territoriais analisados globalmente apresentem uma "resiliência" no tempo. Nos dois casos estudados, constatou-se um processo de inclusão social, com papel importante da alimentação escolar pública (regulado pelo setor público), também encontrado nos casos de Rennes e de Curitiba.

\section{O caso da Região Metropolitana de Rennes}

A cidade de Rennes e seus arredores, região da Bretanha no oeste da França (Figura 2), foram, até a Segunda Guerra Mundial, um exemplo clássico da integração entre a cidade e o campo. Sendo um centro administrativo e acadêmico, com muitos restaurantes e cafés, Rennes sustentou um sistema territorial de produção integrada com leite, manteiga, aves, maçã para produção de sidra $^{10}$ e lenha para aquecimento. Esse modo de cultivo de pasto associado com pomar ("pré-verger"), do tipo agroflorestal, era baseado em normas sociais e legais específicas constituindo o que poderíamos chamar de economia circular.

O período de "modernização da agricultura" nos anos de 1950 e 1960 desestabilizou brutalmente esse sistema. A turbulência afetou diretamente o sistema integrado de agricultura e os excelentes recursos agro-pedoclimáticos. Do mesmo modo, as transformações no mundo urbano também influenciaram as mudanças no uso dos recursos energéticos (petróleo substituindo a lenha), a

10 Bebida obtida pela fermentação alcoólica do suco de maçã. O Ecomuseu da Sidra em Bintinais retrata a história de uma fazenda vizinha a cidade de Rennes que possuía produção integrada e vendia no mercado local, estimando um consumo individual de mais de 300 litros de sidra por ano no século XIX. 
evolução da dieta (regressão de sidra e manteiga) e a abertura de empregos para operários na cidade ${ }^{11}$.

Na década de 1990, a região de Rennes já tinha adotado o "modelo Breton", baseado na especialização de um só produto, no caso o leite, com pacote tecnológico da revolução verde e integração aos mercados internacionais tanto para compra de insumos como para vendas dos produtos. A especificidade ligada às interações rural-urbanas permaneceu sustentada pela dinâmica urbana, com gestores públicos decidindo preservar zonas agrícolas entre bairros periféricos (princípio da "cidade ilha") e mantendo uma feira tradicional (marché des Lices) que virou um evento semanal famoso nacionalmente.

Em resposta a essa "normatização", um grupo de agricultores lançou um projeto ousado: uma dúzia de propriedades ligadas à "Confédération Paysanne"12 e aos movimentos da agricultura alternativa reuniram-se para abrir uma loja cooperativa de produtores em 1992, com foco na venda direta, chamada Brin d'Herbe. O ponto de venda coletivo (PVC) é motivado pela preocupação em preservar as propriedades na "dimensão humana" e incentivar a instalação de jovens. O mesmo grupo abre uma segunda loja em 1998, e um outro grupo lança uma terceira em 2001. Juntos, eles realizam hoje um volume de negócios anual próximo de 4 milhões de euros. Essa experiência permanece como inovadora na dinâmica territorial de Rennes.

Com a explosão das associações de consumidores AMAPs, no início dos anos de 2000, a história toma um rumo diferente. Apesar de lojas coletivas atraírem uma clientela fiel, o seu impacto militante fica restrito aos movimentos alternativos. Com o surgimento das AMAPs, as populações urbanas "redescobrem" a agricultura e a alimentação. As redes militantes incentivam os gestores municipais para atuarem no tema. Por convicção política, alguns políticos propõem as primeiras medidas. O então vice-prefeito de Rennes e encarregado da Secretaria da Agricultura, oriundo do setor agrícola "tradicional", percebe que "algo está surgindo" e propõe um diagnóstico econômico.

Em 2007, um diagnóstico inicial formalizado por uma Organização Não Governamental usa o Sistema Alimentar Territorializado (SALT) para avaliar o volume de negócios e o número de empregos gerados pelos circuitos curtos de

\footnotetext{
11 O desenvolvimento da indústria automobilística favoreceu a integração dos "filhos de agricultores", pouco engajados e politizados, a trabalhar numa jornada dupla como empregados nas fábricas e na agricultura.

12 Movimento francês filiado à Via Campesina.
} 
comercialização na metrópole (DENECHÈRE et al., 2008). O interesse levantado pelo tema é unânime e uma intervenção estruturada foi programada.

Em seguida, em 2008, um "programa local de agricultura” é desenvolvido e entregue pelo mesmo gestor no contexto mais amplo do território de Rennes. Os vários elos da cadeia produtiva agrícola são convidados a trabalhar em conjunto para o desenvolvimento de redes alimentares territoriais, enquanto as práticas agroecológicas aparecem com força nas políticas públicas. Os universitários, em particular as equipes acadêmicas do Agrocampus, participam desde o início. $\mathrm{O}$ projeto "Rennes ville vivrière"13 (DARROT, 2014) permite trabalhar dois cenários associando práticas agrícolas e dieta alimentar. O cenário de busca de mais autonomia pode reduzir significativamente a área do "território externo" necessário para abastecer a cidade em comparação com o cenário de referência. Um novo diagnóstico econômico realizado em 2013 mostrou que houve um aumento de vendas em circuitos curtos de comercialização. Em 2015, a cidade de Rennes formalizou seu plano de dieta sustentável com o objetivo de chegar a $20 \%$ de alimentos orgânicos nas compras públicas e $40 \%$ nos produtos locais. O exemplo de Rennes ilustra, em primeiro lugar, uma articulação multidimensional das iniciativas e atores, com participação de agricultores, consumidores, acadêmicos e gestores públicos responsáveis por implementar as políticas públicas locais. Em segundo lugar, um bom desempenho do sistema alimentar local acontece mais pela conscientização dos diferentes elos da cadeia em direção a práticas mais sustentáveis do que pela simples ampliação das unidades existentes, mesmo observando-se um aumento dos mercados alternativos (34 estabelecimentos em 2007 para 51 em 2016), das AMAPs (atualmente existem 21 AMAPs no território de Rennes), das lojas de produtores e maior envolvimento de municípios nas compras institucionais.

\section{O caso da Região Metropolina de Curitiba (RMC)}

A Região Metropolitana de Curitiba (RMC) foi criada por uma Lei Federal de 1973 para melhorar a gestão e integrar 14 municípios. Em 1974, foi criada a Coordenação da Região Metropolitana de Curitiba (COMEC), uma 
entidade pública para formular e executar políticas públicas ligadas aos interesses metropolitanos dos municípios. Atualmente a RMC é composta por $29 \mathrm{mu}-$ nicípios abrangendo uma área de $15.913 \mathrm{~km} 2$ e uma população de 3,5 milhões de habitantes (cerca de 35\% da população do Paraná).

Figura 3 - Localização da Região Metropolitana de Curitiba

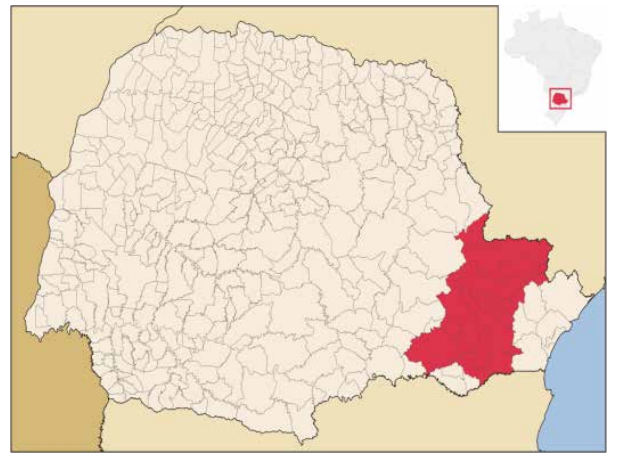

Fonte: Enciclopédia livre - wikipedia.

Em 1950, a população rural representava mais de $50 \%$ da população total da RMC. A partir dos anos 1970, começou a haver uma inversão, sendo que atualmente cerca de $85 \%$ da população está no meio urbano e $15 \%$ no meio rural (IBGE, 2015). A partir de 2000, tem havido um intenso processo de conurbação, formando uma mancha urbana concentrada em 11 municípios lindeiros que formam o cinturão verde de Curitiba, onde predominam sistemas de olericultura e fruticultura.

Parte significativa da área da RMC (56\%) encontra-se sobre mananciais e áreas de proteção ambiental, o que oportuniza o desenvolvimento de sistemas mais sustentáveis, como a agricultura orgânica. Os municípios que estão mais distantes da capital possuem uma densidade populacional mais baixa e com menores níveis de desenvolvimento.

A cidade de Curitiba está situada no centro da RMC, com uma população de 1,89 milhões de habitantes, área de $435 \mathrm{~km} 2$ (sem área rural) e um IDH de 0,82 considerado muito elevado (IBGE, 2015). Economicamente a RMC concentra o maior Produto Interno Bruto (PIB) do sul do Brasil e está entre as quatro maiores do Brasil. 
No Brasil, desde o início dos anos de 1980, agricultores familiares desenvolveram sistemas de produção e comercialização alternativos formando uma rede, muitas vezes com o apoio de organizações da sociedade civil, entidades ligadas à igreja (Pastoral da Terra), agentes de extensão rural pública e Organizações Não Governamentais (ONGs) num esforço de organizar produtores e consumidores com base em princípios de confiança e equidade (BRANDENBURG, 2002).

Tanto no Brasil como na RMC no Paraná, a agricultura familiar tem relevância representando cerca de $78 \%$ dos estabelecimentos rurais e ocupando uma área de $68 \%$ da RMC. Houve um aumento de políticas de proteção ambiental e novas iniciativas de produção agroecológica a partir dos anos de 2000, o que tem colaborado com o processo de transição para sistemas mais sustentáveis (DAROLT, 2012). Atualmente a RMC concentra cerca de $47 \%$ do total de produtores orgânicos (1.700) e 52\% da produção de hortaliças orgânicas do estado do Paraná (MAPA, 2016).

Uma análise do sistema agrialimentar territorial nos últimos 20 anos na RMC mostra que houve avanços significativos na diversidade de iniciativas de programas e políticas alimentares, com destaque para os circuitos curtos. Segundo Santos \& Darolt (2016), a quantidade de feiras orgânicas, por exemplo, apresentou uma evolução de $250 \%$ nos últimos dez anos. A mesma pesquisa identificou um total de 136 estabelecimentos classificados em seis diferentes canais de comercialização de produtos orgânicos: 21 feiras orgânicas, 23 lojas especializadas, 14 deliverys, 14 lojas no Mercado Municipal de Orgânicos (criado em 2009), 49 supermercados e 15 restaurantes, majoritariamente na capital, Curitiba. A comercialização de alimentos orgânicos em redes e circuitos curtos tem se mostrado relevante e diversificada na oferta de produtos, sobretudo em feiras que têm preços médios inferiores aos praticados nas lojas especializadas e supermercados, o que denota avanços na eficiência econômica, inovações técnicas e maior participação social.

A análise da transição para sistemas mais sustentáveis na RMC aponta para uma combinação de fatores, tais como: institucionalização da produção orgânica (Lei 10.831/2003); políticas públicas nacionais, estaduais e municipais de apoio à agricultura familiar, agroecologia e soberania alimentar; programas de alimentação escolar (estadual e municipal); organização e formação de agricultores em redes de agroecologia (Rede Ecovida, por exemplo) e centros de apoio aos agricultores familiares agroecológicos; apoio para processos de certificação 
participativa (via programas com participação de núcleos de estudos em agroecologia nas Universidades); programas de assistência técnica e extensão rural (via instituições estaduais); apoio de uma rede de pesquisa e ensino; organização e apoio de uma rede de consumidores; apoio de políticas públicas municipais, estaduais e federais para produção, transformação (agroindústria - programa denominado Fábrica do Agricultor) e comercialização; abertura de novos canais de comercialização em circuitos curtos (feiras, lojas, cestas), mercados especializados em orgânicos (Mercado Orgânico de Curitiba fundado em 2009; restaurantes; lojas) e integração com circuitos longos (supermercados); além de emergência de atividades não agrícolas como o turismo rural e, mais recentemente, programas para levar as pessoas a conhecerem o meio rural da RMC (programa "caminhadas na natureza").

Nota-se que os processos de transição estão fortemente vinculados a mudanças políticas, em que os atores sociais, através de suas organizações da sociedade civil participam do planejamento do território e da execução de políticas públicas em nível local. Esses fatores garantem outras perspectivas de organização da produção, transformação e comercialização, de forma que os atores possam ter maior autonomia. Entretanto, ainda nota-se pouco engajamento dos atores da sociedade civil para gerar uma mudança estrutural mais efetiva (DAROLT, 2012).

O caso de Curitiba mostra, como os casos anteriores, o efeito de uma diversidade de iniciativas provenientes de redes de agricultores ecológicos (Associação para o Desenvolvimento da Agroecologia - AOPA e Rede Ecovida), associado a uma boa articulação entre os elos do sistema alimentar (produção, assistência técnica, pesquisa, ensino, políticas públicas, agroindústria de transformação e organização de consumidores para o consumo sustentável). Apesar de uma mobilização mais fraca da sociedade civil no caso brasileiro quando comparado aos casos franceses, nota-se a importante presença de políticas públicas (destacadamente nas compras institucionais para a alimentação escolar), permitindo uma crescente ecologização do sistema agrialimentar territorial.

\section{Lições aprendidas e ensinamentos dos casos estudados}

Nos quatro casos estudados observa-se uma grande variedade de iniciativas e projetos destinados à "ecologização" dos sistemas agrialimentares territoriais 
provenientes de redes agrícolas alternativas, da sociedade civil, de políticas públicas, que mobilizam ou não atores do setor convencional. Como mostram os diferentes casos, há um aumento significativo da participação da agricultura orgânica e da agroecologia, mas também formas de relocalização do sistema alimentar nos últimos dez a quinze anos. Esse processo de ecologização é mais eficaz quando todos os elos da cadeia estão engajados no processo (produtores, consumidores, processadores, assistência técnica, políticas públicas locais e sociedade civil organizada) e quando existem instrumentos de governança para garantir uma boa coordenação entre as iniciativas e os elos da cadeia ${ }^{14}$.

Quadro 2 - Comparação entre sistemas agrialimentares territoriais na França e no Brasil

\begin{tabular}{|l|l|l|l|l|}
\hline Características & Ardèche & Biovallée & Rennes & RM Curitiba \\
\hline Envolvimento dos diferentes atores & alto $^{*}$ & alto & alto & médio \\
\hline Governança intersetorial e compartilhada & baixo & alto & médio & médio \\
\hline Papel das políticas públicas & baixo & alto & médio & alto \\
\hline Papel da sociedade civil & alto & alto & alto & baixo \\
\hline
\end{tabular}

* Nota: nível de atuação

Fonte: dados da pesquisa de campo (elaborado pelos autores).

Os casos estudados mostram que existem diferentes equilíbrios entre os respectivos papéis das políticas públicas e da sociedade civil. Nos casos franceses como também na França de forma geral, foram as redes agrícolas alternativas e a sociedade civil que contribuíram como atores principais no desenvolvimento dos circuitos curtos de comercialização e na relocalização ${ }^{15}$ do sistema agrialimentar.

No Brasil, na década de 1990, foram os movimentos sociais e as Organizações Não Governamentais em parceria com a pesquisa, o ensino e a extensão que organizaram as primeiras redes alimentares alternativas; todavia, nos últimos 10 anos, o impacto das políticas públicas tem sido decisivo. De fato, a partir dos anos 2000 houve maior incentivo de instituições públicas através de programas governamentais visando apoiar a agricultura familiar e a agricultura orgânica/ agroecologia, por exemplo. A implementação de leis e medidas para aquisição de alimentos da agricultura familiar de base ecológica via compras institucionais

$14 \mathrm{Na}$ escala europeia uma comparação de formas de governança em diferentes territórios foi elaborada no quadro do projeto Healthygrowth (projects.au.dk/healthygrowth/).

$15 \mathrm{O}$ tema da relocalização ou lugar de procedência, associado à identidade de quem produz são importantes características no processo de revalorização da origem dos alimentos. 
(Programa Nacional de Alimentação Escolar-PNAE e Programa de Aquisição de Alimentos-PAA), contribuiu para articular ações indutoras de transição nos níveis do consumo (alunos e pessoas carentes) e na produção (incentivo à agricultura familiar e agroecologia).

O papel predominante da sociedade civil no caso francês e do setor público no caso brasileiro resultam em dinâmicas diferenciadas. No Brasil, dez anos de intervenções públicas com orçamentos significativos (mais de um bilhão de euros por ano, combinando créditos a fundo perdido e compras institucionais) contribuíram para a manutenção da agricultura familiar e o impulso à agroecologia. Apesar dos efeitos de exclusão, especialmente no que diz respeito aos públicos menos informados e de baixo nível educacional, essas políticas públicas tornaram-se "parte da vida diária" de muitos atores do sistema agrialimentar, sendo um elemento central e legítimo. Ademais uma governança inter-setorial foi estabelecida através da articulação entre vários ministérios e departamentos (agricultura, desenvolvimento social, alimentação, saúde, educação e meio ambiente). Na França, nenhuma intervenção orçamentária significativa ocorreu em nível nacional nos últimos anos, fazendo com que as políticas agrícolas, alimentares, ambientais e de saúde ficassem desconectadas.

Finalmente, nota-se que são os atores da sociedade civil (agricultores e consumidores cidadãos) e as autoridades locais (muitas vezes influenciadas por esses atores) os principais agentes na construção de projetos e demandas locais de alimentos, que moldam a dinâmica de ecologização dos sistemas agrialimentares territoriais. Tanto no Brasil como na França, as dinâmicas baseadas em ações apenas de governos ou de autoridades locais deixam a situação do sistema agrialimentar muito frágil devido ao risco de descontinuidade política.

\section{Considerações finais}

O método de abordagem proposto para analisar as transições dos sistemas agrialimentares territoriais, aplicado a casos franceses e brasileiros, permitiu-nos mostrar a importância, tanto analítica como em termos de ação pública, de um enfoque sócio-histórico, sistêmico e pragmático no estudo das transições. No entanto, é preciso analisar as dinâmicas dos sistemas e suas interações em longo prazo, verificar as inter-relações entre os diferentes elos da cadeia, considerar 
as visões e os argumentos dos diversos atores no seu conjunto e, finalmente, observar como isso se reflete em ações locais concretas (abordagem pragmática).

Essa discussão não é apenas teórica, mas subsidia práticas sociais e métodos de intervenção pública específicos. O exemplo das compras institucionais ou públicas para a alimentação coletiva ilustra bem a importância de uma visão sistêmica para impulsionar um setor. A intervenção pública no Brasil foi baseada em uma visão sistêmica na sua concepção geral, com uma forte ligação entre problemas alimentares (luta contra a fome), de saúde pública, de viabilidade econômica da agricultura familiar, de equilíbrio territorial e da promoção da agroecologia. No entanto, essa visão sistêmica negligenciou o funcionamento do sistema econômico, na medida em que as políticas públicas ficaram centradas em um único canal de comercialização: a venda institucional para alimentação coletiva (basicamente em escolas), que sofre com as descontinuidades políticas.

$\mathrm{Na}$ França, o fornecimento de alimentação pública foi objeto de vários programas de governo, mas os resultados se mostraram aquém do esperado. A deficiência é muitas vezes explicada por argumentos puramente técnicos (dificuldades para cumprir a legislação, falta de logística, oscilações de preços, falta de equipamentos de armazenamento nas escolas, etc.), porém acreditamos que é também devido à falta de visão sistêmica. O setor de refeições coletivas é considerado como dotado de uma lógica própria, como se pudesse desenvolver-se de forma independente de outras formas de comercialização. No entanto, um enfoque pragmático, considerando os argumentos e as práticas dos atores - destacadamente dos produtores - mostra que isso não é verdadeiro: cada produtor pode escolher entre diversos canais de comercialização (refeições coletivas, feiras, lojas, grupos de consumidores, venda na propriedade, etc.), que interagem tanto no plano econômico como organizacional, mas também consideram seus valores e visões.

Essa análise permitiu encontrar pistas para futuras pesquisas em torno de algumas questões importantes. A primeira diz respeito à questão de justiça social e de "sustentabilidade justa" ou "ecologização". Nossa hipótese, que pode ser aprofundada em trabalhos futuros, é de que as alianças de movimentos sociais ativos e de políticas públicas fortes são necessárias para garantir uma equidade social e territorial tanto para agricultores como para consumidores, em termos de acesso a práticas ecológicas, a mercados alternativos e a produtos ecológicos. Nota-se que a política alimentar passa por uma fase de transição do modelo 
dominante "produtivista" para um novo "ecologicamente justo". Nesse sentido, haverá necessidade de reformulações nas políticas alimentares, o que vai exigir um foco especial nas questões relacionadas à mudança de hábitos alimentares, saúde e participação ativa de consumidores e produtores familiares no processo.

A segunda questão a aprofundar está relacionada à dimensão ecológica dos sistemas agroalimentares territoriais na sua diversidade (impacto ambiental, qualidade da paisagem, gestão da água e do solo, entre outros), que exige o envolvimento de equipes multidisciplinares com participação de profissionais das ciências agrárias, biológicas e da saúde, mas também um trabalho com os atores do território sobre como tratar as questões entre produção e consumo ${ }^{16}$. Nesse sentido, as políticas devem privilegiar maior conscientização das pessoas sobre as consequências de seus atos de consumo. Nesse rumo, para além de ações individuais, são necessárias estratégias articuladas de grupos organizados de consumidores, produtores dispostos à transição para sistemas mais sustentáveis, empresas responsáveis investindo em tecnologias limpas e atuação do poder público com políticas de incentivo à transição agroecológica, bem como a regulação e legislação adaptadas às realidades locais (como é o caso das agroindústrias familiares).

A terceira questão trata de formas de investigação do sistema agrialimentar, na qual buscamos adotar tanto uma postura analítica como também uma postura transformadora da realidade pela pesquisa-ação. A articulação dessas duas posturas demandam necessariamente um engajamento de longo prazo sobre os casos estudados.

Finalmente, em termos de políticas públicas, as possibilidades de mudança ou transformações no sistema agrialimentar passam pelo apoio à agricultura familiar com o fortalecimento das ligações entre produtores e consumidores e modelos baseados em princípios agroecológicos combinando medidas de apoio governamental como políticas de preservação ambiental, de desenvolvimento rural, de apoio à agroindustrialização e à comercialização, infraestrutura de apoio à produção, assistência técnica aos produtores e educação dos consumidores.

Tanto nos casos da França como no Brasil, observou-se que as redes alternativas de alimentos aparecem como movimentos de posicionamento político para defender uma transição para formas mais sustentáveis de produção e consumo. 
Comparando os casos franceses e brasileiros, evidencia-se que a demanda forte e crescente da sociedade civil tem influenciado as políticas públicas de diferentes maneiras, dependendo da trajetória histórica dos movimentos sociais, da mobilização e do engajamento dos produtores e consumidores com o tema.

Dessa forma, a influência que as redes alternativas de alimentos têm sobre as políticas públicas e o sistema agrialimentar está - em maior ou menor grau - relacionada às alianças e parcerias que essas redes são capazes de desenvolver. Iniciativas de comercialização por associações e cooperativas de agricultores e consumidores organizados em redes podem aumentar a participação na cadeia de abastecimento de alimentos, criando alianças e cooperação com outras categorias de atores sociais.

Um último ponto a destacar diz respeito aos modos de coordenação e tomada de decisões. Os casos denotam que a influência efetiva de redes alternativas de alimentos no sistema agrialimentar mais amplo depende de alianças que são capazes de construir-se com movimentos similares, mas também com instituições e outros atores do sistema dominante que trabalham em circuitos longos. Formas originais de governança (como acontece em cooperativas de produtores e consumidores e lojas de produtores) devem ser aprimoradas, permitindo envolver não só os produtores, os consumidores e os trabalhadores, mas também autoridades locais e organizações da sociedade civil. Finalmente, outras pesquisas devem investigar como as redes de alimentos podem adotar novas formas de coordenação e gestão, arranjos e inovações que permitam sanar os problemas de falta de mão de obra e fornecer alimentos de qualidade para a maior parte da população.

\section{REFERÊNCIAS}

ALLAIRE, G. ; BOYER, R. La grande transformation de lagriculture. Paris: INRA Economica, 1995.

BUI, S. Transitions vers l'agroécologie: analyse de la pertinence de léchelle territoriale pour impulser des changements au niveau du système sociotechnique. Thèse (Doctorat en Sociologie Rural), INRA/AgroParisTech, Paris, 2015.

BRANDENBURG, A. Movimento agroecológico: trajetória, contradições e perspectivas. Revista Desenvolvimento e Meio Ambiente, Curitiba, UFPR,n. 6, jul- dez 2002, pp. 11-28. 
BUTTEL, F. Sustaining the unsustainable: Agro-food systems and environment in the modern world. In: P. CLOKE, T. MARSDEN AND P. MOONEY. Handbook of Rural Studies, p. 213-229, 2006.

CAMPBELL, H. Breaking new ground in food regime theory: corporate environmentalism, ecological feedbacks and the 'food from somewhere' regime?. Agriculture and Human Values, vol. 26, p. 309-319, 2009.

DINIZ, D. A. S.; CERDAN, C. Produtos da sociobiodiversidade e cadeias curtas: aproximação socioespacial para uma valorização cultural e econômica. In: Gazolla Marcio; Schneider Sergio (Ed.). Cadeias curtas e redes agroalimentares alternativas: Negócios e mercados da agricultura familiar. Porto Alegre: UFRGS, p. 261-282. 2017 (Estudos Rurais).

DAROLT, M. R. Conexão Ecológica: novas relações entre produtores e consumidores. Londrina: IAPAR, 2012. $162 \mathrm{p}$.

DAROLT, M. R.; LAMINE, C.; BRANDENBURG, A. A diversidade dos circuitos curtos de alimentos ecológicos: ensinamentos do caso brasileiro e francês. Agriculturas, v.10, n.2, p. 8-13, jun. 2013.

DARROT, C.; Rennes ville vivrière? Revue Pour, vol. n 224, p. 139-156, GREP, 2014, $442 \mathrm{p}$.

DENÉCHÈRE F., DURAND G., MARÉCHAL G.Systèmes alimentaires territorialisés: les circuits courts comme vecteur de développement territorial. In: G. MARECHAL (Dir.). Les circuits courts alimentaires: bien manger dans les territoires. Éducagri, Dijon, p. 161-171, 2008.

FRIEDMANN, H.; McMICHAEL, P. Agriculture and the state system: the rise and fall of national agricultures, 1870 to the present. Sociologia Ruralis, vol. 29, $\mathrm{n}^{\circ} 2$, p. 93-117, 1989.

GEELS, F. W.; SCHOT, J. Typology of sociotechnical transition pathways. Research Policy, p. 399-417, 2007.

GOTTLIEB, R. Where We Live, Work, Play and Eat: Expanding the Environmental Justice Agenda. Environmental Justice, vol. 2, n 1, p. 7-8, 2009.

INSTITUTO BRASILEIRO DE GEOGRAFIA E ESTATÍSTICA (IBGE). IBGE divulga as estimativas populacionais dos municípios em 2015. Rio de Janeiro: IBGE, 2015. Disponível em: <http://saladeimprensa.ibge.gov.br/ noticias?view=noticia\&id=1\&busca $=1 \&$ idnoticia $=2972>$. Acesso em: 20 set. 2016.

KITCHEN, L.; MARSDEN, T. Creating Sustainable Rural Development through Stimulating the Eco-economy: Beyond the Eco-economic Paradox? Sociologia Ruralis vol. $49, \mathrm{n}^{\circ} 3$, p. 273-294, 2009. 
LAMINE, C. Changer de système ": une analyse des transitions vers l'agriculture biologique à léchelle des systèmes agri-alimentaires territoriaux. Terrains \& Travaux, vol. $\mathrm{n}^{\circ} 20, \mathrm{n}^{\circ} 1, \mathrm{p} .139-156,2012$.

LAMINE, C.; BUI, S.; OLLIVIER, G. Pour une approche systémique non réductionniste de la transition écologique des systèmes agri-alimentaires. Cahiers de recherche sociologique, 58, 95-117, 2015.

LEÃO, M. (Org.). O direito humano à alimentação adequada e o Sistema Nacional de Segurança Alimentar e Nutricional. Brasília: Abrandh, 2013, 263 p.

MALASSIS, L. Nourrir les hommes. Paris: Flammarion (Dominos, 16), 1994.

MINISTÉRIO DA AGRICULTURA, PECUÁRIA E ABASTECIMENTO (MAPA). Municípios brasileiros com produção orgânica. Brasília-DF. Disponível em: $\quad<$ https://blog.agroales.com/225-dos-municipios-brasileiros-tem-producaoorganica/>. Acesso em: 20 set. 2016.

PLOEG, J.D. Van der et al. Rural Development: From Practices and Policies towards Theory. Sociologia Ruralis, vol. 40, n 4, p. 391-408, 2000.

PLOEG, J. D. Van der. Camponeses e impérios alimentares: lutas por autonomia e sustentabilidade na era da globalização. Porto Alegre-RS: UFGRS, 2008.

RENTING, A.; SCHERMER, M.; ROSSI, A. Building Food Democracy: Exploring Civic Food Networks and Newly Emerging Forms of Food Citizenship. International Journal of Sociology of Agriculture and Food, v. 19, n. 3, p. 289-307, jan. 2012.

SANTOS, E. D.; DAROLT, M. R. Circuitos de comercialização de produtos orgânicos em Curitiba-PR. Monografia de Conclusão de Curso de Agronomia. Departamento de Economia Rural e Extensão. Curitiba: Universidade Federal do Paraná-UFPR, 2016. 60 p. 


\title{
Equipamentos públicos de Abastecimento Alimentar no Brasil: trajetória e desafios
}

\author{
Walter Belik \\ Altivo R. A de Almeida Cunha
}

\section{Introdução}

O abastecimento de alimentos envolve um amplo conjunto de atividades que extrapolam a mera função de comercialização agrícola tratada nos textos tradicionais. O abastecimento de alimentos começa já do lado de "dentro da porteira" com as decisões sobre o tipo de produção, época de plantio e características do produto e mercado a ser atendido. As tarefas prosseguem passando os limites da propriedade, atuando sobre a logística de distribuição e sobre os aspectos comerciais e financeiros da transação até atingir o consumidor final. Esse fluxo de atividades que envolve o abastecimento ocorre de forma sequencial para a produção que se dirige ao mercado e está presente na sociedade desde os tempos antigos. De fato, ao longo da história se alteraram as condições objetivas de produção, os hábitos de consumo e a forma de organização da economia, mas as atividades que cercam o abastecimento alimentar permaneceram os mesmos.

O presente texto aborda, em uma perspectiva histórica, as principais iniciativas públicas dos entes federativos nacionais para ordenamento do abastecimento urbano.

As primeiras iniciativas referem-se à construção e administração de Mercados municipais, geralmente nos centros das cidades grandes e médias, como equipamentos de comercialização. A literatura especializada caracteriza estes espaços como "Mercados de Primeira Geração" (GREEN, 2003). 
Com a intensificação do processo de urbanização, o abastecimento alimentar das cidades torna-se crucial para a redução do custo de vida das famílias urbanas e para a garantia do acesso a alimentos diversificados e saudáveis. Ademais, em todo mundo o crescimento das cidades impôs restrições logísticas e sanitárias para os mercados situados no centro do perímetro urbano. A partir dos anos 1960, uma série de mercados atacadistas alimentares públicos foram criados pelos estados nacionais, em uma ação que contou com decisiva influência de organismos internacionais como a FAO. Na América latina, agências de cooperação nacional francesa e espanhola tiveram papel importante nesta difusão (SEIDLER, 2001).

Grandes Centrais de Abastecimento foram criadas no Brasil a partir dos anos 1970 nos principais centros urbanos, bem como uma série de mercados satélites em cidades médias e em municípios produtores, constituindo um sistema de abastecimento articulado e definidor de padrões e preços.

Esse sistema, criado pelo Governo Federal, foi denominado Sistema Nacional de Centrais de Abastecimento (SINAC) e reunia mercados com participação acionária compartilhada entre o governo central e governos estaduais e municipais, e esteve vigente entre 1972 e 1988 (CUNHA, 2010). Nesse período foram criadas $84 \%$ das atuais Ceasas brasileiras.

Seu objetivo era reunir em grandes mercados com escala comercial expressiva produtores e consumidores intermediários, estabelecendo padrões de qualidade, sanidade e preços para uma agricultura em processo de modernização acelerada. Além disso, a política pretendia criar as bases para a estruturação de um segmento de varejo moderno, apto a fornecer alimentos para cidades em crescimento acelerado. A literatura define estes mercados, agora com uma característica atacadista, como "Mercados Atacadistas de Segunda Geração" (GREEN, 2000, 2003).

Com a emergência do setor supermercadista e suas novas formas de organização da comercialização e de relações com o setor produtivo, através de Centros de Distribuição privados, contratos de fornecimento diretos com produtores e diversificação comercial, o setor atacadista público recebe um impacto. Em termos mundiais, a crise é sentida primeiro nos mercados atacadistas europeus, referência dos modelos latinos americanos e do modelo brasileiro. Em seguida os mercados brasileiros passam a sentir os efeitos da concorrência que é potencializada pela crise fiscal do Estado e pelo processo de liberalização apressada dos anos 1990.

$\mathrm{Na}$ Europa, o setor passou por um intenso processo de reformulação, com a profissionalização da gestão dos mercados atacadistas, a melhoria dos sistemas 
logísticos e a geração de novos valores baseados na informação, rastreabilidade, padronização e adequação para novos serviços como catering, segmentação de produtos e minimante processados, configurando a "Terceira Geração de Mercados Atacadistas" (GREEN, 2000; 2003).

Já os tradicionais mercados atacadistas brasileiros, bem como a maioria dos mercados latino-americanos, não acompanharam esse processo de reconfiguração setorial, entrando em uma espiral de decadência operacional e gestão contaminada por interesses político eleitorais de curto prazo, conforme será abordado mais adiante.

O contexto das mudanças na economia brasileira e dos novos hábitos de compra e de consumo abre uma nova perspectiva para as Centrais de Abastecimento. Diante desse panorama, desenha-se a possibilidade de atuação desses equipamentos públicos como instrumento para promoção do desenvolvimento rural e inserção da agricultura familiar nos circuitos de comercialização através de um canal que possa valorizar os aspectos culturais da origem dos produtos, da gastronomia regional e dos alimentos com baixa pegada de carbono estabelecendo uma maior conexão entre o consumidor e as comunidades. Nesse sentido, as Centrais de Abastecimento brasileiras devem se aproximar do conceito de Polos Agroalimentares como os desenvolvidos em várias partes da Europa, em especial na região da Emiglia Romana. Nesses espaços de comercialização se observa uma valorização dos produtos regionais, articulados com uma rede logística eficiente e gestão profissionalizada. Este modelo, definido como um "mercado de Quarta Geração” (CUNHA et. al., 2011), será detalhado na última seção deste capítulo.

\section{Aspectos históricos}

No Brasil, a preocupação com o abastecimento de alimentos surge com o avanço da urbanização, o que vai ocorrer a partir da segunda metade do século XIX. Naquela época, a preocupação das autoridades com a questão do abastecimento estava focada na necessidade de garantir o acesso da população aos alimentos em condições de higiene favoráveis. Caberia, portanto, aos municípios a construção de mercados municipais em condições técnicas adequadas e que fossem de livre acesso ao consumidor e ao que estivessem localizados em áreas de fácil transporte. 
$\mathrm{Na}$ capital federal do Império, cidade do Rio de Janeiro, o primeiro mercado municipal foi construído em 1841 na área da Candelária (demolido em 1911) sendo seguido pelo Mercado Municipal da Praça Mauá em 1908 (demolido nos anos 60), ambos na área portuária e no coração comercial da metrópole (FRANÇA e REZENDE, 2010).

Em São Paulo, segunda cidade em população do país, o primeiro mercado surge em 1867 na Várzea do Carmo, na mesma localidade onde se situava o Barracão (1836-38), às margens do Rio Tamanduateí que era o principal meio de transporte de mercadorias na época (JUNQUEIRA e PEETZ, 2015), próximo do abatedouro municipal (que fazia uso do rio para o despejo dos dejetos) e próximo dos caminhos que vinham da Baixada e do porto de Santos. O Mercado Grande ou da Ribeira, como era conhecido, foi construído na antiga Rua das Casinhas, tradicional ponto de comércio da cidade, com grande presença de ambulantes (quitandeiras) e tinha como objetivo de disciplinar e impor padrões de higiene ao setor. Mais tarde esse mercado foi demolido dando origem a outra instalação mais moderna e, por fim ao mercado municipal da Cantareira em 1938.

Esse mesmo movimento aconteceu em Porto Alegre com a inauguração do Mercado Público em 1869, o Mercado São José em Recife (1875), Mercado Municipal de Campinas (1908) e Mercado Modelo de Salvador (1912), para ficarmos em alguns exemplos e que caracterizam uma primeira geração de mercados públicos no Brasil - a exemplo do ocorria na Europa. Durante esse período de expansão das cidades, o abastecimento passa a ter uma função importante tendo em vista que os quintais domésticos não poderiam atender à demanda de alimentação, assim como os excedentes que vinham das áreas rurais adjacentes.

A especialização da produção e oferta de gêneros fazia com que o comércio ganhasse escala e exigisse condições melhores para o desenvolvimento das suas atividades. Na virada do século XIX, o Rio de Janeiro tinha uma população de 691 mil e São Paulo já estava com 240 mil habitantes. As taxas de crescimento da população urbana eram explosivas. Em um curto período de 40 anos a começar do início do século a população do Rio de Janeiro se multiplica por 2,5 e na cidade de São Paulo a população cresce 5,4 vezes. Segundo Cano (1998) a taxa de crescimento urbano atinge $3,1 \%$ a. a. comparado com a taxa média da população de 1,9\% a.a. comparando-se os censos de 1928-35 com 1941-45.

Durante boa parte do século XX o abastecimento alimentar era um problema das autoridades municipais. Muito embora os movimentos sociais do início do 
século sublinhassem a questão da carestia e o Estado Novo tivesse desenvolvido algumas políticas de reforço alimentar, a relação entre a produção e o consumo doméstico permanecia distante. Durante a República Velha o Ministério da Agricultura reunia também os setores de Indústria e Comércio e não seria exagero afirmar que a Agricultura era basicamente o café, mas os assuntos ligados ao comércio de alimentos permaneciam ignorados. A partir de 1933, o Ministério da Agricultura passa a ser independente e, especificamente, o comércio de alimentos se insere nas atribuições do Ministério da Indústria e Comércio.

Embora os diversos governos do pós-guerra tenham tratado do tema da alimentação, como o Plano SALTE (governo Dutra: 1949-53), Plano de Metas (governo Kubitschek: 1956-61), Plano Trienal com as Reformas de Base (Goulart: 1963-64) o baixo investimento e a baixa capacidade de intervenção impediam uma ação mais eficiente para garantir o aumento da oferta e a estabilização de preços (BELIK, 2007).

Com a entrada dos governos militares e a preocupação em "modernizar" a agricultura surge também o esforço em reduzir as tensões sociais através da melhoria nos sistemas de abastecimento. Após uma rápida etapa liberalizante na economia, capitaneada pelo economista Roberto Campos no Ministério da Fazenda, durante o governo Castello Branco, os programas de governo assumem uma face claramente intervencionista, cobrindo o espaço deixado pelo empresariado inoperante (BELIK, 2007).

No governo Costa e Silva (1967-69) é lançado o PED-Programa Estratégico de Desenvolvimento. O massivo PED vai concentrar seus projetos na área agrícola e numa política de modernização da distribuição e abastecimento com a instalação da rede de centrais atacadistas, as Ceasas, por todo território nacional. Essa rede de Centrais de Abastecimento de economia mista (parcerias municipais, estaduais e federais) era controlada e coordenada diretamente pelo Governo Federal através do SINAC, pois, para os governos militares, tratava-se de um tema ligado à segurança nacional. Paralelamente, os anos 70 são uma época de enorme transformação no varejo de alimentos, que passa a ser liderada pela expansão do sistema de autosserviço no Brasil.

Muito embora o esforço concentrado na criação de centrais de abastecimento tenha levado à criação de dezenas de CEASAs no país por mais de 20 anos, o Abastecimento aparece como uma função complementar e assessória à Agricultura nas políticas públicas. Finalmente, em 1996, o tema do abastecimento volta 
a ter visibilidade com a mudança de nome do antigo Ministério da Agricultura em Ministério da Agricultura e Abastecimento, transformado em Ministério da Agricultura Pecuária e Abastecimento (MAPA) em 2001.

Por outro lado, a inércia da política pública em relação ao abastecimento já estava presente nesse momento. Na realidade, as Centrais Atacadistas que haviam sido criadas para aproximar fisicamente os produtores dos pequenos varejistas (feirantes, quitandeiros etc.) nascem com uma grande dificuldade em atender as estruturas centralizadas e a padronização imposta pela indústria supermercadista. Segundo Cyrillo (1987), no mesmo período em que ocorre o esforço para a construção das Centrais de Abastecimento por parte dos governos militares é lançado o Programa de Modernização e Reorganização da Comercialização (PMRC), voltado para o setor privado, com financiamentos do Banco Nacional de Desenvolvimento Social (BNDE) e recursos do Programa de Integração Social (PIS), visando a instalação de redes de supermercados, o que levava à redução drástica no número de pequenos varejistas.

Olhando em retrospectiva é importante reconhecer que o modelo brasileiro de comércio atacadista público iniciado nos anos 70 sob o SINAC integrava diversas praças comerciais pelos padrões de preços e qualidade. Com um programa de investimentos em infraestrutura de abastecimento sem precedentes no país, o SINAC criou, em articulação com estados e municípios, 22 empresas de abastecimento atacadistas (as Ceasas), 47 entrepostos e mercados expedidores e 158 equipamentos varejistas nos principais centros urbanos do país. Esta estrutura durante muitos anos foi a principal referência brasileira na formação de padrões comerciais para produtos hortigranjeiros com a definição dos padrões de classificação, embalagem e qualidade, bem como da informação de preços e quantidades comercializadas.

$\mathrm{Na}$ segunda metade dos anos 80 , a crise financeira e gerencial do sistema levou à extinção do SINAC, culminando com a transferência do controle acionário das Ceasas para os estados e municípios. A engenharia financeira do mecanismo de financiamento que permitiu a construção da imensa infraestrutura das Centrais de abastecimento se mostraria frágil em função das crises externas e foi determinante para o desmonte do Sistema. O término do SINAC se deu pela conjunção de quatro fatores: a fragilidade dos mecanismos de financiamento, problemas de focos e metas operacionais, dificuldades de relacionamento entre 
65

o governo federal e os estados e municípios e a falta de enraizamento das políticas do SINAC (CUNHA, 2010).

A partir da desarticulação do SINAC, diversas Ceasas passaram sofreram deficiências estruturais e conceituais. Tais deficiências levaram, em maior ou menor grau, à obsolescência das estruturas físicas de comercialização e a perda de eficiência dos métodos de gestão empresarial. Esta perda refletiu-se também na ausência de uma visão estratégica de longo prazo e na falta de aproximação e interação entre os agentes envolvidos no processo de produção, comercialização, distribuição e consumo.

Embora desarticuladas e sem diretrizes estratégicas, as Centrais de abastecimento brasileiras mantiveram uma parte das funções necessárias para alimentar um sistema nacional de informações sobre a comercialização de produtos hortigranjeiros. Esta estrutura é ainda responsável pela comercialização de mais de 16,1 milhões de toneladas anuais de produtos hortigranjeiros, cuja movimentação comercial supera a cifra de US\$ 10 bilhões anuais (dados de 2014).

As Ceasas registram cotidianamente as informações sobre quantidade, valor e origem de expedição da produção que chega a seus entrepostos, constituindo um valioso (ainda que subaproveitado) banco de dados. Estes registros representam uma informação estratégica e diferente dos dados do Censo Agropecuário, e estão reunidos sob a base de dados do Programa de Modernização do Mercado Hortigranjeiro (Prohort), criado em 2005 e vinculado à Companhia Nacional de Abastecimento-Conab.

Neste sistema pouco coordenado, a Ceagesp (a maior Central de Abastecimento do Brasil) atua como um grande $h u b$ de distribuição, sendo responsável por $25 \%$ da comercialização de hortigranjeiros e por $10 \%$ do total de gêneros que passam por todas as Ceasas do Brasil (CUNHA E BELIK, 2015)ํ․

1 Cunha (2015) estimou que pelo menos $6 \%$ da origem total de frutas comercializadas entre as Ceasas têm como origem as grandes centrais de abastecimento, sendo que $4 \%$ vêm do sistema atacadista da Ceagesp. Portanto, qualquer transformação que ocorra na Ceagesp afeta, em efeito cascata, todo abastecimento nacional. 


\section{Transformações recentes: da crise dos sistemas europeus para a crise das Ceasas}

Ainda que sem coordenação, a lógica de hierarquia das Centrais de Abastecimento manteve-se de alguma maneira no aspecto comercial, com as grandes Centrais funcionando como expedidoras para centros regionais. Por outro lado, essas organizações perderam algumas das suas funções, “clássicas”, seja no estabelecimento de padrões de classificação ou na transparência de preços (CUNHA; BELIK, 2012).

O mote da qualidade, da segmentação e diferenciação dos produtos, da rastreabilidade e dos orgânicos passou longe dos entrepostos públicos, dirigindo-se diretamente aos supermercados e agora ao varejo repaginado como gourmet.

Esta realidade podia ser antevista na crise do modelo dos grandes mercados atacadistas de segunda geração, que se revelou na Europa na década de 70, com perda de importância de muitos mercados atacadistas. O serviço oferecido pelos atacadistas tradicionais se tornou caro, não atendendo às necessidades da nova distribuição que requeria seleção, conservação, embalagem, preços competitivos e gestão de marcas. Esta tendência foi agravada por um processo contínuo de depreciação das estruturas, das funcionalidades e principalmente da gestão das Ceasas brasileiras.

O modelo dos mercados de segunda geração entra em crise na Europa em meados da década de setenta com a saída da atividade comercial de diversos operadores e a perda de importância de muitos mercados atacadistas, tanto em volume quanto em valor das transações. As razões da crise do modelo europeu estão fortemente ligadas à emergência de novas formas de coordenação do abastecimento atacadista representado pelas plataformas logísticas estruturadas pelos supermercados e hipermercados (FAO, 2002).

Neste novo paradigma, orientado para a redução de custos, ganhos diferenciais de qualidade e customização de produtos, as instalações físicas se deslocam do espaço das grandes centrais em diversos Centros de Distribuição privados. O serviço oferecido pelos atacadistas tradicionais se tornou comparativamente caro, não atendendo às necessidades da nova distribuição que necessita de pré-seleção, conservação, embalagem, preços competitivos e gestão de marcas (GREEN e SCHALLER, 2000; CADILHON et. al., 2003). 
Alguns mercados europeus reagiram à crise através de um processo de reestruturação que procurou atrair para dentro das grandes centrais as plataformas logísticas privadas. Para isto, as centrais incorporaram um conjunto de investimentos em logística, que ia desde a introdução da cadeia do frio, a partir de estímulos ao investimento privado, até a estruturação do transporte multimodal que ainda não existia nos grandes entrepostos (GREEN, 2003).

Estes mercados orientaram-se para estimular atividades que gerassem novos negócios, como os serviços de fornecimento customizado de alimentos para restaurantes e hotéis e o aumento do valor agregado das atividades realizadas pelos atacadistas, através de cooperações e integração entre diversos segmentos produtivos. Este processo de reestruturação dá origem à emergência um novo modelo de negócios que caracteriza os "mercados de terceira geração" cujas características principais são a busca de respostas mais homogêneas em escala nacional para desenvolver estratégias de cooperação entre os mercados; a integração progressiva e flexível do transporte multimodal e da cadeia do frio; o desenvolvimento de modernas estratégias e tecnologias para rastreabilidade; a incorporação das preocupações ambientais e de tratamento de resíduos e estratégias de flexibilização física e normativa para atender a atacadistas que demandam maior flexibilidade para atender novos nichos de mercados.

\section{A crise das Ceasas}

No Brasil, a crise das Ceasas não teve respostas efetivas do Estado. Os dados de estagnação da movimentação econômica das Centrais de Abastecimento brasileiras na comercialização de FLV refletem uma tendência internacional, mas também um processo depreciação das estruturas, das funcionalidades e principalmente dos processos de gestão dos nossos equipamentos.

As Centrais de Abastecimento brasileiras foram estruturadas originalmente tendo o centro de sua atividade econômica baseada no comércio direto da produção rural de produtos hortigranjeiros. Em sua concepção, o papel das centrais era o de organizar o mercado através do estabelecimento de padrões e regras de comercialização e propiciar condições de competição para favorecer tanto os produtores rurais quanto os consumidores. 
O amadurecimento da atividade comercial das Ceasas conformou aspectos e características que criaram obstáculos para um novo modelo de geração de valores baseados na relação direta, ou identificada, entre produtores e consumidores.

A primeira característica é de natureza organizacional. Aspectos de especificidade dos produtos hortigranjeiros relacionados à perecibilidade (firmeza, amadurecimento biológico, tipos de embalagens), à escala produtiva e comercial suscitam diferentes formatos organizacionais entre agentes econômicos. Por esta razão surgiram diversos atacadistas especializados em produtos específicos que são fornecedores de atacadistas generalistas. Esta situação ocorre mesmo nos mercados spot como os "mercados livres do produtor". Estes formatos geralmente envolvem um número grande de intermediários e agentes comerciais (CUNHA, 2012).

A segunda característica é de origem conceitual. A noção de território e de cultura local, de organização social e comunitária, e em essência, das relações sociais não faziam parte do arcabouço teórico e institucional que norteou a criação do modelo brasileiro de comércio atacadista. Esta certamente é uma das razões pelas quais as Ceasas têm tanta dificuldade em implantar programas efetivos de desenvolvimento rural e de apoio à agricultura familiar (CUNHA, 2014).

Os grupos sociais que hoje se enquadram na categoria de agricultura familiar eram tratados indistintamente como "pequena agricultura", cuja característica era de pequena escala produtiva e baixa modernização. A importação do modelo europeu (francês e espanhol) nunca incorporou no Brasil efetivamente a questão de organização da produção rural.

O terceiro aspecto é de natureza organizacional. Em muitas Centrais de Abastecimento, os espaços de uso livre foram gradativamente apropriados privadamente, com a destinação permanente para produtores ou intermediários de áreas 'livres'. Na maioria dos casos, a lucratividade das atividades comerciais decorrentes da intermediação (funcional ou especulativa) estimula o produtor rural a mudar seu core business da produção para a atividade comercial, mantendo o vínculo rural apenas como passaporte para a utilização do mercado destinado a produtores.

O quarto aspecto é relacionado ao poder de mercado das Centrais de Abastecimento. Na última década a quantidade comercializada de FLV - Frutas, Verduras e Legumes cresceu menos do que a renda e o PIB e o preço dos principais 
produtos FLV não é mais formado dentro das Centrais de Abastecimento, mas nos brokers e mercados especializados (CUNHA, 2010).

A quinta característica é de diretrizes, ou da ausência delas, decorrente da desestruturação do sistema atacadista brasileiro. De forma geral, as Centrais de Abastecimento brasileiras não têm um referencial temático, institucional e organizacional claro, que oriente suas ações estratégicas para promover o desenvolvimento regional e atender novas demandas dos consumidores. As consequências desta ausência de diretrizes resultaram nas seguintes situações:

As Ceasas não criaram espaços diferenciados para comercialização de produtos de locais, orgânicos e comunitários. As ações de estímulo à melhoria de pós-colheita no campo são pontuais e mantêm o conceito de assistência e orientação para técnicas produtivas em detrimento da etapa de transformação (pós-colheita, embalagem) e comercialização.

1. As ações de apoio à agricultura familiar são pontuais nas Centrais de Abastecimento e só recentemente estas passaram a incorporar ou desenvolver alguns projetos voltados para a agricultura familiar. De forma geral, pode-se afirmar que as Ceasas não diferenciam efetivamente a agricultura familiar e não criaram condições diferenciadas para este ator produtivo que está atuando cada vez mais no fornecimento de alimentos para programas públicos - como é o caso da alimentação escolar.

2. Há um virtual desconhecimento por parte das Centrais de Abastecimento sobre as demandas do consumidor final bem como do segmento de restauração alimentar (restaurantes, hotéis, cafés).

3. Dados estatísticos regularmente coletados pelas Ceasas não se tornam informações estratégicas para negócios dos produtores. É lamentável observar que as recorrentes crises de abastecimento de determinados produtos hortícolas, como aconteceu com o tomate em 2012 no Brasil, poderiam ter sido antecipadas pela análise dos dados que as Centrais produzem com regularidade.

A busca por uma maior eficiência e prestação de serviços deve ser um elemento fundamental dos objetivos de Estado em relação a uma Política de Abastecimento. As Centrais de Abastecimento são agentes importantes para a promoção da Segurança Alimentar, viabilizando e garantindo uma da oferta regular e diversificada de alimentos de qualidade, a preços justos e que atendam às demandas e necessidades dos consumidores. 


\section{Referências para um novo modelo de abastecimento: mercados de $4^{\mathrm{a}}$ Geração (4G)}

A análise crítica do desempenho recente das centrais de abastecimento brasileiras não pode ser tomada como argumento para a desconsideração de sua importância no abastecimento. A crise das Ceasas é essencialmente uma crise do modelo vigente, mas o papel das Centrais de Abastecimento permanece fundamental, principalmente em países em via de desenvolvimento como o Brasil.

As Centrais desempenham um papel importante nas estratégias nacionais de promoção de Segurança Alimentar, para consumidores familiares e também institucionais, como a alimentação escolar e entidades assistenciais as atividades de educação alimentar, orientação nutricional, aproveitamento integral de alimentos estímulo ao consumo de alimentos saudáveis e frescos.

Um aspecto que é fundamental, e próprio das Centrais de Abastecimento, e que reflete diretamente no abastecimento urbano é o papel que estas têm na economia e na vida cotidiana do entorno dos entrepostos. Como equipamento urbano, as Centrais de Abastecimento são também locais de negócios, lazer e integração social importante nas áreas onde estão instalados. A dimensão das políticas urbanas e do impacto urbano é também um dos elementos que deve estar no rol de atenções e preocupações.

Há um consenso de que o conceito de Segurança Alimentar expressa as demandas básicas da sociedade em relação ao suprimento de alimentos. Ou seja, a disponibilidade constante de alimentos baratos, com qualidade sanitária, nutritivos, saudáveis, com qualidade comercial e que atendam às demandas de seus hábitos de consumo. No entanto, as demandas por alimentos são muito mais complexas atualmente, em decorrência do processo acelerado de urbanização da sociedade, que estabeleceu uma forte identificação entre alimentação, saúde e modo de vida urbano.

Há uma mudança significativa nas perguntas que os consumidores tendem a fazer para definir o valor dos produtos que desejam consumir. A sociedade se transforma na velocidade do acesso às informações e gera novas formas de organização social e relações de consumo. Hoje a informação é um atributo indissociável dos produtos de consumo e como o custo de obter informações caiu drasticamente, as informações que o consumidor de alimentos procura da procura 
por preço para incorporar quesitos referentes à relação entre alimento e saúde e alimento e estilo de vida na hora da compra (CUNHA, 2015 b).

$\mathrm{O}$ acesso às informações e o empoderamento do consumidor se refletiu no interesse em conhecer aspectos do processo produtivo para escolher produtos produzidos, elaborados, manipulados com segurança, pela ausência de contaminantes químicos e biológicos, ou mesmo pela escolha das técnicas de produção, como os orgânicos. São exemplos desta tendência a busca de alimentos frescos, alimentos com origem identificada e principalmente os produtos orgânicos.

A busca de alternativas ao sistema predominante de cadeias de fornecimento longas e centralizadas pela aliança agroindustrial/grande varejo se revela pela possibilidade de buscar outras formas de acesso e de possibilitar outros quesitos de preferência atribuídos aos alimentos.

É inquestionável que a modernização logística é necessária para promover maior eficiência econômica das atividades de abastecimento. No entanto, é necessário estabelecer uma configuração a geração dos novos valores desejados por consumidores, produtores, atacadistas e varejistas. Essa configuração pode ser definida como Centros/Polos Agroalimentares ou "Mercados de Quarta Geração". Para isto é necessário que as Centrais de Abastecimento incorporem em seu planejamento estratégico os agentes produtivos, produtores e comerciantes, os consumidores sob um conceito ampliado de Segurança Alimentar.

A modernização logística e de infraestrutura - absolutamente necessária deve estar orientada para assegurar novas bases operacionais. Em suma, a tríade Infraestrutura, Informações e Serviços e Gestão e Controle deve promover novos produtos, novos serviços, novos negócios, atendendo aos padrões de consumo. Ainda mais, deve possibilitar a inserção de novos produtores e regiões no mercado, estimulando e desenhando sua base regional de produção.

Os resultados que se espera de uma Central de Abastecimento de Quarta Geração são:

1. Infraestrutura e gestão que favoreçam transações rápidas, com baixos custos de transação em ambiente limpo e seguro;

2. A agregação de valores aos produtos comercializados, baseados na classificação, rastreabilidade, sanidade e qualidade comercial;

3. Valorização dos aspectos locais e regionais e de gastronomia regional que favoreçam e desenvolvimento de marcas locais; 
4. Inteligência de negócios, baseada na geração de informações, a partir de banco de dados multidimensional que estabeleça a identificação do produto, do produtor e do local da produção e conte com cadastro de produtores e compradores atualizado, acessível e informatizado;

5. Desenvolvimento das habilidades e competências de produtores rurais, atacadistas e prestadores de serviço voltados para o atendimento das demandas dos compradores e consumidores finais e serviços de orientação dos consumidores;

6. Realização de novos negócios e serviços, como processamento de alimentos, fornecimento para alimentação institucional, criação de marcas, etc.

\section{Considerações finais}

O presente capítulo apresentou a evolução do sistema de abastecimento de alimentos nas grandes cidades brasileiras desde o final do século XIX até os dias de hoje. Observou-se pela análise que as soluções encontradas para o escoamento da produção voltada para o consumo alimentar urbano sempre surgiram de forma atrasada e, muitas vezes, improvisada. Assim ocorreu com a instalação dos antigos mercados municipais que procuravam disciplinar o comércio de alimentos que se dava de forma descentralizada e sob péssimas condições sanitárias. Mais tarde vieram as Ceasas como forma de racionalizar o atacado reduzindo a intermediação e, como consequência, o preço dos alimentos.

Há 50 anos, quando se instalaram as primeiras Centrais de Abastecimento no Brasil, os grandes centros atacadistas europeus iniciaram uma revolução no atacado de alimentos introduzindo métodos de gestão modernos, controle do capital compartilhado, logística multimodal e, mais tarde, a informática na gestão da informação. Essas mudanças progrediram aproximando o modelo público de atacado da grande distribuição privada. A incorporação de serviços ao atacado de alimentos colocou o pequeno varejista em uma situação um pouco menos desfavorável em relação às grandes redes de supermercados. Os serviços permitiram também a emergência de um setor de refeições coletivas e até mesmo um pequeno setor de processamento de alimentos a partir do novo modelo de Centrais de Abastecimento.

No Brasil, salvo exceções, o modelo de Centrais de Abastecimento permaneceu estagnado e foram realizadas poucas mudanças ao longo do tempo. 
Enquanto até mesmo os países da América Latina e Caribe conseguiram renovar suas Centrais de Abastecimento adaptando-se aos novos tempos no sentido de garantir uma alternativa segura para a comercialização dos produtos da pequena agricultura, as Centrais de Abastecimento brasileiras viam de perto o avanço dos supermercados e a sua incapacidade de atuar em favor das políticas de abastecimento.

Dada a impossibilidade financeira e a falta de determinação política para uma mudança em direção a um modelo de Centrais de Abastecimento de Terceira ou de Quarta Geração as Ceasas caminham para o seu desmantelamento. As ações recentes de iniciativas de privatização das Ceasas federais de São Paulo e Belo Horizonte estão envoltas em uma pesada nuvem de incertezas em relação ao modelo de abastecimento que é necessário para abastecer as cidades brasileiras.

$\mathrm{Na}$ realidade, a questão essencial não é a privatização das Ceasas pois muitas das suas funções já foram apropriadas por interesses particulares. Seria melhor colocar o tema da desprivatização das relações econômicas das Centrais de Abastecimento e com isso garantir a geração de bens públicos como informações, competitividade, eficiência e oportunidades para inserção de produtores alijados do mercado, cabendo até discutir o modelo de gestão e da composição acionária.

A agenda para a construção de um novo sistema de Centrais de Abastecimento de Alimentos é ampla e a sua reestruturação deve mirar objetivos ainda mais desafiadores.

O primeiro é atender aos novos valores desejados por consumidores que querem informação embarcada nos produtos: qual seu valor nutricional, qual sua qualidade sanitária, como foi produzido, onde foi produzido e quem o produziu. A variável preço é resultado desta escolha, sendo que o mais caro não necessariamente é o melhor. Produtos locais, mais frescos e com menor intermediação comercial podem ter preços mais compensadores.

O segundo objetivo é fazer com que a escolha dos consumidores favoreça a entrada de novas regiões agrícolas, valorizando os aspectos locais e regionais associados à gastronomia.

O terceiro desafio é oportunizar aos operadores atacadistas ser também agentes eficientes e inovadores. Para isso as transações nos mercados atacadistas necessitam ser rápidas, com baixos custos de transação em ambiente físico limpo e seguro estando - comprador e vendedor, amparados por uma inteligência de negócios. 
Mais além, mirando as condições presentes da economia nacional as Centrais de Abastecimento devem oferecer condições e oportunidades para inserção de produtores rurais que estão à margem do sistema da grande distribuição supermercadista. Isso pode ser feito facilmente, através da identificação e valorização do quesito regional, social e da forma de produção, como produtos locais, produtos orgânicos, de fair trade e oriundos da produção familiar.

\section{REFERÊNCIAS}

BELIK, W. Agroindústria e Política Agroindustrial no Brasil. In: Dimensões do Agronegócio Brasileiro: Políticas, Instituições e Perspectivas. Brasília: NEAD, 2007, v.1, p. 141-170, 2007.

CADILHON, J. J. et al. Wholesale Markets and Food Distribution in Europe: New Strategies for Old Functions. Discussion Paper N. 2: Centre for Food Chain Research, Department of Agricultural Sciences, Imperial College London, January 2003.

CANO, W. Raízes da concentração industrial em São Paulo. 4. ed. Campinas, SP: UNICAMP/IE, 1998.

CUNHA, A. R. A. A. Dimensionando "o passeio das mercadorias": uma análise através dos dados do Prohort. Revista de Politica Agrícola, Ano XXIV, N. 4, out./nov./ dez., 2015, p. 55-63.

(b)Abastecimento alimentar: a superação do padrão Velho-Obsoleto para o Novo-Ancestral. In: SCHNEIDER, Sergio; CRUZ, Fabiana Thomé da; MATTE, Alessandra. Alimentos para produtores e consumidores: conectando novas estratégias de abastecimento de alimentos. Porto Alegre: UFRGS, 2015. p. 54-70. (Série Estudos Rurais).

. O sistema atacadista alimentar brasileiro: origens, destinos. Campinas: Instituto de Economia - Unicamp (tese de doutoramento). Campinas, 2010.

; CAMPOS, J. B.; ALMEIDA, G. O Sistema Brasileiro de Centrais de Abastecimento e os mercados de Quarta Geração. 49 ${ }^{\circ}$. Encontro da Sober - Sociedade Brasileira de Economia, Administração e Sociologia Rural. Anais. Belo Horizonte. MG. 2011.

CUNHA, A. R. A. A; BELIK, W. (2015) Abastecimento no Brasil: o desafio de alimentar as cidades e promover o Desenvolvimento Rural. Políticas públicas de desenvolvimento rural no Brasil / Organizadores Catia Grisa e Sergio Schneider. Porto Alegre: UFRGS, 2015.

. Entre o declínio e a reinvenção: atualidade das funções do sistema público atacadista de alimentos no Brasil. Revista da SOBER. Vol. 50, n 3, jul/set., 2012. 
CYRILlO, D. C. O papel dos Supermercados no varejo de Alimentos. Relatório de Pesquisa. São Paulo: IPE / USP, 1987.

FAO. Urban Food Distribution in Europe. "Food into Cities Collection" DT/61-02E. Food and Agriculture Organization of the United Nations Rome, 2002.

FRANÇA, C. R. \& REZENDE, V. F. O desaparecimento do Mercado Municipal Praça XV, fator na formação do espaço público da Cidade do Rio de Janeiro. Rio de janeiro: I Encontro Nacional da Associação Nacional de Pesquisa e Pós-Graduação em Arquitetura e Urbanismo, 2010.

GREEN, R. Mercados mayoristas: el inicio de uma nueva era? Distribuicion y consumo. Mercasa. Nov. dec. 2003. Madrid. ES, 2003.

GREEN, R; SCHALLER, B. Logística e racionalização comercial da área dos produtos alimentares frescos. In: BELIK, W. e MALUF, R. S. (Org.). Abastecimento e segurança alimentar: os limites da liberalização. Campinas: IE/UNICAMP, 2000, p 107-130.

JUNQUEIRA, A. H.; PEETZ, M. 100 anos de feiras livres na Cidade de S. Paulo. São Paulo: Via Impressa, 2015.

SEIDLER, E. Wholesale Market Development - FAOs Experience. Paper prepared for the 22nd Congress of the World Union of Wholesale Markets Durban, South Africa. September 2001. 


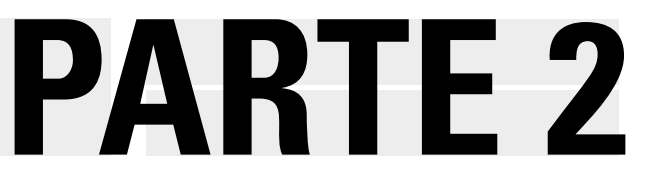

MERCADOS INSTITUCIONAIS 


\title{
Aquisição de produtos da agricultura familiar para a alimentação escolar nos estados de São Paulo, Paraná, Santa Catarina e Rio Grande do Sul
}

\author{
Rozane Marcia Triches \\ José Giacomo Baccarin \\ Carla Rosane Paz Arruda Teo \\ Vanessa Ramos Kirsten
}

\section{Introdução}

Este capítulo pretende realizar uma sistematização de dados de quatro estados brasileiros - São Paulo, Paraná, Santa Catarina e Rio Grande do Sul - no que tange à aquisição de produtos da agricultura familiar (AF) pelo Programa Nacional de Alimentação Escolar (PNAE) ${ }^{1}$.

Para tanto, foram utilizados dados secundários como as chamadas públicas (CPs) e as prestações de contas (PCs) das prefeituras municipais e secretarias estaduais de Educação. Em primeiro lugar, pretendeu-se, a partir das PCs, identificar o percentual médio de recursos destinados a essas compras pelos municípios (escolas municipais) e secretarias estaduais (escolas estaduais), observando como as aquisições evoluíram nos anos de 2011 até 2014, bem como verificar o nível de atendimento dessas entidades executoras (EEx) à legislação do PNAE (Artigo 14 da Lei 11.947/2009). Na sequência, realizou-se uma análise das CPs do ano de 2013 em alguns municípios selecionados, identificando o tipo

\footnotetext{
1 Estes estados foram escolhidos pois foram os estudados nos Editais Chamada MCTI/Ação Transversal - LEI/CNPq No 82/2013 Segurança Alimentar e Nutricional no Âmbito da UNASUL e África e Chamada MCTI-CNPq/MDS-SAGI No 24/2013 Desenvolvimento Social, nos quais os autores eram pesquisadores. São os estados mais meridionais do Brasil, com presença significativa da agricultura familiar modernizada.
} 
de alimento solicitado no que diz respeito ao grau de processamento, à periodicidade, ao número de pontos de entrega e à definição dos preços a serem pagos pelos produtos aos agricultores.

Essas análises são importantes, considerando que, desde a obrigatoriedade da compra pública de alimentos da AF para a alimentação escolar, em 2009, poucos estudos têm realizado avaliações quantitativas que ofereçam dados sobre a evolução dessas aquisições nos estados brasileiros. Além disso, as políticas públicas necessitam de avaliações de sua efetividade, eficácia e eficiência. Por isso, propõe-se aqui fazer esta leitura, enfatizando a análise da eficiência das CPs como um instrumento para realizar tais compras, identificando suas fragilidades. Segundo Marinho e Façanha (2001), eficiência diz respeito à otimização da aplicação dos meios (métodos, recursos financeiros, materiais, pessoais) em relação aos resultados alcançados pelo projeto ou política. Dessa forma, objetiva-se identificar se o instrumento das chamadas públicas é eficiente em alcançar seu objetivo ou se o mesmo ainda possui falhas a serem sanadas.

Por outro lado, também cabe comparar os quatro estados e suas particularidades, observando similaridades e diferenças que podem refletir no maior ou menor sucesso na implementação da política. Em especial, deve-se levar em conta que a presença da agricultura familiar é muito significativa nos três estados da região Sul, com porcentuais acima de $60 \%$ de seus agricultores, e menos importante em São Paulo.

Dito isso, este capítulo está dividido em mais três seções. A seguinte apresenta a metodologia, esclarecendo quais foram os instrumentos e métodos utilizados para a seleção, coleta e análise de dados. Posteriormente, analisa-se o atendimento ao Artigo 14 da Lei 11.947/2009 e a adequação das CPs aos AFs, apresentando, na sequência, as considerações finais.

\section{Metodologia}

A pesquisa desenvolvida teve caráter quantitativo descritivo. As informações foram obtidas por meio de fontes documentais, chamadas públicas e prestações de contas, disponíveis em sites de prefeituras e secretarias de Educação de São Paulo, Paraná, Santa Catarina e Rio Grande do Sul e do Fundo Nacional de Desenvolvimento da Educação (FNDE). 
Para alcançar o primeiro objetivo - avaliar o atendimento ao Artigo 14 da Lei 11.947/2009 -, lançou-se mão das prestações de contas disponíveis no site do FNDE (www.fnde.gov.br) para os anos de 2011 a 2014 de todos os municípios dos estados estudados e das secretarias estaduais de Educação.

Quanto ao atendimento do Artigo 14, as prefeituras foram classificadas de acordo com os seguintes níveis: não atendimento (0\%); atendimento parcial (gasto menor que $25 \%$ com produtos da agricultura familiar); atendimento legal (gasto entre $25 \%$ e $35 \%$ com produtos da agricultura familiar); atendimento diferenciado (gasto acima de $35 \%$ com produtos da agricultura familiar).

Para analisar especificidades das chamadas públicas, realizou-se uma amostragem dos municípios. Foi considerada uma amostra de aproximadamente 5\% das prefeituras dos estados, tomando-se o cuidado de estabelecer uma estratificação entre elas, de acordo com as macrorregiões e a população, de forma que se contemplassem cerca de $10 \%$ do alunado. O número de alunos por município foi obtido através do banco de dados do Instituto Nacional de Estudos e Pesquisas Educacionais Anísio Teixeira (INEP). Os municípios foram caracterizados como: muito pequeno (abaixo de 20.000 habitantes); pequeno (de 20.000 a 100.000 habitantes); médio (de 100.000 a 500.000 habitantes); grande (acima de 500.000 habitantes).

Foram utilizadas as CPs do ano de 2013, obtidas nos sites oficiais das prefeituras e/ou por contato telefônico com os gestores responsáveis pelo PNAE nos municípios. Desses documentos foram analisados os seguintes itens: a) produtos solicitados, segundo grau de processamento; b) adequação das chamadas públicas no que tange às informações sobre periodicidade, pontos de entrega e presença dos preços que seriam pagos pelos alimentos.

Quanto ao grau de processamento, os gêneros alimentícios solicitados nas CPs analisados foram categorizados como in natura, que não passam por nenhum tipo de processamento, e como altamente processados, que exigem, muitas vezes, a transformação industrial fora do espaço produtivo do agricultor familiar ou suas organizações. Destacaram-se essas duas classificações no intuito de identificar a adequação dos produtos solicitados ao público da $\mathrm{AF}$ e à questão de saúde dos escolares, já que na concepção desta política pretendia-se melhorar também a qualidade nutricional dos cardápios.

Quanto à entrega dos produtos, sua periodicidade foi classificada em: entregas de 2 a 5 vezes por semana; semanais; entregas de 1 a 2 vezes por mês; 
não consta a informação. Já em relação aos pontos de entrega, as chamadas foram classificadas em: muito descentralizadas, com mais de 50 unidades de recebimento (URs); descentralizadas, entre 11 e 50 URs; pouco descentralizadas, entre 2 e 9 URs; centralizadas, com uma única UR para os produtos da AF.

Após a coleta dessas informações, os dados quantitativos foram tabulados e analisados por meio de estatística descritiva simples e apresentados como frequências absolutas e relativas, utilizando-se o programa estatístico Microsoft Excel .

\section{Atendimento ao Artigo 14 da Lei 11.947/2009 pelos governos estaduais e por prefeituras municipais}

Ao analisar as prestações de contas dos municípios e das secretarias de Educação dos estados analisados (Tabela 1), verificam-se algumas diferenças e semelhanças entre eles. Em relação à média do percentual de compra dos municípios, o estado do Rio Grande do Sul destaca-se como o que vem atendendo à aquisição mínima desde 2011, em média estável e crescente. Os municípios de Santa Catarina, até 2013, apresentaram média limítrofe, muito próxima de 30\%, chegando a ultrapassá-la em 2014. Já os municípios de São Paulo e Paraná não haviam conseguido atingir essa média no período analisado.

Tabela 1 - Percentual médio de atendimento ao Artigo 14 da Lei 11947/2009 do conjunto dos municípios e secretarias estaduais de Educação (SEE) de São Paulo (SP), Paraná (PR), Santa Catarina (SC) e Rio Grande do Sul (RS), 2011 a 2014

\begin{tabular}{l|l|l|l|l|l}
\hline Ente federativo & 2011 & 2012 & 2013 & 2014 & Média \\
\hline SP - Municípios & 7,4 & 11,6 & 15,1 & 21,2 & 13,8 \\
\hline SP - SEE & 2,5 & 0,0 & 0,0 & 0,1 & 0,6 \\
\hline PR - Municípios & 16,6 & 19,6 & 17,1 & 26,3 & 19,9 \\
\hline PR - SEE & 3,1 & 15,5 & 29,4 & 51,2 & 24,8 \\
\hline SC - Municípios & 25,6 & 29,7 & 29,3 & 38,8 & 30,9 \\
\hline SC - SEE & 0,0 & 1,4 & 0,7 & 0,8 & 0,7 \\
\hline RS - Municípios & 32,3 & 37,4 & 35,6 & 46,0 & 37,8 \\
\hline RS - SEE & 0,0 & 0,0 & 15,9 & 30,6 & 11,6 \\
\hline
\end{tabular}

Fonte: FNDE, 2016 (elaborada pelos autores).

O estudo não se propôs a investigar os motivos das diferenças entre os entes federativos, mas é possível tentar entendê-los a partir de alguns fatores. Um 
desses motivos pode estar relacionado com a quantidade de AFs nos estados e com a produção de alimentos para consumo interno. Nos estados de Santa Catarina (SC) e Rio Grande do Sul (RS), segundo o Censo Agropecuário de 2006, havia maior número de AFs ( $87 \%$ e $86 \%$, respectivamente), se comparado a SP (36\%). No entanto, esse fator não responde totalmente pelas diferenças observadas, já que, nessa lógica, o Paraná também teria possibilidade de atingir maiores níveis de aquisição de produtos no período, visto que $80 \%$ dos estabelecimentos agropecuários do estado são da AF.

Nesse sentido, outro ponto pode ser considerado, como as experiências anteriores verificadas no estado do RS, que desponta como um dos pioneiros nestas compras no Brasil (TRICHES; SCHNEIDER, 2010; EMATER, 2005). Também se deve levar em conta a organização dos AFs no que diz respeito ao seu capital social nos estados mais meridionais. Destaca-se que tanto SC quanto RS e PR possuem uma agricultura familiar fortalecida por diversas organizações representativas que, historicamente, foram sendo mobilizadas na região Sul do Brasil. O Movimento dos Trabalhadores Rurais Sem-Terra (MST), o Movimento dos Atingidos por Barragens (MAB), o Movimento das Mulheres Trabalhadoras Rurais (MMTR), o Movimento de Mulheres Camponesas (MMC) e o Movimento dos Pequenos Agricultores (MPA) e, posteriormente, a Federação dos Trabalhadores na Agricultura Familiar da Região Sul (Fetraf-Sul) articularam o sindicalismo cutista e a seção brasileira da Via Campesina (PICOLOTTO, 2007) na região, demandando maior intervenção estatal com vistas a beneficiar a $\mathrm{AF}$.

Ao atentar-se para a aquisição de produtos pelas secretarias estaduais, os dados são menos positivos, identificando-se médias bem menores do que a soma dos municípios em todos os estados, com exceção do Paraná. Nesse estado, em 2014, mais de 50\% dos recursos foram utilizados para compra de produtos da AF. Com um número menor, mas também expressivo, as escolas estaduais do Rio Grande do Sul conseguiram média superior a 30\% neste mesmo ano. Por outro lado, Santa Catarina e São Paulo demonstraram um atendimento praticamente nulo desde 2011.

Um dos fatores que pode, pelo menos em parte, explicar a baixa aquisição pela SEE do estado de Santa Catarina é o fato de que os serviços de alimentação escolar da rede estadual são terceirizados. A contratação de empresas pode estar interferindo na operacionalização das compras de alimentos, já que a Lei 11.947/2009 e suas resoluções consideram que tais aquisições devem ser feitas 
pelas entidades executoras (EEx) e não por empresas privadas contratadas (CEAE/ SC, 2015). A baixa adesão do Governo do Estado de São Paulo à determinação do Artigo 14 pode estar relacionada ao menor poder de pressão de seus agricultores familiares e à falta de prioridade política em atender esse público.

Em uma tentativa de aprofundar a análise, apresenta-se na Tabela 2 o número e a porcentagem de municípios dos respectivos estados, em cada faixa de atendimento, nos anos de 2011 e 2014. Percebe-se, sem exceções, que em todos os estados vem crescendo o número de locais que estão alcançando um percentual maior do que $25 \%$ do recurso federal destinado ao PNAE, investido em produtos da AF. O destaque, novamente, recai sobre o estado do RS, com 65\% de seus municípios aplicando mais do que $35 \%$ do recurso para este fim, seguido por SC (59\%) e PR (39\%).

Em contrapartida, mais de 53\% dos municípios paulistas ainda não destinavam sequer $25 \%$ dos recursos federais para essas compras, em 2014. Em comparação com outras sistematizações realizadas por Thies et al. (2016) e pelo Programa das Nações Unidas para o Desenvolvimento (PNUD, 2015), a partir da mesma fonte de dados (FNDE), observam-se algumas questões relevantes. Thies et al. (2016) verificaram que, em 2011, apenas $26,8 \%$ das prefeituras brasileiras conseguiram atingir/ultrapassar o percentual mínimo; em 2013, o percentual de prefeituras nessa condição caiu para 25,6\%; e, em 2014, passou para 39,5\%, o que significou um aumento importante. Para os autores, a região Sul, em todos os anos da série, apresenta os percentuais mais elevados, acima da proporção nacional em todo o período (2011 - 59,1\%; 2012 - 66,6\%; 2013 - 64,0\%; $2014-77,0 \%$ ), o que corrobora os resultados desta pesquisa. Ainda conforme os autores, em $2014,88,6 \%$ das prefeituras sulistas que receberam recursos do PNAE realizaram aquisições da agricultura familiar para a alimentação escolar. A região Sudeste, que abrange o estado de São Paulo, apresentou percentuais bastante similares aos números nacionais, sendo que, em 2014, 77,3\% das prefeituras realizaram aquisições da agricultura familiar. 
Tabela 2 - Número de municípios de acordo com cumprimento percentual do Artigo 14 entre 2011 e 2014, nos estados de São Paulo, Paraná, Santa Catarina e Rio Grande do Sul X percentual de compras da $\mathrm{AF}$

\begin{tabular}{|c|c|c|c|c|c|c|c|c|c|}
\hline & & & $\begin{array}{l}\text { Não } \\
\text { consta } \\
\text { PC }\end{array}$ & $0 \%$ & $\begin{array}{l}0,1- \\
10,0 \%\end{array}$ & $\begin{array}{l}10,1- \\
25,0 \%\end{array}$ & $\begin{array}{l}25,1- \\
35,0 \%\end{array}$ & $\begin{array}{l}\text { Mais } \\
35,1 \%\end{array}$ & Total \\
\hline \multirow{4}{*}{$\begin{array}{l}\text { São } \\
\text { Paulo }\end{array}$} & \multirow[t]{2}{*}{2011} & $\mathrm{n}$ & 20 & 345 & 79 & 88 & 58 & 55 & 645 \\
\hline & & $\%$ & 3,2 & 53,5 & 12,2 & 13,6 & 9,0 & 8,5 & 100,0 \\
\hline & \multirow[t]{2}{*}{2014} & $\mathrm{n}$ & 8 & 175 & 55 & 114 & 114 & 179 & 645 \\
\hline & & $\%$ & 1,2 & 27,1 & 8,7 & 17,7 & 17,7 & 27,7 & 100,0 \\
\hline \multirow[t]{4}{*}{ Paraná } & \multirow[t]{2}{*}{2011} & $\mathrm{n}$ & 2 & \begin{tabular}{|l|}
107 \\
\end{tabular} & 30 & 57 & 121 & 82 & 399 \\
\hline & & $\%$ & 0,5 & 26,8 & 7,5 & 14,3 & 30,3 & 20,5 & 100,0 \\
\hline & \multirow[t]{2}{*}{2014} & $\mathrm{n}$ & 1 & 70 & 26 & 62 & 85 & 55 & 399 \\
\hline & & $\%$ & 0,2 & 17,5 & 6,5 & 15,5 & 21,3 & 38,8 & 100,0 \\
\hline \multirow{4}{*}{$\begin{array}{l}\text { Santa } \\
\text { Catarina }\end{array}$} & \multirow[t]{2}{*}{2011} & $\mathrm{n}$ & 4 & 59 & 17 & 33 & 71 & 111 & 295 \\
\hline & & $\%$ & 1,4 & 20,0 & 5,8 & 11,2 & 24,1 & 37,6 & 100,0 \\
\hline & \multirow[t]{2}{*}{2014} & $\mathrm{n}$ & 0 & 33 & 15 & 27 & 46 & 174 & 295 \\
\hline & & $\%$ & 0 & 11,2 & 5,1 & 9,1 & 15,6 & 59,0 & 100,0 \\
\hline \multirow{4}{*}{$\begin{array}{l}\text { Rio } \\
\text { Grande } \\
\text { do Sul }\end{array}$} & \multirow[t]{2}{*}{2011} & $\mathrm{n}$ & 3 & 92 & 20 & 52 & 111 & 219 & 497 \\
\hline & & $\%$ & 0,6 & 18,5 & 4,0 & 10,5 & 22,3 & 44,1 & 100,0 \\
\hline & \multirow[t]{2}{*}{2014} & $\mathrm{n}$ & 1 & 35 & 11 & 58 & 69 & 323 & 497 \\
\hline & & $\%$ & 0,2 & 7,0 & 2,2 & 11,7 & 13,9 & 65,0 & 100,0 \\
\hline
\end{tabular}

Fonte: FNDE, 2016 (elaborada pelos autores). PC: Prestação de Contas.

Para o PNUD (2015) e segundo dados do FNDE, conforme o Gráfico 1, em 2013, a média de compra dos estados do Sul estava em torno de $20 \%$ e a dos estados do Sudeste, em torno de $16 \%$, o que é similar às constatações deste estudo. Chama a atenção, no entanto, a evolução da região Centro-Oeste em 2013, comparada aos anos anteriores, colocando-se à frente dos estados da região Sul e Sudeste neste ano e sendo a única que obteve média superior a 30\% de aquisição de produtos da AF. Segundo Thies et al. (2016), embora as diferenças não sejam tão expressivas, em termos gerais, a região Centro-Oeste é a que apresentou os percentuais mais baixos nos anos anteriores ${ }^{2}$. Em 2014, verifica-se aumento das compras em todas as regiões, mas somente a região Sul consegue atingir o mínimo

2 Identificou-se que, no ano de 2013, nas planilhas do FNDE (2016), a Secretaria Estadual de Ensino de Goiás aparece como se tivesse adquirido da AF mais de $100 \%$ do recurso recebido do governo federal. No entanto, na prestação de contas, verificou-se que a mesma $\mathrm{EEx}$, em seu demonstrativo físico-financeiro, refere que não alcançou os $30 \%$ mínimos exigidos por lei, sugerindo uma divergência de informação. Dessa forma, parece ter ocorrido um erro ao computar este dado nas planilhas elaboradas pelo FNDE. Assim, a informação pode estar incorreta e, pelo seu 
de $30 \%$ exigido por lei, considerando-se a totalidade do recurso utilizado para este fim, frente ao recebido pelo FNDE.

Gráfico 1 - Percentual de recurso utilizado para compras de produtos da agricultura familiar para a alimentação escolar das entidades executoras dos estados que compõem cada região do país - 2011 a 2014

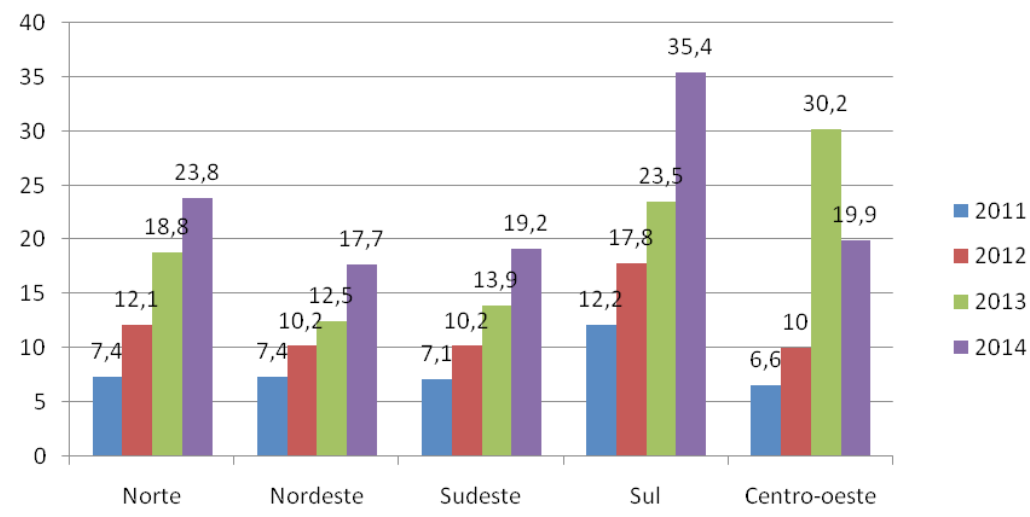

Fonte: PNUD (2015) e dados do FNDE (2011-2014).

Dessa forma, observa-se, em nível nacional, uma ascendência no número de EEx que passam a adquirir produtos da $\mathrm{AF}$ em crescentes proporções, a exemplo dos estados que analisamos neste estudo.

\section{Adequação das chamadas públicas}

O primeiro passo na avaliação dessas compras públicas é identificar se o método utilizado para tal é eficiente. Nesse sentido, importa verificar se as CPs estão sendo adequadas ao público que se deseja alcançar - os AFs. A substituição das licitações convencionais pelas compras via CPs impõe a necessidade de adaptações nas ações das prefeituras municipais. Grande parte delas, tradicionalmente, organizava suas compras de produtos alimentícios através de licitações com participação de empresas fornecedoras especializadas, normalmente não localizadas no município e que ofereciam, geralmente, produtos 
com considerável grau de processamento, facilmente armazenáveis, exigindo pouca manipulação por parte das funcionárias encarregadas do preparo da refeição escolar.

Foram analisadas as CPs de municípios dos quatro estados no ano de 2013. O total de chamadas foi de: 463, 212 de São Paulo (156 municípios); 43 do Paraná (26 municípios); 94 de Santa Catarina (46 municípios); 114 do Rio Grande do Sul (52 municípios).

Ao elaborar uma CP, um quesito bastante importante é identificar os produtos que são produzidos pelos AFs e elaborar os cardápios a partir dessa oferta. Notadamente, a AF caracteriza-se por produzir, em sua maior parte, produtos in natura ou minimamente processados ${ }^{3}$. Dessa forma, observou-se nas CPs o grau de processamento dos gêneros alimentícios solicitados para verificar se eram adequados em relação aos produzidos pelos AFs. Verifica-se que, em todos os estados, mais de $80 \%$ das CPs analisadas solicitavam produtos in $n a-$ tura, o que vem ao encontro desta premissa (Tabela 3). No entanto, os estados do Rio Grande do Sul e de Santa Catarina traziam, em 71,9\% e 62,8\% das CPs, respectivamente, produtos com alto grau de processamento.

Esse dado leva a três considerações importantes. A primeira diz respeito à potencial habilidade e às condições criadas aos AFs desses estados para viabilizar o processamento e a consequente agregação de valor a seus produtos, o que é positivo do ponto de vista da renda desses fornecedores. Alguns estudos (TRICHES e BACCARIN, 2016; TRICHES e SCHNEIDER, 2012) indicam a dificuldade da $\mathrm{AF}$ em adequar-se às normas sanitárias, fiscais, ambientais para formalizar seus produtos e participar dos mercados institucionais. Assim sendo, produtos processados e de origem animal produzidos pelas AFs são mais difíceis de comercializar para o PNAE, pois necessitam adequação às legislações. Portanto, este estudo aponta para a possibilidade de que, nesses estados, as AFs estejam mais desenvolvidas neste quesito do que em São Paulo e no Paraná. A segunda consideração é de que, em vez de ser um ponto positivo, esta constatação seria um ponto negativo, já que as solicitações por produtos altamente processados não seriam compatíveis com a produção da $\mathrm{AF}$ e, portanto,

3 De acordo com o estudo de Monteiro et al. (2010), os alimentos podem ser classificados de acordo com o método de processamento utilizado para a sua produção. A classificação divide-se em: alimentos in natura ou minimamente processados (podem sofrer transformações físicas); ingredientes culinários processados (substâncias extraídas dos alimentos in natura ou minimamente processados); e os alimentos altamente processados (resultam de processos industriais), que possuem alta concentração de sódio, gordura saturada e açúcar. 
demonstrariam apenas incongruência entre a demanda das EEx e a oferta dos AFs. Essa é uma hipótese a ser testada em outros estudos, pois necessitaria da avaliação do que se produz em cada local (município) para observar a coerência entre o que se pede e aquilo que os AFs têm para oferecer. Uma terceira consideração remete às questões de consumo, já que um dos objetivos das compras da AF é ter um abastecimento de alimentos menos processados e de melhor qualidade nutricional, favorecendo a saúde escolar. Nesse ponto, a aquisição de produtos altamente processados prejudicaria a eficácia do processo, ao frustrar este objetivo.

Tabela 3 - Presença de produtos com diferentes graus de processamento nas chamadas públicas de São Paulo, Paraná, Santa Catarina e Rio Grande do Sul, 2013

\begin{tabular}{l|l|l|l|l|l|l|l|l}
\hline \multirow{2}{*}{$\begin{array}{l}\text { Nível de } \\
\text { Processamento }\end{array}$} & \multicolumn{2}{l|}{ São Paulo } & \multicolumn{2}{l|}{ Paraná } & \multicolumn{2}{l}{ Santa Catarina } & \multicolumn{2}{l}{ Rio G. do Sul } \\
\cline { 2 - 10 } & $\mathrm{n}$ & $\%$ & $\mathrm{n}$ & $\%$ & $\mathrm{n}$ & $\%$ & $\mathrm{n}$ & $\%$ \\
\hline In natura & 174 & 82,1 & 39 & 90,7 & 81 & 86,2 & 105 & 92,1 \\
\hline Alt. Processado & 50 & 23,6 & 18 & 42,0 & 59 & 62,8 & 82 & 71,9 \\
\hline
\end{tabular}

Fonte: Chamadas públicas de 2013 (elaborada pelos autores).

Outro aspecto a ser considerado diz respeito ao número de pontos de entrega dos produtos da agricultura familiar. A partir de 2013 (Resolução FNDE no 26), pode-se incluir o custo do transporte no limite de $\mathrm{R} \$ 20$ mil que o agricultor pode vender para cada EEx do PNAE. Mesmo assim, prefeituras que centralizam o recebimento dos alimentos favorecem mais a agricultura familiar do que aquelas que determinam a entrega muito descentralizada, em todas as unidades em que são servidas refeições. Na Tabela 4, observa-se que na maior parte das CPs avaliadas dos estados de SP, PR e RS as entregas são centralizadas, ou seja, ocorrem em apenas um ponto de recebimento. No entanto, mais de um quarto das Cps das prefeituras gaúchas e paulistas solicitam entrega em mais de 10 pontos, o que onera os custos com a logística para os AFs. Porém, mais preocupante é a omissão dessa informação nos editais, o que foi evidenciado em mais de $60 \%$ deles no estado de SC e em quase $30 \%$ no estado do PR. Trata-se de informações essenciais para que os fornecedores tenham condições de avaliar se o preço a ser pago pelos produtos vale a pena ou não e, assim, possam cumprir seus compromissos até o final do contrato, sem prejuízos para ambas as partes. 
Tabela 4 - Número de unidades de entrega registradas nas chamadas públicas de São Paulo, Paraná, Santa Catarina e Rio Grande do Sul em 2013

\begin{tabular}{l|l|l|l|l|l|l|l|l}
\hline \multirow{2}{*}{$\begin{array}{l}\text { Unidades de } \\
\text { Recebimento }\end{array}$} & \multicolumn{2}{l}{ São Paulo } & \multicolumn{2}{l|}{ Paraná } & \multicolumn{2}{l|}{ S. Catarina } & \multicolumn{2}{l}{ R.G. do Sul } \\
\cline { 2 - 9 } & $\mathrm{n}$ & $\%$ & $\mathrm{n}$ & $\%$ & $\mathrm{n}$ & $\%$ & $\mathrm{n}$ & $\%$ \\
\hline 1 & 109 & 51,4 & 43 & 64,6 & 8 & 8,5 & 56 & 49,1 \\
\hline 2 a 10 & 15 & 7,1 & 13 & 7,0 & 8 & 8,5 & 20 & 17,5 \\
\hline 11 a 50 & 49 & 23,1 & 0 & 0,0 & 14 & 14,9 & 28 & 24,6 \\
\hline Mais de 50 & 8 & 3,8 & 0 & 0,0 & 6 & 6,4 & 2 & 1,8 \\
\hline Não consta & 30 & 14,2 & 17 & 29,5 & 58 & 61,7 & 8 & 7,0 \\
\hline
\end{tabular}

Fonte: Chamadas públicas de 2013 (elaborada pelos autores).

Outra análise realizada a partir das CPs tratou da periodicidade de entrega dos produtos. Nos estados de SP e RS, mais de 38\% dos editais previam entregas semanais (Tabela 5). No RS, essa periodicidade é seguida por entregas quinzenais $(37,7 \%)$. No entanto, mais uma vez, chama a atenção a falta de informações nos editais de SC e PR, com 78,7\% e 93\%, respectivamente, de CPs em que não consta este dado (Tabela 5). Trata-se de outro problema que, somado ao anterior, impacta nos custos logísticos, já que, além de saber em quantas unidades serão entregues os gêneros, também é necessário saber quantas vezes isso será feito durante o período de vigência do contrato. Em estudo de Da Silva et al. (2016), foi verificado que o custo de transporte é o mais representativo de todos.

Notou-se, também, que este custo é diretamente afetado pelo grau de processamento e diferenciação dos produtos. Os produtos em estado bruto ou com um grau mínimo de processamento e de diferenciação (caso das categorias in natura e folhosos) apresentam custo de transporte mais elevado, podendo chegar a $96 \%$. Nas demais categorias, o transporte também se apresenta como o custo mais oneroso. Portanto, a ausência dessa informação nas CPs dificulta ao agricultor o cálculo de custo/benefício para tomada de decisão em participar do mercado.

A partir dessas constatações, observou-se também nestes editais a presença dos preços, que, segundo a Resolução FNDE n 26/2013, devem constar nas $\mathrm{CPs}$ e serão os efetivamente pagos aos AFs. Assim, não há competição entre os interessados, sendo que a escolha dos concorrentes se baseia em critérios de desempate como sua localização (município, território, estado e país, nesta ordem), identificação (prioridade para quilombolas, indígenas ou assentados), forma de organização (formal sobre informais e individuais) e tipo de produção (ecológicos sobre convencionais). Contudo, observou-se que muitas $\mathrm{CPs}$ não continham essa informação, situação mais acentuada em São Paulo, onde, em 2013, apenas $37,2 \%$ das chamadas públicas informavam o preço. No Paraná e em Santa 
Catarina esses números foram mais altos, 93,0\% e 85,1\%, respectivamente, enquanto que o Rio Grande do Sul ficou em situação intermediária, com $60 \%$ das CP apresentando esta informação.

Tabela 5 - Periodicidades de entrega registradas nas chamadas públicas de São Paulo, Paraná, Santa Catarina e Rio Grande do Sul, 2013

\begin{tabular}{l|l|l|l|l|l|l|l|l}
\hline \multirow{2}{*}{ Período } & \multicolumn{2}{l}{ São Paulo } & \multicolumn{2}{l|}{ Paraná } & \multicolumn{2}{l}{ Santa Catarina } & \multicolumn{2}{l}{ Rio G. do Sul } \\
\cline { 2 - 10 } & $\mathrm{n}$ & $\%$ & $\mathrm{n}$ & $\%$ & $\mathrm{n}$ & $\%$ & $\mathrm{n}$ & $\%$ \\
\hline 2-5/semana & 20 & 9,4 & 0 & 0 & 4 & 4,3 & 8 & 7,0 \\
\hline Semanal & 81 & 38,2 & 2 & 4,7 & 11 & 11,7 & 54 & 47,4 \\
\hline 1 a 2/mês & 17 & 8,0 & 0 & 0 & 13 & 13,8 & 43 & 37,7 \\
\hline Outro & 26 & 12,3 & 0 & 0 & 7 & 7,5 & 8 & 7,0 \\
\hline Não consta & 87 & 41,0 & 41 & 93,0 & 74 & 78,7 & 25 & 21,9 \\
\hline
\end{tabular}

Fonte: Chamadas públicas de 2013 (elaborada pelos autores).

Em muitos casos, o fato desta informação não constar nas CPs pode se dever a uma orientação jurídica do procurador da prefeitura. Muitos procuradores continuam entendendo que não se deve estabelecer previamente o preço nas $\mathrm{CPs}$ e que o mesmo deve ser objeto de disputa entre os agricultores. Isso fere frontalmente o Artigo 14, que procura garantir um preço mínimo aos agricultores familiares participantes do PNAE.

Estes dados dão conta da dificuldade ainda expressiva que os municípios têm para elaborar uma CP. Este fato prejudica não só as próprias EEx, mas, principalmente, os agricultores, que ficam privados de informações que amparem a sua avaliação sobre a viabilidade de sua participação ou não no Programa. Informações como preço a ser pago, número de locais e periodicidade de entrega facilitariam a decisão do agricultor no sentido de se comprometer com a oferta de determinados produtos, considerando a logística, a frequência, a quantidade que deve ser entregue, em que datas e a que preço. Estas questões são elementares para a melhor organização dos AFs e para a análise de custo/benefício, impactando na eficiência do processo.

\section{Considerações finais}

Este capítulo trouxe algumas informações sobre as compras públicas de AFs para o PNAE nos estados de SP, PR, SC e RS. Verificou-se que o RS se 
destaca, tanto no número de municípios que já adquirem, quanto no percentual de recursos destinado por eles aos AFs. Este estado é seguido por SC, PR e $\mathrm{SP}$, respectivamente. No entanto, verifica-se que, em relação às secretarias estaduais de Educação, o PR é o estado destaque, enquanto SC e SP, infelizmente, não chegaram a uma média de $1 \%$ de compras da AF nos quatro anos (2011 a 2014). Este dado é preocupante, pois não pode ser explicado pela simples falta de produção por AFs ou por qualquer outra condicionalidade do Artigo 14, já que seus municípios estão evoluindo positivamente neste sentido. Os motivos devem ser melhor investigados, mas supõe-se que uma das causas deste baixo índice de aquisição seja o fato de que a gestão dos serviços de alimentação escolar das secretarias de Educação destes estados é, essencialmente, terceirizada. A empresa terceirizada acaba por frustrar a aproximação entre consumidores (Estado) e produtores (AFs), inviabilizando, na maioria das vezes, essa compra.

Por outro lado, observa-se que, na esfera municipal dos estados mais exitosos (RS, SC e PR), há maior presença de AFs e um acúmulo de capital social dado por movimentos sociais que configuram maior pressão desta categoria junto ao Estado. No entanto, mais pesquisas devem ser desenvolvidas para que se tenha melhor entendimento destas diferenças entre os estados.

Nesse sentido, o estudo analisou a eficiência das CPs em alcançar este objetivo nos diferentes lugares, e verifica-se que a sua elaboração pode também estar sendo um dos determinantes da maior ou menor eficácia do Artigo 14. Foram justamente nos estados do Paraná, São Paulo e Santa Catarina que se observaram os maiores problemas na elaboração das CPs. No Paraná, verificou-se uma proporção elevada de CPs que não possuíam informações como a periodicidade das entregas. Em São Paulo, apenas um pouco mais de um terço delas apresentava os preços a serem pagos aos AFs. Em Santa Catarina, observou-se grande proporção de editais sem informações sobre o número de locais de entrega e periodicidade. Já no Rio Grande do Sul, esta falta de informações é bem menor em todos os quesitos, exceto no que tange aos preços. Portanto, há que se observar o quanto é importante a elaboração de uma CP com todas as informações relevantes para que os AFs tenham condições de analisar a possibilidade de acessá-la ou não. Isso será primordial para o maior êxito em alcançar os objetivos propostos pelo PNAE.

Finalmente, este capítulo demonstra algumas lacunas de conhecimento, das quais devem se ocupar outros estudos, de forma a contribuir para o 
aprofundamento desta temática, principalmente a partir de abordagens comparativas e qualitativas, que evidenciem novos elementos que respondam às perguntas que ainda estão em aberto.

\section{REFERÊNCIAS}

CONSELHO ESTADUAL DE ALIMENTAÇÃO ESCOLAR (CEAC) de Santa Catarina. Nota Pública de Esclarecimento. Florianópolis, 2015.

DA SILVA, W. H. et al. Custos logísticos associados ao comércio institucional de alimentos na agricultura familiar: o caso do Programa Nacional de Alimentação Escolar (PNAE). Anais do $54^{\circ}$ Congresso da Sociedade Brasileira de Economia, Administração e Sociologia Rural. Maceió, 2016.

EMATER. Manual sobre Alimentação Escolar Ano I. Porto Alegre: Ascar/Emater, 2005.

MARINHO, A.; FAÇANHA, L. O. Programas sociais: efetividade, eficiência e eficácia como dimensões operacionais da avaliação. Rio de Janeiro: IPEA. Texto para Discussão 787, abril de 2001.

MONTEIRO, C. A. et al. A new classification of foods based on the extent and purpose of their processing. Cadernos de Saúde Pública, Rio de Janeiro, v. 25, n. 11, p. 20392049, nov. 2010.

PICOLOTTO, E. L. Movimentos sociais rurais no sul do Brasil: novas identidades e novas dinâmicas. Revista IDeAS, v. 1, n. 1, p. 60-77, 2007.

PROGRAMA DAS NAÇÕES UNIDAS PARA O DESENVOLVIMENTO (PNUD).

Escala de compras públicas de alimentos no Brasil. Working Paper no 134. 2015.

THIES, V. F.; et al. Potencial das compras públicas como mercado para a agricultura familiar - uma análise do PNAE entre 2011-2014. Anais do 54 ${ }^{\circ}$ Congresso da Sociedade Brasileira de Economia, Administração e Sociologia Rural. Maceió, 2016.

TRICHES, R. M.; BACCARIN, J. G. Interações entre alimentação escolar e agricultura familiar para o desenvolvimento local. In: TEO, C.R.P.A; TRICHES, R.M. (Org.). Alimentação Escolar: construindo interfaces entre saúde, educação e desenvolvimento. Chapecó: Argos, 2016, v. 1, p. 89-109.

; SCHNEIDER, S. Alimentação escolar e agricultura familiar: reconectando o consumo à produção. Saúde e Sociedade (USP. Impresso), v. 19, p. 933-945, 2010.

; SCHNEIDER, S. Desestruturar para construir: interfaces para a agricultura familiar acessar o programa de alimentação escolar. Estudos Sociedade e Agricultura (UFRJ), v. 20, p. 66-105, 2012. 


\title{
Dificuldades e recursos de superação mobilizados por atores sociais na aquisição de produtos da agricultura familiar para a alimentação escolar nos estados de São Paulo, Paraná, Santa Catarina e Rio Grande do Sul
}

\author{
Rozane Marcia Triches \\ Jose Giacomo Baccarin \\ Oscar Agustín Torres Figueredo \\ Aline Luiza Führ \\ Márcia Pozzagnol Mossmann \\ Denise Boito Pereira da Silva \\ Dienifer Heckler \\ Carla Rosane Paz Arruda Teo
}

\section{Introdução}

Este capítulo visa identificar, em diferentes municípios dos estados de São Paulo (SP), Paraná (PR), Santa Catarina (SC) e Rio Grande do Sul (RS) ${ }^{1}$, as dificuldades enfrentadas na aquisição de produtos da agricultura familiar (AF) para a alimentação escolar e as formas de superação empreendidas e relatadas por diferentes atores sociais - gestores, nutricionistas, agricultores familiares, integrantes dos Conselhos de Alimentação Escolar (CAE) e extensionistas rurais.

1 Esses estados foram escolhidos pois foram os estudados nos Editais Chamada MCTI/Ação Transversal - LEI/CNPq No 82/2013 Segurança Alimentar e Nutricional no Âmbito da UNASUL e África e Chamada MCTI-CNPq/MDS-SAGI No 24/2013 Desenvolvimento Social, nos quais os autores eram pesquisadores. 
Essas análises são importantes, na medida em que, após cinco anos de publicação da Lei 11.947/2009, em 2014, 36\% das Entidades Executoras (EEx) ainda não atendiam aos percentuais mínimos de compras da agricultura familiar (FNDE, 2016). Isto remete à seguinte pergunta: quais os problemas que ainda persistem e como os atores sociais estão superando estas dificuldades naqueles municípios mais exitosos?

Alguns estudos feitos (TRICHES; BACCARIN, 2016; TRICHES; SCHNEIDER, 2012; SOUZA, 2012; SARAIVA et al., 2013; BACCARIN et al., 2012), buscando identificar as questões que emperram a implementação destas aquisições públicas, verificaram que são diversas as problemáticas, bem como são diversas as realidades brasileiras e as formas com que, em cada lugar, são produzidas soluções diferenciadas para resolvê-las.

Portanto, análises comparativas de diferentes realidades permitem entender esta complexidade nos pontos em que se assemelham e se diferenciam, oferecendo pistas para que, a partir destas elucidações, possam ser pensadas revisões, intervenções e novas direções que contribuam para maior efetividade desta política.

O capítulo está construído, a partir de sua introdução, em uma seção metodológica e duas seções que abordam as dificuldades e as formas de superação por parte dos atores sociais na implementação do Artigo 14 da Lei 11.947/2009. Por fim, são apresentadas algumas considerações.

\section{Metodologia}

A pesquisa desenvolvida trata-se de um estudo de natureza qualitativa. Foram escolhidos oito municípios de cada um dos estados para realizar as entrevistas com os atores envolvidos com a implementação do Artigo 14 da Lei 11.947/2009.

Para a seleção destes municípios, em cada estado fez-se, em um primeiro momento, uma busca a sites e/ou se solicitou às prefeituras municipais as chamadas públicas referentes à aquisição de produtos da agricultura familiar para o PNAE nos anos de 2012 e 2013. De posse desses documentos, foram elencados os locais para realizar a pesquisa qualitativa a partir dos seguintes critérios:

a) número de habitantes, de forma a abranger a seguinte estratificação: Grupo 1 - municípios muito pequenos (com menos de 20.000 habitantes); Grupo 2 municípios pequenos (de 20.001 a 100.000 habitantes); Grupo 3 - municípios 
médios (de 100.001 a 500.000 habitantes); Grupo 4 - municípios grandes (com 500.001 ou mais habitantes) (IBGE, 2010).

b) Contemplar a diversidade de macrorregiões de cada estado.

Dessa forma, foram selecionados, aleatoriamente, dentro dos estratos estipulados acima, os municípios apresentados no Quadro 1.

Quadro 1 - Municípios participantes da pesquisa e respectivas populações em 2016

\begin{tabular}{|c|c|c|c|}
\hline Município & Habitantes & Município & Habitantes \\
\hline \multicolumn{2}{|l|}{ São Paulo } & \multicolumn{2}{|l|}{ Santa Catarina } \\
\hline São Bernardo do Campo & 736.466 & Joinvile & 515.288 \\
\hline Ribeirão Preto & 590.593 & Chapecó & 183.530 \\
\hline São Carlos & 221.950 & Lages & 156.727 \\
\hline Rio Claro & 178.950 & São Miguel do Oeste & 36.306 \\
\hline Monte Alto & 46.642 & Maravilha & 22.101 \\
\hline Araçoiaba da Serra & 31.321 & Pinhalzinho & 16.332 \\
\hline Capela do Alto & 17.532 & Coronel Freitas & 10.213 \\
\hline Taquaral & 2.726 & Cordilheira Alta & 3.787 \\
\hline \multicolumn{2}{|l|}{ Paraná } & \multicolumn{2}{|l|}{ Rio Grande do Sul } \\
\hline Curitiba & 1.746 .896 & Porto Alegre & 1.409 .351 \\
\hline Londrina & 506.645 & Caxias do Sul & 435.564 \\
\hline Cascavel & 286.172 & Pelotas & 328.275 \\
\hline Apucarana & 120.884 & Carazinho & 59.317 \\
\hline Assis Chateaubriand & 33.028 & São Gabriel & 60.425 \\
\hline Laranjeiras do Sul & 30.783 & Gramado & 32.273 \\
\hline Uraí & 11.472 & Herval & 6.753 \\
\hline Sulina & 3.397 & Cerrito & 6.402 \\
\hline
\end{tabular}

Fonte: Dados da pesquisa, 2016 (elaborado pelos autores).

Participaram da pesquisa os representantes do serviço de alimentação escolar - gestores e/ou nutricionistas do setor de alimentação escolar municipal, conselheiros do CAE do município que tivessem disponibilidade, independentemente do segmento de representação (pais, professores, sociedade civil), extensionista rural e agricultor familiar. Assim, em cada município pesquisado, foram elencados de quatro a cinco entrevistados.

Para cada grupo de atores sociais foram aplicados roteiros semiestruturados diferenciados. Entre os quesitos das entrevistas, abordaram-se as 
modificações no cardápio e no funcionamento do serviço local de alimentação escolar, as dificuldades de implementação do Artigo 14, o nível de participação dos atores sociais e sua experiência ou não com PNAE, suas dificuldades na execução do programa e benefícios alcançados. As entrevistas foram gravadas em dispositivo de áudio Voice Recorder e, posteriormente, transcritas. Os dados foram analisados por categorização temática, segundo a técnica de análise de conteúdo, utilizando-se o software NVivo 8.

\section{Dificuldades de organização da demanda e da oferta}

Em um primeiro momento, foram identificadas as dificuldades relatadas pelos diversos atores entrevistados nos municípios investigados. Verificou-se, a partir das questões levantadas pelos participantes, que vários problemas são recorrentes nos diferentes estados (Organograma 1).

A análise dos dados foi orientada pelas categorias de organização da demanda (das EEx) e de organização da oferta (dos AFs), incorporando questões que dificultam o processo em quatro dimensões temáticas, relativas a planejamento (de consumo e de produção), aspectos administrativos/burocráticos, questões do âmbito financeiro e da esfera de pessoal.

Organograma 1 - Dificuldades na organização da demanda e da oferta para a aquisição de produtos da AF para o PNAE

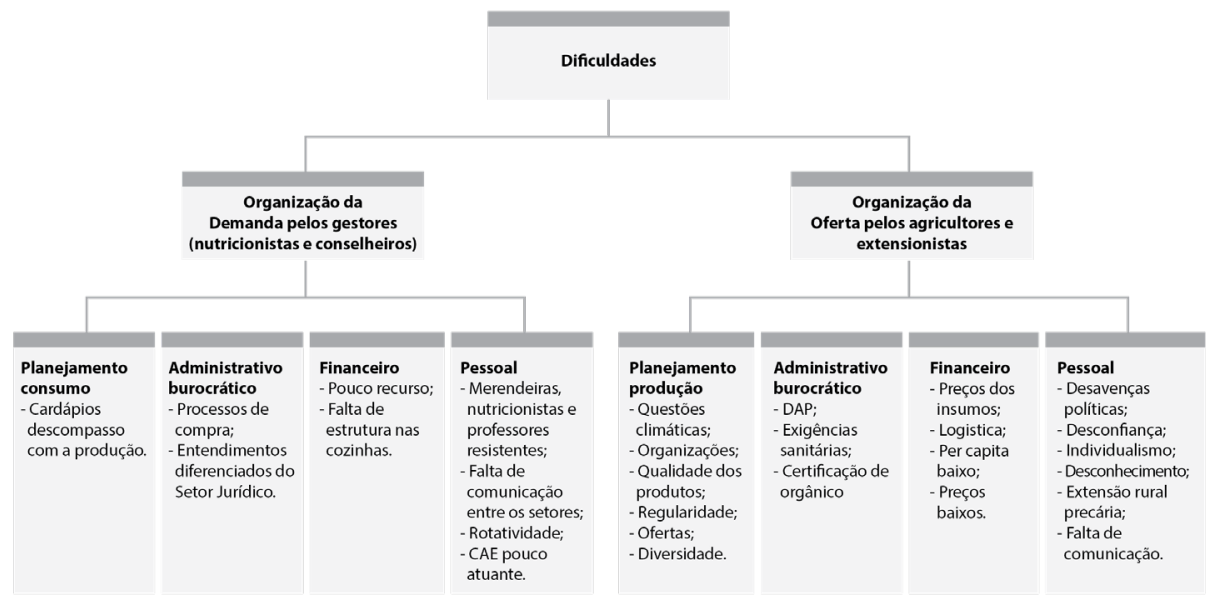




\section{Dificuldades em relação à organização da demanda}

No que diz respeito à organização da demanda, um aspecto considerado importante no planejamento é a elaboração dos cardápios. Muitos agricultores citaram que os nutricionistas planejam o cardápio sem dialogar com os produtores e que não compreendem que a $\mathrm{AF}$ não opera na mesma dinâmica das centrais de abastecimento (CEASAs), que disponibilizam todos os produtos em grandes quantidades, padronizados e em qualquer época do ano (agricultores de SP). Da mesma forma, os nutricionistas também frisaram ter dificuldade de saber o que é produzido no município e na região, quem são os AFs e, assim, mapear a produção local para adequarem a elaboração de cardápios a ela (nutricionistas do PR).

$\mathrm{Na}$ dimensão dos aspectos administrativos/burocráticos, identifica-se que as compras públicas evoluíram no sentido de desburocratizar o processo ao possibilitar a dispensa licitatória, no caso das compras da AF. No entanto, em alguns locais, ainda são observadas dificuldades no entendimento da legislação do PNAE, sobretudo dos setores jurídico e administrativo. Em muitos municípios as aquisições ainda são realizadas por meio de licitações (Pregão Presencial e Carta Convite, principalmente) por considerarem que a dispensa infringe a Lei 8.666/1993. Nesse sentido, corroboram alguns depoimentos:

[...] aí nos deparamos com a seguinte situação que nós tínhamos, que estavam há muitos anos no processo de licitações, que não aceitavam a existência de uma lei nova, então a gente tentava dialogar, mas não. A lei nova, a lei, ela permite, abre mão da licitação [...] (Extensão Rural, RS).

Ah, e uma dificuldade também é o setor de compras entender que a chamada pública não funciona pelo menor preço e, sim, que os critérios são diferenciados, e isso é uma dificuldade, de entendimento, eu acho, por que a Lei 8.666 é o que é levada em consideração, e aí essa dificuldade de adequação a essa legislação específica, do PNAE, pra chamada pública, são essas as dificuldades (Gestor, RS).

Uma dificuldade é com relação ao próprio sistema de compras da prefeitura, por que a chamada pública é diferente da licitação. Então, muitas vezes, por eles não conhecerem o processo a fundo, tem algumas burocracias que são desnecessárias caso se conhecesse o processo, e, quando se trata de alimentos, a própria prefeitura deveria dar uma atenção especial, porque alimento é algo que o produtor vai plantar e, se eu não comprar naquela época, ele não vai mais ter a produção, porque já foi, passou a época. Então, muitas 
96

vezes, chega na prefeitura, por vários motivos, demora muito a ser publicada a chamada pública e, quando de fato ela sai, que assina o contrato, o agricultor já não tem mais o alimento. (Nutricionista, SC).

No meu entender e no do jurídico a 8.666 é soberana. Por isso tem que haver concorrência de preços entre os agricultores. A gente faz a chamada e contrata que tiver o menor preço. (Nutricionista, SP).

Além desse viés de compreensão, observa-se também que a elaboração das chamadas públicas (CPs) nem sempre é adequada, levando às frustrações nas compras. Nesse sentido, muitos agricultores reclamam que são exigidas entregas dispersas com pouco volume de produto por ponto de fornecimento, que a quantidade solicitada de alguns produtos é muito baixa e não compensa financeiramente, que muitos produtos têm produção alta no período de férias escolares (agricultores de SP) e que, às vezes, se deparam com greves nas escolas (agricultores do PR). Todas essas questões fazem com que muitos AFs se desinteressem por este mercado, já que a organização de sua oferta esbarra na organização burocratizada/rígida da demanda.

Outro problema que afeta a organização da demanda são os poucos recursos remetidos à alimentação escolar pelas várias instâncias estatais (governos federal, estadual e municipal), o número limitado de profissionais para trabalhar nos locais e a falta de estrutura adequada nas cozinhas das escolas e depósitos das EEx (gestores do PR). Esses problemas, muitas vezes, prejudicam a compra de produtos dos AFs, visto que há que racionalizar-se recursos, adquirir produtos que exijam menos manipulação, menos processamento nas cozinhas e armazenamento nos depósitos.

Outro ponto que compromete a organização da demanda para adquirir produtos da $\mathrm{AF}$ diz respeito às questões de pessoal. Assim, há relatos de resistências de nutricionistas, cozinheiras e até mesmo de professores/diretores que consideram que comprar desses fornecedores exige mais dedicação, tempo e trabalho e que nem sempre seus produtos são de "boa qualidade" (CAEs de SP e PR; Agricultores e Gestores do PR). Além disso, consta que os diversos setores da Prefeitura não dialogam para realizar o planejamento, organizar as compras públicas e enfrentar os problemas e desafios que se colocam.

Por seu turno, o CAE é apontado em todos os estados como pouco participativo e atuante. Assim, a possibilidade de ser um local propício para debates, 
diálogos, interfaces e resolução de problemas, se mostra subutilizado. Por fim, outra questão foi a rotatividade de pessoal nas prefeituras, o que leva à necessidade permanente de inserção de novos atores no processo, em prejuízo de uma maior agilidade de sua evolução.

\section{Dificuldades em relação à organização da oferta}

Em relação aos problemas de planejamento na organização da oferta pelos AFs, vários pontos foram identificados nas entrevistas. Alguns difíceis de resolver, como as interferências climáticas que, invariavelmente, podem prejudicar a produção de alimentos, levando a quebras de safra e perdas irreparáveis aos AFs. Essa influência da natureza sobre a agricultura impacta nas outras questões levantadas, como a qualidade dos produtos, a regularidade e a diversidade de gêneros disponíveis. No entanto, apesar desta suscetibilidade, as questões mencionadas são passíveis de modificações. Houve, por parte dos gestores, nutricionistas e extensionistas rurais, várias menções a estes quesitos, independentemente do estado. São várias as queixas relativas à falta de oferta de uma gama de produtos em quantidade suficiente nos momentos necessários e em conformidade com o padrão de qualidade esperado. Foi uníssona a reclamação de que faltam agricultores familiares com produção em quantidade e diversidade para abastecer a alimentação escolar. Este relato leva a afirmações dos entrevistados de que os agricultores não se organizam entre eles e nem em sua própria produção, apresentando-se resistentes à adequação de suas condições às exigências do mercado institucional. Muitos depoentes consideraram o AF individualista e não afeito a formar associações e cooperativas, o que prejudicaria a sua inserção neste mercado, já que o planejamento da produção, da logística, das transações comerciais, entre outras questões, poderiam facilitar-se dentro desses espaços.

No que tange aos aspectos administrativos/burocráticos, surgiram dificuldades em conseguir a Declaração de Aptidão ao Pronaf (DAP), que é um dos documentos exigidos para que o agricultor possa participar do processo de $\mathrm{CP} \mathrm{e}$ elaboração do projeto de venda para alimentação escolar. A obtenção deste documento foi considerada pelos produtores como uma dificuldade, uma vez que, para tanto, é necessário que o agricultor atenda a uma série de requisitos que, 
98

até então, não eram necessários para comercializarem seus produtos em outros locais, como mercados e feiras.

Outro empecilho burocrático é entender, ter conhecimento e condições de se adequar às diversas legislações sanitárias, ambientais e fiscais. Muitos AFs revelam desconhecimento em relação aos caminhos que devem percorrer para legalizar suas agroindústrias. Qual a diferença entre legalizar uma agroindústria de laticínios e uma de panificados, por exemplo? São exigências sanitárias diferentes, com órgãos de registros diferentes. Este enredamento legal/burocrático ainda não é bem entendido e conhecido e, quando o é, os AFs podem não considerar vantajosa a formalização, já que os regramentos exigem adaptações que, por vezes, não valem à pena do ponto de vista financeiro.

Esta problemática também ocorre com a certificação orgânica. Verificou-se, nas entrevistas, que alguns municípios adquiriam orgânicos, mas nem sempre eram certificados. Perguntados sobre isso, observou-se que os AFs sentiam dificuldades, mesmo nos processos de certificação participativa, em conseguir este documento.

Identifica-se, deste modo, que tanto as questões de planejamento quanto as administrativas/burocráticas para a organização da oferta se sobressaem às da demanda. Não pareceu diferente com os quesitos financeiro e pessoal. Se um dos problemas da organização da demanda é a escassez dos recursos, na organização da oferta eles são ainda mais limitados. Tanto é assim que os AFs pontuaram os preços dos insumos e os custos da logística (transporte, embalagem, armazenamento e fiscais) como fortemente influenciadores no preço dos produtos finais. Por outro lado, consideraram que, muitas vezes, os preços pagos e o montante per capita que podem acessar por ano é baixo. Equacionando custos e ganhos, argumentam que nem sempre participar deste mercado se mostra atrativo, o que explicaria, em parte, a falta de AFs e de produtos que os gestores/nutricionistas/ CAEs reclamam.

Por fim, em relação às dificuldades da organização da oferta, surgem as questões da esfera de pessoal, como: conflitos e desavenças políticas; desconfiança do AF em relação ao Estado; o já referido individualismo; desconhecimento sobre este mercado; extensão rural precária e falta de comunicação entre AFs e gestores. Não é de hoje, e nem tampouco raro, que as 'politicagens' sejam intervenientes tácitas em relação às políticas - tanto na sua eficiência e implementação, quanto a quem se destinam e favorecem. Portanto, todos os municípios sentem, 
em menor ou maior grau, estas intervenções, que podem levar ao maior êxito ou, simplesmente, esvaziar esta política.

Assim, não é ao acaso que muitos AFs têm medo e desconfiança quando os mercados que acessam são suscetíveis a estas influências. Além do que, essa desconfiança se baseia na historicidade de suas relações com o Estado e suas políticas instáveis. $\mathrm{O}$ agricultor prima pela sua autonomia, o que pode ser confundido com individualismo. Logo, depender do Estado ou da iniciativa privada pode ser muito arriscado para a sua reprodução e a de sua família, o que leva o AF a ponderar com cuidado antes de colocar em risco sua estabilidade familiar. Essa também pode ser a explicação, ao menos parcial, para sua escolha em aderir ou não a uma associação ou cooperativa. A desconfiança é incrementada se ele desconhece este mercado. Mormente, o AF conhece os mercados informais ou utiliza de intermediários para vender seus produtos, pouco se envolvendo com as questões comerciais. Portanto, as muitas regras e exigências do PNAE nem sempre são de conhecimento do agricultor, o que faz com que ele não o acesse ou, quando o faz, se decepcione com os diversos requisitos a serem atendidos, alheios ao seu cotidiano, desistindo de inserir-se.

Sugere-se que fragilidades da comunicação entre AFs e gestores - ou seja, entre a produção e o consumo, ou entre a oferta e a demanda - seja um dos principais fatores que causam e acentuam esse contexto. Os gestores desconhecem os problemas dos agricultores e vice-versa, identificando-se, em muitas falas, uma culpabilização do outro pelo insucesso do Programa.

Fechando a seção, outra unanimidade nos diversos municípios analisados (com exceção daqueles do RS) refere-se à precariedade da extensão rural como facilitadora da organização da produção. Não como mediadora do processo, visto que em vários locais foi muito citada como um dos atores importantes para viabilizar o Artigo 14, dado seu papel na articulação entre produtores e gestores, mas como propiciadora de conhecimentos técnicos para a produção e econômicos para a venda. Vários AFs lamentam que não possuem este auxilio em relação à produção e à comercialização de seus produtos das entidades de ATER. Até a própria ATER dos estados apresenta precariedades em termos de pessoal e de condições materiais para isso, como manifestam representantes dos agricultores e da Extensão Rural: 
Precisaria maior incentivo com a assistência técnica, pois nós sentimos bastante falta (Agricultor, SC)

[...] o município é grande e tem um déficit de funcionários, nós somos dois técnicos só para todo município. Então, na medida do possível, a gente tá atendendo. Nós já tivemos equipes maiores, onde cada um tinha sua atividade (Extensionista rural, PR).

De forma bastante generalista, destacou-se, nesta seção, as dificuldades que vêm sendo referidas pelos atores envolvidos com a alimentação escolar e a agricultura familiar nos diferentes municípios destes quatro estados, observando-se que os percursos são parecidos, embora cada um possua suas particularidades. No entanto, o que faz a diferença em relação ao êxito do Artigo 14 é a forma com que os atores destes municípios encaram os problemas e os solucionam. Assim, a próxima seção trata de analisar como estes locais vêm enfrentando seus desafios para conseguirem adquirir produtos da $\mathrm{AF}$.

\section{Formas de superação: alinhando a demanda e a oferta}

Conforme o Organograma 2, visualizam-se as principais formas de superação relatadas nos municípios investigados.

\section{Formas de superação das dificuldades em relação à organização da demanda}

Em relação ao planejamento, observou-se que um dos passos relativos à demanda para alcançar o objetivo de adquirir produtos da AF foi a mudança dos cardápios de acordo com a produção dos agricultores locais, se adaptando a sua oferta. Alguns depoimentos nesse sentido:

[...] o meu agricultor, aqui, vende uma couve; eu prefiro mudar o cardápio e botar essa couve pra desenvolver o agricultor daqui e não o de fora. Errado ou não eu não sei, mas é minha obrigação fazer um projeto maior do local né, do que do outro (Gestor, RS). 
Eu acho que o primeiro caminho pra dar certo é fazer o mapeamento das chamadas públicas. Porque, daí, você já faz a chamada pública direcionada (Gestor, PR).

A primeira coisa foi conhecer a realidade do município, ver o que tinha, pra depois eu começar a pensar o que poderia colocar no cardápio $(\mathrm{Nu}-$ tricionista, SC).

Assim, coube aos gestores mapear a oferta que havia no município e, a partir do diálogo com os AFs, pensar no cardápio e na lista de compras. Portanto, esta aproximação surge nos depoimentos como um primeiro passo importante para o sucesso da política. Neste sentido, não só foi necessária a aproximação com o AF e a adequação do cardápio, pensando na sua oferta, como também a adaptação da logística para que as entregas fossem possíveis. Neste quesito, as CPs foram revistas, considerando o número e os locais de entrega e a quantidade dos produtos para evitar prejuízos aos AFs e favorecer o seu interesse em participar.

No que tange às formas de aquisição, muitos gestores consideraram que conseguiram mudar as percepções dos setores jurídicos e de compras com a consulta a outras prefeituras e com muitos diálogos esclarecedores e convincentes. É o que se percebe no depoimento de um extensionista rural:

[...] então, tá criado um grupo de trabalho de segmentos, quem deveria tá? Daí fomos dizendo à Secretária de Educação, à EMATER e, principalmente, envolvendo o pessoal das licitações, da Secretaria de Finanças e, a partir daí, fizemos reuniões de 15 em 15 dias. Daí, fomos crescendo cada vez mais... Aí nos damos conta de quem trancava o processo, que demorava a chamada pública... Envolvemos a procuradora do município, que convidamos para as reuniões e, quando ela entendeu a lei, ela mudou todo o cenário de P. ela entendeu que era uma lei de inclusão de pessoas e não uma lei de preços... (Extensão Rural, RS).

Com essas ações, os municípios passaram a planejar melhor sua demanda e oferecer condições menos burocratizadas aos AFs para participação nos editais de compras.

Em relação ao aspecto financeiro, não surgiram, nos depoimentos, incrementos de recursos para as aquisições, mas sim investimento nas estruturas físicas de cozinhas e depósitos para facilitar este processo. Além disso, também, em 
alguns casos, as EEx passaram a custear o transporte (aquisição de veículo para recolher os alimentos nas propriedades) e até as embalagens (gestores de SP e SC).

Outro ponto de destaque refere-se à forma de enfrentar os problemas com o fator humano. Dois pontos se destacam: a formação dos atores envolvidos e a intersetorialidade ou o diálogo entre os setores, como já colocado anteriormente. Em relação ao primeiro, muitos municípios evidenciaram a importância da formação de nutricionistas, cozinheiras, conselheiros, gestores, extensão rural e agricultores para conhecerem as legislações, motivarem-se e trabalharem em conjunto. Essas capacitações aconteceram em parceria com vários órgãos (Centros Colaboradores em Alimentação e Nutrição do Escolar - CECANES, Universidades, ONGs etc.) ou a partir de iniciativa das próprias prefeituras. Em relação à intersetorialidade, como já frisado, houve também relações entre secretarias como as da Agricultura, Saúde, Educação, Administração, entre outras, para resolução de diversos problemas.

Um dos gestores avalia:

Nesse desenvolvimento da proposta, eu acredito que seja importante esse engajamento, a vontade de fazer, o trabalho em equipe faz a diferença. $\mathrm{O}$ trabalho de equipe, então, ele é fundamental (Gestor, PR).

Porém, não só foram tomadas iniciativas em relação à demanda, mas os AFs também tiveram que realizar mudanças nos seus processos organizativos para acessar este mercado, como será apresentado a seguir.

\section{Formas de superação das dificuldades em relação à organização da oferta}

Se houve, por parte dos atores ligados à demanda, uma aproximação com os AFs, também houve um movimento no sentido inverso, a partir da dimensão da oferta, com iniciativas de aproximação dos AFs com os gestores públicos, buscando identificar suas necessidades de forma a poderem inserir-se neste mercado. 
Organograma 2 - Formas de superação das dificuldades na organização da demanda e da oferta para a aquisição de produtos da AF para o PNAE

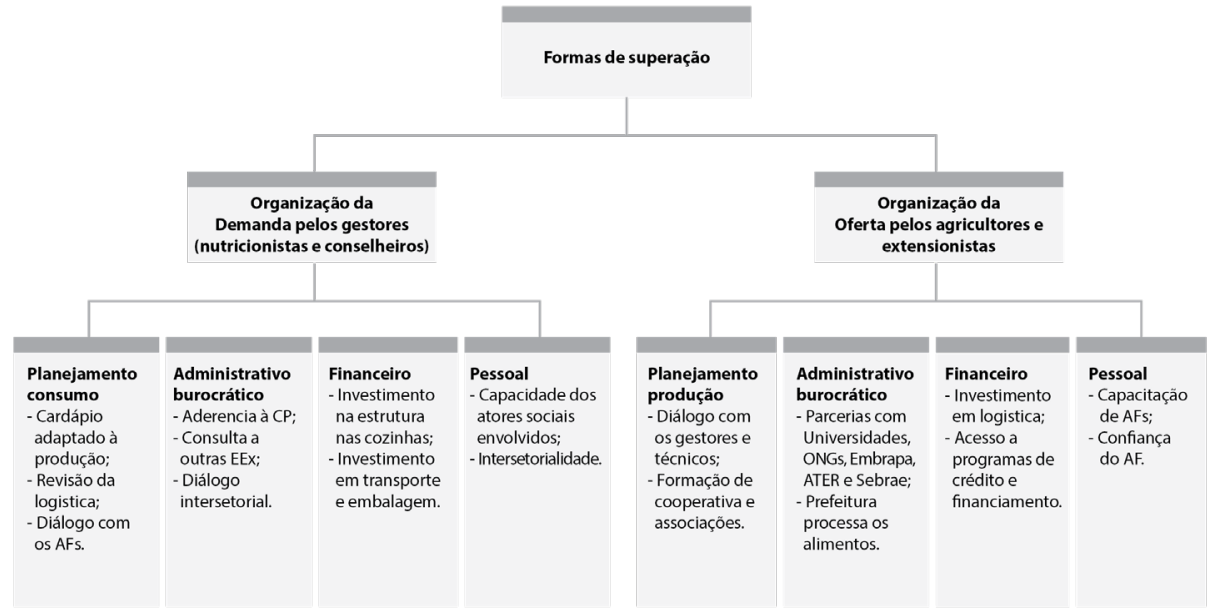

Além dessa estratégia, os AFs usaram, para suplantar os problemas administrativos/burocráticos, parcerias externas com Universidades, Embrapa, ATER, Sebrae, entre outros. Estas parcerias serviram ao compartilhamento de conhecimentos e informações, assim como para viabilizar a documentação para formalização dos produtos no que concerne à certificação orgânica, inspeção sanitária, formação de grupos informais para acessar o PNAE, entre outros aspectos.

Em algumas prefeituras, a questão do processamento dos alimentos foi assumida pelo próprio setor público, contornando a dificuldade de formalização das agroindústrias da $\mathrm{AF}$ (Gestor de SP).

Mesmo com esses apoios, o agricultor também começou a investir mais nos processos logísticos, principalmente para fazer frente às entregas e exigências deste mercado, além de passar a buscar outras políticas para obter créditos e financiamentos. $\mathrm{Na}$ avaliação de um dos agricultores familiares entrevistados, de Santa Catarina, "a cooperativa também teve que se adequar pra poder fornecer pra alimentação escolar. Tivemos que alugar um barracão pra fazer o depósito, comprar caminhões pra entregar os alimentos".

Por fim, foi necessário fazer com que o agricultor entendesse melhor o funcionamento do Programa e confiasse no Estado. Dessa forma, vários municípios citaram momentos em que os AFs foram chamados para participar de atividades no sentido de envolvê-los, motivá-los, esclarecê-los e dar suporte para as questões de produção, processamento e comercialização de seus produtos. Mais do que 
isso, foram necessários esforços para que o AF fosse conquistado, depositando confiança no processo, como avalia um dos gestores:

\begin{abstract}
Ah, isso é uma caminhada, uma caminhada de muito diálogo, de confiança também, porque a gente tem que fazer com que esses agricultores, os novos que a gente quer chamar, acreditem, sim, que vão ser pagos, que podem negociar com a prefeitura, enfim, mas é uma caminhada assim (Gestor, RS).
\end{abstract}

Destarte, verifica-se que, para que haja superação das dificuldades elencadas anteriormente, são necessárias diversas estratégias que reúnem intervenções no planejamento, processos administrativos/burocráticos, investimentos e pessoal, tanto na dimensão da demanda quanto na da oferta. Como já observado, cada realidade é única, mas os pontos abordados aqui são comuns a muitas das experiências analisadas, e, portanto, devem receber mais atenção dos gestores públicos, agricultores e demais atores envolvidos.

\title{
Considerações finais
}

Este capítulo buscou sumarizar a realidade que os municípios dos estados de SP, PR, SC e RS ainda estavam enfrentando depois de cinco anos da existência da obrigatoriedade da aquisição de produtos da AF pelo PNAE. Muitos municípios ainda não conseguiram atender ao Artigo 14 da Lei 11947/2009, frente a várias dificuldades que ainda se opõem a este processo. Evidenciou-se que a organização da oferta se mostra mais complexa do que a da demanda, já que mais problemas foram citados pelos depoentes, sendo vários deles de difícil resolução.

Assim, não é só necessário flexibilizar condutas e convencer atores, como foi possível identificar entre os problemas na maior parte das questões relacionadas à organização da demanda, mas, também, fazer mudanças estruturais profundas para resolver as questões da oferta. Destas, destaca-se a necessária intervenção estatal para criar as condições para que os AFs acessem estes novos canais de comercialização. Exemplo disso são as indispensáveis revisões nas legislações sanitárias e fiscais adequadas à agricultura familiar e o fortalecimento da ATER com base agroecológica. Também é importante que mude a própria visão do agricultor em relação aos mercados e ao Estado, buscando maior pró-atividade.

Em relação às formas de superação, as experiências demonstram que são necessários alguns ingredientes importantes para ultrapassar as dificuldades, 
tanto na oferta quanto na demanda. Observou-se que o diálogo, as parcerias, a intersetorialidade, as formações/capacitações e a soma de esforços, permitiram aos AFs e aos gestores entender melhor o outro, entender o sentido e o funcionamento das coisas, ocorrendo uma flexibilização dos diversos domínios na busca de soluções. Também foram essenciais os investimentos do Estado no nível municipal que se configuraram em vários locais, buscando viabilizar essas aquisições.

A partir desses dados, é possível compreender um pouco melhor porque existem locais mais ou menos exitosos na implementação desta política, mas também salienta-se que, independentemente do local, os problemas estruturais devem ser considerados, cabendo um papel importante ao Estado para que as EEx consigam atender e até suplantar o exigido pelo Artigo 14.

\section{REFERÊNCIAS}

BACCARIN, J. G. et al. Agricultura Familiar e Alimentação Escolar sob a vigência da Lei 11.947/2009: adequação das Chamadas Públicas e disponibilidade de produtos no Estado de São Paulo em 2011. In: $50^{\circ}$ Congresso da Sociedade Brasileira de Economia, Administração e Sociologia Rural. 2012. Vitória-ES, Anais..., Vitória: SOBER, 2012.

BRASIL. Lei N. 11.947, de 16 de junho de 2009. Dispõe sobre o atendimento da alimentação escolar e do Programa Dinheiro Direto na Escola aos alunos da educação básica. Diário Oficial da União. Brasília-DF. 16 de jul de 2009.

SARAIVA, E. B. et al. Panorama da compra de alimentos da agricultura familiar para o Programa Nacional de Alimentação Escolar. Ciência e Saúde Coletiva, Florianópolis - SC, v.18, n.16, p. 927-936, 2013.

SOUZA, L. B. B. Organizações da Agricultura Familiar no Estado de São Paulo e sua Experiência de Fornecimento para o PNAE. In: Projeto Nutre SP: análise da inclusão da agricultura familiar na alimentação escolar no estado de São Paulo. São Paulo: Instituto Via Pública, 2012.

TRICHES, R. M.; BACCARIN, J. G. Interações entre alimentação escolar e agricultura familiar para o desenvolvimento local. In: TEO, C.R.P.A; TRICHES, R.M. (Org.). Alimentação Escolar: construindo interfaces entre saúde, educação e desenvolvimento. Chapecó: Argos, 2016, v. 1, p. 89-109.

TRICHES, R. M.; SCHNEIDER, S. Desestruturar para construir: interfaces para a agricultura familiar acessar o programa de alimentação escolar. Estudos, Sociedade e Agricultura. Rio de Janeiro, vol. 20, n. 1, 2012: 66-105. 


\title{
Agricultura e mercados institucionais em Cabo Verde: avaliação e seguimento do programa-piloto "compras locais"
}

\author{
Vladmir Antero Delgado Silves Ferreira \\ Elsa Barbosa Simões
}

\section{Introdução}

O Programa de Cantinas Escolares em Cabo Verde foi iniciado com apoio do Programa Alimentar Mundial (PAM) em 1979 tendo como metas aumentar a escolarização, combater a insegurança alimentar e cobrir as necessidades nutricionais dos alunos. Com a transição de Cabo Verde para um país de rendimento médio, o PAM retirou-se e as cantinas passaram a ser geridas $100 \%$ pelo governo a partir de 2010. Foi assim estabelecido um programa de alimentação escolar com o objectivo de assegurar uma refeição diária a todas as crianças de escolas do Ensino Básico e do pré-escolar fornecendo pelo menos 15\% das necessidades nutricionais diárias dos estudantes (FICASE, 2015).

A gestão das aquisições eram centralizadas, realizadas com frequência trimestral e de poucos produtos básicos. Todos os alimentos adquiridos para constituir o menu, constituído por uma refeição quente por turno escolar, eram importados. Nenhum era adquirido dos produtores nacionais, menos ainda de agricultores locais. Os menus compostos por arroz, óleo, feijão, farinha de milho, farinha de trigo, sal, carne enlatada, açúcar e macarrão eram provenientes de diversos países ${ }^{1}$ (TRICHES, SCHNEIDER \& SIMÕES, 2013).

1 Macarrão do Egito, leite da Suíça, arroz e o açúcar da Líbia, Brasil ou Estados Unidos e feijão do Peru. 
Os gêneros mais utilizados para compô-los eram cereais como o arroz e o espaguete, os quais não eram produzidos no país. Por outro lado, seus congêneres nutricionais como inhame, mandioca, batata-doce, batata e milho, que configuravam a produção local, não constavam no menu elaborado. Um exemplo emblemático, referenciado no estudo levado a cabo por Triches, Schneider \& Simões, (2013) se refere ao feijão-congo, produzido em todas as ilhas agrícolas de Cabo Verde, no entanto, o que abastecia o Programa era adquirido do Peru.

Assim, tornou-se necessário, por um lado, melhorar a qualidade das refeições escolares e, por outro, promover a educação nutricional, reduzir a pobreza e estimular o setor agroalimentar nacional. Era preciso, portanto, introduzir mudanças estruturais no Programa, descentralizando as compras públicas e introduzindo produtos locais no menu.

Estudos e experiências levadas a cabo em outros países nos apresentam vários exemplos bem-sucedidos de compras de alimentos de agricultores por parte de escolas e do poder público local e o seu potencial em proporcionar o abastecimento com baixos custos, promovendo a produção e circulação de mercadorias, ativando as economias e favorecendo a conexão entre produção e consumo, minimizando os gastos com transporte, incentivando a cultura alimentar e a vocação agrícola do local (TRICHES \& SCHNEIDER, 2010).

É nesse contexto que o projeto-piloto "Compras locais" foi implementado de junho de 2012 a junho 2014 em Cabo Verde, com o intuito de, enquanto um programa experimental, proporcionar inputs com vista diversificação da ementa escolar, abastecimento das cantinas escolares (do pré-escolar e do básico) ${ }^{2}$ com produtos nacionais como frutas, legumes, pescado e feijões e estabelecendo parcerias entre os vários atores envolvidos para melhorar a qualidade nutricional das refeições escolares, estimulando a economia local.

O projeto foi desenvolvido com apoio da Organização das Nações Unidas para Alimentação e Agricultura (FAO), do Programa Alimentar Mundial (PAM), da Organização Mundial da Saúde (OMS) e do Fundo das Nações Unidas para

2 O sistema educativo cabo-verdiano compreende os subsistemas da educação pré-escolar, da educação escolar e da educação extraescolar, complementados por atividades de desporto escolar e os apoios e complementos socioeducativos, numa perspectiva de integração. A educação pré-escolar visa uma formação complementar ou supletiva das responsabilidades educativas da família. A educação escolar abrange os subsistemas do ensino básico (equivalente ao Ensino Fundamental no Brasil), secundário (equivalente ao Ensino Médio no Brasil) e superior, bem como modalidades especiais de ensino, e inclui ainda as atividades de ocupação de tempos livres. Para mais informações, consultar: <http://www.academia.edu/1741846/Lei_de_Bases_do_Sistema_Educativo_cabo-verdiano_em_vigor >. 
a Infância (UNICEF), no âmbito do Programa Conjunto das Nações Unidas 042 "Apoio à Segurança Alimentar e Nutricional nas Escolas" financiado pela Cooperação Luxemburguesa. Localmente foi implementado pela Fundação Cabo-verdiana de Ação Social Escolar (FICASE) ${ }^{3}$ em parceria com os Ministérios da Educação e Desportos (MED), do Desenvolvimento Rural (MDR), da Saúde (MS), das Infraestruturas e Economia Marítima (MIEM), a Autoridade Reguladora de Aquisições Públicas (ARAP), das Agências de Regulação dos Produtos Alimentares (ARFA) e do Desenvolvimento Empresarial e Inovação (ADEI).

Paralelamente foi estabelecido um protocolo de cooperação entre a Escola de Ciências Agrária e Ambientais (ECAA) da Universidade de Cabo Verde, a FICASE e o Programa Conjunto "Apoio à Segurança Alimentar e Nutricional Escolar- UNJP/CVI/042/UNJ tendo como objetivo a realização de um estudo de seguimento e avaliação sobre a implementação do Programa de alimentação escolar nas escolas dos cinco municípios abrangidos pelo projeto-piloto "Compras locais", realizado em 2013/14.

A partir dessa proposta de articulação entre o consumo e a produção de alimentos com foco no mercado institucional, este trabalho estabeleceu como meta analisar como é que se efetivou o processo de aquisição de produtos da agricultura familiar, identificando os fornecedores, os gêneros alimentícios e as quantidades demandadas, bem como os intervenientes e as estruturas existentes nas escolas.

Em termos de estrutura, o presente trabalho, numa primeira instância, nos apresenta em linhas gerais o protocolo metodológico adotado com vista ao recolhimento de dados e de seguida a secção "Agricultura e abastecimento escolar: lições do terreno e boas práticas", apresenta e analisa os dados recolhidos a partir do ponto de vista dos vários intervenientes no programa (gestores, cozinheiras, agricultores e serviços locais).

\footnotetext{
3 O CASE foi criado em 1983 como uma unidade de implementação do programa de alimentação escolar. Em maio de 2010, ICASE transformou-se em Fundação para Acção Social e Educativa (FICASE), fruto de uma fusão do Fundo de Apoio para Edição de Manuais Escolares (FAEME) e do Fundo de Apoio para Educação e Formação (FAEF). A FICASE é uma instituição pública com autonomia administrativa e financeira sob a tutela do Ministério de Educação e Desporto (MED).
} 
109

\section{Metodologia}

Para construir essas sinergias, utilizamos a pesquisa-ação (incluindo visitas e acompanhamento no terreno, entrevistas qualitativas com os vários intervenientes no projeto e análise documental) como forma de promover uma interação entre ações de desenvolvimento e de pesquisa que, para além da compreensão de uma realidade, permitiram sua transformação, através do diálogo entre os vários intervenientes e os atores locais.

Uma equipe constituída por três elementos (um docente/pesquisador e dois estudantes), em colaboração com os técnicos da FICASE e do Programa Conjunto, fizeram todo o trabalho de levantamento, análise e sistematização dos dados recolhidos nos municípios abrangidos pelo programa-piloto. Assim, fez-se o levantamento de dados nas sedes dos polos das 31 escolas envolvidas no programa "Compras locais" e realizaram-se três visitas ao município de Santa Catarina, na Ilha de Santiago para acompanhar as experiências que estão a ser realizadas neste município. Para além das escolas (gestores, cozinheiras e professores responsáveis pelo abastecimento das cantinas), foram inquiridos os responsáveis da FICASE nas delegações dos municípios envolvidos, os delegados dos Ministérios da Educação e do Desenvolvimento Rural, os fornecedores/ agricultores que participaram do programa e a nutricionista da FICASE. No total foram realizadas 67 entrevistas, com um tempo médio de duração de $20 \mathrm{minu}$ tos para cada entrevistado. Para além das entrevistas realizadas, pudemos ainda recolher alguns documentos e registros fotográficos que foram utilizados como elementos complementares para o posterior processo de análise.

\section{Agricultura e abastecimento escolar: lições do terreno e boas práticas}

\section{As escolas}

As escolas contempladas no projeto foram escolhidas, baseando-se nos seguintes critérios: 1) tamanho (escolas pequenas com menos de 250 alunos, e grandes com mais de 250 alunos), 2) meio urbano e rural. Estas escolas tinham de ter condições mínimas de funcionamento da cantina, estar localizada em 
diferentes municípios e em função da produção local ${ }^{4}$. No total o projeto-piloto beneficiou 31 escolas, totalizando 8.924 alunos em cinco municípios do país (Praia e Santa-Cruz na ilha de Santiago, Mindelo na ilha de S. Vicente e, Porto Novo e Ribeira Grande na ilha de Santo Antão). Essa opção permitiu que se privilegiassem escolas com melhores condições de acessibilidade, na sua maioria localizadas nos centros urbanos e com melhores condições logísticas (vias de acesso, proximidade dos mercados ou postos de abastecimento, etc.).

\section{Gestores $^{5}$}

De forma geral todos valorizaram a importância e a pertinência deste projeto, sobretudo por ter trazido maior diversidade e qualidade na oferta alimentar das escolas e por ter permitido a aquisição de equipamentos e melhores condições de armazenamento dos alimentos.

Associado aos investimentos efetuados em bens e equipamentos, ainda se destaca positivamente as várias ações de formação realizadas com os diversos intervenientes neste processo (fornecedores, gestores, responsáveis de cantina, cozinheiras e pessoal da FICASE) que passaram por um processo de formação no âmbito das boas práticas de seleção, embalagem e transporte de produtos, bem como de indicações às escolas sobre as formas de recepção, acondicionamento e conservação. Igualmente, inspetores e auditores participaram em sessões de esclarecimento sobre a verificação da qualidade dos produtos. Na perspectiva dos gestores, todo esse trabalho traduziu-se numa maior satisfação dos alunos, pais, professores e cozinheiras.

4 Segundo os dados do Recenseamento Geral da Agricultura de 2004, Santo Antão e Santiago possuem mais de $90 \%$ do total das terras ocupadas com regadio em Cabo Verde. Santo Antão detém $46 \%$ de terras ocupadas com regadio e Santiago 44\%. Assim o Programa selecionou para uma primeira experiência dos municípios localizados nas ilhas com mair potencial e tradição agrícola. A escolha da ilha de São Vicente deve-se ao fato de ser a segunda maior ilha em termos demográficos e pela sua proximidade relativamente à ilha de Santo Antão.

5 A administração e gestão das escolas públicas do ensino básico (Decreto-Lei no 77/94, de 27 de Dezembro), é assegurada por um órgão singular, denominado Gestor (nomeado de entre os professores da Escola pelo Delegado do Ministério da Educação no município), que é coadjuvado por um ou mais adjuntos, cabendo-lhe planejar, organizar, dirigir, executar e controlar toda a política educativa da escola. Cabe-lhe, assim, assegurar a execução das normas e orientações superiores, gerir os meios humanos, materiais e financeiros de modo a assegurar o funcionamento adequado da escola, cuidar da conservação do edifício e dos equipamentos, coordenar e controlar o funcionamento da cantina escolar, efetuar visitas de supervisão das aulas e apoiar pedagogicamente os professores, promover a cooperação escola/comunidade, avaliar o desempenho dos professores e do pessoal administrativo e gerir as questões disciplinares da escola. 
Em termos dos aspectos a melhorar, algumas escolas, sobretudo em Mindelo e Santa Cruz, alertaram para o fato de (na percepção dos gestores) o dimensionamento das entregas durante o programa-piloto ter sido muito acima das suas reais necessidades. Em alguns segmentos, principalmente nas hortaliças, chegaram a introduzir na panela mais produtos do que era necessário, apenas para cumprir as metas e diretivas do projeto. Outras escolas optaram por partilhar parte dos produtos com as suas satélites e identificamos pelo menos uma escola que em inícios de agosto (época de férias escolares) ainda tinha um importante estoque de produtos nas arcas frigoríficas. Porém, identificamos escolas na Praia e em Porto Novo que alegaram que os produtos recebidos haviam sido o suficiente para a alimentação diária dos alunos. Em termos de rejeição, as escolas de S. Vicente foram as que mais relataram casos de rejeição, sobretudo de hortaliças menos familiares na dieta alimentar das crianças (ex: berinjela, beterraba, etc.). Em sentido contrário, os sumos e as frutas tiveram uma boa aceitação em nível nacional.

Alguma irregularidade no cumprimento dos horários de entrega (que muitas vezes ultrapassaram o período normal do funcionamento da escola) foi apontado como um aspecto a melhorar. Muitas vezes os responsáveis pelas cantinas ou gestores e cozinheiras viram-se obrigados a ficar mais tempo na escola para receber e conferir as entregas que eram feitas semanalmente.

Um constrangimento digno de registro está relacionado com as entregas tardias que foram acontecendo sucessivamente ao longo das sete semanas. Não raras vezes, os produtos só chegavam ao ponto de inspeção por volta do meio-dia, quando eles deveriam estar nas escolas pelo menos antes das 11 horas devido ao intenso calor e sol, que é costume na capital do país (Responsável Municipal pelas cantinas escolares - Praia).

Assim, os dias de entrega representavam um aumento da carga de trabalho quer pelos constrangimentos causados pela entrega, quer pelas exigências de preparo e acondicionamento exigidos pelos produtos frescos. Apesar de as condições dos espaços de inspeção não terem sido as melhores em todos os municípios, as atividades de inspeção, pesagem e embalagem dos produtos decorreram sem grandes sobressaltos.

Cerca de 30\% (9/31) das escolas, um ano depois do fechamento do projeto já não tinham o mesmo gestor que estava em funções na altura da implementação do projeto-piloto. Nesses casos, as entrevistas foram feitas ao gestor atual e, em alguns casos, eles nos indicaram um professor conhecedor do projeto e que 
esteve envolvido na sua implementação na escola. Fica evidente que há, por todo o país, uma certa instabilidade na gestão dos estabelecimentos de Ensino Básico, o que seguramente dificulta o devido acúmulo e a consolidação de boas práticas.

\section{Cozinheiras}

Com a disponibilização de materiais e equipamentos de cozinha, as escolas passaram a ter mais e melhores condições de armazenamento dos produtos. Nesse sentido, as escolas envolvidas no projeto receberam arcas, frigoríficos, cortador, triturador de legumes, placas, facas, etc. Durante o decorrer da primeira fase do programa-piloto, as escolas foram coadjuvadas pelo formador senhor Daniel Guimarães (sobretudo as localizadas na Cidade da Praia), pelo pessoal da FICASE, pelos técnicos da ARFA e, não raras vezes, receberam visitas dos inspetores do MDR. As condições de higiene foram melhoradas significativamente na medida em que as visitas se tornaram mais frequentes e, nesse sentido, passou-se também a disponibilizar às escolas envolvidas mais materiais de limpeza. A percepção geral das cozinheiras vai no sentido de que houve significativas melhorias nas condições de trabalho e na qualidade das refeições oferecidas aos alunos, o que se constata neste depoimento:

\footnotetext{
Muitos alunos, de tanta alegria e ansiedade, logo pela manhã passavam aqui na cozinha para nos perguntarem qual a fruta que iam comer hoje. Foi uma experiência muito boa e que deveria ser repetida. Deu-nos mais trabalho, mas nós não nos importamos porque nos sentimos realizados com a satisfação dos nossos alunos. (Cozinheira, Escola Eugénio Tavares).
}

Por outro lado, verificaram-se algumas dificuldades relativamente aos espaços onde os produtos eram colocados, principalmente devido à falta de ventilação regular. Outro ponto negativo apontado pelas cozinheiras foi o aumento das horas de trabalho. As nossas entrevistadas revelaram-se pessoas com muito amor à profissão, contudo, realçam que o salário é pouco motivador. Porém, o maior constrangimento apontado foi, indiscutivelmente, o término do projeto. O fim do projeto gerou descontentamento por parte das cozinheiras, sobretudo porque se estabeleceu um padrão de qualidade muito bom com o projeto-piloto. 
A grande parte das cozinheiras não possui escolaridade básica e a média de idade das entrevistadas situa-se nos 47 anos. Esse cenário remete-nos para a necessidade de uma mudança de fundo no perfil de contratação das cozinheiras. A idade avançada associada à baixa qualificação será seguramente grandes entraves à melhoria e massificação do projeto de compras locais. No nosso entender, os desafios não serão de todo resolvidos com mais formação, mas, sim, através de uma gradual introdução de novas cozinheiras e chefes de cozinha, rejuvenescendo o efetivo e com qualificação no mínimo equivalente ao Nível $5^{6}$ da formação profissional.

Paralelamente a esse processo, também é notória a grande carência de nutricionistas locais na gestão direta do projeto. Num cenário de eventual retomada e alargamento do programa das compras locais, é recomendável uma acentuada diminuição do rácio: nutricionista/escola. Gradativamente deverá ser atribuído a esses profissionais uma maior proximidade às escolas, maior envolvimento na gestão local das aquisições sobretudo na região de Barlavento. Essa opção permitirá uma maior adequação das ementas à realidade de cada escola e de cada região, e uma diminuição das perdas. E permitiria também uma maior e melhor aproximação entre o nutricionista e os agricultores/fornecedores.

É sabido que os padrões alimentares saudáveis são adquiridos nos primeiros anos de vida e são mantidos por muitos anos; infelizmente, o mesmo acontece também com padrões alimentares inadequados (MAIS et. al., 2015; DOMENE, 2008). Tendo em conta que as práticas alimentares são fortemente influenciadas pelo ambiente em que a criança está inserida, é necessário que as escolas estejam devidamente preparadas em termos de competências que possam efetivamente contribuir para a divulgação de hábitos saudáveis com vista ao equilíbrio nutricional das crianças.

\section{Agricultores/fornecedores}

Na mesma linha dos demais intervenientes neste projeto, os agricultores/ fornecedores ficaram muito satisfeitos, sobretudo pela oportunidade de adquirir

6 Têm acesso aos programas de formação das qualificações de nível 5 os indivíduos habilitados com o Diploma do Ensino secundário ( $12^{\circ}$ ano da via geral), ou Diploma do Ensino secundário ( $12^{\circ}$ ano da via técnica com formação correspondente a qualificações profissionais de nível 4) ou Certificado de Qualificação Profissional de nível 4. 
novas aprendizagens, garantir mais rendimento e conquistar novos mercados. Todos os entrevistados veem com bons olhos a possibilidade deste projeto vir a ser alargado a mais escolas e a ser implementado com maior perenidade.

No início, a adaptação aos critérios de embalagem, acondicionamento, transporte e demais aspectos relativos à qualidade foram difíceis, mas com o evoluir do projeto todos os nossos entrevistados foram unânimes em afirmar que valeu a pena e que hoje se sentem mais e melhores preparados para lidar com as exigências do mercado institucional. Um dos agricultores participantes da pesquisa afirma: "Inicialmente parecia-nos ser difícil mas com tempo fomos nos consciencializando que a qualidade é importante para servir qualquer instituição. É este o mercado da realidade." (Agricultor - São Vicente).

Tabela 1 - Valores investidos na Alimentação Escolar no âmbito do programa "Compras locais" (2a fase)

\begin{tabular}{l|l|l|l}
\hline Município & $\begin{array}{l}\text { Valor contratualizado } \\
\left(\mathbf{E C V}^{31}\right)\end{array}$ & $\begin{array}{l}\text { Valor executado } \\
(\mathrm{ECV})\end{array}$ & $\begin{array}{l}\text { Precentagem de } \\
\text { execução (\%) }\end{array}$ \\
\hline Praia & 1.973 .640 & 1.844 .180 & 93 \\
\hline \multirow{2}{*}{$\begin{array}{l}\text { Santa Cruz } \\
\text { Mindelo }\end{array}$} & 958.788 & 808.738 & 84 \\
\cline { 2 - 4 } & 2.163 .825 & 2.086 .955 & 96 \\
\hline Porto Novo & 583.940 & 583.940 & 100 \\
\hline Ribeira Grande (SA) & 610.592 & 389.280 & 64 \\
\hline TOTAL & 6.290 .785 & 5.713 .093 & 91 \\
\hline
\end{tabular}

Fonte: dados da pesquisa (elaborada pelos autores).

Em termos de execução financeira, o projeto teve uma taxa de realização de cerca de $91 \%$ e se traduziu na aquisição de 2,412 toneladas de peixe, 20,431 toneladas de frutas e 21,136 toneladas de legumes. O caso mais preocupante é, sem dúvida, o de Ribeira Grande de Santo Antão onde os níveis de execução não ultrapassaram os $64 \%$. Porém os dados qualitativos recolhidos no terreno não o diferenciaram dos demais municípios em termos de níveis de satisfação e envolvimento dos vários agentes locais no projeto. Os dados indicam-nos que o projeto foi bem acolhido e que não houve uma percepção de excesso de entregas. Tendo em conta que a Ilha de S. Antão foi contemplada apenas na segunda fase do projeto, há elementos que precisam ser melhor consolidados de forma a se poder recolher mais dados para complementar essa análise. Portanto haverá

7 Escudos cabo-verdianos (1 dólar equivale a 94 ECV: cotação do dia 28/09/17). 
elementos que não foram equacionados neste estudo e que merecerão o devido acompanhamento em futuras pesquisas, sobretudo de caráter qualitativo e de longo prazo. No outro extremo, encontra-se o município de Porto Novo, onde os produtos contratados foram entregues a $100 \%$. Ambos os cenários carecem de mais detalhes para sua análise.

Tabela 2- Quantidade de produtos de origem animal e vegetal

\begin{tabular}{l|l|l|l}
\hline \multicolumn{2}{l|}{ Origem do Produto } & $\begin{array}{l}\text { Quantidade contratado } \\
\text { (quilogramas) }\end{array}$ & $\begin{array}{l}\text { Quantidade entregue } \\
\text { (quilogramas) }\end{array}$ \\
\hline \multicolumn{2}{l}{ Animal (peixe) } & 2.352 & 2.412 \\
\hline \multirow{2}{*}{ Vegetal } & Frutas & 26.813 & 20.431 \\
\cline { 2 - 4 } & Legumes & 21.752 & 21.136 \\
\hline
\end{tabular}

Fonte: dados da pesquisa (elaborada pelos autores).

A inexperiência em lidar com exigências de qualidade, a pouca prática de participação em editais e processos competitivos (concursos públicos/chamadas públicas), o curto espaço temporal entre a assinatura dos contratos e o início das entregas, os contratos de duração muito curtos, os prazos de liquidação de faturas demasiadamente dilatados e a oscilação dos preços ao longo do período de entrega foram, certamente, os maiores constrangimentos apontados pelos agricultores/fornecedores

A esses fatos acrescentamos ainda que, em muitos casos, as viaturas utilizadas não apresentavam os requisitos necessários para o carregamento de alimentos perecíveis. Por exemplo, no município da Praia, devido à pequena dimensão da viatura, só foi possível concluir a maioria das entregas através de dois ou mesmo três carregamentos e, portanto, as verduras foram entregues muito tarde nas escolas, não dando às cozinheiras, aos responsáveis de cantina e gestores margens para sua conservação imediata.

Destacam-se também como aspetos a melhorar a articulação e coordenação na montagem de todo o processo de candidatura e seleção dos fornecedores de forma a se garantir um tempo razoável entre a assinatura do contrato, a programação da produção e a entrega dos produtos.

Os vencedores da primeira fase do projeto não foram contemplados no concurso relativo à segunda fase. Se, por um lado, essa abordagem competitiva permitiu a seleção das melhores propostas numa relação preço/qualidade/ 
condições de entrega, por outro, acabou por não permitir a continuidade do processo de melhoria e consolidação do serviço prestado pelos agricultores/ fornecedores selecionados na primeira fase. Assim, não houve acúmulo e consolidação de experiências. Grande parte do trabalho de formação e fiscalização com vista à garantia de qualidade dos produtos entregues teve que ser reintroduzido na segunda fase.

Pela quantidade e diversidade dos produtos propostos a concurso convém avaliar se efetivamente o agricultor cabo-verdiano está realmente capacitado e preparado para assumir uma relação direta com as escolas. Isso porque, em muitos casos, o agricultor ou a associação de agricultores que venceu o concurso não tinha capacidade interna para fornecer todos os produtos solicitados e eles tiveram que recorrer a terceiros para adquirir grande parte dos produtos, assumindo, dessa forma, muitas vezes, o papel de intermediários e não de produtores. Nessa linha, torna-se pertinente questionar se o agricultor deve efetivamente estar envolvido na produção ou na comercialização dos produtos.

Se analisarmos com detalhe as duas fases do projeto, podemos identificar que participaram do programa agricultores, fornecedores (com pouco ou nenhuma relação direta com a produção), associações de produtores e cooperativas. Nos próximos projetos há que refletir-se sobre quais desses segmentos efetivamente estão melhor preparados (e em que circunstâncias e que regiões) para garantir um abastecimento às cantinas escolares com qualidade. Em determinados municípios a opção por um desses segmentos poderá ser útil, mas, seguramente, em outras regiões do país o cenário poderá ser diferente.

Apesar de a designação terminológica do programa ter sido de "compras locais", na prática o projeto incorporou a aquisição de alguns produtos não produzidos localmente (ex.: bissap $^{8}$, alho, etc.) e vários produtos foram adquiridos noutras ilhas. De forma geral, a maioria dos produtos foram adquiridos no país, mas nem sempre contemplou o agricultor localizado mais perto da escola beneficiada.

Estudos realizados noutras realidades (TRICHES 2010, SILIPRANDI \& BELIK, 2012) têm apontado para o fato de que há a necessidade de uma revisão de condutas e posturas de ambos os lados - poder público e agricultores. Se, por um lado, os agricultores têm dificuldades em entender os ritos e vicissitudes dos trâmites e das exigências legais e regulatórias, por outro, os gestores públicos 
raramente conseguem compreender ou supor os esforços de um agricultor para produzir e comercializar seus produtos.

Mostra-se necessária, também, a realização de levantamentos periódicos sobre o potencial regional dos municípios para a produção local de gêneros alimentícios in natura, as principais culturas, a criação de animais e outros fatores (MARQUES et al., 2014). No nosso caso, o desconhecimento pode estar favorecendo a compra de produtos fora dos limites regionais definidos pelo programa. Uma sugestão seria a realização de parcerias mais consolidadas e regulares com as universidades e estruturas desconcentradas do Ministério do Desenvolvimento Rural de forma que se possa melhor acompanhar os agricultores no processo de planificação da produção.

\section{Serviços locais, concentrados e desconcentrados}

As estruturas locais desconcentradas (Delegações do MDR, do MED e responsáveis concelhios ${ }^{9}$ da FICASE) de uma forma geral, consideram que houve uma boa articulação entre os vários serviços locais e centrais (ARFA, ADEI, ARAP, etc.) envolvidos na implementação do projeto. Apesar de a participação não ter sido acompanhada de acréscimo de recursos, esse fato não se traduziu em menor envolvimento. Essa forte articulação contribuiu grandemente para que o projeto fosse bem-sucedido através da gradual diminuição dos produtos rejeitados, melhoria significativa na regularidade das entregas que culminou com o nível médio nacional de execução efetiva das entregas na ordem dos $91 \%$.

Os efeitos de programas públicos de comercialização dirigidos a pequenos agricultores familiares, claramente vão além da simples injeção de novos recursos no mercado local, ainda que essa questão também seja importante (BELIK \& DOMENE, 2011). Serviços locais deverão ter um papel importante no surgimento e fortalecimento de entidades representativas dos agricultores que possam atuar como mediadoras no diálogo com o poder público.

Contudo, não podemos deixar de registrar a fraca ou quase nula participação das câmaras municipais em todas as fases do projeto. Num cenário 
de alargamento e massificação dessa experiência é de todo recomendável um efetivo envolvimento das autoridades descentralizadas.

\section{Considerações finais}

A implementação de ações no campo do abastecimento alternativo no mercado institucional demanda uma engrenagem de ações e atores que exige o redesenho das relações sociais, políticas e econômicas no âmbito local e regional, nem sempre muito simples de serem efetivadas. Por outro lado, estudos recentes e observações a campo (BEZERRA \& PEREZ-CASSARINO, 2016; TRICHES, SCHNEIDER \& SIMÕES, 2013; TRICHES \& SCHNEIDER, 2012; TRICHES \& SCHNEIDER, 2010) têm demonstrado que a partir do momento em que essas engrenagens começam a encaixar-se, os resultados demonstram-se extremamente favoráveis à promoção da alimentação saudável e ao redesenho dos sistemas agroalimentares, particularmente no caso do mercado institucional, em que o fornecimento de refeições às escolas passa a assumir uma nova dimensão, tornando-se meio para construção de processos educacionais promotores de saúde e desenvolvimento regional.

Apesar das limitações apontadas, o projeto-piloto foi muito bem avaliado pelos gestores, pelas cozinheiras e pelos demais profissionais envolvidos no programa. Assim, lamentam o fato de o projeto ter cessado e a maioria não tem informações consistentes em relação a uma possível retomada. Nota-se um grande distanciamento dos gestores em relação aos responsáveis nacionais pela implementação dos programas das cantinas escolares no que toca ao acesso às informações. Muitos se manifestaram impotentes perante os sucessivos questionamentos dos pais e/ou encarregados de educação, dos professores e sobretudo dos alunos. Na percepção dos gestores e, usando a expressão coloquial, saíram do 8 para o 80 e regressaram de novo ao 8 com o fim do projeto-piloto.

A melhoria da dieta alimentar dos alunos com refeições diversificadas e que foram apreciadas pelos alunos, a formação dos atores envolvidos, os equipamentos fornecidos que melhoraram as condições das cantinas, o trabalho conjunto de vários parceiros, a criação de um mercado potencialmente seguro para agricultores e fornecedores, assim como a criação de um sistema de gestão da 
qualidade em nível nacional são elementos a reter na definição e na implementação de práticas futuras.

É fundamental criar condições nas escolas (infraestruturas e equipamentos) como um dos pré-requisitos ao seu abastecimento com produtos frescos. Por fim, é preciso realizar um seguimento mais sistemático e definir claramente as responsabilidades de cada um dos parceiros no processo. Não será possível alargar essa experiência sem descentralizar responsabilidades, especialmente quanto à definição das ementas, gestão das compras, etc.

A introdução da aquisição do pescado (apenas nas escolas do município da Praia) trouxe resultados bastantes positivos. Quanto à execução do programa, o pescado ficou claramente acima dos produtos agrícolas e, na percepção do gestor e responsável conselho, a montagem de toda a logística de inspeção, embalagem, transporte e armazenamento decorreram de forma satisfatória.

O financiamento e a sustentabilidade de um programa de promoção das compras locais é, sem dúvida, um dos grandes desafios em relação ao futuro desse modelo. Inicialmente, os custos da alimentação poderão sofrer um acentuado aumento, mas, a médio prazo, com agricultores melhor preparados, com a evolução da cadeia de produção e da logística e a melhoria no desempenho de todos os envolvidos, os resultados serão positivos. À semelhança do que vem ocorrendo noutros países (BEZERRA \& PEREZ-CASSARINO, 2016), o mercado institucional tem potencial de gerar outras consequências para além da dimensão econômica, pois poderá ter impacto direto na diversificação da produção, na organização da propriedade, na organização política e social, na diversificação dos mecanismos de comercialização, mas, principalmente, criará condições para o (auto)reconhecimento da agricultura familiar e local, retirando-a da situação de invisibilidade social e política e colocando-a como um interlocutor de um projeto político para o país. 


\section{REFERÊNCIAS}

BELIK, W.; S. DOMENE. Experiências de programas combinados de alimentação escolar e desenvolvimento local em São Paulo Brasil. Agroalimentaria, vol. 18, № 34; enero-junio 2012 (57-72).

BEZERRA, I.; PEREZ-CASSARINO, J (Org.). Soberania Alimentar (SOBAL) e Segurança Alimentar e Nutricional (SAN) na América Latina e Caribe. Curitiba: UFPR, 2016.

DOMENE, S. A escola como ambiente de promoção da saúde e educação nutricional. Psicologia USP, São Paulo, outubro/dezembro, 2008, 19 (4), 505-517.

FUNDAÇÃO CABO-VERDIANA DE ACÇÃO SOCIAL ESCOLAR. (2015). Alimentação escolar como fator de emancipação das crianças e jovens de Cabo Verde: a experiência da FICASE. Cidade da Praia.

MAIS, L. A; S. DOMENE; M. BARBOSA, J. TADDEI. Formação de hábitos alimentares e promoção da saúde e nutrição: o papel do nutricionista nos núcleos de apoio à saúde da família - NASF. Revista APS, abr/jun; 18(2): 248 - 255. 2015.

MARQUES, A; M. FERNANDES; I. LEITE; R. VIANA; M. GONÇALVES\& A CARVALHO. Reflexões de agricultores familiares sobre a dinâmica de fornecimento de seus produtos para a alimentação escolar: o caso de Araripe, Ceará. Saúde e Sociedade. São Paulo, v.23, n.4, p.1329-1341. 2014.

MINISTÉRIO DO DESENVOLVIMENTO RURAL. Recenseamento Geral da Agricultura. Praia: Direção Geral de Planejamento, Orçamento e Gestão. Direção de Estatística e Gestão de Informação. 2004.

TRICHES, R. M; SCHNEIDER, S; SIMÕES, E. Aquisições públicas em Cabo Verde: desafios e potencialidades para promover o desenvolvimento rural. Revista Angolana de Sociologia. N. ${ }^{\circ}$ 11, pp. 63-80. 2013.

TRICHES, R. M.; SCHNEIDER, S. Desestruturar para construir: interfaces para a agricultura familiar acessar o Programa de Alimentação Escolar. Estudos, Sociedade e Agricultura, vol. 20 (1), p. 66-105. 2012.

- Reconstruindo o elo perdido: a reconexão da produção e do consumo de alimentos através do Programa de Alimentação Escolar no município de Dois Irmãos (RS). Segurança Alimentar e Nutricional, vol.17, p. 1-15.2010. 


\title{
Compras institucionales: estado del arte del proceso uruguayo
}

\author{
Adriana Machado \\ Alejandro Pizzolon \\ Jorge Vaz Tourem
}

\section{Introducción}

En la última década Uruguay ha generado diversos avances en lo que refiere a promoción y fortalecimiento de la producción familiar, en el marco de una estrategia de desarrollo rural. El diseño de estas políticas ha tomado como referencia el conocimiento acumulado en la región y ha tenido en cuenta el acuerdo de diferentes actores (estatales, organizaciones de productores, academia, etc.). Este desafío ha requerido innovaciones a nivel de la legislación, de los procesos administrativos, la organización social y ajuste en los programas de promoción y apoyo al desarrollo de la producción familiar.

Un hito importante del proceso uruguayo es la aprobación de la Ley 19.292 de compras públicas a la producción familiar en el año 2014. Esta ley caratulada "Declaración de interés general: Producción Familiar Agropecuaria y Pesca Artesanal" y su decreto reglamentario, reservan un porcentaje de las compras de alimentos realizada por los mercados institucionales para organizaciones de la producción familiar y la pesca artesanal.

El objetivo del presente artículo es presentar brevemente la producción familiar uruguaya, analizar el proceso de creación de la ley 19.292 y sus mecanismos de reserva de mercado, así como los potenciales aportes al sector en función del dimensionamiento de la demanda estatal. Se propone un recorrido sobre la conceptualización y reconocimiento público de la PAF, posteriormente se realiza 
un resumen de las características y dimensiones de las compras institucionales de alimentos, para luego presentar el proceso de gestación de la ley de compras públicas a la producción familiar y los avances y desafíos en su instrumentación.

\section{Sobre el concepto Producción Agropecuaria Familiar (PAF)}

En Uruguay el concepto de agricultura familiar se remonta a principios de la década del 80' (últimos años de la dictadura militar), cuando algunos autores vinculados a organizaciones no gubernamentales como CIEDUR (Centro Interdisciplinario de Estudios sobre el Desarrollo Uruguay) y CIESU (Centro de Informaciones y Estudios del Uruguay) comenzaron a definir y caracterizar la agricultura familiar uruguaya. Al retomarse el gobierno democrático y el reingreso de varios de esos autores al ámbito académico dicho tema comenzó a investigarse y se realizaron algunas tesis de grado sobre la situación y perspectivas del sector, con lo cual la agricultura familiar fue reconocida como sujeto social, por la universidad, pero no a nivel de los gobiernos de la época.

En la década de los 90' nuevamente a nivel académico un autor que profundizó en el estudio del concepto fue el Ing. Agrónomo especializado en sociología rural Diego Piñeiro quien en 1994 definió tres categorías. La primera de ellas el productor familiar capitalizado, aquellos que utilizan predominantemente trabajo familiar pero complementariamente contrata asalariados, al mismo tiempo que con su actividad agrícola obtiene excedentes suficientes para sobrevivir hasta el siguiente ciclo productivo. Una segunda categoría es el productor familiar propiamente dicho; el que aplica el trabajo de toda la familia y eventualmente puede contratar trabajo asalariado, pero siempre en menor cantidad a la mano de obra familiar y sus ingresos son apenas suficientes para cubrir el presupuesto familiar del año. En tercer lugar, definió el productor semi-asalariado, quien por la escasa superficie de campo propio y la baja rentabilidad que percibe, debe emplearse él o su familia fuera del predio para completar sus ingresos.

En 2005, se comenzaron a diseñar políticas específicas de apoyo a la producción familiar. Lo cual a nivel institucional se vio reflejado en la creación en el ámbito del Ministerio de Ganadería, Agricultura y Pesca (MGAP) de la Dirección General de Desarrollo Rural (DGDR), y en el Ministerio de Desarrollo Social en el ámbito de la DINESIL (Dirección Nacional de Economía Social e 
Integración Laboral) del Departamento de Ruralidad para apoyar la agricultura familiar y participar de la Red Especializada de Agricultura Familiar (REAF) que desde 2004 se había creado a iniciativa del gobierno brasileño en el ámbito del MERCOSUR, sin mayor apoyo del Estado uruguayo en los primeros años de su existencia.

Uno de los productos concretos de esta nueva etapa de participación en la REAF fue la definición conjunta de los principales criterios que actualmente se siguen utilizando en la región para definir agricultura familiar: "1) mano de obra predominantemente familiar, limitando mano de obra contratada, 2) familia como responsable directa de la producción y gestión de las actividades agropecuarias debiendo residir en el predio o una localidad cercana, 3) recursos productivos compatibles con la capacidad de trabajo de la familia (tierra, capital, etc)" (REAF, s/f).

En el año 2008 una resolución (527/008) del MGAP definió la condición de Productor o Productora Familiar Agropecuario/a para aquellas personas físicas que cumplían, simultáneamente con los siguientes cuatro requisitos:

1. Realizar la explotación con la colaboración de, como máximo, dos asalariados permanentes o su equivalente en jornales zafrales (500 jornales anuales)

2. Explotar tierra hasta un total de 500 ha índice CONEAT (índice de producción de pasturas y carne en campo natural) 100 bajo cualquier forma de tenencia

3. Obtener su ingreso principal de su trabajo en la explotación o cumplir su jornada laboral en la misma,

4. Residir en la explotación o en una localidad ubicada a una distancia no mayor a $50 \mathrm{~km}$.

Esta definición en 2014 se modificó parcialmente por medio de las resoluciones 219 y 387/2014 (MGAP. s/f) y estableció que en aquellos casos donde exista trabajo extra predial, los ingresos no deben superar las 14 BPC (bases de prestaciones y contribuciones), lo cual a 2017 equivale a unos mil setecientos cincuenta dólares americanos mensuales. A la vez que para los productores hortícolas, frutícolas y vitícolas se definió como límite máximo la contratación de mano de obra asalariada no familiar por un equivalente de hasta 1250 jornadas zafrales anuales. También para el caso de la producción apícola, determinó que no se aplican los requisitos de superficie ni de residencia y se sustituye la definición 
por los productores que cuentan con un máximo de 1000 colmenas. En 2016, se ajusta nuevamente incorporando la definición de productor familiar pesquero.

Posterior a la primera definición se crea el Registro de Productores Familiares, cuya implementación y procesamiento ha estado a cargo de la DGDR. Su propósito es determinar quiénes son los productores que están comprendidos en la definición y por tanto reconocer los potenciales beneficiarios de las políticas diferenciadas que se otorgan por parte de la DGDR y otras instituciones del estado.

De acuerdo con el Censo General Agropecuario MGAP-DIEA (2011), existían 44.781 explotaciones totales. Según Sganga et al. (2014) en el año 2013 el registro de productores familiares tenía un total de 21.038 explotaciones familiares registradas, representando un $47 \%$ de las explotaciones, las que ocupan 1.534.053 hectáreas aproximadamente, casi un $10 \%$ de la superficie de suelos explotables del país. De esta cantidad la mayoría son ganaderos pequeños (bovinos y ovinos), seguido de productores lecheros y horticultores.

A partir del 2016 y como consecuencia de la Ley de Compras Estatales para la agricultura familiar y pesca artesanal se comenzó a implementar el registro de los pescadores artesanales familiares.

El proceso de reconocimiento por parte de la institucionalidad publica ha posibilitado, en parte, una mayor visibilidad del sector y ha propiciado el reconocimiento social y político de la PAF como un sector que aporta gran parte de la producción de alimentos nacionales. Con un valioso aporte económico al país y como actores claves de la Seguridad y Soberanía Alimentaria Nacional. Siendo a la vez, un potente generador de trabajo genera radicación en el medio rural, constituye un importante reservorio de saberes, cultura y capacidades, difícilmente recuperables de continuar el proceso de pérdida actualmente en curso.

Sin embargo, a pesar del reconocimiento y de las políticas diferenciadas para este sector, la PAF uruguaya presenta una alta fragilidad socioeconómica, se encuentra bajo presión de la agricultura agroindustrial y presenta diversas dificultades para el acceso a los mercados. Las incertidumbres para la comercialización de sus productos y los bajos precios que reciben los productores explican en parte una continua pérdida de esta población. Esta problemática que se acentúa en los años 90’ y 2000, continúa sin revertirse.

Por mucho tiempo las políticas orientadas a los productores rurales se han focalizado en desarrollar los aspectos productivos, de asistencia técnica e incluso de transformación o generación de valor agregado en las cadenas tradicionales, 
pero se ha dado poco énfasis a la comercialización de la producción. La inserción de productores familiares al mercado se ha realizado en un contexto de poca intervención estatal en la regulación de los mercados. Los diferentes apoyos no logran sus cometidos en todos los casos y en ocasiones terminan diluyéndose en otros eslabones de la cadena, no capitalizándose en una mejora del precio recibido por la PAF.

Con la intención de superar estas fragilidades de mercado, en el periodo de gestión de gobierno de 2010 - 2015, se comenzó a promover a nivel político la idea de trabajar el acceso a los mercados institucionales como una herramienta para apoyar la organización y generación de capacidades comerciales a través de diferentes procesos asociativos que posteriormente podrán mejorar su inserción competitiva en los mercados no estatales. En la administración siguiente se avanzó en la consolidación de herramientas de políticas institucionales específicas.

Chiappe et al (2015) analizando la exposición de motivos de la ley 19.292 apuntaba:

\footnotetext{
las compras públicas como instrumento de desarrollo económico fomentan la consolidación de un modelo de desarrollo económico basado en el trabajo nacional, impulsando cadenas productivas con tecnologías apropiadas que promueven el poblamiento de la campaña, favorecen la distribución de riquezas, contribuyen a la diversificación de la matriz productiva y disminución de las brechas sociales.
}

Así entendidas, las adquisiciones gubernamentales son un instrumento relevante a la hora de potenciar el desarrollo de la agricultura familiar permitiendo la obtención de precios justos para productores y consumidores, evitando las tendencias oligopólicas de la distribución y garantizando el acceso a mercados.

\section{Características del mercado institucional en Uruguay}

El mercado institucional en Uruguay es relativamente pequeño en comparación con otros países sudamericanos, dada la baja población uruguaya, y presenta sus propias particularidades. Si bien la mayor parte de los alimentos frescos que se consumen en el país provienen de la producción familiar, las características del proceso por el cual el Estado realiza sus compras de alimentos 
han determinado que la mayor parte de quienes se presentan y ganan las licitaciones de compra de alimentos, son grandes empresas acopiadoras o intermediarias, con serias dificultades por parte de la PAF de abastecer directamente y obtener un precio más justo.

La norma legal que aplica a los procedimientos de compras y contrataciones estatales se denomina Texto Ordenado de Contabilidad y Administración Financiera (TOCAF). Esta normativa comprende todo tipo de compras y contrataciones de obras y servicios realizados por los organismos estatales.

Para la compra de alimentos existen dos mecanismos de compra, que son licitación (pública y abreviada) y la compra directa (común y por excepción). Cada procedimiento (definidos en el Art 33 del TOCAF) es aplicable en función del monto de contratación, los máximos admitidos en 2017 para cada procedimiento de compra fueron:

- Compra directa común: USD 14.140 aprox.

- Licitación abreviada: USD 282.725 aprox.

- Licitación Pública: por encima de USD 282.725 aprox.

Las oficinas estatales que participan de la regulación y control de las compras públicas son la Agencia de Contrataciones y Compras del Estado (ACCE) y la Unidad Centralizada de Adquisiciones (UCA), quienes tienen distintos roles y participan en alguno de los procedimientos utilizados para ejecutar cada compra. La compra puede ser centralizada o no centralizada:

\section{Compras centralizadas}

Este tipo de compra es la realizada en forma conjunta mediante licitaciones anuales realizadas por la UCA, quién recibe las necesidades de los distintos organismos estatales ubicados en la zona Metropolitana (que ocupa un radio de unos $50 \mathrm{~km}$. alrededor de Montevideo). Los productos comprados por los llamados de la UCA, comprende frutas y hortalizas frescas, huevos, legumbres, carne vacuna, hortalizas procesadas, dulces y mermeladas, leche fresca y larga vida. Es importante destacar que la UCA no participa en la compra de carne de aves, carne de cerdo, pescado ni quesos.

Este mecanismo de compras presenta ventajas y desventajas para las organizaciones de productores familiares, por un lado, concentra un volumen 
importante de alimentos lo cual lo hace muy atractivo, pero a la vez implica un importante trabajo logístico de organización, dado que muchas veces requiere de entregas diarias o semanales en muchas instituciones.

\section{Compras descentralizadas}

Son aquellas que cada organización lo ejecuta directamente, como por ejemplo las escuelas rurales, hospitales y otras instituciones públicas alejadas de Montevideo, que compran los alimentos en sus lugares de establecimiento.

En relación a las compras de alimentos las instituciones más importantes en función de los volúmenes de compra son; el Ministerio de Defensa Nacional (que comprende el Ejército, la Armada y la Fuerza Aérea); el Ministerio del Interior (que comprende principalmente las cárceles, hospital Policial, Bomberos, Oficinas Centrales, Escuela Nacional de Policía, Guardia Republicana, etc.); la Administración de los Servicios de Salud del Estado (37 hospitales ubicados en las principales ciudades del país); la Administración Nacional de Educación Pública a través del Programa de Alimentación Escolar (alimenta unos 250.000 niños); el Instituto Nacional de Alimentación (que abastece comedores para ciudadanos en condiciones de alta vulnerabilidad y financia la alimentación de los niños entre 0 y 3 años cubiertos por el plan Centros de Atención de la Infancia y la Familia, que ejecutan ONG con financiamiento público) Chiappe et al. (2015).

\section{Dimensionamiento de las compras públicas de alimentos}

Un reciente estudio realizado por docentes de la Universidad de la República, Chiappe et al (2015), estudió los volúmenes de compra del Estado de los principales productos de la producción familiar uruguaya (frutas, verduras, huevos y carne).

Para las compras de frutas y verduras establecieron que alcanzan las 15.130 toneladas por año. "En volumen las compras centralizadas representan 45,5\% y las descentralizadas $55,5 \%$, mientras que en dinero las compras centralizadas representan $33,9 \%$ y las descentralizadas $66,1 \%$ del total". 
Tomando en cuenta la producción total de frutas y hortalizas y el consumo estimado en fresco, los autores obtienen que las compras públicas apenas representan 2,05\% de la producción nacional y 3,84\% del consumo, por lo cual, si bien puede resultar importante para una parte de la agricultura familiar, su aporte es menor en relación con otros países de la región.

Con respecto a los productos comprados, el siguiente gráfico establece la distribución de dicho volumen:

Gráfico 1. Principales productos comprados por bulto a través de la UCA en 2014

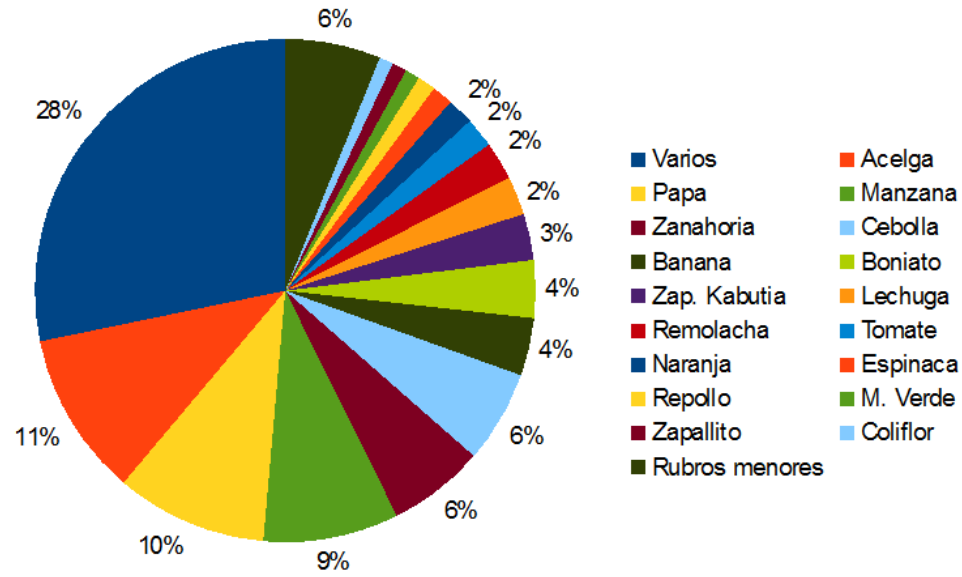

Fuente: Chiappe et al., 2015

Como observamos en el gráfico, sin considerar el rubro "Varios", el cual agrupa todo tipo de hortalizas, los principales productos adquiridos por los organismos públicos son acelga, papa, manzana, zanahoria y cebolla.

En el caso de los hues las compras centralizadas fueron 163.347 docenas por un monto total de aproximadamente 160 mil dólares. Las compras descentralizadas en 2014 acumularon 123.492 docenas que, sumadas a las compras centralizadas, completaron un volumen de compras públicas de huevos en 2014 de 286.839 docenas. La producción anual uruguaya es del orden de los 67 millones de docenas, por lo cual la compra pública representa $4,34 \%$ de la producción (CHIAPPE et al., 2015).

La compra total de carnes en 2014 fue estimada por Chiappe et al. (2015) en 5.048 toneladas, de las cuales un 79,3\% correspondió a carne vacuna, 
seguida por el pollo con $12,9 \%$, el cerdo con $4,4 \%$ y el pescado con $4 \%$, lo cual significan 4.004 toneladas de carne vacuna. Las otras tres carnes fueron adquiridas sólo de forma descentralizada, acumulando 627 toneladas de pollo, 224 toneladas de cerdo y 193 de pescado. pú peso relativo de las compras purne en función del consumo interno anual en Uruguay significó para el año 2014; en el caso de la carne vacuna $2,2 \%$ del consumo interno, en el caso del pescado $2,1 \%$, en el caso del cerdo $1,5 \%$ y en el caso del pollo el $1 \%$. Considerando el consumo interno anual total de carnes, las compras públicas representan el 1,8\%. El siguiente gráfico resume los porcentajes en volumen de la compra pública sobre el total de la producción nacional.

Gráfico 2. Porcentajes en volumen de la compra pública en relación a la producción total nacional

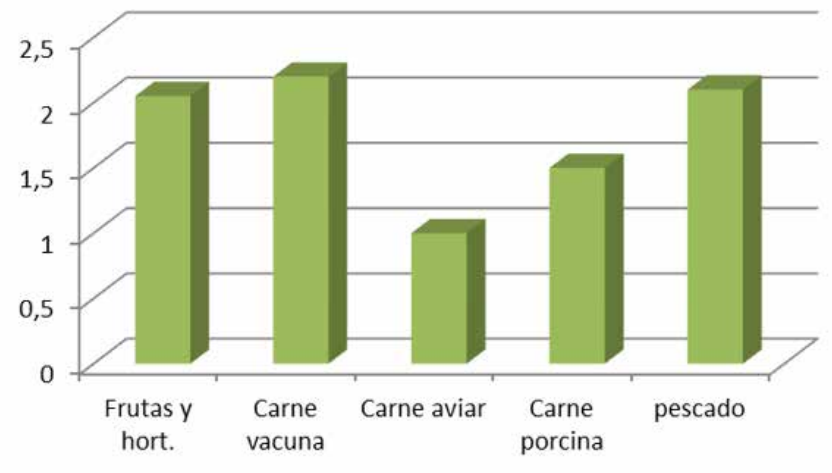

Fuente: Chiappe et al (2015).

A partir de un contexto regional y nacional favorable al desarrollo de políticas públicas de promoción de la producción familiar se implementan en Uruguay un conjunto de acciones orientadas a facilitar las condiciones de vida, producción y acceso a los canales comerciales.

Este "contexto favorable" se explica por algunas condiciones que se establecen a nivel regional, así como otras propias del proceso socioeconómico de Uruguay. En la región se establecen esfuerzos liderados por organismos públicos, organizaciones sociales, así como organismos internacionales de cooperación, para la definición de lineamientos específicos en torno a la promoción de políticas de estado de seguridad alimentaria de la población. 
En ese sentido se buscó avanzar en las metas de superación del hambre, combatiendo la pobreza y logrando mayores niveles de equidad. En el marco de esta estrategia, la producción familiar de alimentos se convierte en un sector clave en el doble sentido de abastecimiento de alimentos sanos y frescos; pero a su vez en una forma de economía social alternativa al modelo del agronegocio en términos de sustentabilidad social y ambiental.

Es así como desde bloques de integración regional (CELAC, UNASUR, MERCOSUR), y de Organismos Internacionales como FAO, FIDA, IICA, CEPAL se generaron ámbitos formales de trabajo de estas temáticas. En este contexto, a nivel nacional se buscó articular los esfuerzos de coordinación y desarrollo de aprendizajes en estas cuestiones, aunque es importante resaltar que los actores centrales de este proceso son las organizaciones de la producción familiar, quienes han sostenido sus reclamos y encontrado en este nuevo escenario un marco más favorable para hacer escuchar sus demandas históricas.

Uruguay presenta algunas particularidades que se relacionan a su tradicional forma de transitar los cambios, así como la manera de procesar las tensiones entre las demandas sociales o de sectores productivos, con las respuestas del Estado. Desde principios del siglo XX el país se ha caracterizado por un Estado de amplias funciones y presencia, una forma de estado social que en varias oportunidades se adelanta a las demandas generando respuestas en forma de normativa y políticas públicas. A esta característica general se suma que las organizaciones representativas de la producción familiar de alimentos se encuentran integradas a espacios institucionales sectoriales ${ }^{1}$ y de discusión política ${ }^{2}$, por los que se canalizan demandas específicas. De esta base surge como una forma de promover la integración de la producción familiar a las cadenas comerciales la necesidad de utilizar a las compras estatales como herramienta de promoción, articulada a un conjunto de políticas de desarrollo social y productivo.

A mediados de 2013, se conforma un equipo interinstitucional del poder ejecutivo que intenta sintetizar en un proyecto de ley las ideas respecto a las compras públicas de alimentos, a la vez que se gestan experiencias puntuales de compras de alimentos a organizaciones de productores por parte de organismos públicos.

1 Instituto Nacional de Investigación Agropecuaria, Instituto Nacional de la Carne, Instituto Nacional de la Leche, Instituto Nacional de Vitivinicultura, Instituto Plan Agropecuario, Dirección General de la Granja.

2 REAF Nacional, Mesas Sectoriales, Mesas de Desarrollo Rural. 
La conformación del equipo intersectorial integró a técnicos de los ministerios de Ganadería Agricultura y Pesca; Desarrollo Social; Industria, Energía y Minería, así como a la oficina de Planeamiento y Presupuesto dependencia de Presidencia de la República.

El producto fue un proyecto de ley enviado al parlamento por el poder ejecutivo, y presentada por el Ministro de Desarrollo Social el cual se integra a la discusión parlamentaria a través de la Comisión de Población y Desarrollo de la Cámara de Representantes, lo que se explica por el énfasis de promoción del sector de la producción familiar desde un enfoque socioeconómico, de inclusión de la población rural desde formas de organización social asociativas.

El tratamiento del proyecto género apoyo de todas las bancadas de los partidos políticos, recibiendo aprobación unánime, lo que permite entender a las compras estatales como una forma de política pública de Estado.

En paralelo y se han venido gestando experiencias de adquisición de productos alimenticios por parte del Ministerio del Interior, para el abastecimiento de Centros de Reclusión. Esas compras de carne de ave y cerdo y posteriormente de hortalizas y harinas, a organizaciones que nuclean a productores familiares (en un principio de la zona metropolitana). Permitió generar aprendizajes sobre las limitantes a levantar a la hora de sostener el abastecimiento a compradores públicos y por parte de los compradores, el sortear una serie de dificultades asociadas a los procedimientos instituidos.

Fue posible avanzar en este proceso por la voluntad y determinación política de los diferentes actores involucrados, siendo conscientes de la necesidad de desarrollar marcos normativos, adaptar procesos administrativos, generar programas de promoción, para que se logren las metas planteadas.

\section{Instrumentación de la ley de compras públicas}

El proceso parlamentario de aprobación de la Ley 19.292 finalizó en diciembre de 2014 y es posteriormente reglamentada por el poder ejecutivo a través del decreto 411/015 firmado por el ex presidente José Mujica el 28 de febrero de 2015, último día de su mandato. 
Algunas particularidades de la reglamentación aprobada:

1. Establece una reserva de mercado;

- del 30 \% (como mínimo) para las compras de bienes alimenticios de carácter centralizados.

- del $100 \%$ del mercado para el caso de las compras descentralizadas de alimentos.

- prevé condiciones de salvaguarda en las cuales el estado no se verá obligado a comprar como ser: incumplimientos previos, deficiencias en calidad, precios más elevados al promedio del producto en mercado durante los últimos 3 años.

2. Establece como sujetos beneficiarios a colectivos: conformados por al menos 5 integrantes, de los cuales como mínimo el 70\% de sus integrantes deben ser productores familiares y/o pescadores artesanales siendo estos los que aportan al menos el 50\% de la oferta del colectivo.

3. Crea un registro de colectivos que cumplan con las condiciones del punto anterior, denominado "Registro Nacional de Organizaciones Habilitadas" (RENAOH). Con el objetivo de monitorear la oferta de productos y colocar esta información a disposición de las instituciones compradoras. Por otra parte, permite desarrollar políticas diferenciadas enfocadas a fortalecer estas organizaciones.

4. Encomienda al MIDES y MGAP a través de su Dirección General de Desarrollo Rural, a implementar las acciones correspondientes para la efectivización y puesta en práctica de la ley. Estas deben realizar la difusión, capacitación y el apoyo al fortalecimiento de las organizaciones con especial énfasis en aquellos colectivos más vulnerables.

Como se mencionaba anteriormente estas características tienen su base en la estructura de compra que presenta el Estado uruguayo y en una decisión política del gobierno de promover procesos de asociativismo en el medio rural, como herramienta para mejorar la escala y competitividad de la producción familiar y pesquera artesanal, como estrategia de desarrollo rural que se propone apostar a nuevas formas de relacionamiento de la producción familiar con los mercados.

Poner en práctica esta herramienta y asegurar la efectiva llegada a los beneficiarios que apunta la ley, es posible debido a una política anterior de la DGDR, que es la creación de un registro nacional de productores familiares, a través del 
cual es posible identificar el conjunto de productores que cumplen con la característica de producción familiar.

Una de las principales restricciones para la puesta en práctica del registro de organizaciones fue la inexistencia de una definición de productor familiar pesquero. Una vez definido, estos comienzan por primera vez a ser reconocidos como sujetos de las políticas públicas diferenciadas aplicadas por la DGDR, previamente este sector venía siendo atendido desde el punto de vista social por el MIDES.

Por otra parte, el estado debió embarcarse en un proceso de desarrollo de conocimiento sobre los montos, productos y diferentes mecanismos de compras que presentan sus instituciones. Esto se realizó mediante la contratación de una consultoría encargada por MIDES y MGAP, financiada por FAO y ejecutada por investigadores de la Universidad de la República que analiza y sistematiza los procesos de compras que el estado viene realizando. También analiza las experiencias y capacidades de las organizaciones que previamente a la ley habían hecho intentos de comercializar con el estado.

A partir de la misma, quedan en evidencia algunas de los principales puntos que deben ser abordados:

\footnotetext{
desarrollar e implementar políticas diferenciadas dirigidas a la PAF y pescadores artesanales que faciliten los procesos de comercialización, en particular con el Estado. Generar condiciones para que puedan formalizar sus organizaciones, recibir apoyos técnicos especializados, y generar capacidades logísticas y de gestión para abastecer al Estado en tiempo y forma. La pesca artesanal presenta condiciones de vulnerabilidad que deberían ser específicamente atendidas. (CHIAPPE et al., 2015).
}

Superar estas limitantes es el principal desafío actualmente, en ese sentido tanto el MIDES como el MGAP han desarrollado estrategias tendientes a levantarlas:

- Creación en el MIDES de un Departamento de Ruralidad con un área específica para el trabajo en torno a procesos de facilitación del comercio. La cual se propone brindar apoyo técnico (productivo, comercial, social) a productores familiares y/o pescadores en situación de vulnerabilidad para desarrollar estrategias de comercialización con el estado en circuitos cortos (compras descentralizadas). 
- Procesos de difusión de la ley y sus alcances, tanto en las instituciones del estado (demandantes), como en espacios de las organizaciones de productores y pescadores (ofertantes).

- La DGDR en coordinación con el Departamento de Ruralidad del MIDES y el Instituto Nacional de Cooperativismo ejecutan un proyecto de apoyo de planes de fortalecimiento de las capacidades de las organizaciones de la PAF y la pesca artesanal de forma de hacer posible su incorporación al régimen de compras públicas.

El MIDES a través del INDA y DINESIL han implementado acciones de abastecimiento de alimento producidos por productores agropecuarios familiares, a servicios sociales, así como también en situaciones de emergencia por eventos climáticos (inundaciones).

En 2017 realizaron el proceso de registro de organizaciones habilitadas (RE$\mathrm{NAOH}-\mathrm{DGDR}$ ) productores de diferentes rubros, consolidando la previsión de alimentos en el marco del régimen establecido por la ley 19.292.

\section{Consideraciones finales}

La puesta en marcha de una política de compras estatales a la PAF ha implicado una innovación importante en diseño de las políticas de desarrollo rural del país, con participación de actores públicos y privados.

La inserción de los productores asociados a una "reserva de mercado", puede permitir que estos capten un mayor excedente del precio final del producto (sin que por ello el Estado los adquiera a mayor precio) al eliminar actores de intermediación.

Los avances regionales en estas temáticas resultaron importantes insumos técnicos y políticos para el desarrollo de la normativa uruguaya. Si bien dichos aportes resultaron muy valiosos, fue necesario adaptar muchos aspectos a la realidad local, caracterizada por: a) un peso muy importante de la esfera pública, y procedimientos de gestión administrativa burocrática; b) estructura de la producción familiar con gran peso del sector ganadero y de producción hortifrutícola; c) existencia de una plataforma de trabajo en políticas diferenciadas para la PAF con pocos años de desarrollo. 
La reorientación de las formas de ejecución del gasto público buscado con esta ley, constituye una potente herramienta de redistribución de la riqueza del país en sectores considerados estratégicos. Esta alternativa de relativa "simple" implementación puede ser de gran utilidad en contextos donde no es posible aumentar el gasto en políticas sociales o productivas.

Uno de los factores claves para su implementación tiene que ver con la existencia de amplias voluntades políticas, aunque no exenta de lógicos conflictos entre los distintos modelos de desarrollo productivo.

Las compras institucionales han comenzado a ser visualizadas a nivel político como un camino sustentable de apoyo a la agricultura familiar, aunque también se reconoce la necesidad de acompañar estas políticas con otros instrumentos focalizados a la PAF.

La evaluación de los impactos de esta política requerirá ser analizados luego de un período prudente de ejecución, ya que es de reciente implementación.

\section{REFERENCIAS}

CHIAPPE, M; OYANTCABAL, G., PIZZOLON, A.; RODRIGUEZ, L. Desarrollo Rural y Aplicación de Políticas Públicas a Productos Alimenticios Provenientes de la Agricultura Familiar. Informe final de Consultoría FAO, MGAP-DGDR, MIDES, 2015, $76 \mathrm{p}$.

DECRETO reglamentario Ley 19292, consultado el 26 de agosto $2016 \mathrm{em}:<\mathrm{http} / / /$ www.ecolex.org/details/legislation/decreto-no-86015-reglamentase-la-ley-19292que-declara-de-interes-general-la-produccion-familiar-agropecuaria-y-la-pescaartesanal-y-establece-un-regimen-de-compras-estatales-que-beneficia-a-lasorganizaciones-habilitadas-para-la-utilizacion-del-mismo-lex-faoc142461/>.

LEY 19292. Consultada el 26 de agosto 2016 en: <http://www.impo.com.uy/bases/ leyes/19292-2014/2>.

MGAP. s.f. resolución 527/2008. Consultada el 26 de agosto de 2016. Disponible en:<http://www.mgap.gub.uy/portal/page.aspx?2,drural,drural-registro-de-laproduccion- familiar, $\mathrm{O}, \mathrm{es}, 0,>$.

MGAP. s/f. resolución 219 y 387/2014, consultada el 15 de agosto de 2016. Disponible en:<http://www.mgap.gub.uy/portal/page.aspx?2,drural,drural-registro-de-laproduccion- familiar,O,es, $0,>$.

PIÑEIRO, D. Formas de resistencia de la agricultura familiar; el caso del Noreste de Canelones. Montevideo, Banda Oriental, 1985. 177 p. 
REAF (Reunión Especializada de Agricultura Familiar. s/f. (En línea). Consultado el 20 agosto de 2016. Disponible en: <http://www.reafmercosul.org/index.php/ grupos- temáticos/producción-familiar $>$.

SGANGA, F.; CABRERA, C.; GONZÁLEZ, M.; RODRÍGUEZ S.: Producción Familiar Agropecuaria Uruguaya y sus Productores Familiares a partir de los datos del Censo General Agropecuario y el Registro de Productores Familiares. Anuario Opypa 2014. 


\title{
Programa Nacional de Alimentação Escolar e o atendimento à cultura alimentar em municípios do Paraná
}

\author{
Carmine Marcon Piano
}

Camila Elizandra Rossi

\section{Introdução}

O respeito à diversidade e à sustentabilidade cultural são premissas para a alimentação saudável previstas na Lei Orgânica de Segurança Alimentar e Nutricional (BRASIL, 2006). Dessa forma, os programas públicos devem se preocupar com o respeito e a preservação da cultura alimentar de cada povo, sem que lhe seja imposto um padrão alimentar estranho a sua cultura e tradição (BRAGA, 2004; FREITAS, 2007). Salienta-se que atualmente não há um conceito concreto para definição de alimentos regionais. Entretanto, é consenso que a comida tradicional é aquela que, além de estar associada a valores simbólicos, lembranças passadas e tradições culturais, também está vinculada à produção em pequena escala, normalmente fabricada por comunidades locais, com destaque para a agricultura familiar (CERJAK, 2014; CSERGO, 1998; FABRI, 2015; LANG, 2014; LODY, 2008; SARAIVA, 2013).

$\mathrm{O}$ atendimento à cultura alimentar local e a previsão da compra de alimentos da agricultura familiar estão previstos no Programa Nacional de Alimentação Escolar (PNAE), considerado o mais antigo do Brasil na área da Segurança Alimentar e Nutricional e garantido atualmente pela Lei no 11.947, de junho de 2009 (PEIXINHO, 2013). No Art. $2^{\circ}$, em sua primeira diretriz, cita o uso de alimentos que respeitem a cultura, tradições e hábitos alimentares saudáveis. Destaca-se 
também o Art. 12, que reafirma a necessidade de elaboração de cardápios destinados à alimentação escolar que respeitem os hábitos alimentares, a cultura e tradição local (BRASIL, 2009).

Essas regulamentações visam à aproximação dos cardápios escolares aos hábitos alimentares de seus comensais, promovendo, portanto, a maior participação dos escolares no programa e a preservação da identidade cultural local (DA CUNHA, 2014; DE PAIVA, 2012; GABRIEL, 2012).

Para que seja facilitada a inclusão dos alimentos regionais na alimentação escolar, a Resolução $\mathrm{n}^{\circ}$ 26, de 17 de junho de 2013, prevê a dispensa do processo licitatório e a compra de gêneros da agricultura familiar via chamada pública. O documento também afirma a necessidade de elaboração de cardápios que utilizem gêneros alimentícios básicos, com respeito às referências nutricionais, aos hábitos alimentares e à cultura alimentar da localidade (BRASIL, 2013), relembrando as diretrizes previstas na Lei no 11.947/2009. A Resolução no 4/CD/ FNDE, de 2 de abril de 2015, mais recente, dispõe sobre a ampla divulgação da chamada pública às organizações locais da agricultura familiar e a entidades de assistência técnica e extensão rural do município que executa o PNAE. Além disso, estabelece estratégias para priorizar a compra de alimentos produzidos em comunidades tradicionais, priorizando-se os assentamentos de reforma agrária e as comunidades indígenas e quilombolas, não havendo prioridade entre estes (BRASIL, 2015).

Nesse sentido, este capítulo objetiva descrever se os cardápios e as chamadas públicas destinados à oferta da alimentação escolar de municípios pertencentes ao Estado do Paraná apresentam-se em concordância com o disposto na Lei $\mathrm{n}^{\mathrm{o}} 11.947 / 2009$, especificamente quanto aos artigos $2^{\circ}$ e 12 , que tangem sobre o emprego de alimentos que respeitem os hábitos alimentares, cultura e tradição alimentar da localidade.

\section{Metodologia}

O presente estudo teve caráter quantitativo, descritivo, de base documental, tendo sido realizado entre os anos de 2014 a 2015, em municípios do Estado do Paraná. As variáveis analisadas foram o percentual de inclusão de alimentos considerados regionais, presentes nos cardápios escolares e chamadas públicas. 
A identificação dos alimentos e preparações regionais presentes nas chamadas públicas e cardápios foi realizada com base nos seguintes documentos de referência: a) listagem de alimentos regionais do Ministério da Saúde, b) Cadernos Paraná da Gente no 1, e c) pesquisa bibliográfica em sites como CAPES, Scielo, Lilacs, utilizando-se os termos de indexação: alimentos; preparações regionais/ tradicionais do Paraná; cultura alimentar do Paraná; hábito alimentar do Paraná (BRASIL, 2002, 2015; PARANÁ, 2004).

Foram escolhidos oito municípios, por critério de conveniência, e solicitado aos mesmos o envio dos cardápios e das chamadas públicas referentes ao ano de 2013. Dos municípios escolhidos, quatro (50\%) disponibilizaram os documentos requeridos: Curitiba, Cascavel, Assis Chateaubriand e Sulina. Dessa forma, foram analisadas oito chamadas públicas (média de duas por município), 24 cardápios para maternal e pré-escola e 90 cardápios para Ensino Fundamental e EJA (Educação de Jovens e Adultos).

\section{Resultados e discussão}

Os alimentos regionais do Estado do Paraná citados nos documentos de referência pesquisados totalizaram 137 diferentes itens ou preparações. Alguns destes e suas respectivas regiões de origem podem ser vistos no Quadro 1. Tais alimentos e preparações foram objeto de busca nos cardápios e nas chamadas públicas da alimentação escolar dos municípios avaliados, com o intuito de observar se estão sendo ofertados aos escolares e, portanto, se o hábito cultural alimentar dos paranaenses está sendo valorizado por meio do PNAE. 
Quadro 1 - Principais alimentos considerados típicos da região Sul do Brasil ou de alguns municípios do Estado do Paraná

\begin{tabular}{|c|c|c|c|c|c|}
\hline $\begin{array}{l}\text { Alimento/ } \\
\text { preparação }\end{array}$ & $\begin{array}{l}\text { Locais onde é } \\
\text { típico }\end{array}$ & $\begin{array}{l}\text { Alimento/ } \\
\text { preparação }\end{array}$ & $\begin{array}{l}\text { Locais onde é } \\
\text { típico }\end{array}$ & $\begin{array}{l}\text { Alimento/ } \\
\text { Preparação }\end{array}$ & $\begin{array}{l}\text { Locais onde é } \\
\text { típico }\end{array}$ \\
\hline $\begin{array}{l}\text { Almeirão } \\
\text { Roxo }\end{array}$ & Sul do Brasil & $\begin{array}{l}\text { Bolo de } \\
\text { tangerina }\end{array}$ & Sul do Brasil & Cravo & Sul do Brasil \\
\hline $\begin{array}{l}\text { Almeirão/ } \\
\text { chicória- } \\
\text { amarga/ } \\
\text { radiche }\end{array}$ & Sul do Brasil & Broa polonesa & Araucária & $\begin{array}{l}\text { Crem/ batata- } \\
\text { crem/raiz } \\
\text { forte }\end{array}$ & Sul do Brasil \\
\hline $\begin{array}{l}\text { Arroz tro- } \\
\text { peiro/ arroz } \\
\text { carreteiro }\end{array}$ & $\begin{array}{l}\text { Coronel } \\
\text { Domingos } \\
\text { Soares, Lapa, } \\
\text { Campina do } \\
\text { Simão }\end{array}$ & Cuca alemã & $\begin{array}{l}\text { Marechal } \\
\text { Cândido } \\
\text { Rondon }\end{array}$ & $\begin{array}{l}\text { Cuca de } \\
\text { banana }\end{array}$ & Sul do Brasil \\
\hline Azedinha & Sul do Brasil & $\begin{array}{l}\text { Cará do ar, } \\
\text { batata do } \\
\text { ar, batata da } \\
\text { rama }\end{array}$ & Sul do Brasil & $\begin{array}{l}\text { Canela/ } \\
\text { Canela } \\
\text { da índia / ca- } \\
\text { nela da china }\end{array}$ & Sul do Brasil \\
\hline Barreado & $\begin{array}{l}\text { Litoral } \\
\text { (Morretes, } \\
\text { Antonina, } \\
\text { Guaratuba, } \\
\text { Paranaguá) } \\
\end{array}$ & $\begin{array}{l}\text { Cará, cará } \\
\text { inhame }\end{array}$ & Sul do Brasil & Cuca missal & Missal \\
\hline $\begin{array}{l}\text { Batata-doce, } \\
\text { batata } \\
\text { jerimum, ba- } \\
\text { tata- cenoura, } \\
\text { batata- abó- } \\
\text { bora }\end{array}$ & Sul do Brasil & $\begin{array}{l}\text { Charque a } \\
\text { vapor }\end{array}$ & $\begin{array}{l}\text { São Mateus } \\
\text { do Sul }\end{array}$ & $\begin{array}{l}\text { Cuscuz } \\
\text { caipira }\end{array}$ & $\begin{array}{l}\text { Região Norte } \\
\text { Pioneiro }\end{array}$ \\
\hline \begin{tabular}{|l} 
Batata/ \\
batatinha, \\
batata in- \\
glesa/batata \\
portuguesa \\
\end{tabular} & Sul do Brasil & $\begin{array}{l}\text { Chimia/ } \\
\text { geleia de figo }\end{array}$ & Sul do Brasil & $\begin{array}{l}\text { Feijão de } \\
\text { metro, feijão } \\
\text { verde }\end{array}$ & Sul do Brasil \\
\hline Beterraba & Sul do Brasil & $\begin{array}{l}\text { Chimia/ } \\
\text { geleia de } \\
\text { amora }\end{array}$ & Sul do Brasil & Feijão safrista & Farol \\
\hline $\begin{array}{l}\text { Biscoito tia } \\
\text { Mariquinha }\end{array}$ & Lapa & Cominho & Sul do Brasil & $\begin{array}{l}\text { Frango ao } \\
\text { molho de } \\
\text { laranja e } \\
\text { especiarias }\end{array}$ & $\begin{array}{l}\text { Laranjeiras } \\
\text { do Sul }\end{array}$ \\
\hline $\begin{array}{l}\text { Bolacha de } \\
\text { Araruta }\end{array}$ & Lapa & Amora & Sul do Brasil & $\begin{array}{l}\text { Frango na } \\
\text { Laranja }\end{array}$ & Capanema \\
\hline $\begin{array}{l}\text { Bolinho de } \\
\text { Polvilho }\end{array}$ & $\begin{array}{l}\text { Litoral } \\
\text { Paranaense }\end{array}$ & Banana & Sul do Brasil & $\begin{array}{l}\text { Frango na } \\
\text { telha }\end{array}$ & Umuarama \\
\hline
\end{tabular}




\begin{tabular}{|l|l|l|l|l|l|}
\hline $\begin{array}{l}\text { Pão de bafo } \\
\text { (farinha de } \\
\text { trigo, fermen- } \\
\text { to, água, ovo }\end{array}$ & Palmeira & $\begin{array}{l}\text { Polenta com } \\
\text { frango caipira } \\
\text { ao molho }\end{array}$ & $\begin{array}{l}\text { Ariranha do } \\
\text { Ivaí }\end{array}$ & Quirera & Sul do Brasil \\
\hline Tomate & Sul do Brasil & $\begin{array}{l}\text { Stolen } \\
\text { (panetone } \\
\text { alemão) }\end{array}$ & $\begin{array}{l}\text { São Mateus } \\
\text { do Sul }\end{array}$ & Sagu & Sul do Brasil \\
\hline $\begin{array}{l}\text { Bolo de } \\
\text { laranja }\end{array}$ & $\begin{array}{l}\text { Laranjeiras } \\
\text { do Sul }\end{array}$ & $\begin{array}{l}\text { Compota de } \\
\text { pêssego }\end{array}$ & Sul do Brasil & $\begin{array}{l}\text { Nhoque de } \\
\text { batata-doce }\end{array}$ & Sul do Brasil \\
\hline $\begin{array}{l}\text { Bolo de } \\
\text { Pinhão }\end{array}$ & $\begin{array}{l}\text { Litoral } \\
\text { Paranaense } \\
\text { / Sul do } \\
\text { Estado }\end{array}$ & $\begin{array}{l}\text { Couve à } \\
\text { Paraná }\end{array}$ & Farol & $\begin{array}{l}\text { Ora-pro-no- } \\
\text { bis/ } \\
\text { groselheira } \\
\text { das antigas }\end{array}$ & Sul do Brasil \\
\hline
\end{tabular}

Fonte: Documentos de referência pesquisados - 2013.

Nos documentos de planejamento de compra e fornecimento das refeições da alimentação escolar apresentados pelos quatro municípios, foram identificados 25 alimentos regionais (Quadro 2), correspondendo a 18,3\% do total de alimentos regionais do Estado do Paraná identificados nos documentos de referência $(\mathrm{n}=137)$, demonstrando limitada variedade de alimentos regionais inclusos nos cardápios escolares.

Quadro 2 - Alimentos e preparações regionais encontrados nas chamadas públicas e cardápios analisados nos quatro municípios paranaenses - 2013

\begin{tabular}{|l|l|l|}
\hline $\begin{array}{l}\text { Arroz tropeiro/ arroz } \\
\text { carreteiro }\end{array}$ & Morango & Maçã \\
\hline Banana & Pêssego & Milho \\
\hline Barreado & Polenta & Cuca \\
\hline Batata-doce/ batata jerimum & Quirera & Uva \\
\hline Batata inglesa/ batatinha & Repolho & $\begin{array}{l}\text { Sopa de milho verde e frango } \\
\text { caipira }\end{array}$ \\
\hline Beterraba & Risoto/ arroz com galinha & Tangerina/ bergamota \\
\hline Bolo de laranja & Sagu & Tomate \\
\hline Bolo nega maluca & Canjica & Couve à Paraná \\
\hline
\end{tabular}

Fonte: Documentos de referência pesquisados - 2013.

Uma das possíveis explicações para essas diferentes proporções é que nos quatro municípios paranaenses avaliados não puderam ser analisados aqueles cujos cardápios apresentavam uma descrição genérica, tais como suco, saladas, frutas, legumes, pão, carne, bolacha, visto que não podiam ser identificados 
conforme suas especificidades. Também não foram considerados como alimentos regionais itens como gelatina de morango, iogurte de morango, chá de pêssego, chá de morango, pois consistem em alimentos que, embora apresentem a fruta como alimento regional, foram adquiridos sob sua forma ultraprocessada, cuja produção não costuma ocorrer em comunidades locais (MONTEIRO, 2010).

O município que mais atendeu ao requisito de inclusão de alimentos regionais em sua alimentação escolar foi Sulina, seguido de Assis Chateaubriand. Em último lugar, esteve o município de Cascavel com 6,9\%. Ao analisar-se se a proveniência dos alimentos regionais era da agricultura familiar, percebeu-se que a chamada pública que mais continha esses itens era a de Assis Chateaubriand, seguida de Sulina. Curitiba foi o município com menor percentual de alimentos regionais provenientes da agricultura familiar entre as quatro cidades avaliadas (Tabela 1).

Tabela 1 - Alimentos/preparações regionais encontrados nos cardápios e chamadas públicas, por município - 2013

\begin{tabular}{l|l|l|l|l|l|l|l|l|l|l}
\hline \multirow{2}{*}{ Município } & \multicolumn{3}{l}{ Ambos os documentos } & \multicolumn{2}{l|}{ Cardápios } & \multicolumn{2}{l}{ Chamadas Públicas } \\
\cline { 2 - 13 } & $\begin{array}{l}\text { Total de } \\
\text { alimentos }\end{array}$ & \multicolumn{2}{l}{$\begin{array}{l}\text { Alimentos } \\
\text { regionais }\end{array}$} & $\begin{array}{l}\text { Total de ali- } \\
\text { mentos no } \\
\text { documento }\end{array}$ & $\begin{array}{l}\text { Alimentos } \\
\text { regionais }\end{array}$ & $\begin{array}{l}\text { Total de ali- } \\
\text { mentos no } \\
\text { documento }\end{array}$ & \multicolumn{2}{l}{$\begin{array}{l}\text { Alimentos } \\
\text { regionais }\end{array}$} \\
\cline { 2 - 13 } & $\mathrm{N}$ & $\mathrm{N}$ & $\%$ & $\mathrm{~N}$ & $\mathrm{n}$ & $\%$ & $\mathrm{~N}$ & $\mathrm{n}$ & $\%$ \\
\hline $\begin{array}{l}\text { Assis } \\
\text { Chateaubriand }\end{array}$ & 134 & 20 & 14,9 & 109 & 12 & 11,0 & 25 & 8 & 32,0 \\
\hline Cascavel & 172 & 12 & 6,9 & 146 & 5 & 3,4 & 26 & 7 & 26,9 \\
\hline Curitiba & 404 & 35 & 8,6 & 344 & 23 & 6,7 & 63 & 12 & 19 \\
\hline Sulina & 58 & 15 & 25,8 & 45 & 11 & 24,4 & 13 & 4 & 30,8 \\
\hline TOTAL & 768 & 82 & 10,7 & 642 & 51 & 7,9 & 126 & 31 & 24,6 \\
\hline
\end{tabular}

Fonte: Documentos de referência pesquisados - 2013.

Dessa forma, destaca-se que, ainda que apresentem baixos percentuais de alimentos regionais em seus cardápios, 94,73\% dos cardápios analisados atendem aos artigos $2^{\circ}$ e 12 da Lei 11.947/2009, empregando alimentos regionais na alimentação de seus escolares.

Paralelamente aos percentuais de alimentos regionais encontrados, verifica-se, segundo dados do FNDE, que os municípios de Sulina e Assis Chateaubriand atenderam aos requisitos mínimos para compra da agricultura familiar, apresentando, respectivamente, $42,2 \%$ e $58,1 \%$ dows recursos gastos com gêneros 
alimentícios provenientes do agricultor familiar (FNDE, 2015). Segundo a Resolução $n^{\circ}$ 26/FNDE/2013, há a exigência de que do total de recursos financeiros repassados pelo FNDE para a alimentação escolar, no mínimo 30\% devem ser utilizados para compra de alimentos vindos da agricultura familiar (BRASIL, 2013). É possível, portanto, inferir que nestes municípios o respeito à cultura alimentar local e o uso de alimentos in natura típicos da agricultura familiar tenda a ser crescente, estando em consonância com as legislações vigentes (TURPIN, 2009, BRASIL, 2009, BRASIL, 2013).

Em análise de dados referentes ao censo agropecuário (2015), verifica-se que o município de Sulina apresenta a agropecuária como principal atividade econômica do município, correspondendo a $\mathrm{R} \$ 29.046,00$ do produto interno bruto (PIB), dado este não observado nos demais municípios. Também é importante considerar que, segundo dados d o Instituto Paranaense de Desenvolvimento Econômico e Social (IPARDES), o referido município apresenta um maior número de estabelecimentos agropecuários, com 3,8 estabelecimentos a cada $\mathrm{km}^{2}$. Dessa forma, pode-se sugerir que o maior percentual encontrado para a inclusão dos alimentos regionais do município é devido à expressiva presença da agricultura familiar, visto que dinamiza a economia local, utilizando de seus recursos agropecuários para inserção de alimentos que atendam à cultura e tradição local (BRASIL, 2015; INSTITUTO PARANAENSE DE DESENVOLVIMENTO ECONÔMICO E SOCIAL, 2006, 2014).

Nessa perspectiva, também se pode justificar o menor percentual encontrado no município de Curitiba (8,6\%), visto que o município dispõe de 0,39 estabelecimentos agropecuários por $\mathrm{km}^{2}$ de município. Segundo Oliveira (2013), a inclusão de alimentos oriundos da agricultura familiar na alimentação escolar em regiões metropolitanas torna-se um desafio, uma vez que nessas regiões há menor número de agricultores familiares, insuficientes trabalhos com a agricultura urbana e periurbana, assim como déficit de espaço físico tradicional que limita essas atividades.

Outro aspecto a ser considerado consiste na localização do município de Sulina, que se situa na região Sudoeste do Paraná. Segundo dados do IPARDES (2010), do total de estabelecimentos agropecuários do sudoeste paranaense, $85 \%$ correspondem à agricultura familiar, demonstrando, portanto, que este segmento apresenta-se organizado em relação às demais mesorregiões, com importante participação no mercado interno e acesso a políticas de financiamento 
e comercialização para o setor. Dessa forma, faz-se necessário investigar se tal comportamento também pode ser encontrado nos demais municípios pertencentes a esta mesorregião. (INSTITUTO PARANAENSE DE DESENVOLVIMENTO ECONÔMICO E SOCIAL, 2010).

Embora tenham sido identificados alimentos regionais nos documentos de compra e fornecimento de alimentos destinados à alimentação escolar, apresentando-se em consonância com os artigos $2^{\circ}$ e $12^{\circ}$ da Lei 11.947/09, destaca-se que se observou uma variedade limitada de alimentos regionais, questionando-se, portanto, se o atendimento à cultura e ao hábito alimentar regional estão sendo considerados durante a elaboração dos cardápios escolares.

\section{Análise de cardápios}

Os resultados anteriormente apresentados referem-se a uma análise geral de todos os itens regionais encontrados nos cardápios e nas chamadas públicas. Nesta seção abordam-se resultados pertinentes às particularidades dos cardápios, contabilizando-se quantas vezes cada item regional (mesmo que oferecido repetidamente), esteve presente nestes documentos (Tabela 2).

Destaca-se que em avaliação à presença de alimentos regionais em cardápios escolares da região Sul do Brasil, Chaves (2009) e Fabri (2015), respectivamente, verificaram que $86,5 \%$ e $82,5 \%$ dos cardápios continham preparações regionais. De forma semelhante, o presente estudo observou que $94,73 \%$ dos cardápios analisados apresentam alimentos regionais, verificando que apenas seis dos cardápios referentes aos berçários não apresentavam alimentos regionais.

Dentre os alimentos e/ou preparações contidas nos cardápios (Quadro 1), o alimento mais frequente foi o tomate, sob a forma de saladas ou associado a pratos proteicos como carne moída com tomate e cheiro verde, omelete e minipizza integral de queijo. Salienta-se que o Paraná é o quarto maior produtor do fruto, estando o município de Marilândia do Sul como maior produtor do Estado (PARANÁ, 2012). Destaca-se, portanto, que o consumo deste alimento já perfaz o hábito alimentar brasileiro, tanto sob a forma de saladas ou sopas frias, como em cozidos, molhos, assados ou ingredientes de inúmeras preparações (PHILIPPI, 2006). 
Frutas, legumes e verduras também foram encontrados, como banana, maçã, morango, uva, pêssego, tangerina, beterraba, repolho. As frutas eram ofertadas na forma de sucos ou sobremesas, e os legumes e verduras, sob a forma de saladas ou refogados. Dados referentes à Pesquisa de Orçamentos Familiares (POF) (2008/2009) apontam que a região Sul do país apresenta uma aquisição per capita anual aquém da média nacional em relação à aquisição de frutas $(36,53 \mathrm{Kg})$ e hortaliças $(38,59 \mathrm{~kg})$. Cabe ressalvar que, conforme exposto na Resolução $\mathrm{n}^{\circ}$ 26/FNDE/2013, devem ser oferecidas semanalmente frutas e hortaliças no cardápio escolar, incentivando, dessa forma, a inclusão destes alimentos no hábito alimentar das crianças.

Tabela 2 - Cardápios analisados conforme modalidade de ensino e respectiva presença de alimentos regionais -2013

\begin{tabular}{l|l|l|l|l|l|l|l}
\hline & \multicolumn{4}{l|}{ Maternal e Pré-Escola } & \multicolumn{3}{l}{ Ensino Fundamental e EJA } \\
\hline \multirow{2}{*}{ Município } & \multicolumn{4}{l}{$\begin{array}{l}\text { Cardápios } \\
\text { analisados }\end{array}$} & \multicolumn{2}{l}{$\begin{array}{l}\text { Alimentos } \\
\text { regionais }\end{array}$} & \multicolumn{2}{l}{$\begin{array}{l}\text { Cardápios } \\
\text { analisados }\end{array}$} & \multicolumn{2}{l}{$\begin{array}{l}\text { Alimentos } \\
\text { regionais }\end{array}$} \\
\cline { 2 - 9 } & $\mathrm{n}$ & $\mathrm{n}$ & $\%^{*}$ & $\mathrm{n}$ & $\mathrm{N}$ & $\%^{*}$ \\
\hline Assis Chateaubriand & 11 & 86 & 62,8 & 11 & 58 & 42,3 \\
\hline Cascavel & 1 & 4 & 2,9 & 1 & 4 & 2,9 \\
\hline Curitiba & 12 & 479 & $349,6 \%$ & 74 & 1082 & 789,8 \\
\hline Sulina & $\mathrm{ND}$ & $\mathrm{ND}$ & - & 4 & 27 & 19,7 \\
\hline
\end{tabular}

Fonte: Documentos de referência pesquisados - 2013.

Legenda ND = Dado não disponível.

${ }^{*}$ Percentual referente ao número total $(\mathrm{n}=137)$ de alimentos regionais encontrados nos documentos de referência.

Com relação às preparações regionais, observou-se a presença de polenta, quirera (também denominada de canjiquinha), risoto de frango, canjica, sagu, barreado e arroz tropeiro/arroz carreteiro. Chaves (2009) também encontrou grande oferta dessas preparações em cardápios das regiões Sul, Sudeste e Centro-Oeste, evidenciando a importância desses alimentos para a cultura alimentar local.

Das preparações não identificadas como correspondentes à cultura alimentar local, muitas continham ingredientes considerados regionais, como é o caso da batata-inglesa e do milho verde, contidos em preparações como do purê de batata, coxa/sobrecoxa assadas com batatas, panificados à base de milho ou batata.

Segundo dados da Secretaria da Agricultura e Abastecimento (SEAB) (2013), o Paraná classifica-se como o segundo maior produtor do país de batata-inglesa 
e o primeiro na produção de milho. Esses dados refletem, portanto, o respeito à vocação agrícola e à promoção de hábitos alimentares regionais dos cardápios.

Sabe-se que uma alimentação adequada é fundamental em todas as fases do crescimento e desenvolvimento de crianças, especialmente no período pré-escolar, que é decisivo em termos de formação de hábitos alimentares saudáveis, os quais se solidificam durante a vida adulta (GOES, 2012). Dessa forma, é importante que a alimentação oferecida nas instituições destinadas a atender este público esteja de acordo com as recomendações nutricionais do PNAE, respeitando também a cultura, a tradição e os hábitos alimentares (BRASIL, 2009, 2013).

O consumo de alimentos regionais apresenta um papel muito importante na tradição de diversas culturas e regiões, contribuindo para o sentido de identidade e valor de um indivíduo. Segundo Lody (2008), o consumo de determinados alimentos em detrimento a outros traduz a atestação cultural de um indivíduo, visto que, por intermédio deles, expõe-se a categoria "comida/ povo", podendo-se identificar suas origens, seus hábitos alimentares, costumes, territórios, rituais de produção e sua comensalidade, dentre outros (CERJAK, 2014).

Estudo realizado por Cerjak et al. (2014), o qual consistiu em explorar as diferenças entre os motivos de consumo para a compra de comida tradicional em dois países europeus, identificou que, para os indivíduos estudados, os alimentos regionais caracterizam-se como mais saudáveis, apresentando melhor sabor, menos resíduos químicos que os produtos convencionais, com benefícios ambientais, expressando também o apoio aos agricultores familiares e/ou locais.

Diante disso, expõe-se que são poucos os estudos que relatam o consumo de alimentos regionais por crianças. Entretanto, trabalho realizado por Martins (2007) revelou que muitas mães assistidas pelo Programa Saúde da Família (PSF) no Ceará não incluem alimentos regionais na alimentação de seus filhos em decorrência do desconhecimento dos alimentos típicos de sua localidade.

Destaca-se que o Ministério da Saúde dispõe de documentos gratuitos que versam sobre os alimentos regionais característicos de cada local, que devem ser utilizados pelos profissionais nutricionistas para elaboração de cardápios pautados no respeito à cultura, aos hábitos alimentares e à tradição da localidade, associando-os à vocação agrícola de cada município (BRASIL, 2002, 2009, 2015).

Salienta-se, portanto, que o processo de elaboração de cardápios deve basear-se em novos referenciais de promoção da saúde, associando a qualidade 
nutricional dos alimentos a sua sustentabilidade ambiental, cultural econômica e social (SARAIVA, 2013).

Uma preocupação recorrente sobre a inclusão dos alimentos regionais está fundamentada na qualidade nutricional dos cardápios oferecidos, uma vez que muitos alimentos regionais podem conter elevadas quantidades de gordura saturada e açúcar. É importante, nesse sentido, que os gestores da alimentação escolar busquem o equilíbrio entre os aspectos simbólicos e nutricionais para o planejamento de cardápios, tendo em vista a necessidade da oferta de alimentos saudáveis que promovam a identidade cultural local (BRASIL, 2009, 2013).

\section{Análises das chamadas públicas}

Ao comparar-se o número de alimentos regionais encontrados nas chamadas públicas e cardápios, verificou-se um maior percentual de inclusão de alimentos/ preparações regionais nas chamadas públicas (24,6\%), conforme apresenta a Tabela 1.

Embora este percentual esteja se apresentando superior ao encontrado nos cardápios $(7,9 \%)$, pode-se observar uma baixa variedade de alimentos regionais, quando comparado ao potencial agrícola da região Sul, com uma limitada oferta de frutas, tubérculos, legumes, verduras e cereais (PARANÁ, 2013).

Fabri (2015), em estudo sobre a inclusão dos alimentos regionais em um município do Estado de Santa Catarina, verificou um aumento de 192\% na variedade de produtos oriundos da chamada pública no ano de 2010 a 2013, sendo que destes $58 \%$ foram relativos aos alimentos regionais. De forma semelhante, Saraiva (2013), em estudo sobre o panorama da compra de alimentos provenientes da agricultura familiar, identificou que a região Sul apresenta o maior percentual de compras de gêneros da agricultura familiar (71,3\%).

Entretanto, apesar do aumento na demanda de alimentos regionais via chamada pública, alguns entraves ainda são verificados: inviabilidade de fornecimento regular e constante dos alimentos; falta de interesse dos agricultores; demora da Prefeitura em elaborar a chamada pública; produção destinada ao Programa Aquisição de Alimentos (PAA); sazonalidade de alguns gêneros alimentícios que não condizem com período letivo; falta de profissionalização e especificação sanitária dos produtos; impossibilidade de formalização dos agricultores devido 
à exigência de padrões de qualidade dos produtos agroindustrializados, falta de mão de obra qualificada na preparação dos alimentos, infraestrutura precária das cozinhas e burocracia dos processos de compra (OLIVEIRA, 2013; SARAIVA, 2013; TRICHES \& SCHNEIDER, 2010; TURPIN, 2009).

Diante disso, observa-se que há muito a ser feito para a efetiva consolidação do mercado institucional entre agricultores familiares e gestores. Para isso são necessárias ações de planejamento e organização, em que os agricultores familiares, organizados em cooperativas ou individualmente, planejem a produção, a fim de evitar oscilações de produtos, bem como os gestores atuem de forma a disponibilizar a estes agricultores familiares a infraestrutura e o apoio logístico, promovendo eventos que valorizem a agricultura familiar e o consumo de alimentos regionais e inserindo o tema no currículo escolar, dentre outras ações que propulsionem os objetivos propostos pelo PNAE. (SARAIVA, 2013; TURPIN, 2009).

\section{Considerações finais}

Considerando que a alimentação passou a ser um direito social garantido pela Constituição Brasileira, aponta-se a necessidade desta alimentação ser reconhecida culturalmente pelo seu comensal, com vistas à valorização dos hábitos alimentares regionais, preservação da identidade cultural local e empoderamento do direito humano à alimentação adequada.

Dessa forma, a Lei ${ }^{\circ} 11.947 / 2009$, em específico os artigos $2^{\circ}$ e 12 , demonstram o comprometimento do Programa Nacional de Alimentação Escolar em promover o respeito à cultura e tradição local. Entretanto, os dados apontados neste estudo refletem que a presença desses alimentos ainda se faz de forma discreta $(n=25 ; 18,3 \%)$ quando comparada com a pluralidade de alimentos regionais encontrados no Estado $(n=137)$. Portanto, conclui-se que o respeito à cultura alimentar regional ainda pode ser melhorado nos municípios paranaenses, especialmente nos de maior porte.

Também se notou que os alimentos regionais em sua maioria são encontrados nas chamadas públicas $(24,6 \%)$ do que nos cardápios (7,6\%), demonstrando, portanto, que sua inclusão na alimentação escolar requer ação conjunta de agricultores familiares e gestores, de forma a atender aos requisitos estipulados 
na Resolução n 26/FNDE/2013. Ainda há, contudo, a necessidade de incluir um maior número de gêneros alimentícios da agricultura familiar, consistindo em um desafio para os gestores do programa, com vistas à dinamização da economia local e à preservação dos hábitos alimentares locais.

Considerando as bases legais que subsidiam a inclusão dos alimentos regionais no hábito alimentar dos escolares e sua relação direta com a compra de gêneros locais vindos da agricultura familiar, sugere-se que os municípios fomentem as atividades da agricultura familiar municipal, permitindo maior participação dos agricultores no trâmite das chamadas públicas, incentivando-os à iniciação de cooperativas de forma a abranger maior número de agricultores, expandindo também a diversidade dos produtos por eles fabricados. Esse desafio exige trabalho conjunto com diversos setores dos municípios, como as secretarias de Educação e de Agricultura, assim como de agências de extensão rural.

Tendo em vista as limitações atemporais e geográficas deste estudo, levanta-se a necessidade de aprofundamento da temática abordada, com base em análises que considerem maior número de anos de pesquisa, bem como uma maior extensão territorial do Estado do Paraná, para que haja um maior conhecimento a respeito do atendimento à cultura alimentar local.

\section{REFERÊNCIAS}

BRAGA V. Cultura alimentar: contribuições da antropologia da alimentação. Saúde em Revista. Piracicaba 2004; 6(13): 37-44.

BRASIL. Constituição (1988). Emenda Constitucional no 64, de 4 de fevereiro de 2010. Alterado art. $6^{\circ}$ da Constituição Federal, para introduzir a alimentação como um direito social.

BRASIL. Instituto Brasileiro de Geografia e Estatística (IBGE). Censo demográfico 2010. Disponível em: <http://www.ibge.gov.br/home/estatistica/populacao/censo2010/ resultados_dou/PR2010. Pdf $>$. Acesso em: 15 jun. 2014.

BRASIL. Instituto Brasileiro de Geografia e Estatística (IBGE), em parceria com os Órgãos Estaduais de Estatística, Secretarias Estaduais de Governo e Superintendência da Zona Franca de Manaus (SUFRAMA). Produto Interno Bruto (PIB), 2015. Disponível em: <http://cidades.ibge.gov.br/painel/economia.php?codmun=412665\&lang=_ES $>$. Acesso em: 09 set. 2015. 
BRASIL. Ministério da Educação. Fundo Nacional do Desenvolvimento da Educação. Resolução $N^{o}$ 26, de 17 de julho de 2013. Dispõe sobre o atendimento da alimentação escolar aos alunos da educação básica no âmbito do Programa Nacional de Alimentação Escolar (PNAE).

BRASIL. Pesquisa de orçamentos familiares 2008-2009: análise do consumo alimentar pessoal no Brasil / IBGE. Coordenação de Trabalho e Rendimento. Rio de Janeiro: IBGE, 2011. P. 150.

BRASIL. Lei $n^{\circ} 11$. 346, de 15 de setembro de 2006. Cria o Sistema Nacional de Segurança Alimentar e Nutricional, 15 de setembro de 2008. Publicado no Diário Oficial da União, 2006.

BRASIL. Lei $n^{\circ} 11.947$, de 16 de junho de 2009. Dispõe sobre o atendimento da alimentação escolar e do Programa Dinheiro Direto na Escola aos alunos da educação básica; altera as Leis $\mathrm{n} \underline{\mathrm{OS}} 10.880$, de 9 de junho de 2004, 11.273, de 6 de fevereiro de 2006, 11.507, de 20 de julho de 2007; revoga dispositivos da Medida Provisória $\mathrm{n}^{\mathrm{O}}$ 2.178-36, de 24 de agosto de 2001, e a Lei no 8.913 , de 12 de julho de 1994; e dá outras providências, 16 de junho de 2009. Diário Oficial da União 2009, 17 jun.

BRASIL. Ministério da Educação. Fundo Nacional de Desenvolvimento da Educação. Resolução $n^{\circ} 4$, de 2 abril de 2015. Altera a redação dos artigos 25 a 32 da Resolução $\mathrm{n}^{\circ} 26$ de 17 de junho de 2013 no âmbito do Programa Nacional de Alimentação Escolar (PNAE).

BRASIL. Ministério da Saúde. Secretaria de Atenção à Saúde. Departamento de Atenção Básica. Alimentos regionais brasileiros. 2. ed. Brasília: Ministério da Sa úde, 2015.

BRASIL. Ministério da Saúde. Secretaria de Políticas de Saúde. Coordenação-Geral da Política de Alimentação e Nutrição. Alimentos regionais brasileiros. Brasília: Ministério da Saúde, 2002.

CERJAK, M.; BRUNNER, F.; HAAS, R.; TOMIC, M. What motivates consumers to buy traditional food products? Evidence from Croatia and Austria using word association and laddering interviews. British Food Journal, vol. 116, №. 11, 2014, p. 1726-1747.

CHAVES, L. G.; MENDES, P. N. R.; BRITO, R. R.; BOTELHO, R.B.A.; O programa nacional de alimentação escolar como promotor de hábitos alimentares regionais. Revista de Nutrição. Campinas, nov./ dez. 2009; 22 (6): 857-866.

CSERGO, J. A emergência das cozinhas Regionais. In: Flandrin JL, Montanari M. História da Alimentação [tradução de Luciano Vieira Machado e Guilherme JF Teixeira]. São Paulo: Estação Liberdade; 1998. P. 806-824.

DA CUNHA, D.T.; GONÇALVES, H. V. B.; DE LIMA, A.F.A.; MARTINS, P.A.; DE ROSSO, V. V.; STEDEFELDT, E. Regional food dishes in the Brazilian National School Food Program: Acceptability and nutritional composition. Revista de Nutrição. Campinas jul./ago 2014; 27(4):423-434. 
DE PAIVA, J.B.; DE FREITAS, M.C.S.; SANTOS, L.A.S. Hábitos alimentares regionais no Programa Nacional de Alimentação Escolar: um estudo qualitativo em um município do sertão da Bahia, Brasil. Revista de Nutrição. Campinas mar./abr., 2012; 25(2):191-202.

FABRI, R.K.; PROENÇA, R.P.C.; MARTINELLI, S.S.; CAVALLI, S.B. Regional foods in Brazilian school meals. British Food Journal Vol. 117 No. 6, 2015 pp. 1706-1719.

FREITAS, M.C.S.; PENA, P.G.L. Segurança alimentar e nutricional: a produção do conhecimento com ênfase nos aspectos da cultura. Revista de Nutrição. Campinas 2007; 20 (1): $69-81$, jan./ fev.

FUNDO NACIONAL DE DESENVOLVIMENTO DA EDUCAÇÃO. Prestação de contas. Disponível em:<http://www.fnde.gov.br/>. Acesso em: 8 dez. 2015.

GABRIEL, C. G.; COSTA, L. C.; FEIO CALVO, M. C. M.; VASCONCELOS, F. A. G. Planejamento de cardápios para escolas públicas municipais: reflexão e ilustração deste processo em duas capitais brasileiras. Revista de Nutrição, Campinas 2012; 25 (3): 363-372, maio/ jun.

GOES, V. F.; SOARES, B. M.; VIEIRA, D. G.; CORTESE, R. D. M.; PICH, P. C.; CHICONATTO, P. Avaliação do Estado Nutricional e do Consumo Alimentar de PréEscolares Atendidos nos Centros Municipais de Educação Infantil de Guarapuava-PR. Alim. Nutr., Araraquara jan./mar. 2012; v. 23, n. 1, p. 121-129.

LANG, M.; STANTON. J. Q. U. Y.; Consumers' evolving definition and expectations for local foods. British Food Journal, Vol. 116, No. 11, 2014, pp. 1808-1820.

LODY, R. Eu como. In: Lody R. Brasil bom de boca: temas da antropologia da alimentação. São Paulo: Senac São Paulo, 2008. P. 29-79.

MARTINS, M.C. Promoção da Saúde de Crianças em Alimentação Complementar por meio da Utilização dos Alimentos Regionais. [Dissertação]. Fortaleza: Universidade de Fortaleza, 2007.

MONTEIRO, C. A.; LEVY, R. B.; CLARO, R. M.; DE CASTO, R. R.; CANNON, G. Increasing consumption of ultra-processed foods and likely impact on human health: evidence from Brazil. Public Health Nutrition: 2010; 14(1), 5-13.

OLIVEIRA, T. R. P. R.; SOUSA, H. C.; SILVA, A. P.; Agricultura familiar na alimentação escolar. Nutrire: Rev. Soc. Bras. Alim. Nutr. J. Brazilian Soc. Food Nutr dez. 2013; São Paulo, SP, v. 38, n. 3, p. 256-268.

PARANÁ. Instituto Paranaense de Desenvolvimento Econômico e Social (IPARDES). Total de estabelecimentos agropecuários por município do Estado do Paraná, 2006. Disponível em: $<$ http://www.ipardes.gov.br/imp/imp.php?page=consulta\&action=new $>$. Acesso em: 10 set. 2015. 
PARANÁ. Instituto Paranaense de Desenvolvimento Econômico e Social (IPARDES), Área territorial em $\mathrm{Km}^{2}$ por municípios do Estado do Paraná, 2014. Disponível em: $<$ http://www.ipardes.gov.br/imp/imp.php?page=consulta\&action=new $>$. Acesso em: 10 set. 2015.

PARANÁ, Secretaria de Estado da Cultura. Pratos típicos paranaenses. Coordenador Renato Augusto Carneiro Jr.; Equipe de pesquisa Cíntia Maria Sant'Ana Braga Carneiro, José Luiz de Carvalho, Myriam Sbravati. Curitiba, 2004.

PARANÁ. Secretaria de Estado do Planejamento e Coordenação Geral. Instituto Paranaense de Desenvolvimento Econômico e Social (IPARDES). Nota Técnica IPARDES, Curitiba, n. 16, novembro 2010.

PARANÁ. Secretaria do Estado da Agricultura e do Abastecimento (SEAB). Departamento de Economia Rural (DERAL). Olericultura - Análise da Conjuntura Agropecuária, dezembro, 2012. Disponível em: Acesso em: 15 set. 2015.

PARANÁ. Secretaria do Estado da Agricultura e do Abastecimento (SEAB). Departamento de Economia Rural (DERAL). Evolução da área colhida, produção, rendimento, participação e colocação Paraná/Brasil, 2013. Disponível em: <http:// www.agricultura.pr.gov.br/arquivos/File/deral/cprbr.pdf>. Acesso em: 10 set. 2015.

PEIXINHO, A. M. L. Trajetória do Programa Nacional da Alimentação Escolar no período de 2003-2010: relato do gestor nacional. Ciência \& Saúde Coletiva, 2013; 18 (4): 909-916.

PHILIPPI, S.T. Verduras e legumes. In: Philippi, ST. Nutrição e Técnica Dietética. 2 ed. rev. e atual. Barueri-SP: Manole, 2006, p. 77.

SARAIVA, E. B.; DA SILVA, A. P. F.; DE SOUZA, A. A.; CERQUEIRA, G. F.; CHAGAS, C. M. S.; TORAL, N. Panorama da compra de alimentos da agricultura familiar para o Programa Nacional de Alimentação Escolar. Ciência \& Saúde Coletiva, 2013, 18(4):927-936.

TRICHES, R. M.; SCHNEIDER, S. Alimentação escolar e agricultura familiar: reconectando o consumo à produção. Saúde Soc. 2010; 19(4):933-945.

TURPIN, M.E. A Alimentação Escolar como Fator de Desenvolvimento Local por meio do Apoio aos Agricultores Familiares. Segurança Alimentar e Nutricional, Campinas 2009; 16(2): 20-42. 


\title{
Grau de processamento dos gêneros alimentícios solicitados aos agricultores familiares para a alimentação escolar e a adequação das chamadas públicas: um estudo realizado nos estados de São Paulo, Santa Catarina e Paraná
}

Cassiani Gotâma Tasca Suélen Regina Lothermann

\begin{abstract}
Alimentação escolar saudável e sustentável: da promoção da segurança alimentar e nutricional ao fortalecimento da agricultura familiar
\end{abstract}

Nas últimas décadas, muitos movimentos vêm sendo realizados na perspectiva de incorporar o Direito Humano à Alimentação Adequada (DHAA) no conceito de Segurança Alimentar e Nutricional (SAN), nas políticas públicas e leis direcionadas a garantir a melhoria das condições de SAN no Brasil. Neste âmbito, insere-se a implementação de ações e programas nacionais e estaduais que visam promover a garantia do abastecimento alimentar, através da ampliação ao acesso a alimentos em qualidade e quantidade suficiente às condições da população (COSTA e MALUF, 2001).

Um exemplo é o Programa Nacional de Alimentação Escolar (PNAE), que visa estabelecer condições favoráveis no enfrentamento de problemas referentes ao consumo alimentar e à produção de alimentos. Isso se dá a partir do incentivo a modelos de produção mais sustentáveis, como os empreendimentos 
da agricultura familiar, que contribuem para uma relação mais estreita entre o campo e a cidade (TRICHES e SCHNEIDER, 2010).

Diante disso, destaca-se o Artigo 14 da Lei Federal 11.947/2009, que regulamenta o PNAE e determina que, do total de recursos financeiros repassados pelo Fundo Nacional de Desenvolvimento da Educação (FNDE) aos estados e municípios para gastos na alimentação escolar, no mínimo 30\% devem ser utilizados na aquisição de gêneros alimentícios oriundos de agricultores familiares ou de suas organizações (BRASIL, 2009). Iniciativas como esta são de suma importância, não apenas por incentivar a reprodução da segurança alimentar e nutricional dos produtores rurais, mas também por fortalecer a oferta de alimentos saudáveis e adequados a indivíduos vulneráveis, como crianças e adolescentes (TRICHES e SCHNEIDER, 2012).

Uma das principais maneiras de garantir a comercialização dos produtos provenientes da agricultura familiar é através do Programa de Aquisição de Alimentos (PAA), que é gerido pelo Ministério de Desenvolvimento Social e Combate à Fome (MDS) e pelo Ministério do Desenvolvimento Agrário (MDA) (SOARES et al., 2013; BRASIL, 2014).

Tal programa é executado por meio de seis modalidades: compra direta da agricultura familiar; compra com doação simultânea; apoio à formação de estoque pela agricultura familiar; aquisição de sementes; incentivo à produção de leite (para os estados da região Nordeste e o estado de Minas Gerais); compra institucional - antiga aquisição de alimentos para atendimento da alimentação escolar. No ano de 2012, através da Resolução n 50, de 26 de setembro, a modalidade compra institucional passou a ser executada através das chamadas públicas nos moldes do funcionamento do PNAE (CAMARGO; BACCARIN; SILVA, 2013).

Essa modalidade, além de contribuir para o aumento da quantidade e garantia da qualidade dos alimentos nas escolas e creches, também contribui com a manutenção dos agricultores no campo, pois eles podem manter a diversidade produtiva, garantindo e assegurando uma fonte de renda (TURPIN, 2009; CASTRO; BOMBARDI, 2012).

Tendo em vista que a legislação do PNAE aponta para a oferta de uma alimentação saudável, ou seja, com restrição de alimentos ricos em sódio, gorduras totais, saturadas e açúcar, que são os principais constituintes dos alimentos processados, entende-se que a escolha dos alimentos a serem adquiridos para este programa deve levar em consideração o seu grau de processamento. Como 
aponta a referida legislação, os alimentos básicos devem se fazer presentes no cardápio escolar, já que eles são indispensáveis para a promoção da alimentação saudável, possibilitando, portanto, a utilização de alimentos que condizem com a cultura alimentar local, articulando-se as diretrizes do PNAE. Porém, é necessário atentar-se para as características dos alimentos que condizem com a cultura alimentar local, pois, muitas vezes, esses alimentos podem não ser saudáveis, como o salame e a banha, proveniente das culturas alemã e italiana (TEO; MONTEIRO, 2012).

Os cardápios da alimentação escolar devem ser elaborados por nutricionista responsável, utilizando gêneros alimentícios básicos e respeitando hábitos alimentares e culturais e especificidades nutricionais, sendo que a aquisição de gêneros alimentícios com os recursos do FNDE, ficam restritos àqueles que possuem elevado teor de sódio, gordura saturada e açúcar, ou seja, os alimentos altamente processados, bem como os produtos de baixo teor nutricional (BRASIL, 2009).

Salienta-se a necessidade de uma maior adequação da legislação do PNAE, referente à definição de quais os tipos de produtos que devem ser adquiridos para a alimentação escolar, tendo em vista as preconizações que remetem a oferta de alimentos saudáveis e que condizem com a cultura alimentar. Uma forte alternativa para que essa proposição seja atendida é através da definição do grau de processamento dos alimentos a serem adquiridos, o que facilitaria a execução do programa, pois os cardápios seriam elaborados com vistas à cultura alimentar, porém dentro dos padrões considerados saudáveis. Cabe salientar que a partir da elaboração de um cardápio adequado a essas exigências, as chamadas públicas também estariam apropriadas, facilitando, portanto, a aquisição de alimentos condizentes com a produção da agricultura familiar.

Conforme aborda a Lei no 11.947/2009, que regulamenta o PNAE desde a sua aprovação, a aquisição de gêneros alimentícios da agricultura familiar deve ser feita por meio de chamadas públicas. As chamadas públicas são procedimentos voltados à seleção de proposta específica para a aquisição de alimentos da agricultura familiar e devem ser divulgadas em diversos meios de comunicação, para que os agricultores possam ter acesso à sua abertura (BACCARIN et al., 2012).

Ainda segundo Baccarin et al. (2012), em uma mesma chamada pública pode haver a presença de alimentos in natura, bem como alimentos com alto grau de processamento, contrariando as preconizações do PNAE, que restringem a presença de alimentos altamente processados (ricos em sódio, gordura e açúcar) 
na alimentação escolar. Diante dessa observação, questiona-se: os agricultores familiares estariam aptos a fornecer tais gêneros alimentícios?

Como pode-se verificar, a nova forma de gestão do PNAE ainda é recente, portanto, ainda ocorrem alguns entraves para o sucesso de sua execução. Em se tratando da aquisição dos alimentos da agricultura familiar, Souza (2012), em estudo realizado em São Paulo, verificou que os principais desafios vivenciados pelos agricultores familiares se referem à dificuldade para adequar-se à legislação, pois muitos ainda não conseguem adquirir a Declaração de Aptidão ao Programa Nacional de Fortalecimento da Agricultura Familiar (PRONAF), documento que possibilita a participação no mercado institucional. Dentre as dificuldades citadas pelos agricultores no referido estudo, destacam-se necessidades de produzir variedade de alimentos para atender às exigências do mercado e ao planejamento da produção, considerando que, na maioria das vezes, há ausência da programação prévia por parte das prefeituras, o que faz com que os agricultores não tenham conhecimento de quando serão publicados os editais das chamadas públicas.

Soares et al. (2013) realizaram um estudo de caso em municípios catarinenses que executavam o PAA. Os resultados apontaram para a necessidade de constante diálogo entre os envolvidos no processo, em especial nutricionistas e produtores, objetivando minimizar possíveis interrupções no fornecimento e nas modificações dos cardápios escolares, através da elaboração de critérios de substituição dos produtos que sirvam como referência aos agricultores. Ressalta-se que, no caso analisado, não existiam critérios preestabelecidos de substituição de produtos, comprometendo, assim, a continuidade das entregas e a execução dos cardápios previamente elaborados nas unidades de ensino.

De acordo com Baccarin et al. (2012), entre os diversos desafios encontrados pelos agricultores familiares para atendimento da Lei $n^{\circ} 11.947 / 2009$, encontra-se, muitas vezes, a dificuldade de oferecer boa parte dos produtos descritos nas chamadas públicas, pois em muitos editais são encontrados tanto produtos in natura, quanto produtos altamente processados. Ou seja, sabendo-se que esses gêneros alimentícios passam por diversos processos industriais até chegar no produto final, fica difícil acreditar que os agricultores estariam aptos a fornecer tais alimentos, além desses gêneros ferirem as recomendações do PNA.

Considerando os princípios norteadores para o fornecimento da alimentação escolar, denota-se que, como demonstra o cenário atual, é de extrema 
importância uma maior adequação do poder público com relação à compra de alimentos mais frescos e saudáveis. Conforme o estudo realizado por Souza (2012), os gestores que trabalham diretamente com a aquisição dos gêneros alimentícios enfrentam alguns obstáculos, como o desconhecimento da produção da agricultura familiar, dúvidas sobre como elaborar uma chamada pública e dificuldades na hora de fazer as especificações dos alimentos.

Diante disso, evidencia-se que estudos devem ser realizados a fim de contribuir para a análise da adequação das chamadas públicas para a alimentação escolar, em relação ao grau de processamento dos gêneros alimentícios solicitados à agricultura familiar. Um ponto-chave para a elaboração da chamada pública de maneira adequada é o atendimento dos regramentos do PNAE e o conhecimento dos produtos que são produzidos pelos agricultores familiares da região. Essa conexão com a realidade e o cuidado com o grau de processamento dos alimentos solicitados favoreceriam a aquisição de alimentos condizentes com a produção da agricultura familiar e também contribuiriam para a oferta de uma alimentação adequada às necessidades nutricionais do público atendido.

Sabendo-se da importância da adequação das chamadas públicas à oferta de produtos da agricultura familiar, procura-se, neste capítulo, verificar o tipo de gênero alimentício solicitado, considerando seu grau de processamento em uma amostra de municípios dos estados do Paraná, Santa Catarina e São Paulo.

Este estudo, cujo enfoque é a identificação do grau de processamento dos alimentos fornecidos pela agricultura familiar ao Programa Nacional de Alimentação Escolar, nos estados de São Paulo, Santa Catarina e Paraná, vincula-se a um projeto de pesquisa financiado pelo Conselho Nacional de Desenvolvimento Científico e Tecnológico (CNPq). Trata-se da pesquisa intitulada "Agricultura Familiar sob a Vigência da Lei Federal 11.947/2009: Abrangência e Adequação das Chamadas Públicas, Impactos na Agricultura Local e Preços Recebidos pelos Agricultores Familiares", contemplada com recursos da Chamada MCTI-CNPq/ MDS-SAGI, número 24/2013, Desenvolvimento Social. 
158

\section{O consumo de alimentos ultraprocessados e as consequências para a saúde da população}

No que tange à promoção de hábitos alimentares saudáveis, a escola desempenha um papel fundamental no que diz respeito à formação de hábitos e estilos de vida saudáveis, pois como este é um espaço de aquisição de conhecimentos e valores, pode contribuir para a reversão da tendência de doenças crônicas não transmissíveis, com origem na infância, e possivelmente presente na vida adulta (ACCIOLY, 2009).

Estudos realizados nas últimas décadas apontam um fenômeno chamado "transição nutricional", caracterizado por um aumento dos índices de sobrepeso e de doenças crônicas não transmissíveis, associados ainda à prevalência de déficits nutricionais na população (KAC; VELASQUES-MELENDEZ, 2003). Avancini et al. (2013) verificaram que o consumo excessivo de alimentos altamente processados pode auxiliar no surgimento de sobrepeso e obesidade, que, por sua vez, contribuem para o aumento do risco do surgimento de doenças crônicas não transmissíveis (circulatórias, câncer, diabetes, respiratórias).

Segundo World Health Organization (2015), na América Latina, o consumo per capita de alimentos altamente processados aumentou em $38,9 \%$ entre 2000 e 2013. Em 2013, os brasileiros e peruanos foram de longe os maiores consumidores de altamente processados. No Brasil, de acordo com este estudo, há maiores riscos de doenças cardiovasculares, obesidade adulta, síndrome metabólica em adolescentes e dislipidemias em crianças.

Diante disso, no ano de 2014 o Ministério da Saúde publicou o novo Guia Alimentar para a População Brasileira, o qual traz uma abordagem mais contemporânea. Ou seja, em vez de trabalhar somente os grupos alimentares e porções recomendadas da pirâmide alimentar, utiliza como meio de orientações o nível de processamento dos alimentos. Indica que a alimentação deve ter como base os alimentos in natura (frutas, carnes, legumes) e minimamente processados (arroz, feijão e frutas secas), limitar o consumo de alimentos processados (queijos, pães, conservas), evitar o consumo de ultraprocessados (macarrão instantâneo, refrigerantes, salgadinhos de pacote, doces industrializados) e usar óleos, gorduras, sal e açúcar em quantidades moderadas (BRASIL, 2014). Tal guia surgiu com o intuito de promover a alimentação adequada e saudável e, nessa medida, 
acelerar o declínio da desnutrição e reverter as tendências desfavoráveis do aumento da obesidade e de outras doenças crônicas, visto que, com os padrões alimentares atuais, a frequência desses problemas vem aumentando cada vez mais (BRASIL, 2014).

De acordo com o estudo de Monteiro et al. (2010), os alimentos podem ser classificados de acordo com o método de processamento utilizado para sua produção. As classificações dividem-se em: alimentos in natura ou minimamente processados (podem sofrer transformações físicas); ingredientes culinários processados (substâncias extraídas dos alimentos in natura ou minimamente processados); alimentos altamente processados (resultam de processos industriais), que possuem alta concentração de sódio, gordura saturada e açúcar. Os autores destacam que, com o passar dos anos, o consumo de alimentos não transformados ou minimamente processados, bem como ingredientes culinários processados, foi sendo progressivamente substituído pelo consumo de alimentos prontos para comer, isto é, por produtos alimentares ultraprocessados, tanto em famílias de baixa renda quanto em famílias de renda superior.

Assim, destaca-se a importância de considerar o grau de processamento dos alimentos na elaboração das chamadas públicas para a compra de alimentos da agricultura familiar para a alimentação escolar.

\section{Delineamento do estudo}

Os métodos empregados para a realização desta pesquisa foram apoiados na abordagem quantitativa, tendo como base a análise de documentos oficiais (chamadas públicas para a agricultura familiar) sobre a execução do Programa de Alimentação Escolar.

A pesquisa foi realizada a partir de uma amostra de aproximadamente 5\% das prefeituras dos estados de São Paulo, Paraná e Santa Catarina, tomando-se o cuidado para estabelecer uma estratificação entre elas, de acordo com o alunado atendido na alimentação escolar e de forma que contemplasse $10 \%$ do número de alunos por municípios, obtido através do banco de dados do Instituto Nacional de Pesquisas Educacionais (INEP).

Foram consideradas as faixas populacionais, buscando-se verificar se há diferença entre as muito pequenas (abaixo de 20.000 habitantes), as pequenas 
(de 20.000 a 100.000 habitantes), as médias (de 100.000 a 500.00 habitantes) e as grandes (acima de 500.000 habitantes). A partir disso, foram selecionados dois municípios de cada faixa populacional: um que mais atendeu ao Artigo 14 da Lei Federal 11.947/2009 e um que menos atendeu. Tal dado foi verificado a partir das prestações de contas das prefeituras.

Para a coleta de dados, foram consultadas as chamadas públicas para aquisição de produtos da agricultura familiar realizadas nos três estados, nos anos de 2012 e 2013, através dos portais de transparência pública localizados nos sites das prefeituras e contatos com os municípios por meio de visitas ou telefônicos e/ou eletrônicos.

A partir da análise dos dados obtidos referentes aos alimentos que constam nas chamadas públicas, foi possível tabulá-los em planilhas no programa Microsoft Excel com informações quanto à origem do produto, se é animal ou vegetal, bem como seu grau de processamento. Cabe salientar que muitos alimentos apareceram com a mesma descrição em mais de uma chamada, no entanto eles não foram contabilizados, sendo tabulados apenas uma vez para cada estado. Com relação ao grau de processamento, os produtos foram classificados por meio de um critério que se apoia no estudo realizado por Monteiro et al. (2010), porém com inclusão de mais um grau.

Utilizou-se, para o presente estudo, a seguinte classificação: produtos in natura, que não passam por nenhum grau de processamento; mínimo grau de processamento, para os alimentos que passam apenas por transformações físicas; médio grau de processamento, para os alimentos passíveis de transformação físico-químicas; alto grau de processamento, para os produtos que necessitam diferentes ingredientes culinários para sua fabricação, incluindo sal, açúcar, óleos, outras gorduras e substâncias de uso industrial. A inclusão de mais um critério de classificação deu-se pelo fato de acreditar-se que alimentos in natura são classificados distintamente de alimentos com mínimo grau de processamento, portanto, não pertencentes a um único grupo de classificação, como consta no critério adotado por Monteiro et al. (2010).

A partir dessa classificação, realizou-se a quantificação em percentual dos valores encontrados para, posteriormente, associar a possíveis impactos na saúde dos escolares. Destaca-se que, para a comparação entre os estados, utilizou-se o teste de qui-quadrado, sendo considerado como nível de significância o valor de 0,05 ou $5 \%$. 
161

\section{A interface entre a demanda e a oferta de alimentos da agricultura familiar para a alimentação escolar}

A partir do levantamento de documentos oficiais sobre a execução do PNAE nos estados de São Paulo, Paraná e Santa Catarina, foi possível obter as chamadas públicas para a compra de alimentos provenientes da agricultura familiar dos anos de 2012 e 2013. Conforme demonstra a Tabela 1, obtiveram-se no total 606 chamadas públicas, sendo que, pelo menos, no ano de 2013, conseguiu-se obtê-las de um mínimo de 5\% dos municípios de cada estado. Em Santa Catarina e Paraná, o número de chamadas poderia ser maior, no entanto muitas delas não foram disponibilizadas via site, por meio de visitas aos municípios e contatos telefônicos/eletrônicos.

Tabela 1 - Número de chamadas públicas coletadas e número de municípios correspondentes, em 2012 e 2013, nos estados de São Paulo, Paraná e Santa Catarina

\begin{tabular}{l|l|l|l|l|l|l}
\hline \multicolumn{2}{l}{} & 2012 & & 2013 & & Total \\
\hline Estados & Chamadas & Municípios & Chamadas & Municípios & Chamadas & Municípios \\
\hline São Paulo & 197 & 161 & 212 & 156 & 409 & 241 \\
\hline Paraná & 21 & 11 & 43 & 26 & 64 & 37 \\
\hline $\begin{array}{l}\text { Santa } \\
\text { Catarina }\end{array}$ & 39 & 29 & 94 & 46 & 133 & 75 \\
\hline Total & 257 & 201 & 349 & 228 & 606 & 353 \\
\hline
\end{tabular}

Fonte: Dados da pesquisa (elaborada pelas autoras) -2015 .

A partir das chamadas públicas analisadas, verificou-se que o estado que apresentou uma maior variedade de alimentos in natura foi Santa Catarina (54,7\%), seguido de São Paulo (50,6\%) e Paraná (42\%). Em relação aos alimentos com mínimo grau de processamento, o Paraná se destacou (28\%), seguido de São Paulo (17,7\%) e Santa Catarina (14,4\%). Somando-se os percentuais acima, verificou-se que o estado que apresentou maior variedade de alimentos in natura e com mínimo grau de processamento foi o Paraná (70\%). Acredita-se que um dos fatores determinantes para este resultado possa estar relacionado à adoção da Lei Estadual do Paraná n. 16.751/2010, a qual prevê a inclusão obrigatória de produtos orgânicos na alimentação escolar dos alunos da rede pública estadual e municipal de ensino. A respeito dos alimentos de médio grau de processamento, verificou-se que o estado de São Paulo apresentou percentual acima dos demais 
estados (14\%), seguido do Paraná (13,7\%) e de Santa Catarina (8,3\%). O percentual de alimentos com alto grau de processamento ficou maior no estado de Santa Catarina (22,7\%), seguido por São Paulo (17,7\%) e Paraná (16,4\%).

O número de chamadas públicas adquiridas foi maior no estado de São Paulo, o que certamente influencia na obtenção de resultados significativos, no entanto, mesmo o estado do Paraná possuindo um menor número de chamadas públicas, possui uma maior variedade de alimentos a serem adquiridos por meio da agricultura familiar, sendo predominante, alimentos in natura e minimamente processados. Nesse caso, acredita-se que se o número de chamadas públicas aumentasse, a variedade de alimentos consequentemente também aumentaria.

De acordo com a origem dos produtos presentes nas chamadas públicas, verificou-se que nos três estados o maior percentual encontrado refere-se à origem vegetal, seguido da origem animal e animal/vegetal. Cabe salientar que o grupo "animal/vegetal" diz respeito aos panificados, que são elaborados com alimentos condizentes tanto à origem animal quanto vegetal. A Tabela 2 demonstra a quantificação da variedade de alimentos encontrados em cada estado, de acordo com sua origem.

Tabela 2 - Quantificação da variedade dos produtos presentes nas chamadas públicas, de acordo com sua origem nos estados de SP, PR e SC - 2012-2013

\begin{tabular}{l|l|l|l}
\hline & São Paulo & Paraná & Santa Catarina \\
\hline Origem do produto & Total / Percentual & Total / Percentual & Total / Percentual \\
\hline Animal & $29 / 17,7 \%$ & $34 / 11,6 \%$ & $24 / 13,3 \%$ \\
\hline Vegetal & $126 / 76,8 \%$ & $233 / 79,5 \%$ & $127 / 70,2 \%$ \\
\hline Animal/Vegetal & $9 / 5,5 \%$ & $26 / 8,9 \%$ & $30 / 16,6 \%$ \\
\hline
\end{tabular}

Fonte: Dados da pesquisa (elaborada pelas autoras) -2015 .

Teste de qui-quadrado $\mathrm{p}=0,004 \%$ *

${ }^{*}=$ valor estatisticamente significante.

Os principais produtos de origem animal verificados foram leite, ovos, queijos, diferentes tipos de cortes de carne (bovina, suína, aves e peixes), bebida láctea e mel. No que diz respeito aos produtos de origem vegetal, verificou-se que a maioria refere-se a frutas, legumes, verduras, temperos, ingredientes culinários, como açúcar, farinha, óleo de soja, também arroz e feijão. Já com relação ao grupo animal/vegetal, encontram-se pães, massas, bolachas e cucas. 
De acordo com a análise estatística, há diferença significativa nas chamadas públicas dos três estados, tanto com relação ao grau de processamento quanto à origem dos alimentos $(\mathrm{p}<0,05)$.

No Quadro 1 são demonstrados os alimentos de acordo com o grau de processamento. Pode-se verificar que a maioria dos alimentos classificados como médio e alto grau de processamento necessitam passar por diversas técnicas de processamento, assim como requerem a adição de muitos ingredientes e embalagens diferenciadas para sua fabricação. Alguns produtos, como panificados, doces e conservas podem ser elaborados no espaço produtivo do próprio agricultor familiar, no entanto, alimentos embutidos, como salsicha, apresuntado, mortadela, assim como lácteos, achocolatado e caldo de galinha necessitam passar por processos industriais para que possam ser fabricados, o que pode dificultar sua aquisição por meio das chamadas públicas.

Em estudo realizado por Baccarin et al. (2012), constatou-se a presença de vários produtos alimentícios altamente processados nas chamadas públicas analisadas, destacando-se biscoito tipo cookie, gotas de chocolate com glúten e pó químico, bebida láctea U.A.T ou U.H.T sabor chocolate, barra de cereal, óleo de soja refinado tipo 1 e macarrão de sêmola. Cabe destacar que o método de classificação dos alimentos utilizado na referida pesquisa, é distinto do método utilizado para o presente estudo. Segundo os autores, os produtos citados possuem uma grande quantidade de corantes, aromatizantes e outras substâncias químicas, evidenciando que não poderiam ser produzidos por agricultores familiares.

Quadro 1 - Alimentos encontrados nas chamadas públicas, de acordo com o grau de processamento

\begin{tabular}{|l|l|}
\hline $\begin{array}{l}\text { Grau de } \\
\text { processamento }\end{array}$ & Alimentos encontrados nas chamadas públicas \\
\hline $\begin{array}{l}\text { In natura } \\
\text { 305 itens) }\end{array}$ & $\begin{array}{l}\text { Frutas: abacate, abacaxi, acerola, ameixa, amora, banana, caju, caqui, cambuci, } \\
\text { carambola, figo, goiaba, graviola, jabuticaba, jaca, kiwi, laranja, lichia, limão, } \\
\text { maçã, mamão, manga, maracujá, melancia, melão, mexerica, morango, pera, } \\
\text { pêssego, tangerina, uva; } \\
\text { Hortaliças: abóbora, abobrinha, acelga, agrião, alcachofra, alface, almeirão, be- } \\
\text { rinjela, beterraba, brócolis, caxi, cenoura, chuchu, chicória, couve, couve-flor, } \\
\text { escarola, espinafre, maxixe, nabo, pepino, pimentão, rabanete, radite, repolho, } \\
\text { rúcula, quiabo, tomate, vagem; } \\
\text { Raízes e tubérculos: batata, batata-doce, cará, inhame, mandioca/aipim; } \\
\text { Temperos naturais: alho, cebola, cebolinha, cheiro-verde, coentro, hortelã, } \\
\text { louro em folhas, manjericão, mostarda, salsa; } \\
\text { Outros: ovos, pinhão; }\end{array}$ \\
\hline
\end{tabular}


164

\begin{tabular}{|l|l|}
\hline $\begin{array}{l}\text { Mínimo grau } \\
\text { (137 itens) }\end{array}$ & $\begin{array}{l}\text { Carnes: carne bovina moída, carne bovina em pedaço, carne suína com/sem } \\
\text { osso, filé de tilápia, peito de frango sem osso; } \\
\text { Frutas, hortaliças e raízes/tubérculos descascadas/embaladas, polpa de fruta; } \\
\text { suco integral de fruta; } \\
\text { Lácteos: leite pasteurizado; } \\
\text { Leguminosas: feijão, lentilha e ervilha embalados; } \\
\text { Oleaginosas: amendoim descascado; } \\
\text { Cereais: milho verde sem palha; } \\
\text { Temperos naturais: cravo-da-índia, orégano seco; } \\
\text { Outros: chás, banha, mel sachê, melado; }\end{array}$ \\
\hline $\begin{array}{l}\text { Médio grau } \\
\text { (75 itens) }\end{array}$ & $\begin{array}{l}\text { Lácteos: requeijão, manteiga, queijo; } \\
\text { Cereais: amido de milho, arroz, cereal cozido à base de milho, farinha, fubá, sagu; } \\
\text { Outros: açúcar cristal/refinado, canela em pó, colorau, extrato de soja em pó, } \\
\text { molho de tomate, fermento, óleo de soja, pó para preparo de gelatina, sal; }\end{array}$ \\
\hline $\begin{array}{l}\text { Alto grau } \\
\text { (121 itens) }\end{array}$ & $\begin{array}{l}\text { Panificados: agnoline caseiro, biscoitos/bolachas (cookie, manteiga, polvilho, } \\
\text { mel), cuca/bolo, grôstoli, lasanha, macarrão, minipizza, pães; } \\
\text { Embutidos: apresuntado, linguiça, mortadela, salsicha, salame; } \\
\text { Doces: doces de frutas/leite, pamonha, pé-de-moleque, palito de banana cris- } \\
\text { talizado, rapadura; } \\
\text { Conservas: champignon, ervilha em conserva, palmito; } \\
\text { Lácteos: leite UHT, bebida láctea, iogurte; } \\
\text { Outros: achocolatado, bebida a base de soja, caldo de galinha, creme vegetal; }\end{array}$ \\
\hline
\end{tabular}

Fonte: Dados da pesquisa (elaborado pelas autoras) - 2015.

Outro estudo realizado no município de Capitão Leônidas Marques (PR), verificou que as principais barreiras citadas pelos agricultores para viabilizar o fornecimento dos alimentos para o PNAE foram as condições climáticas e a adequação as exigências sanitárias. Os agricultores também relataram algumas desvantagens com relação à participação em cooperativas, como dificuldade em negociar, menor valor pago, lucratividade fica concentrada na cooperativa e, ainda, que há burocracia no processo de formalização da diretoria (BALESTRIN, 2014).

Em estudo realizado no estado de São Paulo, Silva (2014) avaliou as diferentes visões de atores envolvidos no processo de implantação da Lei Federal 11.947, dando destaque para agricultores familiares, gestores públicos e técnicos de extensão rural. No estudo, verificou-se que, dentre as dificuldades encontradas para o funcionamento do programa, está a incompatibilidade entre a demanda e oferta dos alimentos, ou seja, nos cardápios são inseridos alimentos que não condizem com a produção da agricultura familiar, dificultando, assim, a entrega dos produtos pelos agricultores. 
Outra questão de suma importância na aquisição de alimentos da agricultura familiar diz respeito à cultura alimentar. Como aponta a legislação do PNAE, os alimentos básicos devem se fazer presentes no cardápio escolar, já que eles são indispensáveis para a promoção da alimentação saudável, possibilitando, portanto, a utilização de alimentos que condizem com a cultura alimentar local, articulando-se com as diretrizes do PNAE. O problema está nas características dos alimentos que condizem com a cultura alimentar local, pois, muitas vezes, esses alimentos podem não ser saudáveis, como o salame e a banha, proveniente das culturas alemã e italiana (TEO; MONTEIRO, 2012).

Conforme citam Amorim; Staduto (2008), das propriedades rurais pesquisadas em seu estudo, 100\% (40 unidades de produção) delas diversificam seus produtos, tanto para subsistência, quanto para comercialização. A matéria-prima produzida é utilizada pelas agroindústrias para serem transformadas em novos produtos, de origem animal e vegetal. Os produtos mais encontrados nas agroindústrias são chás, derivados suínos (embutidos, banha, torresmo), hortaliças embaladas, produtos orgânicos, panificados (bolachas, bolos, pães, cucas, salgados), derivados de amendoim (paçoca, pé-de-moleque), derivados de leite (queijo, requeijão, manteiga, nata), sal temperado, compotas, doces, mel, própolis, entre outros. De acordo com os autores, $95 \%$ das 40 unidades de produção pesquisadas citaram uma elevação da renda através do processamento da matéria-prima.

Em um estudo realizado em dois municípios, de pequeno e grande porte, Bevilaqua; Triches (2014) verificaram que, segundo o presidente de uma cooperativa de laticínios, vender o leite in natura para laticínios não traz muitos benefícios, pois o valor pago por litro é muito baixo. Ainda de acordo com ele, a transformação do leite in natura em leite fluído pasteurizado e iogurte foi decisiva na manutenção e crescimento da Cooperativa.

Segundo Mosimann (2014), a agroindustrialização pode ser importante no atendimento ao mercado institucional, visto que aumenta a variedade de produtos com maior prazo de validade, permitindo que sejam adquiridos em grandes quantidades pelos processos licitatórios e chamadas públicas dos diferentes municípios.

Claro que é válido afirmar que a comercialização de produtos da agricultura familiar de forma mais diversificada é de suma importância no que diz respeito ao aumento da renda das famílias, o que consequentemente auxilia na redução do êxodo rural, bem como aumenta a variedade de produtos adquiridos, no entanto 
deve-se ter a consciência que muitos dos produtos elaborados nas agroindústrias possuem elevada quantidade de gordura, açúcar e sal. Assim, verifica-se a importância de tomar-se um cuidado na aquisição desses produtos da agricultura familiar, assim como de outros fornecedores. Ou seja, a proporção de processados adquiridos para a alimentação escolar não deve sobressair aos produtos in natura, conforme a legislação do PNAE.

Diante disso, evidencia-se a necessidade de uma maior adequação da legislação do PNAE referente à definição de quais os tipos de produtos devem ser adquiridos para a alimentação escolar, tendo em vista as preconizações que remetem à oferta de alimentos saudáveis e que condizem com a cultura alimentar.

Uma forte alternativa para que essa proposição seja atendida é através da definição do grau de processamento dos alimentos a serem adquiridos, o que facilitaria a execução do programa, pois os cardápios seriam elaborados com vistas à cultura alimentar, porém dentro dos padrões considerados saudáveis. Cabe salientar que a partir da elaboração de um cardápio adequado a tais exigências, as chamadas públicas também estariam apropriadas, facilitando, desse modo, a aquisição de alimentos condizentes com a produção da agricultura familiar, dando preferência aos produtos in natura e minimamente processados.

\section{Considerações finais}

Neste capítulo foi possível verificar-se a importância do PNAE no que diz respeito à garantia de melhores condições de SAN no Brasil. Muitas mudanças positivas já ocorreram desde seu surgimento na década de 1940, no entanto, ainda há lacunas a serem preenchidas para sua melhor execução, a exemplo da elaboração das chamadas públicas para a agricultura familiar, que, muitas vezes, é realizada de maneira inadequada, interferindo na aquisição de produtos condizentes com a produção da agricultura familiar, bem como na qualidade da alimentação servida aos escolares.

É necessário que as chamadas públicas sejam adequadas ao grau de processamento dos alimentos a serem adquiridos, pois isso está diretamente associado à oferta de uma alimentação saudável nas escolas e à possibilidade dos agricultores familiares em conseguir atendê-las. Entende-se que, se houver a definição do grau de processamento dos alimentos, as chamadas públicas seriam elaboradas 
com vistas às preconizações do PNAE, as quais restringem a presença de produtos ricos em gordura saturada, sódio e açúcar.

É válido mencionar que se deve priorizar a oferta de alimentos in natura e minimamente processados na alimentação escolar, pois, como demonstra o cenário atual, o número de pessoas com problemas relacionados ao consumo de alimentos altamente processados vem aumentando. Verifica-se, portanto, a importância da implementação de ações que visem estimular a adoção de hábitos alimentares adequados e a aquisição de alimentos saudáveis para a alimentação escolar. O que pode ocorrer através das chamadas públicas, contribuindo de maneira satisfatória para a promoção de estilos de vida saudáveis e, consequentemente, para uma melhor qualidade de vida dos escolares.

Há poucos estudos que avaliaram a adequação das chamadas públicas para a agricultura familiar em relação ao grau de processamento dos alimentos solicitados. Nesse sentido, espera-se que as discussões evidenciadas neste estudo contribuam para a realização de pesquisas futuras, a fim de auxiliar no melhor cumprimento da legislação que regulamenta o PNAE.

Com relação aos resultados obtidos, verificou-se que o número de chamadas públicas disponibilizadas foi desproporcional entre os três estados, certamente influenciando na obtenção de resultados mais concretos.

\section{REFERENNCIAS}

AMORIM, L. S. B.; STADUTO, J. A. R. Desenvolvimento territorial rural: a agroindústria familiar no oeste do Paraná. Rev. de Economia Agrícola, São Paulo, vol.55, n.1, p. 15-29, 2008.

ACCIOLY, E. A escola como promotora da alimentação saudável. Vol.2, n.2, Rio de Janeiro, 2009.

AVANCINI, M. Um desafio de peso para as políticas públicas. Com Ciência, Campinas, 2013, n.145.

BACCARIN, J. G. et al. Alimentação Escolar e Agricultura Familiar: alcance e dificuldades para a implantação do Artigo 14 da lei 11.947/2009 no estado de São Paulo. Sociedade brasileira de economia, administração e sociologia rural, Vitória, 2012.

BALESTRIN, É. L. B. As estratégias de inserção dos agricultores familiares no Programa de Alimentação Escolar de Capitão Leônidas Marques. 2014. 152 f. Dissertação (Mestrado em Desenvolvimento Regional) - Universidade Tecnológica 
Federal do Paraná, Curso de Pós-Graduação em Desenvolvimento Regional, Pato Branco - PR, 2014.

BEVILAQUA, K.; TRICHES, R. M. Implicações da venda de gêneros alimentícios ao Programa de Alimentação Escolar nos aspectos de renda e organização dos agricultores familiares. Segurança Alimentar e Nutricional, Campinas, vol. 21, n.2, p. 448-460, 2014.

BRASIL, Lei no 11.947 de 16 de junho de 2009. Dispõe sobre o atendimento da alimentação escolar e do Programa Dinheiro Direto na Escola aos alunos da educação básica. Diário Oficial da União, 2009. Disponível em: <http://www.planalto.gov.br/ ccivil_03/_ato2007-2010/2009/lei/111947.htm>. Acesso em: 15 jun. 2015.

BRASIL, M. S. Guia Alimentar para a população brasileira. 2. ed. Brasília, 2014.

CAMARGO, R. A. L; BACCARIN, José Giácomo; SILVA, Denise Boito Pereira. O papel do Programa de Aquisição de Alimentos (PAA) e do Programa Nacional de Alimentação Escolar (PNAE) no fortalecimento da agricultura familiar e promoção da segurança alimentar. Vol. 8, n. 2, 2013.

CASTRO, T. P; BOMBARDI, L. M. Programa Nacional de Alimentação Escolar PNAE: o elo entre a educação e a cultura. 2012.

COSTA, C; MALUF, R. Diretrizes para uma política municipal de segurança alimentar e nutricional. Publicações Pólis, São Paulo, 2001.

KAC, Gilberto; VELASQUEZ-MELENDEZ, Gustavo. A transição nutricional e a epidemiologia da obesidade na América Latina. Cad. Saúde Pública. Rio de Janeiro, v. 19, supl. 1, p. S4-S5, 2003.

MONTEIRO, C. A. et al. A new classification of foods based on the extent and purpose of their processing. Cadernos de Saúde Pública. Vol. 26, n.11, 2010. MOSIMANN, E. N. Agricultura familiar e alimentação escolar nas encostas da Serra Geral de Santa Catarina: desafios e potencialidades. 2014. Dissertação (Mestrado em Agrossistemas) - Universidade Federal de Santa Catarina, Santa Catarina, 2014.

MOSIMANN, E. N. Agricultura familiar e alimentação escolar nas encostas da Serra Geral de Santa Catarina: desafios e potencialidades. 2014. Dissertação (Mestrado em Agrossistemas) - Universidade Federal de Santa Catarina, Santa Catarina, 2014.

SILVA, D. B. P. Alimentação escolar e agricultura familiar: a viabilidade da aplicação da lei federal 11.947 de 2009 sob o ponto de vista de diferentes atores sociais. 2008. Dissertação (Mestrado em Geografia) - Universidade Estadual Paulista, São Paulo, 2014.

SOARES, Fábio Veras et al. Structured Demand and Smallholder Farmers in Brazil: the case off PAA and PNAE. Brasília, 2013.

SOUZA, L. B. B. Organizações da agricultura familiar no estado de São Paulo e sua experiência de fornecimento para o PNAE. In: Projeto Nutre São Paulo: Análise da 
inclusão da Agricultura Familiar na alimentação escolar no estado de São Paulo. São Paulo: Instituto Via Pública, 2012.

TEO, C. R. P.; MONTEIRO, C. A. Marco legal do Programa Nacional de Alimentação Escolar: uma releitura para alinhar propósitos e prática na aquisição de alimentos. Rev. Nutr., Campinas, vol. 25, n.5, p. 657-668, 2012.

TRICHES, R. M.; SCHNEIDER, S. Reconstruindo o "elo perdido": a reconexão da produção e do consumo de alimentos através do Programa de Alimentação Escolar no município de Dois Irmãos (RS). Segur. Aliment. Nutr., Dois Irmãos-RS, vol.17, n.1, p. 1-15, 2010.

Desestruturar para construir: interfaces para a agricultura familiar acessar o programa de alimentação escolar. Estud. Soc. e Agric., Rio de Janeiro, vol. 20, n.1, 2012.

TURPIN, M. E. A alimentação escolar como fator de desenvolvimento local por meio do apoio aos agricultores familiares. Sociedade Brasileira de Economia, Administração e Sociologia Rural, Campinas, 2009.

WORLD HEALTH ORGANIZATION, Pan American Health Organization. Ultraprocessed food and drink products in Latin America: Trends, impact on obesity, policy implications. Washington, DC: PAHO, 2015. 


\title{
Programa de Aquisição de Alimentos e diversificação: possibilidades para a recampesinização e suas limitações estruturais
}

\author{
André A. Michelato Ghizelini
}

\section{Introdução}

As compras institucionais da agricultura camponesa no Brasil é algo extremamente recente e tem como marco a implantação do Programa de Aquisição de Alimentos, o $\mathrm{PAA}^{1}$, a partir do ano de 2003, o qual trouxe inovações do ponto de vista burocrático-legal, possibilitando a construção de outros formatos de arranjos produtivos, organizativos e da relação produtor-consumidor.

Para tanto, as compras institucionais da agricultura camponesa não se restringem, atualmente, ao Programa de Aquisição de Alimentos, mas a um leque de ações e instrumentos que tem como objetivo e princípios articular e aproximar a produção da agricultura camponesa e o consumo. Desde 2003, sete instrumentos de compras governamentais foram implementados: 1) Compra com Doação Simultânea; 2) Compra Direta; 3) Incentivo à Produção e ao Consumo de Leite; 4) Apoio à Formação de Estoques; 5) Aquisição de Sementes; 6) Programa Nacional de Alimentação Escolar (PNAE); e 7 ) as compras governamentais de alimentos dos órgãos públicos federais.

1 O Programa de Aquisição de Alimentos (PAA) surge, no Brasil, a partir do debate da política nacional de segurança alimentar e do combate a fome e a pobreza, no período eleitoral da campanha de 2002, no âmbito do Instituto da Cidadania, organização não governamental ligada ao Partido dos Trabalhadores (PT), que será base para a elaboração do Programa Fome Zero. Com a vitória do PT nas eleições presidenciais, já em 2003 encaminham e aprovam a lei 10.696, de 02 de julho de 2003, instituindo o PAA como Programa governamental e que ficaria sob a coordenação do Ministério Extraordinário de Segurança Alimentar e Nutricional (MESA), e futuramente seria alocado, no ano de 2004, sob responsabilidade executiva do Ministério do Desenvolvimento Social e Combate à Fome (MDS). 
No entanto, neste estudo ${ }^{2}$, utilizar-se-á o PAA com doação simultânea como objeto de análise, pois foi o instrumento de compra governamental com impacto de quase quatro bilhões de reais em 12 anos de funcionamento (2003-2015) e, para tanto, é de grande importância compreender em que medida as compras institucionais interferem no funcionamento e na organização da agricultura camponesa brasileira.

Nessa perspectiva, este capítulo tem como objetivo apresentar dados que possam contribuir para o debate sobre a necessidade da construção de políticas e ações governamentais que interfiram diretamente na produção e comercialização da agricultura camponesa, garantindo a segurança alimentar no campo e na cidade. Mas, fundamentalmente, assegurar que sejam delineados processos que possibilitem certa autonomia para a agricultura camponesa e para os territórios e as comunidades urbanas que estão no seu entorno.

O leitor encontrará, portanto, uma discussão em torno do processo de implementação do PAA (Doação Simultânea) - consequências positivas do programa para a agricultura camponesa, algumas limitações para o avanço do PAA -, assim como um outro modelo de agricultura e desenvolvimento que tenha o campesinato como ator central. Além disso, este capítulo também problematiza a perspectiva de que o PAA tem contribuído de forma ímpar para um certo processo de recampesinização da pequena agricultura brasileira, que se encontra bastante integrada aos complexos agroindustriais.

\section{O Estado e o caráter inovador do PAA}

O Programa de Aquisição de Alimentos traz a partir do seu surgimento em 2003, com a publicação da Lei No 10.696 e o Decreto 4.772, ambos publicados em 02 de julho deste mesmo ano, trouxe inovações para a forma como o Estado, através da burocracia estatal, organiza a compra de alimentos para atender grupos sociais em situação de insegurança alimentar.

2 Este estudo é fruto de uma trajetória de mais de 12 anos em que o autor acompanhou e foi agente de execução do PAA nos Estados do Paraná e no Espírito Santo, entre os anos 2003 e 2015. Portanto, não só os dados serão apresentados, mas também relatos da experiência que o autor desenvolveu enquanto pesquisador e técnico durante este período. 
Art. 19. Fica instituído o Programa de Aquisição de Alimentos com a finalidade de incentivar a agricultura familiar, compreendendo ações vinculadas à distribuição de produtos agropecuários para pessoas em situação de insegurança alimentar e à formação de estoques estratégicos. (Regulamento) [...]

$\$ 2^{\circ} \mathrm{O}$ Programa de que trata o caput será destinado à aquisição de produtos agropecuários produzidos por agricultores familiares que se enquadrem no Programa Nacional de Fortalecimento da Agricultura Familiar - PRONAF, ficando dispensada a licitação para essa aquisição desde que os preços não sejam superiores aos praticados nos mercados regionais.

Será então, a partir desta lei, principalmente no que se refere ao Artigo 19, inciso 2, que o Estado brasileiro "quebra" a Lei 8.666, que estabelece o regramento das licitações e contratos governamentais, e, a partir desta nova lei, permite que as compras institucionais de alimentos possam ser operacionalizadas não mais através das licitações públicas, nas quais o menor preço deve ser o único parâmetro para que as compras sejam realizadas, tendo como atores empresas legalmente constituídas no território nacional. Claramente necessária para dar transparência e eficiência à coisa pública, a lei de licitações e contratos tem sua importância na regulação e realização dos recursos públicos. No entanto, deixou de fora das compras governamentais a agricultura camponesa, pois além da baixa capacidade organizativa neste momento histórico, apresenta incapacidade estrutural de competir com as empresas de atacado e varejo de distribuição de alimentos no país. A partir da lei que permite o funcionamento do PAA em território nacional, os camponeses e suas organizações passam a ser também atores no processo de compras governamentais de alimentos. Além de serem legitimados a participar desses processos, eles também passam a ser reconhecidos no processo de estabelecimento de preços, quando o Governo Federal publica o Decreto 4.772, que estabelece:

Art. 3० O Grupo Gestor de que trata este Decreto definirá:

I - a sistemática de aquisição dos produtos agropecuários, cuja definição dos preços citados no $\$ 2$ o do art. 19 da Lei no 10.696, de 2003, deverá levar em conta as diferenças regionais e a realidade da agricultura familiar.

A partir desse aparato legal, o Estado passa a legitimar as compras de alimentos da agricultura camponesa, mas também a regular os preços dos produtos 
e alimentos que serão adquiridos, respeitando e reconhecendo as características do processo de compra que caracteriza o PAA, varejo e baixa escala, além de realizar a "quebra" da lei de licitações e contratos para a agricultura camponesa e suas organizações.

Dessa forma, o Estado brasileiro não apenas transformou sua política de compra de alimentos, que vinha, desde a década de 40 do Séc. XX, sendo operacionalizada diretamente através de grandes empresas de distribuição de alimentos, o que inviabilizava a participação de pequenas e médias empresas, mas, principalmente, inviabilizava a participação da agricultura camponesa e suas organizações (associações, cooperativas, agroindústrias familiares e a própria família camponesa através da nota de produtor rural) nos processos de compras institucionais. Esse processo de centralização que se deu através da Lei No 8.666 coloca-se como um aparato importante do capital para fundar e consolidar uma política de desenvolvimento baseada nos complexos agroindustriais e na produção de monoculturas (ERTHAL, 2006).

Essas novas regulamentações que possibilitaram a inserção da agricultura camponesa nos processos de compras institucionais surgem enquanto inovações do ponto de vista da lógica do Estado brasileiro até então e passa a imprimir para a agricultura camponesa um "novo" cenário de produção e comercialização. Mais do que inserção num mercado institucional, essas novas regras abrem espaço para que a agricultura de base familiar, que vinha num processo acelerado de integração agroindustrial e integração à agricultura conservadora, tenha a possibilidade de produzir-se a partir de outro contexto, que será de uma agricultura fundada na diversificação e na aproximação campo-cidade, produção-consumo, possibilitando maior autonomia para o campesinato brasileiro.

\section{A diversificação da produção enquanto centralidade}

O Programa de Aquisição de Alimentos com doação simultânea tem uma característica no seu modo de funcionamento que faz dele uma ação pública que permite estimular e fortalecer processos de diversificação produtiva na agricultura de base familiar e, assim, possibilitar até que famílias integradas à agricultura de 
monocultura e agroexportadora possam rever e assumir uma posição de restituir suas características enquanto camponeses ${ }^{3}$.

No entanto, é importante demarcar quais seriam essas condições que o PAA traz enquanto inovação e permitirá que a agricultura de base familiar possa se ressignificar para assumir sua condição camponesa. Assim, as compras governamentais da agricultura de base familiar não seriam por si só pré-condição para estimular e alterar a forma como a agricultura modernizadora estreitou a relação entre a forma industrial de agricultura e o campesinato. Porém, a característica de ser um programa que se realiza na comunidade ou na municipalidade, faz com que os agricultores entreguem diretamente para as entidades e organizações sociais, com constância e regularidade, mas, principalmente, com uma pauta diversificada de alimentos que, em sua maioria, são alimentos in natura e não agroindustrializados, o que faz com que as entregas sejam constantes e permanentes, com baixa escala, mas com diversidade (MICHELATO-GHIZELINI, 2010).

Nesse contexto a agricultura camponesa afirma-se enquanto condição para a realização do PAA, pois a organização da produção e do trabalho familiar exigido para responder as demandas do programa, das entidades sociais, extrapola a forma de produção dada pela agricultura industrial, que prima pela grande escala, especialização, concentração, alimentos altamente processados industrialmente e com distribuição via atacadistas numa dimensão regional e/ou nacional.

Com garantia da compra dos alimentos por parte do Estado, elevou o interesse dos agricultores de base familiar a reduzir seu tempo e trabalho nas atividades de monocultura especializadas, e eles passaram a investi-lo nas áreas de produção diversificadas, como a horta, o pomar, os pequenos animais, a “agroindustrialização” artesanal (MICHELATO-GHIZELINI, 2010).

Para além da qualificação da renda e da diversificação produtiva, apregoada e verificada em pesquisas realizadas sobre o programa (DIAS, 2013; MARIOTO e HESPANHOL, 2012; SILVA, 2011; VIEIRA e VIANA, 2006), o PAA tem permitido a reorganização do trabalho familiar, como também a reorganização

\footnotetext{
3 A noção de camponês utilizada neste capítulo traz como referencial uma definição de um modo de vida que tem como característica a preocupação central com reprodução social da família, a produção planificada a partir da concepção de uma agricultura fundada na policultura-pecuária, a aproximação cultural e política com a sociedade envolvente, com capacidade de gerenciar os recursos de produção a partir da gestão dos recursos presentes na propriedade, ter a agroecologia como importante elemento para a busca da autonomia e com relações de comercialização que busquem processos colaborativos e territorialmente circunscritos, a exemplo dos circuitos curtos.
} 
da produção e da forma como a propriedade é organizada. Para tanto, articular a diversificação da produção com a reorganização do trabalho familiar tem demonstrado impacto direto em algumas dimensões do processo do trabalho e da reprodução social das famílias camponesas, dentre elas: 1) direcionamento do trabalho familiar para a produção de alimentos considerados de consumo da família, pois esses alimentos passam a fazer parte da pauta de produtos disponibilizados para comercialização via PAA; 2) ingresso ou ampliação da agroindustrialização artesanal, que já faz parte do cotidiano das famílias camponesas, mas ainda numa dimensão privada, e que a partir do PAA passa a ser também uma fonte importante de trabalho e renda; 3 ) diversificação dos mecanismos de comercialização, pois o PAA tem permitido aos camponeses vislumbrar, a partir da garantia de compra do Estado, organizar outras formas de comercialização que deem conta do excedente de trabalho e produção investidos na pauta de alimentos produzidos para o PAA, e que agora podem ser direcionados para mercados locais (MICHELATO-GHIZELINI, 2010).

Tabela 1 - Produção destinada para comercialização pelos agricultores familiares e camponeses período anterior ao PAA (2004) - e 2008, quando participavam do PAA

\begin{tabular}{|c|c|c|c|c|}
\hline \multirow[t]{2}{*}{ PRODUTOS } & \multicolumn{2}{|c|}{ ANTES DO PAA - 2004} & \multicolumn{2}{|l|}{ PAA - 2008} \\
\hline & $\mathrm{N}^{\circ}$ Agricultores & $\%$ Agricultores & $\mathrm{N}^{\circ}$ Agricultores & \% Agricultores \\
\hline Amendoim & 02 & 04 & 27 & 60 \\
\hline Batata doce & 01 & 02 & 37 & 82 \\
\hline Derivados de leite & 00 & 00 & 06 & 13 \\
\hline Frutas & 00 & 00 & 25 & 56 \\
\hline Geleias e doces & 00 & 00 & 06 & 13 \\
\hline Hortaliças & 02 & 04 & 44 & 98 \\
\hline Legumes & 01 & 02 & 30 & 67 \\
\hline Mandioca & 02 & 04 & 37 & 82 \\
\hline Milho verde & 00 & 00 & 27 & 60 \\
\hline Ovos & 01 & 02 & 30 & 67 \\
\hline Panifícios & 02 & 04 & 17 & 38 \\
\hline Pinhão & 02 & 04 & 26 & 58 \\
\hline Sucos & 00 & 00 & 05 & 11 \\
\hline Não comercializava & 09 & 20 & 00 & 00 \\
\hline
\end{tabular}

Fonte: MICHELATO-GHIZELINI, 2010.

4 Vale destacar que os agricultores passaram a produzir para comercializar, isto não quer dizer que não produziam esses alimentos anteriormente, pois se o produziam não comercializavam. 
A partir desses dados é possível verificar que há um aumento significativo dos produtos que agregam maior valor e, de outro lado, produtos como soja (de $16 \%$ para $7 \%$ ), feijão (de $67 \%$ para $47 \%$ ), milho seco (de $51 \%$ para $0 \%$ ), fumo (de $4 \%$ para $2 \%$ ), que tiveram uma redução na quantidade de camponeses que produziam para comercializar (MICHELATO-GHIZELINI, 2010). Culturas estas que estão ligadas diretamente ao agronegócio produtor de commodities agrícolas e que tem como perspectiva intensificar a mão de obra, os recursos naturais, os recursos financeiros e a utilização do espaço da propriedade, com um retorno de baixo valor agregado e com alto risco para a agricultura camponesa.

Os dados apresentados na Tabela 1 permitem afirmar que o PAA tem impactado diretamente no processo de diversificação da produção, principalmente na retomada da produção para a comercialização de determinados tipos de produtos que fazem parte da cultura alimentar e do modo de vida camponês, fato fundamental para compreender a dimensão com que o PAA tem impactado sobre a perspectiva da recampesinização. Processo este que significa a retomada, por parte da família, de estratégias de produção e organização do trabalho cuja centralidade seja a diversificação da produção pautada na produção de alimentos que façam parte da cultura alimentar e de produção dos camponeses, na diversificação produtiva, em pensar a propriedade enquanto espaço de vida e gerenciá-lo como um território de autonomia e gestão a partir do olhar de quem vive e trabalha nele.

Tabela 02 - Produção destinada à comercialização pelos agricultores familiares referente a 2003 (período anterior ao PAA) e 2008 (quando participavam do PAA)

\begin{tabular}{l|l|l|l|l}
\hline \multirow{2}{*}{ PRODUTOS } & \multicolumn{2}{|l|}{ ANTES DO PAA - 2003 } & \multicolumn{2}{l}{ DURANTE O PAA - 2008 } \\
\cline { 2 - 5 } & $\mathrm{N}^{\circ}$ agricultores & $\%$ agricultores & N $^{\circ}$ agricultores & $\%$ agricultores \\
\hline Bicho da seda & 03 & 07 & 00 & 00 \\
\hline Carvão & 02 & 04 & 01 & 02 \\
\hline Fumo & 02 & 04 & 01 & 02 \\
\hline Milho seco & 23 & 51 & 00 & 00 \\
\hline Soja & 07 & 16 & 03 & 07 \\
\hline
\end{tabular}

Fonte: MICHELATO-GHIZELINI, 2010.

Segundo os dados desta pesquisa, é possível afirmar que a produção de alimentos para o consumo local é aumentada na medida em que passa a ser considerada fonte importante de renda das famílias camponesas. Para tanto, é 
necessária a intervenção do Estado, como foi o caso do PAA, para que haja intencionalidade dos camponeses em passar a investir recursos (financeiros, trabalho e naturais) e tempo para inverter a produção que anteriormente estava destinada à produção de alimentos e produtos destinados aos complexos agroindustriais e para agroexportação. E que, a partir do PAA, passa a investir em alimentos que serão disponibilizados local e regionalmente, aumentando o valor agregado e, consequentemente, reduzindo os riscos para a família.

\footnotetext{
No que concerne às alterações na matriz produtiva, o PAA tem sido responsável por restaurar a policultura predicado de um "modo de vida camponês" (WANDERLEY, 1999; SEYFERTH, 1974). Isto porque, em muitas regiões do Brasil, a "modernização da agricultura" nas décadas de 1960-1970 conduziu os agricultores a ingressarem na especialização produtiva, na monocultura e na produção de commodities, não raro, destinadas ao mercado externo, o que, por sua vez, expôs estes agricultores a contextos de acentuada vulnerabilidade social. Neste sentido, o PAA tem se destacado por incitar a diversificação da produção na medida em que conecta a oferta com uma demanda diversificada. Frutas, verduras, produtos de origem animal e processados são exemplos dos bens adquiridos pelo PAA (GRISA et. al., 2009, p. 7).
}

Ou seja, a partir do PAA, os agricultores passam a imprimir menos intensidade - de tempo, mão de obra, capital, terra - para a produção de uma agricultura para o mercado integrador e agroexportador. E passam a investir mais em uma agricultura produtora de alimentos para o mercado local, ampliando a autonomia no que se refere à segurança alimentar da família, qualificando as condições de segurança alimentar da sociedade envolvente e aumentando a renda a partir da produção e comercialização de alimentos para o programa, ao mesmo tempo em que passa a diversificar as formas de comercialização (MARTINS e CAVALCANTI, 2012).

Esse processo tem imprimido condições para que a pequena agricultura redimensione sua relação com a terra, com a organização da produção, com o trabalho realizado pela família e sua relação com a sociedade envolvente, de forma a garantir sua reprodução social a partir da condição camponesa, como descreve Ploeg (2008, p. 40):

[...] as características fundamentais da condição camponesa são 1) a luta por autonomia que se realiza em 2) um contexto caracterizado por relações de dependência, marginalização e privações. Essa condição tem como 
178

objetivo e se concretiza em 3) a criação e desenvolvimento de uma base de recursos auto-controlada e auto-gerenciada, a qual por sua vez permite 4) formas de co-produção entre o homem e a natureza viva que 5) interagem com o mercado, 6) permitem a sobrevivência e perspectivas de futuro e 7) se realimentam na base de recursos e a fortalecem, melhorando o processo de co-produção e fomentando a autonomia e, dessa forma, 8) reduzem a dependência. Dependendo das particularidades da conjuntura socioeconômica dominante, a sobrevivência e o desenvolvimento de uma base de recursos própria poderão ser 9) fortalecidos através de outras atividades não agrícolas. Finalmente, existem 10) padrões de cooperação que regulam e fortalecem essas inter-relações.

Assim, o PAA tem contribuído de forma significativa para que a pequena agricultura brasileira visualize outro cenário com condições de reprodução social que vão para além da integração agroindustrial atrelada fortemente a especialização, a intensificação do trabalho e a tecnificação.

Portanto, é possível afirmar que, segundo os dados, a partir do PAA, as famílias camponesas passam a reorganizar o tempo do trabalho, o tempo da família, o direcionamento do tempo do trabalho, a organização e o planejamento da produção, a relação com os consumidores e a cidade, a relação com o status social dado pelas commodities ${ }^{5}$, a concepção do que vem a ser agricultor e a perspectiva de reprodução social da família camponesa.

\section{O campesinato e as limitações do PAA}

Diante da realidade expressa pela atuação do PAA na agricultura camponesa brasileira, é possível afirmar que as compras institucionais possuem condições de proporcionar certo estancamento e reversão dos avanços da agricultura baseada na monocultura e na integração agroindustrial (GRISA et al, 2009; DELGADO, 2013; PORTO et al., 2014; SCHIMITT, 2014; MICHELATO-GHZIELINI, 2010).

\footnotetext{
5 Nas comunidades onde a prevalência é de agricultura familiar e camponesa a pressão por parte de uma certa cultura de "superioridade", de "sucesso", de "moderno", é pautada pelas commodities, pois os que não produzem dentro da lógica estabelecida por este status quo passam a ser tachados de atrasados e diminuídos social e politicamente perante seus pares e a comunidade. Quebrar esta lógica não passa apenas por uma vontade individual, mas é necessário um esforço coletivo e estrutural para que haja avanços na perspectiva de uma outra lógica, pautada pelo desenvolvimento local, pela segurança e soberania alimentar e pela agroecologia.
} 
Portanto, o PAA tem demonstrado impactos positivos para o ganho de autonomia e qualidade de vida por parte dos agricultores que ingressaram no Programa. No entanto, é necessário ressaltar que o PAA não é uma fórmula mágica que retirará a agricultura camponesa das condições de precariedade e especialização em que está inserida, pois seja pela limitação de recursos financeiros ou da própria demanda das doações realizadas pelo PAA (CAMPOS e BIANCHINI, 2014), a atuação do programa restringe-se a uma dimensão diminuta do que representa a agricultura camponesa e familiar no país.

Gráfico 01 - Número de agricultores fornecedores para o PAA entre 2011-2017

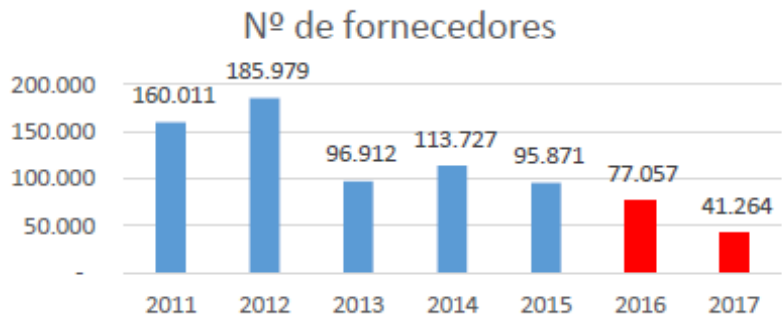

Fonte: INTINI, 2017

Considerando que o número de agricultores familiares no Brasil chegou a 4,4 milhões de propriedades no ano de 2017 (IBGE, 2006), o número de participantes do PAA não representa nem 2\% da agricultura familiar no ano de 2012, quando alcançou sua maior meta desde sua criação, o que implica uma ação extremamente restrita e circunscrita a um número de agricultores muito aquém do que realmente é a agricultura camponesa e familiar no Brasil (CAMPOS e BIANCHINI, 2014).

Ainda que se compreenda que o PAA não surgiu para substituir os tradicionais canais de comercialização, surpreende o número relativamente pequeno de agricultores familiares que aderiram ao Programa. Os mais de 180 mil referidos nas estatísticas para o ano de 2012 representam aproximadamente $4,2 \%$ dos agricultores familiares nacionais, e em diversos estados essa proporção é baixíssima. (MIELITZ, 2014, p. 67).

Isso faz com que o PAA não seja uma política universal e estrutural para alavancar uma transformação efetiva da agricultura conservadora, integrada aos 
complexos agroindustriais e agroexportadores, para uma agricultura diversificada e articulada local e territorialmente. O programa, dessa forma, coloca-se muito mais como um instrumento que permite gerar processos "didáticos e simbólicos" importantes para agregar elementos ao avanço do debate e da pauta do campesinato brasileiro do que propriamente para alterar a realidade da agricultura, assim como foi possível através das políticas de crédito agrícola (MICHELATO-GHIZELINI, 2010). Processos, “didáticos e simbólicos”, que se materializam quando agricultores visualizam a possibilidade de articular campo-cidade, produção-consumo, a partir de uma base territorial que lhes permite gerar condições de fazer avanços para um ganho de autonomia.

O Programa de Aquisição de Alimentos com doação simultânea, além de não atuar num conjunto amplo de famílias camponesas, coloca-se no cenário das políticas públicas do campo como uma política isolada e descolada da política de extensão rural, do crédito agrícola, da política de agroindustrialização, da política de abastecimento de alimentos nas cidades, dentre outras, em que destina ao PAA um papel de política compensatória, tanto por parte de quem produz, como para quem consome (DELGADO, 2013).

Outra limitação importante que o PAA tem gerado junto aos camponeses é a especialização produtiva (VELOSO e HESPANHOL, 2012), pois ao mesmo tempo em que o programa tem estimulado, num primeiro momento, a diversificação, a produção de alimentos para o abastecimento local e a produção em pequena escala, de outro lado, a médio e longo prazo, tem estimulado os agricultores que fazem parte do programa a assumirem uma postura de potencializar os recursos, naturais e de mão de obra, na perspectiva de, mesmo com certa diversificação, aproximar-se de uma especialização. Com essa perspectiva, os agricultores têm se estimulado a organizar projetos coletivos de PAA com o objetivo de distribuir tarefas para cada família, sendo que cada uma passa a especializar-se em algum ou alguns poucos produtos. Não é possível afirmar em que medida isso tem se realizado nos participantes do programa, mas foi objetivamente identificado por Veloso e Hespanhol (2012) e Michelato-Ghizelini (2010) nas pesquisas de campo realizadas, sendo que tais dados contribuem para afirmar que, sem a articulação entre as políticas públicas e sem subsídios e investimentos diretos em formação e infraestrutura, a agricultura camponesa terá pouca capacidade para competir e reverter a condição de exploração e baixa autonomia dada pela agricultura conservadora. 
Desse modo, o programa carece de revisão e mudança estrutural para que possa rever sua própria atuação e papel na agricultura camponesa. E, nessa perspectiva, garantir a articulação com outras políticas públicas e o investimento em infraestrutura e a formação, objetivar a diminuição da dependência dos agricultores com o programa e com a agricultura de commodities, o que possibilita condições para que a agricultura camponesa utilize-se do PAA enquanto um instrumento de "aprendizado" para dar condições ao avanço da construção de outros mecanismos de comercialização, como feiras, pontos fixos, cestas, agroindústrias familiares, etc.

\section{Considerações finais}

A complexidade com que o programa tem se colocado diante da realidade rural brasileira faz dele uma importante peça no debate e nos avanços para a agricultura camponesa, como também para a soberania e segurança alimentar da população brasileira.

Os avanços que o Programa de Aquisição de Alimentos com doação simultânea trouxeram para a agricultura camponesa é inegável, desde: 1) alteração do processo de compras institucionais que, mudando o aparato burocrático legal, possibilitou pela primeira vez a quebra da lei de licitações e contratos, permitindo, assim, a construção de redes de segurança alimentar nos territórios a partir dos próprios atores envolvidos; 2) possibilidade de reordenar a agricultura de base familiar para um cenário da produção voltada para a diversificação produtiva e a diversificação dos mecanismos de comercialização, apontando para a construção de cenários que possibilitem estancar em certa medida o processo de modernização conservadora em determinados espaços e territórios da agricultura camponesa; 3 ) efetivação de condições para repensar as políticas públicas, de forma a contribuir para qualificar a autonomia e as condições de vida do campesinato brasileiro; 4) possibilitar a efetivação de processos que tem "revertido", ressignificado, alterado a realidade da agricultura de base familiar com foco na integração agroindustrial a ponto de permitir sinais claros de recampesinização, haja vista os efeitos e impactos que o programa tem demonstrado na diversificação da produção e dos mecanismos de 
comercialização, apontando para maior autonomia dos agricultores em pensar e planejar a produção, a propriedade, o trabalho e a família.

No entanto, é fato que o programa tem apresentado certo esgotamento no seu caráter de inovação, pois, decorridos mais de 15 anos de sua implementação, as mudanças foram meramente formais, com o intuito de desburocratizar e ampliar os tipos de ação do PAA, porém o número de agricultores que tiveram acesso ao programa está muito aquém do que expressa a realidade de agricultores/as no país. Nessa perspectiva, o PAA aparece e coloca-se muito mais como uma política compensatória e não uma política de desenvolvimento que terá a agricultura camponesa como ator.

Assim, o Programa de Aquisição de Alimentos situa-se num campo de disputa. De um lado está o Estado se reafirmando enquanto operador de políticas compensatórias para a agricultura camponesa, exigindo que ela avance para um modelo empresarial ou então permaneça em condições precárias de funcionamento e sobrevivência. De outro lado, estão os movimentos sociais, o movimento sindical, os coletivos e as organizações sociais da agricultura camponesa, que se colocam em disputa para que o Estado seja estimulador, financiador, regulador e operador de ações e políticas que garantam investimentos na produção, na organização administrativa, na infraestrutura, na logística e na comercialização, assim como o faz com o agronegócio agroexportador. O PAA acabou sendo o principal deflagrador da ampliação das pautas de reivindicação dessas organizações camponesas, pois o que num primeiro momento se restringia a políticas de crédito, a partir do PAA, a agricultura camponesa passa a vislumbrar outras formas do Estado intervir com o objetivo de proporcionar que a agricultura camponesa seja ator político, econômico e social do desenvolvimento nacional. 
183

\section{REFERENNCIAS}

BRASIL. 2006. Censo Agropecuário. Resultados preliminares. Disponível em: <http:// www.ibge.gov.br/home/estatistica/economia/agropecuaria/censoagro/200>. Acesso em: 15 jul. 2016.

CAMPOS, A. de; BIANCHINI, V. A Agricultura Familiar passa a ser uma prioridade de Estado. In: BRASIL. PAA: 10 anos de Aquisição de Alimentos. Ministério do Desenvolvimento Social e Combate à Fome. PAA: 10 anos de Aquisição de Alimentos. Brasília, DF: MDS; Secretaria Nacional de Segurança Alimentar e Nutricional; Secretaria de Avaliação e Gestão da Informação, 2014.

DELGADO, G. C. Relatório de avaliação do PAA - III Síntese. Brasília, 2013.

DIAS, T. F. et al. Programa de Aquisição de Alimentos da Agricultura Familiar (PAA) como estratégia de inserção socioeconômica: o caso do Território da Cidadania Sertão do Apodi (RN). Revista Brasileira de Gestão e Desenvolvimento Regional. V. 9. N. 3. 2013.

ERTHAL, R. Os complexos agroindustriais no Brasil: seu papel na economia e na organização do espaço. Revista Geo-Paisagem, ano 5, No 9. janeiro/junho 2006.

INTINI, J. M. Nota Técnica sobre a execução dos Programas de Compras Públicas Federal. Brasília, 2017.

GRISA, C. et. al. O Programa de Aquisição de Alimentos (PAA) em Perspectiva: apontamentos e questões para o debate. Seminário Temático Programa de Aquisição de Alimentos. 2009.

MARIOTO, A; HESPANHOL, R. A. de M. Desenvolvimento rural, novas ações para velhos problemas: o PAA. XXI Encontro Nacional de Geografia Agrária. Uberlândia. 15-19/10/2012.

MARTINS, S. P.; CAVALCANTI, L. I. Avaliação do impacto da execução do PAA no estado do Rio Grande do Norte. Relatório de Pesquisa. Disponível em: <file://C:/ Users/Andr\%C3\%A9/Downloads/27-109-1-PB.pdf>. Acesso em: 20 jul. 2016.

MICHELATO-GHIZELINI, A. A. Atores sociais, agricultura familiar camponesa e o espaço local: uma análise a partir do programa de aquisição de alimentos. 2010. 267 f. Tese (Doutorado em Sociologia) - Programa de Pós-Graduação em Sociologia, Universidade Federal do Paraná, Curitiba, 2010.

MIELITZ, C. Dez Anos de PAA e a Constituição de uma Estratégia Nacional de Segurança Alimentar. In: BRASIL. PAA: 10 anos de Aquisição de Alimentos. Ministério do Desenvolvimento Social e Combate à Fome. Brasília-DF: MDS; Secretaria Nacional de Segurança Alimentar e Nutricional; Secretaria de Avaliação e Gestão da Informação, 2014. 
PLOEG, J. D. V. D. Camponeses e impérios alimentares: lutas por autonomia e sustentabilidade na era da globalização. Porto Alegre: UFRGS, 2008.

PORTO, S. I. et al. Programa de Aquisição de Alimentos (PAA): dez anos de uma política pública múltipla e inovadora. In: BRASIL. PAA: 10 anos de Aquisição de Alimentos. Ministério do Desenvolvimento Social e Combate à Fome. Brasília, DF: MDS; Secretaria Nacional de Segurança Alimentar e Nutricional; Secretaria de Avaliação e Gestão da Informação, 2014.

SCHMITT, C. J. et al. O Programa de Aquisição de Alimentos em assentamentos de reforma agrária: implantação, impactos e perspectivas. In: BRASIL. PAA: 10 anos de Aquisição de Alimentos. Ministério do Desenvolvimento Social e Combate à Fome. Brasília-DF: MDS; Secretaria Nacional de Segurança Alimentar e Nutricional; Secretaria de Avaliação e Gestão da Informação, 2014.

SILVA, V. da. O Programa de Aquisição de Alimentos (PAA) como fomentador da diversificação e a agregação de valor na agricultura familiar. Revista Espaço Acadêmico, N. 117, fevereiro de 2011.

VELOSO, F; HESPANHOL, R. A. de M. O PAA na Região de Dracena: da diversificação à especialização produtiva. Caderno Prudentino de Geografia. Presidente Prudente, n. 34, v.1, p.161-178, jan./jul, 2012.

VIEIRA, D. de F. A; VIANA, C. A. dos S. O programa de aquisição de alimentos e sua relação com o modo de funcionamento da agricultura familiar. Mestrado em Agronegócios, Universidade de Brasília. Grupo de Trabalho 6: Políticas públicas e práticas dos atores: dilemas teóricos e práticos, 2006. 


\section{Os (des)caminhos do Programa de Aquisição de Alimentos na região semiárida: novas governanças, antigas armadilhas ${ }^{1}$}

\section{Cimone Rozendo}

\section{Introdução}

Criado em 2003, como uma das ações estruturantes do Programa Fome Zero, o Programa de Aquisição de Alimentos (PAA) tem se constituído em uma importante estratégia de fortalecimento da agricultura familiar e de garantia de segurança alimentar tanto para as famílias que produzem quanto para aqueles que recebem as doações de alimento. Estudos sob diferentes enfoques e contextos sobre o PAA apontam não apenas o alcance desses objetivos, em que pese ainda as limitações das mais diversas ordens que sua implementação enfrenta, mas também a extensão que o referido programa tem assumido em ambientes cujos níveis organizacionais encontram-se mais consolidados. (BRASIL, MDS, 2014; SCHMITT et al., 2014; PORTO, 2014; GRISA E SCHNEIDER, 2014; GRISA et al, 2011; ROZENDO e MOLINA, 2010; BASTOS, 2007). Nesse aspecto, o PAA é concebido como uma estratégia de desenvolvimento, uma ferramenta potencializadora das capacidades e, consequentemente, da expansão das liberdades (SEN, 2000).

A internacionalização do Programa, com a criação do PAA África, também evidencia o grau de importância desse instrumento de política pública, não

\footnotetext{
1 Parte do conteúdo desse capítulo foi trabalhado no texto "Ambiente institucional, governança e performance do PAA: Uma análise nos estados do Rio Grande do Sul e do Rio Grande do Norte" como resultado da pesquisa financiada pelo Edital Chamada MCTI-CNPq/MDS-SAGI No 24/2013 - Ministério do Desenvolvimento Social de autoria de Grisa et al., 2017, publicada no site da instituição.
} 
apenas para o caso brasileiro, mas para regiões que partilham condições socioeconômicas similares. A potencialidade do PAA parece estar pautada principalmente numa configuração que faz convergir, do ponto de vista das concepções e do ponto de vista prático, diferentes dimensões da política agrícola e da política de segurança alimentar e nutricional, como assevera Schmitt (2005, p. 78), com incidência em aspectos muito mais amplos do que o acesso ao mercado, como demonstram as pesquisas realizadas em diferentes regiões do país (BASTOS, 2007, GRISA el al, 2010; ROZENDO E MOLINA, 2010; SCHMITT et al 2013, TRICHES e SCHNEIDER, 2010).

De um modo geral, as análises evidenciam que a partir do PAA se delinearam uma infinidade de arranjos institucionais (ARNS, 2010) que tem oportunizado tanto por parte do Estado quanto da sociedade civil formas renovadas de governança (SANTOS, 1997) com repercussões também no ambiente institucional. Foram justamente esses aspectos que esta pesquisa buscou identificar e analisar tomando como referência o processo de implementação do PAA no município de Apodi, no estado do Rio Grande do Norte. A investigação quis compreender: a) como se conforma a rede de governança desse Programa, identificando os principais atores envolvidos, as relações estabelecidas entre eles e os resultados para os diferentes grupos, em especial agricultores e entidades beneficiárias; b) como são sustentados os processos engendrados pelo Programa, bem como seus desafios e limitações em um contexto marcado, do ponto de vista socioeconômico, por altos índices de pobreza rural e também pela forte presença de organizações de agricultores familiares com níveis de atuação igualmente consideráveis, e, do ponto de vista ambiental, pela convivência deles com as condições de semiaridez, como é o caso de município de Apodi.

O capítulo está organizado em quatro partes, além da introdução. A primeira contempla uma revisão sumária das perspectivas teóricas e metodológicas que orientaram a análise. A segunda apresenta o contexto político e socioeconômico de Apodi, bem como os processos de implementação do Programa de Aquisição de Alimentos. São destacadas as inovações organizacionais criadas para a adequação ao PAA, os processos de aprendizagem coletiva ensejadas por esse dispositivo e a emergência de formas de governança mais horizontalizadas favorecendo maior participação. As reflexões procuram dar destaque ao papel que os consumidores assumem nessa governança. A terceira parte do capítulo traz um panorama do desempenho do Programa em Apodi, sublinhando a 
emergência de atores externos a sua tradicional rede de governança, mas que, por uma série de circunstâncias, passam a incidir decisivamente em suas orientações. A última parte apresenta as considerações sobre os processos analisados a partir da recuperação dos conceitos-chaves da pesquisa.

\section{Perspectivas teórico-metodológicas da análise: mercados institucionais, arranjos institucionais e governança}

Em outro texto, de Rozendo e Molina (2014), a criação de mercados institucionais foi concebida como uma importante inovação social à medida que contribui para "ativar recursos, sobretudo ligados às relações sociais, antes desvalorizados (PIRAUX et al., p. 104). Esse potencial inovador do Programa deriva, em parte, de seu próprio desenho, que requer formas de coordenação mais articuladas e horizontais entre os diferentes atores da sociedade civil e entre ela e o Estado. Isso pressupõe a construção de espaços de concertação capazes de dar suporte aos novos arranjos que emanam desse processo. Conforme assevera Torre (2010): [...] "Em razão das inovações institucionais, os atores são levados a experimentar novas formas de ação pública e de participação nas decisões, passando progressivamente da pirâmide para a rede" (OST, 2004, citado por TORRE, p. 110). Essas mudanças não constituem meros detalhes, pois o que está em jogo é a distribuição de poder implicada em dispositivos constituídos a partir de perspectivas mais democráticas.

Chia et al. apud Piraux et al. (2010, p. 105), analisando a performance dos Colegiados Territoriais, alertam para a capacidade de determinados dispositivos ensejarem processos de aprendizagem organizacional, o que permite aos atores, num sistema de ação, orientar-se, mobilizando conhecimento e saberes anteriores com a finalidade de criar procedimentos e regras que favoreçam a governança. Se para esses autores a aprendizagem organizacional tem como resultado um certo tipo de governança, para Arns (2010) é o próprio processo de aprendizagem.

Os espaços em que ela (a governança) se realiza são concebidos como espaços de oportunidades para os atores exercitarem novos valores, comportamentos, práticas e condutas, ajustados a uma nova realidade que exige maior diálogo entre os diferentes atores da sociedade e destes com o Estado (ARNS, 2010, p. 123). 
Arns (2010) concebe a governança como uma construção social que se expressa de modo diferenciado dependendo dos contextos social, econômico e político e em função dos atores públicos e privados envolvidos nos projetos. Por isso, para o autor, a cultura local tem grande relevância à medida que define o tipo e a forma de como a governança pode processar-se no território.

Em sentido semelhante, Piraux et al. (2010) advertem que novas formas de governança dependem da existência de certos tipos de capital social, pois são eles que permitirão qualificar as parcerias estabelecidas entre sociedade civil e Estado. Complementarmente, Arns (2010) afirma que a governança depende do funcionamento dos arranjos institucionais e de um ambiente institucional adequado. Os arranjos institucionais são concebidos como "os acordos e contratos estabelecidos entre agentes específicos”; já o ambiente institucional é compreendido como "um conjunto de grandes normas e regras que orientam o contrato" (p. 128). Há uma interação constante entre essas dimensões que se redefinem mutuamente. A performance dessas dimensões é a própria governança (SANTOS, 1997). Arns (2010) considera que mudanças ocorridas em arranjos institucionais locais podem resultar em importantes transformações do ambiente institucional, criando uma "ambiance específica favorável às performances individuais e coletivas", conforme sugerem Muchnik e Sainte Marie (2010) apud Lamine (2012) em sua análise sobre o papel dos circuitos curtos de comercialização de alimentos.

Para compreender as dinâmicas dessa rede de governança, optou-se pela metodologia de estudo de caso com pesquisa qualitativa. Concebeu-se que esse procedimento possibilita um nível de detalhamento e refinamento necessário ao tipo de reflexão empreendido aqui.

A seleção da área de pesquisa obedeceu aos seguintes parâmetros: município com maior tempo de execução do PAA no estado do Rio Grande do Norte, grau de participação do município no PAA avaliado em termos de números de contratos firmados, valores comercializados e número de entidades beneficiadas. Para essa fase da pesquisa foram levantados os dados da atuação do PAA via CONAB operado com recursos do MDS e MDA entre 2006 e $2013^{2}$ e do PAA Estadual através do PAA Data, entre os anos de 2011 e 2013, em dez municípios

2 Do ponto de vista da operacionalização da pesquisa, é importante destacar as dificuldades na obtenção dos dados do Programa, em âmbito nacional ou estadual. As bases de dados são descontínuas e a tabulação segue um padrão diferenciado a cada ano, impossibilitando comparações e dificultando análises mais precisas. Os dados mais consistentes foram fornecidos pela CONAB, mas ainda assim apresentam problemas, pois os registros não permitem, por exemplo, compreender a diversidade de formas sob as quais a agricultura familiar se apresenta. 
do estado do Rio Grande do Norte. De acordo com esses dados, o município de Apodi destacou-se em todos os itens avaliados. A partir desse primeiro panorama foram realizadas entrevistas com a coordenação do Programa na CONAB/RN e EMATER com o intuito de qualificar e complementar as informações.

Foram realizadas entrevistas semiestruturadas com representantes das cooperativas, agricultores participantes do PAA, representantes das entidades beneficiadas, conselho municipal de desenvolvimento territorial e outros atores locais considerados chaves na conformação da rede do Programa. Ao todo foram entrevistados 18 agricultores familiares e três pescadores artesanais que participam do PAA, selecionados através da indicação dos representantes das cooperativas, contemplando aqueles que forneciam alimentos ao PAA há mais tempo e a diversidade do grupo (agricultores familiares, assentados, pescadores, etc.). Do ponto de vista das organizações, dentre as 15 cooperativas existentes no município que participaram do PAA, foram selecionadas as que apresentaram maior frequência na comercialização, de acordo com dados disponíveis no PAA Data. Foram entrevistados os representantes da Cooperativa Potiguar de Apicultura e Desenvolvimento Rural Sustentável (COOPAPI), da Cooperativa da Agricultura Familiar de Apodi (COOAFAP), da Associação dos Aquicultores do Apodi (AQUAPO) e a Associação dos Produtores de Arroz do Vale do Apodi (APAVA).

Para a seleção das entidades beneficiárias do PAA, que compuseram essa investigação, foram considerados os seguintes critérios: maior tempo de participação no PAA e a diversidade de público das entidades. Foram entrevistados os representantes de 18 entidades do município de Apodi. Além disso, foram ouvidos a representante da ONG Terra Viva, importante instituição que atua na organização política de agricultores familiares e na assistência técnica para este segmento e, por fim, os responsáveis pela execução do PAA na EMATER de Apodi. Foram realizadas três fases de campo: as duas primeiras no mês de agosto e outubro de 2014, respectivamente, e a última no mês de março 2015. A primeira fase permitiu a obtenção de informações para construir uma visão geral do Programa e as demais possibilitaram complementar esse quadro, inclusive junto a CONAB-RN e EMATER-RN, além de incorporar aqueles sujeitos da rede de governança que iam sendo citados à medida que a pesquisa avançava. 


\section{O contexto e a chegada do Programa de Aquisição de Alimentos em Apodi}

Entre os pesquisadores e gestores públicos do Rio Grande de Norte há um pressuposto tácito de que se alguma política pública fracassar no município de Apodi dificilmente terá êxito em outras localidades, dado a presença de um tecido associativo capaz de dar sustentação às diferentes experiências de ação coletiva e de políticas públicas. $\mathrm{O}$ fato de o PAA estar praticamente paralisado há dois anos (2013-2014) nesse município é um indicativo importante. Os resultados desta pesquisa alertam para o fato de que o excesso e/ou a inadequação de regulamentações que, mais recentemente, passaram a incidir de forma incisiva sobre o PAA, em especial, as relacionadas à inspeção sanitária, têm provocado a judicialização de suas operações com consequente criminalização das organizações de agricultores familiares. Essa situação conduziu o Programa a uma verdadeira encruzilhada, da qual ele dificilmente sairá sem que haja, por parte dos diferentes entes do Estado, um entendimento de que a promoção da agricultura familiar e garantia da segurança alimentar e nutricional, preconizadas pela referida política, passam pela necessidade premente de construção de parâmetros de qualidade, adaptados à realidade da agricultura familiar (WILKINSON, 2008). A pesquisa mostra as dificuldades de construir-se uma política pública com equidade social como a do PAA quando seus mecanismos de regulação são os mesmos que regem os mercados convencionais, ou seja, a competição e a concorrência. O texto que segue apresenta o desenredar desse processo em Apodi.

\section{Boa semente em solo fértil: o contexto socioeconômico de Apodi e o PAA}

O município de Apodi (RN) está localizado na região do Oeste Potiguar, na microrregião da Chapada do Apodi e no Território Sertão do Apodi, junto à divisa do Estado do Ceará. O município é um dos maiores do Território, possui uma área 1.602,480 $\mathrm{Km}^{2}$ e 34.763 habitantes sendo que, de acordo com dados do IBGE (2010), sua população rural é de 17.531 habitantes, (49,57\%) e a urbana de 17.531 (50,43\%), com uma densidade populacional de 22,50 habitantes por $\mathrm{Km}^{2}$ 
(IBGE, 2010). Apesar da melhoria significativa no Índice de Desenvolvimento Humano entre os anos de 1991 de 2010 de 0,493 para 0,727, respectivamente, 30,3\% da população de Apodi com 25 anos ou mais, ainda é analfabeta (Atlas Brasil, 2013). Segundo dados do MDS (2015), 27\% da população rural encontra-se em situação de extrema pobreza. Entre os 5.086 beneficiários do Programa Bolsa Família município 2.358 são agricultores familiares que recebem média de 168 reais mensais.

O município de Apodi comporta quatro formações geomorfológicas: a Chapada do Apodi, as superfícies planas ou levemente onduladas, as planícies aluviais e a Depressão Sertaneja (SANTANA JÚNIOR, 2010). A cada uma delas correspondem características edafoclimáticas específicas que resultam em uma produção agropecuária bastante diversificada concedendo à Apodi uma posição de destaque em termos de potencial produtivo. ${ }^{3}$ A agricultura de base familiar é a forma majoritária de organização social da produção totalizando $93 \%$ das 3274 propriedades existentes, que se dividem em 94 comunidades rurais (IBGE, 2006). Quase a metade dessas propriedades (48\%) possui até 10 hectares. Há ainda a presença de 14 assentamentos de reforma agrária no município (MDS, 2015) que ocupam $25 \%$ do total das propriedades rurais (DIAS et al., 2013). Outro segmento presente são os pescadores. Segundo o Censo Agropecuário de 2006, Apodi tem 256 pescadores artesanais cadastrados (IBGE, 2006), este grupo tem 55 beneficiários do Programa Bolsa Família (PBF). Conforme o Plano Territorial de Desenvolvimento Rural Sustentável do Sertão do Apodi, há no município a colônia de pescadores Z-48, que possui 32 gaiolas para criação de tilápias e 35 tanques de rede (BRASIL, 2005).

Apodi é o município do Rio Grande do Norte com maior participação no PAA desde seu inicio. Até 2008, aproximadamente, era responsável por $80 \%$ das operações do PAA no estado, segundo relatos do coordenador do Programa na

3 Os principais produtos cultivados nestas formações são: a) Chapada do Apodi - o algodão, o milho e o feijão, tendo ainda áreas de pastagem natural que dão suporte às duas principais produções animais: caprinos e bovinos; b) Superfícies Planas - apresenta uma zona agropecuária tradicional integrada, na qual são cultivados algodão, milho, mandioca, feijão e sisal, além disso, conta com áreas de pastagens naturais para a criação de bovinos; c) Depressão Sertaneja - principais lavouras são: algodão, milho, feijão e mandioca, cultivados em regime de sequeiro, além da pecuária de corte; d) Planícies Aluviais - Atividades agropecuárias, além da pesca artesanal e a aquicultura de tilápias em gaiolas. As principais lavouras são: algodão herbáceo, arroz, feijão e milho e na pecuária predomina a criação de caprinos. Nas áreas de agricultura irrigada são cultivados: manga, coco, sorgo, capim elefante, arroz, banana, dentre outros, sendo a rizicultura a exploração mais expressiva, ocupando uma área de aproximadamente 200 ha (SANTANA JÚNIOR, 2010). 
$\mathrm{CONAB/RN}$. Isso se deve, em parte, à presença de uma forte organização da agricultura familiar na localidade animada por instituições ligadas à Igreja Católica ${ }^{4}$ e pela convergência sinérgica de projetos governamentais e não governamentais desenvolvidos na região. Estas experiências propiciaram aos longos dos anos um acúmulo de capital social por parte das organizações de agricultores familiares, responsável por atrair para a região projetos importantes com enfoque no desenvolvimento local/regional sustentável, como foi também o caso do PAA.

Quando o PAA surgiu, no ano de 2003, poucos municípios do estado do Rio Grande do Norte (RN) dispunham de condições para o enquadramento no Programa, a começar pela falta de Declaração de Aptidão (DAPs), requisito básico para o acesso às políticas para agricultura familiar, passando pela insuficiência na oferta de produtos e dificuldades logísticas (armazenamento, embalagem, transporte). Já em Apodi, além de níveis produtivos melhores, havia uma organização social mais forte com a presença de associações, cooperativas e ONGs. Essas condições motivaram os gestores da CONAB a iniciar o PAA no município, por volta do ano de 2004, como uma espécie de projeto-piloto no estado. Dois anos mais tarde chegaria também o PAA operacionalizado pela EMATER.

De forma geral, em Apodi, há dois caminhos para a operacionalização do programa: o PAA Estadual, na modalidade de Compra Direta com Doação Simultânea - CPR Doação, operacionalizada pela Empresa de Assistência Técnica e Extensão Rural (EMATER), e o PAA CONAB, nas modalidades Formação de Estoques da Agricultura Familiar (CPR Estoque) e Compra direta da Agricultura Familiar (CDAF), operacionalizadas pelas CONAB RN. Além dessas modalidades, existe também o PAA Leite que não foi objeto dessa investigação.

\section{O processo de implementação do PAA em Apodi: atores, aprendizagens e conquistas}

Como o objetivo deste estudo foi compreender a performance do PAA do ponto de vista da rede de atores envolvidos, privilegiou-se, neste item, a análise

\footnotetext{
4 Segundo Plano Territorial de Desenvolvimento Rural, a ação da Igreja Católica no município teve início na década de 1960 através dos Movimentos de Educação de Base que incentivaram a organização do movimento sindical. Esse por sua vez esteve também, na década de 1990, na base das mobilizações por Reforma Agrária na região, reanimando os processos participativos e dando um novo impulso as organizações de agricultores (PTDR, 2007, 19).
} 
do papel dos agricultores familiares. Foram selecionados para a pesquisa aqueles que pudessem ser ilustrativos da diversidade etária, fundiária, geográfica e social existente em Apodi. Assim, foram entrevistados 21 agricultores, sendo 14 homens e sete mulheres, de diferentes faixas etárias. No que se refere à condição fundiária do grupo, nove são proprietários, nove são assentados da reforma agrária e três são pescadores. Dentre os que vivem na zona rural a área média das propriedades é de aproximadamente 20 ha.

A produção comercializada via PAA por este grupo, nos últimos anos, abrangeu produtos hortifrutigranjeiros, arroz, castanha de caju, oleaginosas, carne caprina, suína e bovina, mel, bolos e biscoitos, além de frutas como caju, manga, goiaba, acerola, coco, tamarindo, mamão, limão, melancia, banana, cajarana e laranja. Embora aqui estejam elencados apenas os principais produtos comercializados via PAA, a sua produção atual extrapola em muito as demandas do Programa, por isso as feiras livres e a venda a particulares seguem sendo estratégias de comercialização fundamentais. Além disso, desses canais os agricultores familiares têm procurado inserir-se no PAA estadual em outros municípios da região ampliando suas possibilidades de comercialização.

Como se disse anteriormente, apesar das condições de semiaridez, Apodi possui não apenas o maior potencial agrícola entre os municípios do estado do Rio Grande do Norte, como também o maior número de agricultores com DAPs ativas no estado, o que aponta para possibilidades de inserção em um conjunto de políticas públicas voltadas ao segmento da agricultura familiar. Essas condições produtivas e organizacionais são conquistas recentes e se devem ao trabalho conjunto de agricultores familiares locais e de instituições governamentais e não governamentais que há mais de trinta anos realizam projetos com vistas ao desenvolvimento local/regional.

Segundo a representante da ONG Terra viva, instituição que presta assessoria às organizações de agricultores familiares, a comercialização da produção sempre foi o grande entrave ao desenvolvimento da agricultura familiar na região. Em geral, as justificativas para tanto se pautavam na falta de escala e nas dificuldades de manutenção da oferta durante determinado período. Para as instituições que trabalhavam na assessoria dos agricultores familiares, entre elas, a Terra Viva, a solução sempre esteve na criação de cooperativas, proposta vista, frequentemente, 
com desconfiança e resistência por parte dos agricultores em razão da memória do fracasso que guardavam de experiências anteriores. ${ }^{5}$

Apesar das circunstâncias, as instituições continuaram apostando nessa saída e estimulando o debate sobre o cooperativismo. Dessas ações resultou a fundação, no ano de 2001, da Cooperativa da Agricultura Familiar de Apodi (COOAFAP). Já no início das atividades da cooperativa, estava claro para os cooperados que a garantia de escala não era condição suficiente para acessarem os mercados existentes. A complexidade dos processos de comercialização somada à baixa qualificação dos dirigentes e a sua inexperiência nesse campo fizeram com que a cooperativa ficasse praticamente inoperante por cerca de dois anos, passando a funcionar somente a partir da implementação do PAA no município. Impulsionada pela chegada do Programa, foi criada também, em 2004, a COOPAPI, cujo objetivo era estruturar a cadeia do mel e do caju.

Embora o contexto social e produtivo de Apodi tivesse criado ao longo dos anos condições favoráveis ao desenvolvimento de ações com o perfil do PAA, estas eram ainda insuficientes para colocar em curso um programa dessa complexidade. Era necessário inicialmente que a confiança no Estado fosse restituída, sobretudo porque o projeto previa o envolvimento ativo de agricultores familiares advindos de processos sucessivos de exploração e de exclusão, de uma das regiões mais pobres do país, acostumados ao descaso governamental com suas condições. Um Estado que sempre os tratou como problema e não como vítimas de escolhas políticas equivocadas não haveria agora de ser benevolente. Foi à custa de muito trabalho das ONGs, por intermédio das cooperativas e de entidades do governo, como foi o caso da CONAB, que as "resistências" ao Programa foram gradativamente quebradas.

Outros aspectos necessitavam, contudo, ser igualmente superados. As cooperativas que haviam sido criadas (COOPAPI e a COOAFAP) funcionam em um grau de informalidade incompatível com as exigências do PAA. Além disso, a produção existente, que se orientava pelas parcas e precárias possibilidades de mercado sob o domínio de atravessadores, era insuficiente diante da demanda do Programa. Havia ainda uma ideia generalizada entre os agricultores familiares, de que sua produção era inferior quando comparada às dos demais segmentos

5 As primeiras cooperativas que se estabeleceram na região se organizaram em torno da produção de algodão. A praga do "bicudo" que assolou os cultivos e as denúncias de desvio de verbas das instituições pôs fim às atividades das cooperativas, causando prejuízos financeiros aos agricultores e desacreditando iniciativas dessa natureza. 
e, por isso, acreditavam não ter condições de acessar outros mercados, senão aquele organizado pelos atravessadores, em que a prática de desqualificação da produção, como estratégia para formação de preços, reforçava a concepção de inferioridade. Como relatou um agricultor: "a venda para o PAA me fez ver que a minha produção era de qualidade. Eu disse: se o Estado quer comprar, deve ter algo de bom. Eu mesmo não acreditava em mim, depois eu me senti valorizado e isso me estimulou a produzir mais... Mas quem vai fazer investimento para produzir para atravessador? (apud GRISA et al., 2016, p. 22).

Recuperar a confiança no Estado por parte das organizações da agricultura familiar, formalizar suas instituições em níveis compatíveis com as exigências do Programa, construir uma percepção em que os agricultores familiares se vissem como protagonistas de uma projeto mais amplo de segurança alimentar e nutricional, compunham o rol de desafios iniciais do PAA em Apodi, cujo enfrentamento se deu tanto com apoio dos agentes de mediação quanto das organizações governamentais como o executivo municipal, a EMATER e a CONAB.

Esse período foi marcado, segundo relatos, pela intensificação das atividades das organizações de agricultores familiares e gestores públicos em vários níveis e por um processo de articulação continua entre elas. Diversas estratégias foram desenvolvidas tanto para enquadrar os agricultores ao Programa quanto para ampliar as operações, como: a continuidade da divulgação do Programa entre agricultores e entidades beneficiárias em Apodi e outros municípios do território, a realização de campanhas para atualização e emissão de DAPS, a capacitação de agricultores para elaboração dos projetos de venda, os esforços para fazer coincidir a oferta da produção (quando possível) com o período de vigência dos projetos da CONAB e do PAA estadual, a capacitação para beneficiamento de produtos, a ampliação nos investimentos para produção (aumento dos cultivos, ampliação área plantada, a melhoria da infraestrutura, priorização da produção agroecológica - que já vinha sendo estimulada anteriormente, etc. Também várias associações e cooperativas foram criadas sob influência desse momento como a Associação dos Aquicultores do Apodi (AQUAPO), no ano de $2005^{6}$ e a Associação dos Produtores de Arroz do Vale do Apodi (APAVA), em 2008, objetos desta pesquisa.

6 Apoiados pela EMPARN a organização contou, em sua fase áurea, com 80 sócios envolvidos com a criação e comercialização de tilápias. A partir da entrada no PAA, expandiram o mercado criando estruturas próprias para criação, beneficiamento e comercialização do pescado. 
196

A divulgação do Programa provocou uma verdadeira corrida pela emissão de DAPs e por solicitações de adesão às cooperativas. Esse movimento teve ampla repercussão, resultando na vinculação de associações de municípios próximos às cooperativas de Apodi ${ }^{7}$. A chegada do PAA Estadual, em 2006, trouxe um novo impulso ao Programa. Além de contemplar o público não vinculado formalmente a alguma organização coletiva (e que não eram atendidos pela CONAB), o envolvimento da EMATER local garantiu a celeridade nas emissões de DAPS para agricultores familiares proprietários. $\mathrm{O}$ mesmo não ocorreu com os assentados de reforma agrária, que constituem o maior público do PAA em Apodi, cuja emissão de DAPS pelo INCRA encontra toda sorte de dificuldades ${ }^{8}$. Após ter resolvido parcialmente o problema das DAPs, as organizações logo se depararam com um novo obstáculo: a elaboração dos projetos de venda. Essa situação se agravava num quadro marcado por baixos níveis de escolaridade. Tanto que a primeira proposta de comercialização via PAA em Apodi foi rejeitada por apresentar muitas falhas no projeto. Para solucionar o problema a CONAB capacitou alguns membros das cooperativas e ONGs que trabalhavam com assistência técnica e esses passaram, posteriormente, a capacitar outros membros do grupo.

À medida que se avançava na formalização dos processos do PAA novos atores se incorporavam à rede do Programa em um processo constante de redefinição de papéis e estratégias. Os problemas ligados à logística de entrega e à atestação de qualidade dos produtos, por exemplo, foram resolvidos em parceria com o executivo local que, além criar uma central de recebimento dos produtos, disponibilizou uma equipe com uma nutricionista, um veterinário e uma assistente social, responsáveis por realizar o serviço de inspeção sanitária, conforme destacou-se também em Grisa (2016). Ainda que não constituído formalmente como

\footnotetext{
7 Em 2004 foi criado o Comitê Territorial do Sertão do Apodi com a participação de 125 membros. A capilaridade dessa organização foi fundamental para as estratégias de divulgação do Programa e os níveis de articulação que se desenvolveram para sua execução.

8 A morosidade desse processo e a falta de clareza dos técnicos do INCRA sobre os requisitos para emissão do documento causou e tem causado uma série de problemas, impedindo que muitos agricultores participem de forma legal do Programa. Conforme relatos, o INCRA tem demorado até 10 meses para emitir e/ou renovar uma DAP. Na prática significa que, considerando a necessidade de adequação entre a vigência dos projetos e a produção, um agricultor deixa de participar do PAA por, aproximadamente, dois anos consecutivos. Isso justifica em parte o empréstimo de DAPs entre agricultores para que os projetos de venda se viabilizem. Se por um lado essa estratégia resolve a situação momentânea por outro causa uma série de problemas. Além de esbarrar nos aspectos legais que regulamentam o programa, abrindo espaço para questionamentos; subestimam o número de famílias que fazem parte efetivamente do Programa.
} 
um órgão de inspeção sanitária, até 2012, esta instância foi suficiente para garantir a comercialização dos produtos da agricultura familiar via PAA.

Os desafios ligados à oferta dos produtos também não foram poucos. Além das exigências de escala, a garantia da diversidade, de qualidade e frequência de produção se impunham sistematicamente aos grupos. Assim, vários projetos produtivos que já vinham se desenvolvendo com o apoio de instituições da agricultura familiar ${ }^{9}$ foram potencializados, em especial os de orientação agroecológica. Merecem destaque as iniciativas para a produção mel ${ }^{10}$, arroz vermelho ${ }^{11}$, caprinos $^{12}$, frutas ${ }^{13}$ e alimentos manufaturados que constituíram inovações im-

9 Como no caso do Projeto Dom Helder Câmara que prestou assessoria técnica aos agricultores de Apodi durante 10 anos consecutivos. O projeto é uma ação operacional descentralizada do Ministério do Desenvolvimento Agrário no Nordeste, iniciado em 2001. Na sua essência ele desenvolve de ações de combate à pobreza e apoio ao desenvolvimento rural sustentável embasado no conceito de convivência com o semiárido, articulando às dimensões sociopolíticas, ambientais, culturais, econômicas e tecnológicas e por processos participativos de planejamento, gestão e controle social (PDHC, 2015). Disponível em: <http://www.projetodomhelder.gov.br/site/o-projeto-dom-helder/area-de-atuacao.html $>$. Acesso em: 15 maio 2015.

10 A comercialização do mel foi assegurada a partir do forte lobby das organizações da agricultura familiar junto aos potenciais consumidores do produto. A CONAB havia se recusado a comercializar o mel sob a alegação de que este não era alimento e que, dificilmente teria aceitação pelo público do PAA. Para provar o equívoco do posicionamento da instituição, os agricultores percorreram escolas e instituições assistenciais em vários municípios do território fazendo degustações do produto. A partir da relação com os potenciais consumidores, testaram a aceitabilidade e aperfeiçoaram as formas de acondicionamento para facilitar a distribuição. Reunidos os argumentos sobre a pertinência da proposta de aquisição do mel, os agricultores conseguiram negociar com a CONAB e garantir a entrada do produto na pauta de comercializações. Assim, o incremento desta cadeia produtiva que já vinha se desenvolvendo na região foi potencializado pelo PAA, o que resultou na melhoria e ampliação das unidades de beneficiamento na abertura de postos de trabalho para as mulheres. Esse processo foi tão intenso que, no de 2008, Apodi foi o segundo maior produtor de mel no Brasil (TORRES et al., 2013).

11 As experiências com a produção e comercialização do arroz vermelho resultaram também num aprendizado importante. Nas primeiras aquisições, uma grande quantidade de arroz vermelho foi doada de uma só vez às entidades que acabaram limitando as refeições do dia a este produto. A oferta sucessiva de arroz nos cardápios fez com que os consumidores, em geral formado pelo público escolar, recusassem o alimento. Para não perder este mercado a cooperativa, em parceria com a prefeitura, contratou uma cozinheira que montou um cardápio com uma grande variedade de receitas de arroz vermelho e capacitou as merendeiras das entidades. Assim, melhoraram a aceitabilidade e ampliaram a comercialização. Isso repercutiu na ampliação das áreas de cultivo e na valorização de um produto local que era anteriormente considerado uma praga. Muitos rizicultores deixaram de produzir o arroz branco para produzir a espécie nativa. A própria formação da Associação dos Produtores de Arroz do Vale do Apodi (APAVA) se deu em função das possibilidades de comercialização do arroz via PAA.

12 Quando as primeiras aquisições da carne de bode foram feitas por meio do Programa, houve uma grande rejeição por parte dos beneficiários, em geral crianças das escolas públicas da região. Temendo que isso pudesse excluí-los do PAA, os agricultores reagiram capacitando as merendeiras para prepararem o alimento de forma mais atrativa para as crianças. Para assegurar a eficácia desta estratégia foram feitas degustações do prato nas escolas, ocasião em que os agricultores trataram de divulgar que se tratava de carne caprina e com isso produzir uma visão positiva do produto. Estas ações não apenas asseguraram a continuidade da comercialização do produto no município Apodi como também possibilitaram sua expansão para outros municípios do território. Como disso um agricultor: "as crianças falam a verdade, se elas gostassem então era garantia de venda".

13 A ONG Terra Viva, por exemplo, através do Projeto Dom Helder Câmara (PDHC) estimulou a expansão das áreas de cultivo de frutas, assegurando assessoria técnica e apoiando o processamento dos produtos por meio da doação 
198

portantes que ultrapassaram simples mudanças na matriz produtiva. Além disso, tais experiências possibilitaram a abertura de postos de trabalhos com geração significativa de renda, em especial, para as mulheres com a comercialização de mel $^{14}$, polpa de frutas e produção de bolos, biscoitos etc.

Nos casos citados, a conexão entre produtores e consumidores possibilitada pela comercialização via PAA engendrou melhorias também no beneficiamento, no armazenamento e processamento de produtos. Contudo, não se pode afirmar que essa reconexão tenha sempre os mesmos resultados, pois este não é um processo "automático" e tampouco linear. Ele depende de diversas condições que vão desde a modalidade que está sendo operacionalizada bem como o perfil dos coordenadores da instituição executora, passando pelo tipo de produto comercializado até nível de engajamento de produtores e consumidores nos projetos de venda. Ao longo da trajetória de comercialização essa reconexão assume formas e intensidade diferenciadas.

Um aspecto importante a destacar no processo de implementação do PAA é o aprendizado organizacional que os esforços para o enquadramento no programa possibilitaram aos agricultores e gestores. A recuperação dessa trajetória releva claramente também a importância que o capital social dos grupos de agricultores desempenhou no desenvolvimento de estratégias capazes de enfrentar, até um certo nível, as demandas sistemáticas do Programa. Sob tal aspecto vale destacar: a capacidade dos grupos em estabelecer novas relações com entes públicos transformando-os em parceiros, as habilidades para mobilizar os grupos de consumidores e incorporá-los como copartícipes nas estratégias de venda, à disposição para inovações no campo produtivo etc.

de equipamentos como liquidificadores, freezers e outros. Com o início da comercialização de polpa houve também a valorização de espécies muito apreciadas culturalmente na região, como a cajarana (fruta nativa da região) cuja produção foi realizada com o apoio do Instituto Federal de Educação, Ciência e Tecnologia - IFRN de Apodi.

14 Em Apodi existem 15 casas de mel e um entreposto que fica na comunidade Laje do Meio, no qual o beneficiamento do mel é realizado por um grupo de mulheres que prestam serviços para a Cooperativa da Agricultura Familiar de Apodi (COOAFAP). 


\section{Consumidores e produtores: os elos ainda frágeis de uma conexão desejada}

É importante salientar as dificuldades de se fazer uma análise do papel das entidades beneficiadas com a doação do PAA ao longo da trajetória do Programa. Isso se deve, em parte, à rotatividade dos representantes dessas instituições nos cargos de direção, que, em função disso, raramente dispõem de informações sobre os momentos iniciais de implementação do PAA e mesmo sobre a execução atual.

Como mencionado anteriormente, a mobilização das entidades beneficiadas pelas doações foi feita inicialmente tanto pelas associações e cooperativas quanto pela própria Conab. Os agricultores familiares além de divulgarem sua produção, organizaram os seus potenciais consumidores. Quando o PAA Estadual iniciou no município de Apodi (dois anos mais tarde que o da Conab), eles já possuíam experiência suficiente com a mobilização das entidades e por isso auxiliaram a coordenação local da EMATER a realizar o cadastro das instituições. A capilaridade das organizações de representação da agricultura familiar, notadamente o Colegiado Territorial, foi fundamental para que mobilização e sensibilização das entidades beneficiárias se estendessem a vários municípios vizinhos a Apodi. Quando as novas regulamentações do Programa passaram a exigir que as doações fossem feitas somente mediante o cadastramento das instituições no Conselho Municipal de Assistência Social todas elas já conheciam o PAA e, ao contrário do que ocorrera nos primeiros projetos de comercialização, agora eram as instituições que buscavam os agricultores e as cooperativas para integrar-se aos projetos de venda. Atualmente, todas as instituições cadastradas em Apodi são contempladas com doações do PAA, seja via EMATER ou CONAB. No caso da Emater, a seleção dos alimentos bem como o montante que as instituições recebem é feita pelos técnicos de acordo com as informações contidas nos cadastros das instituições no qual constam: o público, o número de pessoas atendidas e as refeições oferecidas. Há maior diversidade de produtos nas aquisições feitas pela EMATER enquanto nas da CONAB prevalecem as aquisições por cadeia produtiva (mel, caju, etc). Em Apodi as entidades beneficiadas são escolas, hospitais, entidades de assistência social e associações de moradores. Os principais produtos recebidos foram peixe (tilápia), arroz vermelho, castanha de caju, mel, 
doces variados (caju, banana, coco e leite), jerimum, cocada, broa preta, bolinho de mel, iogurte, polpas de frutas, como também, carne caprina e bovina.

No caso das escolas participantes, é comum que os representantes não saibam de qual programa os alimentos recebidos são provenientes, se é do PAA ou PNAE. Como as entidades podem receber alimentos de diferentes cooperativas essa conexão entre a produção e consumo não fica clara. Além disso, a intermediação da prefeitura nas entregas por um lado facilita a vida das instituições ao fornecer apoio logístico, por outro dificulta a construção de uma relação mais orgânica. Apenas no caso da doação via PAA Emater, os vínculos entre consumidores e produtores pareceram mais fortes, mas para uma minoria. Algumas instituições inclusive tinham dificuldades de identificar se os alimentos eram oriundos das verbas da assistência social ou do PAA.

Quando questionados a respeito da característica dos alimentos recebidos através do PAA, todos os representantes das entidades entrevistadas compartilharam da mesma opinião: afirmaram receber sempre alimentos em bom estado de conservação e de boa qualidade. Em razão da baixa condição econômica das famílias beneficiadas, a doação via PAA é a única forma de acesso a alimentos como tilápia, castanha de caju, iogurte e carne. Alimentos que, embora sejam produzidos em grande quantidade na região, têm um custo muito elevado para essas famílias. Em um quadro de vulnerabilidade socioeconômica, ter acesso a produtos de qualidade e raramente consumidos pela população não é um resultado qualquer. Esse aspecto foi sistematicamente sublinhado pelos representantes das entidades beneficiárias, embora o impacto das doações seja diferente para cada público atendido.

Nas escolas, por exemplo, elas têm um papel complementar à alimentação fornecida diariamente. As doações estão sob avaliação constante dos gestores escolares ainda que eles não tenham uma visão geral do funcionamento do Programa. Esses parecem ter uma avaliação mais qualificada sobre os efeitos das doações. Em seus relatos são sublinhados aspectos como os benefícios da alimentação no aprendizado e na frequência escolar e a aceitabilidade dos alimentos pelo alunado. Os gestores escolares são portadores de um repertório de avaliação mais consistente, inclusive com sugestões muito precisas sobre a frequência das entregas, a qualidade dos produtos, as formas mais adequadas de armazenamento. Suas apreciações foram fundamentais na adequação da frequência de entrega e beneficiamento de vários produtos comercializados, conforme mencionado. 
Já as entidades que mantêm uma relação menos orgânica com seu público tendem a ter uma avaliação menos elaborada sobre o impacto das doações, colocando-se quase sempre de forma passiva nos processos de aquisição. Em geral, imputam ao PAA a intensificação na participação de seu público em atividades realizadas e o aumento na adesão de novos membros, como nos casos das Pastorais da Criança, do Idoso e das Associações de Moradores.

Vários representantes destacaram que avaliar o impacto do Programa apenas pelo número de membros atendidos pela entidade é ter uma perspectiva limitada sobre seu alcance, pois, em geral, é o grupo familiar que acaba se beneficiando com as doações. Essa visão do núcleo familiar como beneficiário do Programa e não apenas dos membros cadastrados fornece, evidentemente, um panorama bem mais abrangente sobre o alcance da política, mas que é de difícil mensuração.

Quando inquiridas sobre a qualidade dos produtos, mesmo nos casos em que foram constatados problemas inclusive relatados pelos próprios representantes das cooperativas, como no caso da carne bovina que possuía excesso de ossos, as avaliações dos representantes das instituições foram sempre positivas. Ficou evidente o receio de que uma avaliação mais rigorosa pudesse excluí-los das doações. Situações como essa indicam que, embora as comercializações via PAA proporcionem uma reconexão importante entre consumidores e agricultores, elas ainda ocorrem de forma assimétrica. Grande parte das instituições beneficiárias não se sentem implicadas nos processos, e as doações, de modo geral, não são concebidas como uma concessão, um favor. Outro indício disso é que, na época da pesquisa, a maioria das entidades entrevistadas desconhecia o fato de o Programa estar paralisado há dois anos no município. Vários afirmavam tratar-se apenas de mais uma descontinuidade do PAA, o que, aliás, foi sistematicamente sublinhado e criticado por eles.

Durante todo o período em que as doações foram paralisadas, apesar de inúmeros relatos dos representantes das entidades sobre a importância para a manutenção de suas organizações, não houve por parte deles qualquer ação junto às cooperativas para esclarecer os motivos daquela situação. Nesse sentido, parece fundamental que $o$ ato de doar via PAA seja politizado e que os cidadãos beneficiários assumam um papel mais ativo nos processos de aquisição de alimentos, que não se reduza apenas ao seu consentimento na ocasião da elaboração dos projetos de venda. 


\section{As mudanças no ambiente institucional do PAA e as repercussões no contexto local: o programa na encruzilhada e a crise de governança}

Segundo dados da CONAB, no Estado do Rio Grande do Norte a modalidade de CPR com Doação Simultânea foi a única que se manteve ininterruptamente até 2014. Além disso, alocou o maior volume de recursos do Programa. Entre os anos de 2006 e 2012, os valores destinados a essa modalidade aumentaram sistematicamente, de pouco mais de 140 mil para aproximadamente 21 milhões respectivamente, apresentando uma queda drástica nos anos subsequentes acompanhando a tendência do Programa no cenário nacional, que enfrentou uma grande crise em 2013 desencadeada por denúncias de irregularidades em sua operacionalização pela CONAB, atingindo mais fortemente o estado do Paraná. A importância da referida modalidade não se expressou apenas em termos de recursos alocados, como também no número de agricultores atendidos. Em 2006 apenas noventa agricultores haviam aderido ao PAA e, em 2012, foram quase cinco mil.

Já o Compra Direta da Agricultura Familiar só operou pelo MDA até 2008 e pelo MDS até 2010. Segundo um dos gestores da CONAB, essa interrupção no CDAF ocorreu porque a modalidade atuava apenas quando os preços dos produtos no mercado estavam abaixo do preço mínimo estipulado pelo governo. No caso das regiões do Nordeste, com a ocorrência das secas, os produtos mantiveram seus valores acima da média do mercado, não havendo razão para acionar a referida modalidade.

Em relação à modalidade $\mathrm{CPR}$-Estoque do $\mathrm{MDA}$, os técnicos da $\mathrm{CONAB}$ informaram que ela operava de forma muito similar ao crédito rural. A CONAB financiava a produção de determinada cultura e depois adquiria o produto do agricultor como forma de liquidar a dívida. Muitas cooperativas da região acessaram essa modalidade. Contudo, as novas regulamentações do PAA estabeleceram que os valores financiados só poderiam ser pagos em espécie e não mais em produtos, como previsto anteriormente. Em razão da estiagem desse período e, consequentemente, da perda total das safras, os agricultores foram impossibilitados de efetuar o pagamento ficando em débito com a CONAB. Essa situação prejudicou sobremaneira as cooperativas, pois uma vez inadimplentes ficaram 
impedidas de participar de novos projetos. A referida modalidade cessou suas operações no ano de 2012, deixando a maior cooperativa do município praticamente inoperante.

A partir de 2009, a CONAB passou a implementar o PAA, respeitando os Territórios da Cidadania (PTC) por orientação do núcleo central do Governo Federal (ARAÚJO, 2009). A criação do PTC, embora tenha tido pouco alcance no que se refere aos seus objetivos específicos, como sugerem os resultados da pesquisa de campo, teve a virtuosidade de fazer convergir as ações empreendidas por diversos atores anteriormente dispersas na região. No caso do PAA, esse dispositivo foi fundamental na expansão do Programa para outros municípios, aumentando as possibilidades de venda e estimulando a entrada de novos agricultores em processo de comercialização.

No Rio Grande do Norte, a CONAB, ao longo dos 11 anos estudados, executou acumuladamente mais de 77 milhões de reais. No caso de Apodi, de acordo com dados do PAA Data, entre 2011 e 2013 o PAA/MDS atendeu 2.072 agricultores no território da cidadania Sertão do Apodi e distribuiu R $\$ 8.664 .723,90 \mathrm{em}$ recursos, seguido pela região do Alto Oeste que teve 1.457 agricultores envolvidos no programa, com um total de recursos de $\mathrm{R} \$ 6.225 .719,55$.

Entre 2011 e 2013, Apodi foi o município que teve o maior número de participantes no PAA operado com recursos do MDS, no total foram 517 agricultores. Já no PAA do MDA, entre 2011 e 2012, dos 242 agricultores envolvidos no Rio Grande do Norte, 88 foram do município de Apodi e dos R \$ 1.064.204,80 reais investidos, $\mathrm{R} \$ 373.720,00$ foram para este município. Além disso, Apodi foi o único município do Rio Grande do Norte a ser atendido pelo PAA com recursos do MDA em 2012.

Para o gestor da CONAB, 2012 foi o ano em que a entidade obteve uma participação "ideal” no PAA, pois conseguiram expandi-lo para todas as regiões do estado chegando a operar aproximadamente 200 projetos. Essa expansão foi acompanhada de sucessivas auditorias da Controladoria Geral da União que identificou diversas falhas nos processos de compra exigindo que CONAB acompanhasse de forma mais efetiva o andamento dos projetos. Diante dessa orientação e contando com recursos humanos limitados, a decisão da CONAB foi a de diminuir o número de projetos aprovados nos anos seguintes. Técnicos da CONAB relataram que uma equipe formada por apenas cinco pessoas era responsável por todo processo de implementação e fiscalização do Programa no estado. A 
CONAB desempenhava inúmeras funções que iam desde capacitar os agricultores nas cooperativas e associações para elaboração dos projetos de venda até a mobilização das entidades que seriam beneficiadas pela doação. Nesse quadro, apenas uma parte dos projetos eram devidamente acompanhados. A fiscalização se dava por amostragem, deixando margem a muitos questionamentos. Em 2012, entre os projetos aprovados, apenas $40 \%$ foram fiscalizados pela CONAB.

Conforme relato de técnicos da CCONAB RN, apesar de estarem à frente da execução do PAA há alguns anos, ainda neste período, muitas das rotinas dos processos de compra, principalmente contábeis, não estavam claras para a equipe de técnica. Por isso, temendo complicações futuras, a CONAB-RN convidou a CGU para juntos realizarem uma oficina com o objetivo esclarecer os propósitos do Programa, suas particularidades e encontrar uma adequação dentro do que fosse permitido por lei. O coordenador do projeto na CONAB afirmou que esta foi uma decisão importante, à medida que tornou claro que as falhas nos processos de compra advinham de problemas ligados à falta de estrutura, principalmente de recursos humanos e mesmo da inexperiência de alguns técnicos em relação às compras institucionais. Contudo, essa iniciativa não impediu que a CONAB RN fosse alvo de uma série de auditorias. Nesse quadro prevaleceram as orientações normativas da entidade econômica sobre os objetivos de promoção da agricultura familiar e soberania alimentar do PAA com impactos substanciais para o conjunto dos beneficiários, como se verá adiante.

Ainda em 2012 uma auditoria da CGU sugeriu informatizar os processos, pois grande parte deles era manual, o que tornava a tramitação e avaliação muito lenta e de difícil controle. A instituição alertou também que fosse observado o cumprimento dos limites de valores estipulados em cada modalidade, uma vez que alguns projetos apresentavam valores superiores ao estabelecido pelas regulamentações. Até mesmo a conformação do público beneficiado pelas doações foi questionada, como no caso das doações a instituições religiosas. Segundo técnicos da CONAB RN, só no ano de 2013 foram 6 auditorias, envolvendo tanto a parte de análise dos projetos quanto visitas às cooperativas, às associações que vendiam os produtos e às entidades beneficiadas pelas doações. ${ }^{15}$ Neste mesmo ano, o que eram apenas recomendações da CGU se tornaram motivos para uma

15 Essas ações foram tão intensas que durante as pesquisas de campo deste trabalho, vários representantes de entidades perguntavam se os pesquisadores eram da CGU. 
grande investigação do Programa, por parte da Policia Federal em vários estados. O caso mais emblemático foi o do estado do Paraná, envolvendo prisões e afastamentos de dirigentes da CONAB em vários níveis.

Nessa ocasião dois técnicos da CONAB RN também foram afastados, causando um grande problema à operacionalização do $\mathrm{PAA}^{16}$. Com um quadro técnico já insuficiente, a situação da CONAB RN se tornara quase insustentável. Os três técnicos que restaram eram responsáveis por avaliar as propostas de projetos de todo o estado e tinham muito receio em fazê-lo. O Ministério Público também esteve à frente em várias das denúncias. Os efeitos de todas essas ações tornaram as rotinas do PAA demasiado tensas, e o resultado imediato disso foi a diminuição no número de contratos, como já mencionado. Conforme relato do coordenador do Programa, passado um ano dessas ocorrências, as situações começaram a ajustar-se do ponto de vista administrativo. E a equipe passou a trabalhar com mais segurança nos procedimentos, já que o volume de propostas diminuiu. Se do ponto de vista da CONAB RN, o aumento de fiscalização teve como consequência principal a acomodação das rotinas das equipes técnicas, os efeitos para os agricultores foram bem distintos. Além de enfrentarem o segundo ano consecutivo de secas, com perda de grande parte da produção agropecuária, tiveram limitado um canal importante de comercialização para escoar o pouco que conseguiram produzir. Outra alteração importante foi que os órgãos de inspeção sanitária passaram a exigir a certificação dos produtos de origem animal e de derivados de leite.

Os aprendizados organizacionais e as formas de governança colocadas em curso pelas entidades executoras em interação com as organizações dos agricultores familiares não foram suficientes para fazer frente a esse novo cenário. A ausência de sistemas de inspeção sanitária e a forte fiscalização dos órgãos de controle deste setor impediram os agricultores de comercializarem seus produtos via PAA.

Em razão dessas circunstâncias, a partir de 2012 houve uma queda drástica na atuação do Programa operado pela CONAB/RN no Rio Grande do Norte, agravando-se no ano seguinte. Em 2013, o PAA só atuou na modalidade Compra Direta com Doação Simultânea, operada com recursos do MDS. Das 100 
propostas submetidas à CONAB/RN, apenas 44 foram aprovadas, pois, segundo relato do coordenador do Programa, a instituição só dispunha de condições técnicas para realizar a visita prévia neste número de projetos. Dos 10 milhões de reais que a CONAB/RN recebeu em 2013, 5 milhões foram devolvidos por impossibilidade de atender às exigências da CGU. Em 2014, a persistência da seca diminuiu ainda mais as operações do PAA. Apenas 6 projetos na modalidade Doação Simultânea foram executados. Dos 167 municípios do Rio Grande do Norte, apenas 5 - Apodi, Ceará Mirim, Doutor Severiano, São Francisco do Oeste e Umarizal - que representam 3\%, dos municípios do estado participaram do PAA operacionalizado pela CONAB (PAA DATA, 2015).

Segundo os gestores da CONAB, a retração do número de operações do PAA ocorreu pela combinação das secas e das exigências de inspeção dos produtos através da obtenção do Selo de Inspeção Municipal e SIF. Conforme relatos de técnicos da EMATER, sempre houve a exigência de um serviço de inspeção municipal (SIM). No entanto, o aval técnico fornecido, no caso pesquisado, pelo veterinário, nutricionista e assistente social, responsáveis pela recepção dos produtos comercializados pelo PAA era suficiente. Mas a partir de 2013, a exigência do Serviço de Inspeção Municipal passou a vigorar. Apesar de todos os esforços despendidos por parte dos agricultores e suas organizações, a partir desse período, suas expectativas quanto às possibilidades do PAA mudaram drasticamente. A exigência de serviços de inspeção sanitária para a comercialização de produtos derivados de produção animal e vegetal foi um duro golpe para os agricultores. Isso foi um impacto muito grande com relação ao PAA porque o PAA beneficia o pequeno agricultor, então essa mudança foi muito impactante porque o pessoal não estava preparado, na verdade o município é que tem que estar preparado para dar esse suporte de Serviço de Inspeção Municipal - SIM. [...] 70\% dos produtos que a gente adquiria era de origem animal, então teve esse impacto. ${ }^{17}$

As inspeções realizadas por técnicos da prefeitura não eram mais consideradas suficientes pelos órgãos reguladores, colocando em xeque uma organização que vinha se estruturando há uma década, mas que ainda carecia de tempo para estabelecer. O caso da cadeia produtiva de polpa de frutas foi bastante

\footnotetext{
17 Vale salientar que dadas as condições climáticas do semiárido, a produção pecuária desempenha um papel fundamental para a manutenção e reprodução da agricultura familiar nessa região. Como os agricultores costumam dizer, "o gado é a nossa poupança" é a estratégia de resistência à semiaridez e fonte de alimentação quando as situações se agravam.
} 
emblemático nesse aspecto. Apesar de o PAA ter sido o principal motivador na estruturação da produção de polpa de frutas em Apodi, atualmente os agricultores estão impossibilitados de vender para o programa, pois as exigências sanitárias que se fundamentam nos modelos dominantes de agricultura, empurraram para a ilegalidade as unidades familiares de beneficiamento.

Segundo relatos dos agricultores, em 2012, o sindicato dos produtores de polpa de frutas de Apodi fez uma denúncia alegando que a comercialização das polpas, via PAA, estava ocorrendo sem o selo de inspeção. Após o ocorrido, o MAPA, com o apoio da Polícia Federal, realizou uma fiscalização na COOAFAP apreendendo os estoques do produto e descartado-os. A cooperativa foi multada e impedida de comercializar as polpas. Logo após esse episódio, a vigilância sanitária também cassou o SIF da Associação Laje do Meio, alegando problemas de infraestrutura. Essa situação suscitou muita indignação entre os agricultores do município e da região. Primeiro, porque entre as várias associações produtoras de mel esta era a única com selo e servia como suporte à comercialização das demais. Assim, a possibilidade das associações da região de comercializarem o mel certificado foi comprometida. Além disso, segundo relatos dos associados, o fiscal do MAPA questionou o fato de ter sido concedido o SIF a esse grupo. Segundo relato, o fiscal ainda argumentou: "vocês são agricultores familiares não poderiam ter SIF".

Para os agricultores, este episódio configurou uma ação declarada de tentativa de desestruturar a agricultura familiar da região, até porque foram acontecimentos encadeados, o da polpa de frutas, o do mel, sem falar da conduta pouco adequada dos técnicos dos órgãos fiscalizadores nessas ações e de uma governança policialesca que passou a dominar todos os processos envolvendo o PAA.

Essa sucessão de episódios gerou um clima de descrédito em relação ao Programa e em relação às reais possibilidades de manutenção da agricultura familiar na região. Para os agricultores era difícil conceber que um Programa ficasse sob a tutela de equipes técnicas com concepções não apenas diferenciadas, mas também contraditórias e divergentes. Sob tais circunstâncias, muitos agricultores argumentavam que não havia qualquer garantia de que mesmo com a liberação do SIF eles pudessem retomar seu lugar na comercialização. Afirmavam que outras exigências certamente seriam criadas. Assim, sentiam que a promoção da agricultura familiar, preconizada pelo PAA, era afrontada agora em um nível em que eles ainda não dispunham de condições para subsistir. Após essas 
interdições os atravessadores retomaram seu espaço como intermediários na compra e venda dos produtos. ${ }^{18}$

Apesar do contexto político e climático extremamente desfavorável, à época da pesquisa estavam em curso várias articulações com o propósito de criar um sistema de certificação. As primeiras barreiras a esse processo já se colocavam. O SIM, por exemplo, está circunscrito a um município, não possibilitando o fornecimento de alimentos para outras localidades, contrariando a forma de governança em rede, empreendida até então. Nesse caso, os agricultores associados ou individualmente precisariam do Selo de Inspeção Estadual (SAE) e para outros estados era exigido o Selo de Inspeção Federal. Isto coloca em xeque as redes de comercialização criadas a partir do PAA fragilizando um tecido associativo que ainda estava em construção.

No caso de Apodi a solução apresentada ao problema tem sido a formalização de um consórcio municipal, que assegure essa comercialização para além dos limites locais. Esses novos dispositivos têm sido discutidos no Fórum da Agricultura Familiar mesmo que reconhecidas suas dificuldades de operacionalização, haja vista a pouca experiência no estado, principalmente no que se refere à acomodação dos diversos interesses em jogo (GRISA et al., 2016).

Segundo dados do PAADATA, ano de 2014, em Apodi, o PAA operou na modalidade CPR-Doação, na qual a participante foi a Cooperativa da Agricultura Familiar de Apodi (COOAFAP) com a venda de mais de 96 mil quilos de arroz vermelho beneficiado, favorecendo 33 agricultores cooperados e 14 entidades sociais. Essa venda só ocorreu por não tratar-se de produto com maior exigência de certificação, como são, principalmente, os de origem animal.

\section{Considerações finais}

A recuperação da trajetória de implementação do PAA no município de Apodi revela que a implementação de um Programa dessa natureza, em condições de capital social relativamente forte, engendra processos coletivos de inovação organizacional contribuindo de modo decisivo para novas formas de governança. Os processos de formalização das organizações da agricultura familiar

18 Conforme relatos, boa parte da produção de mel da região até então destinada ao PAA, passou a ser comercializada com um empresário de Fortaleza responsável por "Sifar" o produto. 
impulsionados pela chegada do Programa, bem como as formas de interação entre elas e os entes do Estado, são expressões desse processo. A implementação do Programa em articulação com outras políticas (PRONAF, PRONAT, PDS) ativou recursos latentes no território, ressignificando práticas existentes e habilitando novas parcerias, inclusive públicos e privadas. Além disso, como conclui também Sabourin (2010), "as experiências estudadas estão associadas a recuperação da dignidade dos agricultores, ou seja, a revalorização do estatuto de camponês pobre" (p. 161), possibilitando a eles o reconhecimento de seu protagonismo tanto na garantia da segurança alimentar como no processo de desenvolvimento mais geral. Esse protagonismo também pode ser revelado na capacidade desses grupos de interferirem nas orientações do Programa, como foi o caso da comercialização do mel com a CONAB/RN. Nesse sentido, o PAA se constitui um dispositivo de ampliação das capacidades e consequentemente de expansão da liberdade (SEN, 2000). As dimensões de melhoria de qualidade de vida, da dignidade, da participação política são referenciadas sistematicamente nos relatos.

As mudanças no ambiente institucional, operadas, sobretudo, por atores sociais externos ao Programa, alteraram drasticamente as formas de governança. As diretrizes do PAA passam a ser definidas de fora, por atores completamente alheios às especificidades da realidade do mundo rural. Muito do que anteriormente se considerava flexibilidade da política assume um caráter completamente oposto. $\mathrm{O}$ conteúdo de certas regulamentações, que tem como parâmetros os padrões dominantes de produção agrícola bem como o excesso das mesmas, gerou um processo fiscalizador policialesco, criminalizando várias estratégias desenvolvidas no âmbito das organizações de agricultura familiar com grandes prejuízos morais e sociais para elas. Apesar da capacidade de articulação, de inovação organizacional e de uma série de habilidades e estratégias desenvolvidas por parte dos agricultores e de parcela do Estado para sustentar e manter o PAA, elas não foram suficientes para fazer frente a uma ideologia latifundista que sustenta e se traveste de norma técnica, nas regulamentações infinitas e incompreensíveis. Ideologia que se institucionaliza na regra, mas também nas mentes daqueles que, a serviço do capital, insistem em silenciar os que não podem e não querem mais calar. Embora, atualmente, os agricultores disponham de melhores condições de comercialização, tanto porque estruturaram sua produção como passaram a revalorizar outros canais de comercialização a partir do PAA, como as feiras e a venda direta aos consumidores, acreditam não estar 
preparados para o fim do Programa. Quando inquiridos sobre essa possibilidade foram unânimes em afirmar "isto seria um desastre, estamos melhores, mas ainda precisamos desse mercado".

\section{REFERÊNCIAS}

ARAÚJO, R.M. Programa de Aquisição de Alimentos (2003-2010): Avaliação da implementação pela CONAB no Rio Grande do Norte. 2012. Tese (Doutorado) Curso de Administração, Universidade Federal do Rio Grande do Norte, Natal, 2012.

ARNS, P.C. Um Olhar sobre os dispositivos de governança. In: PIRAUX, M e CANNIELO, M. (Org.). RAIZES, Revista de Ciências Sociais e Econômicas. Dossiê: Territórios, Sustentabilidade e ação Pública, V. 28, n 1-2, jan.-dez., 2010.

BASTOS, F. Ambiente institucional no financiamento da agricultura familiar. São Paulo-SP: Polis, 2006.

BRASIL, MDS. Relatórios de informações sociais. 2015. Disponível em: <http:// aplicacoes.mds.gov.br/sagi/RIv3/geral/index.php>. Acesso em: 28 maio 2015. 2010. P. 117-132.

Brasília: 2003.

CONAB. Programa de Aquisição de Alimentos: Ações da CONAB em 2003. . CONAB. Programa de Aquisição de Alimentos: Sumário Executivo. Brasília: 2004.

. CONAB. Programa de Aquisição de Alimentos: Ações da CONAB em 2005. Brasília: 2006.

CONAB. Programa de Aquisição de Alimentos: Resultado das Ações da CONAB em 2007. Brasília: 2007

CONAB. Programa de Aquisição de Alimentos: Resultado das Ações da CONAB em 2008. Brasília: 2008

. CONAB. Programa de Aquisição de Alimentos: Resultado das Ações da CONAB em 2009. Brasília: 2009

. CONAB. Programa de Aquisição de Alimentos: Resultado da CONAB em 2010. Brasília: 2010.

- CONAB. Programa de Aquisição de Alimentos: Resultado das Ações da CONAB em 2011. Brasília: 2011.

. CONAB. Programa de Aquisição de Alimentos: Resultado das Ações da CONAB em 2012. Brasília: 2012. 
. CONAB. Programa de Aquisição de Alimentos: Resultado das Ações da CONAB em 2013. Brasília: 2013.

CONAB. Programa de Aquisição de Alimentos: Resultado das Ações da CONAB em 2014. Brasília: 2015

. CONAB. Objetivos do PAA. 2015. Disponível em: <http://www.conab.gov.br/ conteudos.php? $\mathrm{a}=1125 \& \mathrm{t}=2>$. Acesso em: $20 \mathrm{fev} .2015$.

. IBGE. IBGE CIDADES: Apodi, Histórico. 2013. Disponível em: <http://ibge. gov.br/cidadesat $/$ painel/historico.php?lang=\&codmun $=240100 \&$ search=rio-grandedo-norte|apodi|infograficos:-historico>. Acesso em: 06 abr. 2015.

. MINISTÉRIO DO DESENVOLVIMENTO SOCIAL E COMBATE À FOME. Programa de Aquisição de Alimentos - PAA. Brasília: MDS, 2010. 40 p.

. Constituição (2014). Decreto no 8.293, de 12 de agosto de 2014. Traz mudanças ao Decreto 7.775 que regulamenta o Programa de Aquisição de Alimentos da Agricultura Familiar. Disponível em: $<$ http://www.planalto.gov.br/ccivil_03/_ato20112014/2014/Decreto/D8293.htm>. Acesso em: 19 fev. 2015.

. Constituição (2012). Decreto ${ }^{\circ} 7775$, de 04 de julho de 2012. Regulamenta O Art. 19 da Lei no 10.696, de 2 de Julho de 2003, que institui o Programa de Aquisição de Alimentos, e o Capítulo III da Lei no 12.512, de 14 de outubro de 2011, e dá outras providências. Disponível em: <https://www.planalto.gov.br/ccivil_03/_ato20112014/2012/decreto/d7775.htm>. Acesso em: 27 fev. 2015.

Decreto $N^{\circ} 10.696$, de 02 de julho de 2003. Dispõe sobre a repactuação e o alongamento de dívidas oriundas de operações de crédito rural, e dá outras providências. Disponível em: <http:/www.planalto.gov.br/CCIVLIL/Leis/2003/ L10.696.htm>. Acesso em: 22 ago. 2014.

Lei 11.326, de 24 de julho de 2006. Estabelece as diretrizes para a formulação da Política Nacional da Agricultura Familiar e Empreendimentos Familiares Rurais. Diário Oficial da União. Disponível em: <http://www.planalto.gov.br/ccivil_03/_ ato2004-2006/2006/lei/l11326.htm>. Acesso em: 20 fev. 2015.

. MDS. PAA DATA. 2015. Disponível em: <http://aplicacoes.mds.gov.br/sagi/ paa/visi_paa_geral/pg_principal.php?url=abertura $>$. Acesso em: 10 abr. 2015.

. MINISTÉRIO DO DESENVOLVIMENTO SOCIAL E COMBATE À FOME. Balanço de Avaliação da Execução do Programa de Aquisição de Alimentos (PAA) de 2003 a 2010. Brasília: PAA, 2010.

DIAS, Thiago Ferreira et al. O Programa de Aquisição de Alimentos da Agricultura Familiar (PAA) como estratégia de inserção socioeconômica: $\mathrm{O}$ caso do Território da Cidadania Sertão do Apodi (RN). Revista Brasileira de Gestão e Desenvolvimento Regional, Taubaté, v. 9, n. 3, p.100-129, 2013. 
GRISA, Catia et al. Governança e performance do PAA: Um estudo comparativo entre o Rio Grande do Sul e Rio Grande do Norte. Pelotas: Universidade Federal de Pelotas, 2013. Proposta de pesquisa.

GRISA, Catia et al. Ambiente institucional, governança e performance do PAA: uma análise nos estados do Rio Grande do Sul e do Rio Grande do Norte. In: Avaliação de Políticas Públicas: Reflexões acadêmicas sobre o desenvolvimento social. Ministério do Desenvolvimento Social, 2016.

INSTITUTO BRASILEIRO DE GEOGRAFIA E ESTATÍSTICA. Censo agropecuário 2006. Rio de Janeiro: Ministério do Planejamento, Orçamento e Gestão, 2006. 267 p.

Censo Demográfico 2010. Disponível em: <http://www.censo2010.ibge.gov.br. Acessado em: 14 ago. 2014.

LEITE, Sergio Pereira et al. Análise de políticas públicas de enfrentamento da pobreza rural na perspectiva do desenvolvimento territorial: estudos de caso em diferentes territórios do Brasil. Disponível em: <http://www.planalto.gov.br/ccivil_03/_ato20042006/2006/lei/111326.htm>. Acesso em: 20 mar. 2015.

LIMA, Jéssica Samára Soares de et al. O processo de construção da agroindústria familiar de polpa de fruta no município de Apodi. In: SOBER NORDESTE, 8., 2013, Parnaíba. Anais... . Parnaíba: SOBER, 2013. p. 1 - 18.

MINISTÉRIO DO DESENVOLVIMENTO AGRÁRIO (MDA). Plano Territorial de desenvolvimento rural sustentável do Alto Oeste Potiguar: Sertão do Apodi. 2010. 188 p.

MINEIRO, Fernando (Mandato Mineiro). Perfil dos Fornecedores do Programa do Leite no RN. Gabinete do Deputado Fernando Mineiro. Natal/RN, novembro de 2007.

MOLINA, Wagner S. L. et al. Práticas e mecanismos de inovação na construção de mercados para agricultura familiar. In: SCHNEIDER, Sergio et al. (Org.). Sementes e brotos da transição: inovação, poder e desenvolvimento em áreas rurais do Brasil. Porto Alegre: UFRGS, 2014. Cap. 9. p. 193-214.

NUNES, Emanoel Márcio et al. A inserção da agricultura familiar em mercados: o Programa de Aquisição de Alimentos (PAA) no Território da Cidadania Sertão do Apodi (RN). In: CONGRESSO DA SOCIEDADE BRASILEIRA DE ECONOMIA, ADMINISTRAÇÃO E SOCIOLOGIA RURAL, 50, 2012, Vitória. Anais da SOBER. Vitória: SOBER, 2012. p. 1-19.

OLIVEIRA, Alba Barbosa de et al. Uma análise do processo gestionário do programa de aquisição de alimentos (PAA): o caso do Rio Grande do Norte. Revista de Políticas Públicas, São Luís, v. 14, n. 1, p.157-171, jan./jun, 2010.

OLIVEIRA, Vanicleide Soares Gomes de; FERREIRA, Luiz Leonardo; PORTO, Vânia Christina Nascimento. Agricultura familiar e agroecologia: um estudo no município de Apodi - RN. Revista Agropecuária Científica no Semiárido, Patos, v. 9, n. 3, p.1-5, jun-ago, 2013. 
PERROW, Charles. La escuela institucional: sociologia de lasorganizaciones. Madrid: McGraw - Hill, 1990.

PIRAUX, M. AZEVEDO, S. G. , TONNEAU J. P. Os mediadores, os políticos e a sociedade civil: a realidade e os limites da governança territorial. $\mathrm{O}$ caso do território do taspp no nordeste brasileiro In: PIRAUX, M e CANNIELO, M. (Org.). RAIZES, Revista de Ciências Sociais e Econômicas. Dossiê: Territórios, Sustentabilidade e ação Pública, V. 28, n 1-2, jan.-dez., 2010.

PNAD, 2013 - Pesquisa Nacional por Amostra de Domicílios - Segurança Alimentar.

ROZENDO, Cimone Rozendo de Souza; MOLINA, Wagner de Souza Leite. O Programa de Aquisição de Alimentos no rio Grande do Norte e os desafios da construção de mercados para a agricultura familiar. In: VII CONGRESSO LATINOAMERICANO DE SOCIOLOGIA RURAL., 2010, Porto de Galinhas. p. 1 - 20.

ROZENDO, Cimone de Souza; BASTOS, Fernando Costa; MOLINA, Wagner de Souza Leite. Desafios institucionais para inclusão da agricultura familiar no Programa Nacional de Alimentação Escolar. Natal (RN): Revista CRONOS/UFRN, 2013.

SABOURIN, Eric. Dispositivos coletivos e apoio a produção e dinâmicas territoriais. In: PIRAUX, M e CANNIELO, M. (Org.) RAIZES, Revista de Ciências Sociais e Econômicas. Dossiê: Territórios, Sustentabilidade e ação Pública, V. 28, n 1-2, jan.-dez., 2010.

SANTANA JÚNIOR, Henrique Eufrásio de. Zoneamento Agroecológico do Município de Apodi/RN. 2010. 151 f. Dissertação (Mestrado) - Curso de PósGraduação em Desenvolvimento e Meio Ambiente, Universidade Federal do Rio Grande do Norte, Natal, 2010.

SANTOS, M.H.C. Governabilidade, governança e democracia: criação da capacidade governativa e relações executivo-legislativo no Brasil pós-Constituinte. Dados, 1997, v. 40, n. 3.

SEN, Amarthya. O desenvolvimento como liberdade. São Paulo: Companhia da Letras, 2000.

TORRE, Andre. Conflitos e governança dos territórios. In: PIRAUX, M e CANNIELO, M. (Org.). RAIZES, Revista de Ciências Sociais e Econômicas. Dossiê: Territórios, Sustentabilidade e ação Pública, V. 28, nº 1-2, jan.-dez., 2010. 


\title{
Compra institucional de alimentos: uma estratégia para impulsionar sistemas alimentares saudáveis e sustentáveis
}

\author{
Panmela Soares \\ Rafaela Karen Fabri \\ Suellen Secchi Martinelli \\ Vitória Uliana Bianchini \\ Suzi Barletto Cavalli
}

\section{Introdução}

O processo de liberalização intensificado na década de 1990 vem sendo relacionado a uma série de transformações no sistema alimentar, com consequências sociais, econômicas e ambientais (RAYNER et al., 2006; FAO, 2015). Essas transformações estão fomentando um debate mundial acerca da sustentabilidade, que deve transcender a dimensão do consumo, incorporando as etapas de produção, processamento e comercialização dos alimentos. Estratégias como valorização da alimentação tradicional, da cultura e agricultura local podem minimizar a transformação dos sistemas alimentares locais em um sistema alimentar global, que exacerba o problema da desigualdade e da sustentabilidade (GLIESSMAN, 2001). Desse modo há uma necessidade de melhoria da qualidade dos alimentos em todas as etapas do sistema alimentar (FORNAZIER; BELIK, 2013) considerando suas implicações para a biodiversidade e economia local (COLEY; HOWARD; WINTER, 2009).

Os consumidores caracterizam-se como atores-chave no processo de modificações do sistema alimentar por serem detentores do poder de pressão sobre 
o mercado, podendo influenciar diretamente a produção de alimentos. Nesse contexto, reconhece-se o potencial aumentado das Unidades de Alimentação e Nutrição (UANs) em determinar modificações no sistema alimentar, principalmente pela utilização de grande quantidade de alimentos para a produção de refeições diárias para suas clientelas. Dessa forma, a demanda por alimentos sustentáveis pode ter um elevado potencial para reduzir o impacto ambiental causado pela produção de refeições (CERUTTI, 2016), fomentando o desenvolvimento de sistemas agroalimentares sustentáveis (MARTINELLI et al., 2015).

Nos últimos anos cresceu o interesse de diversos países na utilização de contratos públicos como instrumento de política para influenciar o comportamento dos setores público e privado (SONNINO, 2014). No Brasil, intervenções governamentais demonstram as potencialidades do Estado na reorganização do sistema agroalimentar e nas relações de mercado a partir do foco no desenvolvimento rural sustentável e no provimento de refeições adequadas (FAO, 2016). Evidencia-se o interesse em fomentar os sistemas agrícolas produtivos localizados, a partir do desenvolvimento de políticas de compras diretas de alimentos da agricultura familiar (AF) por instituições públicas. Essas políticas iniciaram no país no ano de 2003, com a criação do Programa de Aquisição de Alimentos (PAA). Por meio desse programa é promovido o fortalecimento da AF em conjunto com estratégias para a distribuição de alimentos às populações em situação de insegurança alimentar. Dessa forma, a compra pública se converte em um instrumento para fortalecer os circuitos curtos de comercialização ${ }^{1} \mathrm{de}$ alimentos, ao mesmo tempo que pode incentivar hábitos alimentares saudáveis (BRASIL, 2012b).

Além disso, pode contribuir para a sustentabilidade ambiental, dada a valorização da compra de alimentos provenientes de produção orgânica de base agroecológica.

Com o intuito de expandir a aquisição de alimentos da AF, no ano de 2012 instaurou-se a modalidade Compra Institucional do PAA, obrigatória a partir de 2016 (BRASIL, 2012a; b; BRASIL, 2016). O que significa que todos os equipamentos públicos municipais, estaduais e federais que compram alimentos e fornecem refeições, como restaurantes universitários (RU), restaurantes

1 Relacionados à comercialização direta entre produtor e consumidor, na propriedade por meio de venda direta ou cestas, ou fora de propriedade por meio de feiras e cooperativas (DAROLT; LAMINE; BRANDEMBURG, 2013). 
populares (RP), cozinhas comunitárias, hospitais públicos e do exército, dentre outros, devem comprar alimentos da AF. A incorporação de alimentos de produção familiar responde ao objetivo desses equipamentos de fortalecer as ações de Segurança Alimentar e Nutricional (SAN) em toda a cadeia produtiva, promovendo a integração entre produção e consumo de alimentos e atuando na melhoria da qualidade de vida dos atores envolvidos no processo.

Entre esses equipamentos destacam-se os RP, por sua relevância enquanto política de distribuição de alimentos, que visa oferecer refeições saudáveis e acessíveis à população em insegurança alimentar e nutricional. Os restaurantes populares têm como princípios fundamentais a produção e a distribuição de refeições saudáveis, com alto valor nutricional, a preços acessíveis, devendo localizar-se preferencialmente em grandes centros urbanos (BRASIL, 2013). No entanto, para além da oferta de refeições adequadas, o Manual de Implantação de Restaurantes Populares já apontava a preocupação com o incentivo e o fortalecimento da agricultura familiar. Tal situação pode ser observada diante da recomendação para a compra de gêneros oriundos da agricultura familiar de forma a estimular a economia local e a geração de emprego e renda (BRASIL, 2004).

Considerando a ausência de estudos que abordam a compra pública de alimentos em restaurantes populares e visando uma aproximação com o atual panorama da compra de alimento por esses equipamentos, inicialmente este capítulo apresenta uma caracterização dos RP brasileiros. Além disso, dada a relevância da compra de alimentos locais de agricultores familiares para a promoção de sistemas alimentares mais sustentáveis, é apresentada uma proposta de etapas a serem seguidas para auxiliar na efetivação da compra pública de alimentos da AF.

\section{Ferramentas metodológicas para caracterização dos Restaurantes Populares brasileiros}

Foi realizado um estudo transversal com uso de questionário estruturado dirigido aos gestores de todos os restaurantes que receberam financiamento do Ministério do Desenvolvimento Social e Combate à Fome (MDS) (N=100 restaurantes). 
O questionário foi construído tomando como referência a experiência prévia da equipe de pesquisadores em projetos de compra de alimento da $\mathrm{AF}$ em instituições públicas (CAVALLI, 2012; SOARES et al., 2015; MARTINELLI et al., 2015). As questões versavam sobre: localização da unidade (cidade/ estado); tempo de funcionamento (anos); tipos de refeições servidas (café da manhã/almoço/jantar); número de refeições servidas por dia $\left(\mathrm{n}^{\circ}\right)$; valor cobrado pelo almoço (reais); v alor diferenciado por público atendido (sim, quais/ não); parcerias estabelecidas (sim, instituições parceiras/não); responsável pela elaboração do cardápio (cargo responsável); presença de nutricionista como responsável técnico ( $\operatorname{sim} /$ não); tempo de atuação do nutricionista (meses ou anos); forma de gestão ${ }^{2}$ (direta/indireta/semidireta); método de aquisição de alimentos (processo licitatório/ dispensa de licitação); origem dos alimentos (agricultura familiar/ outros fornecedores); recebimento de alimentos via PAA Doação Simultânea (sim/não); compra de alimentos via PAA Compra Institucional (sim/não).

Os dados foram coletados em um período de um ano, entre os meses de dezembro de 2014 e 2015. Para contatar os restaurantes foram utilizadas as informações de contato disponibilizadas na página web do MDS. Para garantir a taxa de resposta, foram realizadas quatro tentativas de contato com o gestor responsável pela compra, em dia e horário diferentes, com intervalos aproximados de cinco dias. Mediante aceite para participação, estabeleceu-se dia e hora para a aplicação do questionário telefônico, conforme disponibilidade do participante. Na impossibilidade de aplicação via telefone, o questionário foi enviado por correio eletrônico e autopreenchido via ferramenta Google Docs. A pesquisa foi aprovada pelo Comitê de Ética em pesquisas com seres humanos da Universidade Federal de Santa Catarina (parecer no 1.240.666).

Do total de RP cadastrados ( $\mathrm{N}=100$ restaurantes), obteve-se uma taxa de resposta de $81 \%$. Dos 19 restaurantes que não participaram da pesquisa, 7 estavam desativados e com os outros 12 não foi possível estabelecer contato em nenhuma das tentativas. Entre os 81 restaurantes pesquisados, 71 responderam

2 Gestão direta: quando provida integralmente por órgãos ou entidades públicas, podendo a gestão ser realizada pelo estado, Distrito Federal ou município; Gestão indireta: quando provida integralmente por meio de entidades privadas com ou sem fins lucrativos de acordo com a legislação vigente, mantida a gestão pelo estado, Distrito Federal ou município; Gestão semidireta: quando provida parcialmente por órgãos ou entidades públicas, podendo a gestão ser realizada pelo estado, Distrito Federal ou município; ou seja, quando a compra dos gêneros alimentícios é realizada pelo ente, a equipe administrativa é composta por servidores, efetivos ou não, e a equipe operacional é terceirizada. 
o questionário por telefone e 10 foram autopreenchidos. Os dados foram registrados em planilhas eletrônicas. Realizou-se uma análise descritiva dos dados.

\section{Caracterização dos restaurantes populares brasileiros}

Os RP participantes $(\mathrm{n}=81)$ eram responsáveis pelo preparo de 109.945 refeições diariamente em todo o país. A Figura 1 apresenta a distribuição geográfica dos RP e o número de refeições servidas diariamente em cada região do país.

Figura 1: Distribuição geográfica dos restaurantes populares e o número de refeições servidas diariamente por região do país

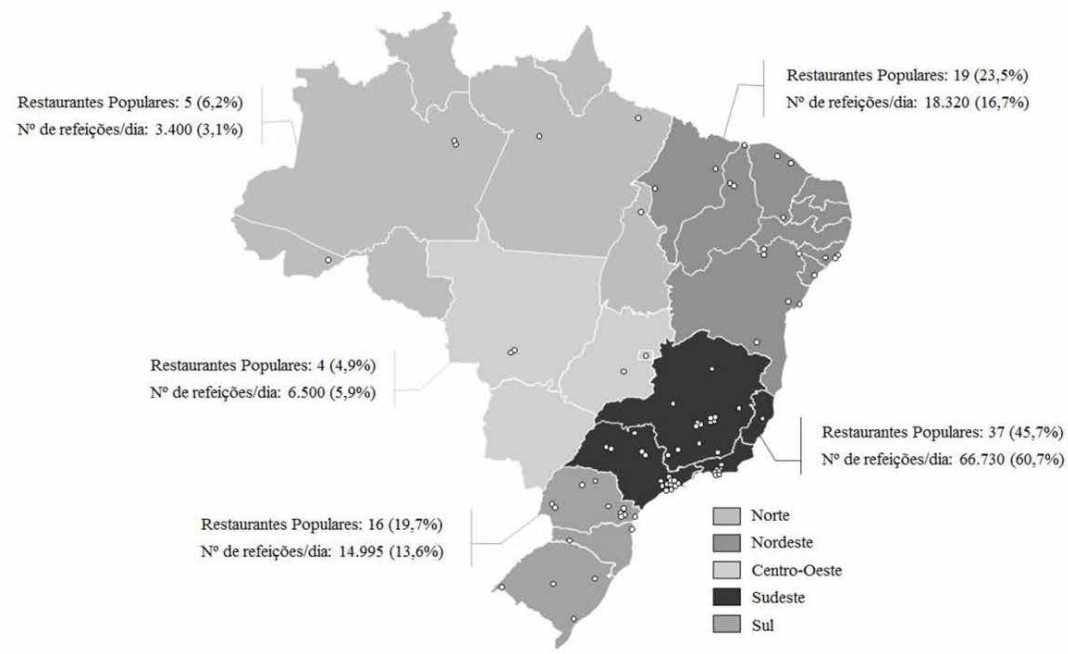

Fonte: Dados da pesquisa (elaborada pelas autoras).

As características gerais dos RP podem ser observadas no Quadro 1. Identificou-se que $87 \%$ dos restaurantes entraram em funcionamento nos últimos 10 anos (a partir de 2005). As refeições servidas incluíam café da manhã, almoço e jantar, sendo que o almoço era oferecido em todos os restaurantes. As demais refeições eram servidas em $19,8 \%(n=16)$ dos restaurantes. O preço do almoço pago pelos consumidores variou entre $\mathrm{R} \$ 1,00$ e $\mathrm{R} \$ 2,00$ em $79 \%$ dos restaurantes. Ainda, em 17,38\% ( $n=14)$ dos RP havia diferenciação de preços para grupos mais vulneráveis da população, como pessoas acima de 60 anos, deficientes físicos 
e participantes do Programa Bolsa Família, ou isenção para moradores de rua atendidos por centros especializados de assistência social.

Quadro 1 - Características gerais dos restaurantes populares brasileiros financiados pelo Ministério de Desenvolvimento Social e Combate à Fome

\begin{tabular}{|c|c|c|c|}
\hline \multirow[t]{3}{*}{ Tempo de funcionamento ${ }^{*}$} & 0-3 anos & 9 & 11,7 \\
\hline & 4-10 anos & 58 & 75,3 \\
\hline & $\geq 11$ anos & 10 & 13 \\
\hline \multirow[t]{2}{*}{ Café da manhã } & Sim & 11 & 13,6 \\
\hline & Não & 70 & 86,4 \\
\hline \multirow[t]{2}{*}{ Almoço } & Sim & 81 & 100 \\
\hline & Não & 0 & 0 \\
\hline \multirow[t]{2}{*}{ Jantar } & Sim & 9 & 11,1 \\
\hline & Não & 72 & 88,9 \\
\hline \multirow[t]{3}{*}{ Refeições servidas por dia (almoço) } & Até 1000 & 48 & 59,3 \\
\hline & $1001-2000$ & 23 & 28,4 \\
\hline & $\geq 2001$ & 10 & 12,3 \\
\hline \multirow{3}{*}{ Valor da refeição ( $\mathrm{R} \$$ por almoço) } & $1,00-2,00$ & 64 & 79 \\
\hline & $2,01-3,00$ & 11 & 13,6 \\
\hline & $\geq 3,10$ & 6 & 7,4 \\
\hline \multirow{2}{*}{$\begin{array}{l}\text { Valor diferenciado por público } \\
\text { atendido }\end{array}$} & Sim & 14 & 17,3 \\
\hline & Não & 67 & 82,7 \\
\hline \multirow[t]{2}{*}{ Parcerias } & Sim & 30 & 37 \\
\hline & Não & 51 & 63 \\
\hline \multirow{2}{*}{$\begin{array}{l}\text { Responsável pelo planejamento do } \\
\text { cardápio }\end{array}$} & Nutricionista de empresa terceirizada & 45 & 55,6 \\
\hline & Nutricionista da prefeitura ou estado & 36 & 44,4 \\
\hline \multirow[t]{3}{*}{ Tempo de atuação do nutricionista ${ }^{*}$} & $\leq 12$ meses & 18 & 31,6 \\
\hline & 13 meses -4 anos & 26 & 45,6 \\
\hline & $\geq 5$ anos & 13 & 22,8 \\
\hline \multirow[t]{3}{*}{ Gestão } & Indireta & 53 & 65,4 \\
\hline & Direta & 21 & 25,9 \\
\hline & Semidireta & 7 & 8,6 \\
\hline
\end{tabular}

Fonte: Dados da pesquisa (elaborado pelas autoras).

${ }^{*} \mathrm{~N}<81$

A maioria dos restaurantes (63\%) relatou não possuir parceria com instituições para auxiliar no melhor funcionamento do RP. As parcerias mais citadas foram: Universidades ( $\mathrm{n}=22$ ); Banco de Alimentos ( $\mathrm{n}=5$ ); Programa Mesa Brasil $(\mathrm{n}=3)$; Organizações Não Governamentais $(\mathrm{ONGs})(\mathrm{n}=3)$; Conselho Nacional de Segurança Alimentar e Nutricional (CONSEA) $(\mathrm{n}=1)$; Empresa de assistência técnica 
e extensão rural (EMATER) $(\mathrm{n}=1)$; Serviço Nacional de Aprendizagem Comercial (SENAC) ( $\mathrm{n}=1)$ e empresas privadas por meio da Lei da Solidariedade $(\mathrm{n}=1)$.

Todos os restaurantes afirmaram contar com nutricionista para o planejamento dos cardápios, sendo na maioria dos casos vinculadas às empresas terceirizadas $(55,6 \%)$ e com tempo de atuação superior a um ano $(68,4 \%)$. No que se relaciona à forma de gestão dos restaurantes, a gestão indireta foi predominante $(65,4 \%)$.

A Tabela 1 apresenta dados relativos à procedência dos alimentos adquiridos e à modalidade de aquisição utilizada para a compra de alimentos pelos RP. Mais da metade dos restaurantes afirmaram possuir alimentos procedentes da AF $(53,1 \% ; n=43)$, recebidos principalmente por meio da modalidade Doação Simultânea do PAA. Todos os restaurantes que adquiriam alimentos via PAA Compra Institucional $(n=10)$ já haviam recebido ou ainda recebiam alimentos via PAA Doação Simultânea. Esses restaurantes se localizavam na região Sudeste $(n=5)$, Nordeste $(n=3)$ e Sul $(n=2)$, e a maioria $(n=6)$ era gerido pelo governo. Aqueles RP com gestão indireta que realizavam a Compra Institucional $(n=4)$ eram administrados por ONGs.

Em relação à modalidade de aquisição de alimentos, observou-se o predomínio de "dispensa de licitação" nos restaurantes geridos de forma indireta (terceirizados) e licitação nos restaurantes de gestão direta.

Tabela 1. Modalidade de aquisição e procedência dos alimentos adquiridos pelos restaurantes populares brasileiros

\begin{tabular}{l|l|l}
\hline Origem e modalidade de aquisição dos alimentos $(\mathrm{n}=81)$ & $\mathrm{n}$ & $\%$ \\
\hline Agricultura familiar & 43 & 53,1 \\
\hline PAA & 31 & 38,3 \\
\hline PAA modalidade Doação Simultânea & 31 & 38,3 \\
\hline PAA modalidade Compra Institucional & 10 & 12,3 \\
\hline Compra direta com agricultores & 11 & 13,6 \\
\hline Licitação - outros fornecedores & 1 & 1,2 \\
\hline Total & 81 & 100 \\
\hline
\end{tabular}

Fonte: Dados da pesquisa (elaborada pelas autoras).

Com a caracterização dos RP, observou-se uma maior concentração de unidades na região sudeste e uma expansão no número de unidades no país a partir do ano de 2005. Os incentivos governamentais para fomentar a compra de alimentos de agricultores locais parecem ter impactado de forma positiva 
para a incorporação da AF como fornecedora de alimentos aos restaurantes, já que todos os RP que iniciaram a compra por PAA Compra Institucional haviam participado anteriormente do programa PAA Doação Simultânea. Porém, uma grande parcela de restaurantes ainda não havia dado início ao processo de Compra Institucional.

Observou-se uma distribuição irregular do número de RP no território nacional, com maior concentração de restaurantes na região sudeste (45\%), responsável por $61 \%$ do total de refeições servidas pelos RP de todo o país. Esse resultado poderia explicar-se por essa região possuir maior densidade populacional, concentrando $42 \%$ da população brasileira ${ }^{3}$ em uma área que representa $11 \%$ do território nacional ${ }^{4}$. Porém, considerando que esta é também uma das regiões com maiores Índice de Desenvolvimento Humano (IDH) e Produto Interno Bruto (PIB) per capita do Brasil, os resultados sugerem uma desigualdade na distribuição dos equipamentos de SAN, que se traduzem em uma possível desigualdade de acesso por parte das populações mais vulneráveis, público-alvo desses equipamentos.

$O$ fato de que a maioria dos RP pesquisados (87\%) foram implantados nos últimos dez anos chama a atenção, evidenciando a reconhecida centralidade dada pelo governo federal a partir de 2003 para as estratégias direcionadas à garantia do acesso à alimentação para toda a população do País. Estratégias que, juntamente às políticas econômicas, levaram à diminuição inédita no número de pessoas em situação de insegurança alimentar e nutricional (FAO, 2015).

Ultrapassando a dimensão do consumo, as políticas públicas de SAN brasileiras vêm fomentando a disponibilidade de alimentos por meio de ações direcionadas à garantia de mercado aos agricultores familiares, utilizando para isso a demanda dos equipamentos públicos de SAN. Ainda que os resultados indiquem a participação da AF como fornecedora de alimentos em grande parte dos RP brasileiros, observa-se também o predomínio de outros fornecedores. Resultados similares são observados no âmbito do Programa Nacional de Alimentação

3 IBGE. Estimativas de população no dia $1^{\circ}$ de julho de 2015. Disponível em: <http://www.ibge.gov.br/home/estatistica/populacao/estimativa2015/estimativa_tcu.shtm>. Acesso em: 10 jul. 2016.

4 IBGE. Área Territorial Brasileira. Disponível em: <http://www.ibge.gov.br/home/geociencias/cartografia/default_territ_area.shtm>. Acesso em: 10 jul. 2016. 
Escolar (PNAE) e comprometem o desenvolvimento de sistemas agroalimentares locais saudáveis e sustentáveis (SARAIVA, 2013).

Reconhece-se que a implementação do PAA em 2003 favoreceu a inclusão de alimentos da agricultura familiar nos equipamentos públicos de alimentação e nutrição no país. No entanto, o curto período de tempo transcorrido entre a implantação da modalidade Compra Institucional e a coleta de dados deste estudo e o fato de que o PAA Doação Simultânea não possuía recurso fixo para a sua execução, poderiam explicar a baixa participação da AF no abastecimento de alimentos do RP.

Ainda assim, os resultados sugerem que o PAA Doação Simultânea representa um fator promotor para a implementação do PAA Compra Institucional. Isso porque nossos resultados evidenciaram que os dez restaurantes que iniciaram a Compra Institucional da AF tinham experiências prévias com a modalidade Doação Simultânea.

A efetivação da aquisição de alimentos da AF por restaurantes apresenta dificuldades comuns a várias instituições. Visando superar essas dificuldades e auxiliar no planejamento e operacionalização da compra, observa-se a necessidade de instrumentalização dos atores envolvidos. Dessa forma foram propostas estratégias para auxiliar no processo de implementação da compra de alimentos da AF, elaboradas com base na experiência dos pesquisadores na realização de pesquisas direcionadas para compra de alimentos da agricultura familiar por equipamentos públicos de alimentação (CAVALLI, 2012; 2014; 2015; SOARES et al., 2015). Salienta-se que a sistemática sugerida não se aplica exclusivamente a restaurantes populares e pode ser utiliza em outras instituições.

\section{Operacionalização da compra pública de alimentos da agricultura familiar para restaurantes institucionais}

O processo de compra foi detalhado em 13 etapas, resumidamente divididas em três fases de ações: Adequação entre oferta e demanda; Efetivação da Compra Institucional; Qualificação da entrega de produtos. A Figura 2 apresenta as etapas incluídas em cada fase de execução da compra pública de alimentos. 
Figura 2. Fases e etapas para a execução da compra pública de alimentos

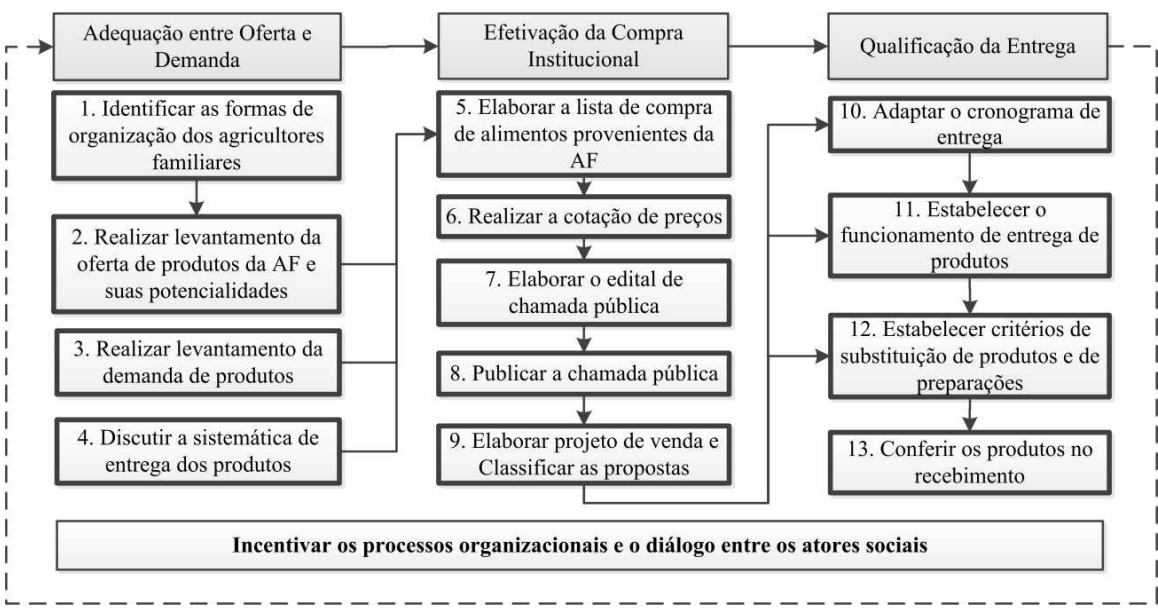

Fonte: Projetos de pesquisa e extensão sobre a temática (elaborada pelas autoras).

\section{Fase 1: Adequação entre oferta e demanda}

A compra de alimentos de produtores locais consiste em uma ferramenta para a inclusão social, que permite o acesso a mercados estáveis por parte de agricultores familiares. No entanto, a adequação entre oferta e demanda pode representar uma barreira para a integração da AF na cadeia de abastecimento alimentar de restaurantes institucionais. Estudos prévios referem a necessidade de realizar o mapeamento da produção agrícola previamente a elaboração dos cardápios e da chamada pública (SOARES et al., 2015). Nesse sentido, visando um maior alcance dos resultados do programa, recomenda-se inicialmente a realização das etapas 1 a 4 (Figura 3). 
Figura 3. Etapas, operacionalização e atores envolvidos na fase de adequação entre oferta e demanda de alimentos para a aquisição institucional de alimentos da agricultura familiar

\begin{tabular}{|c|c|}
\hline $\begin{array}{l}\text { Realizar levantamento } \\
\text { da oferta }\end{array}$ & $\begin{array}{l}\text { Discutir sistemática de entrega } \\
\text { dos produtos }\end{array}$ \\
\hline $\begin{array}{l}\text { - Realizar levantamento dos } \\
\text { produtos que poderiam ser } \\
\text { ofertados: O que produz? } \\
\text { Quanto produz? Quando } \\
\text { produz? } \\
\text { - Listar os alimentos produzi- } \\
\text { dos e os que possam vir a ser } \\
\text { cultivados no município e/ou } \\
\text { municípios próximos (utilizar } \\
\text { lista na etapa 4); } \\
\text { - Elaborar mapeamento de } \\
\text { plantio e programas de pro- } \\
\text { dução. }\end{array}$ & $\begin{array}{l}\text { - Explicar o funcionamento da entrega } \\
\text { de produtos: quantidade de cada tipo de } \\
\text { produto por entrega; frequência de } \\
\text { recebimento; forma de entrega (proces- } \\
\text { sado, minimamente processado, in } \\
\text { natura); } \\
\text { - Caracterizar as estruturas de armaze- } \\
\text { namento das unidades atendidas e das } \\
\text { unidades familiares de produção; } \\
\text { - Discutir possibilidade de adequação } \\
\text { da entrega de cada item; } \\
\text { Fomentar a articulação dos agricultores } \\
\text { familiares para entrega de produtos. }\end{array}$ \\
\hline
\end{tabular}

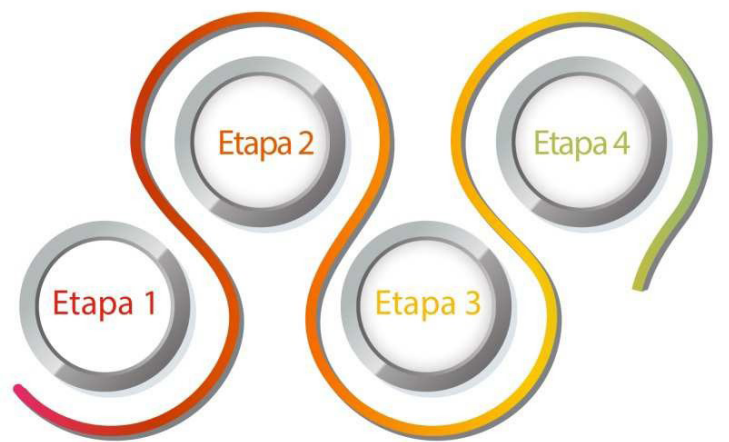

Agentes envolvidos

Nutricionistas Cozinheiros

Assistência técnica Secretaria de agricultura Organizações de agricultores ONGS Universidade Controle social

\section{IIdentificar agricultores}

- Realizar o levantamento de fornecedores de alimentos junto aos órgãos representantes da classe, as cooperativas/associações do município e aos grupos de agricultores informais;

- Realizar oficinas de socialização e integração dos envolvidos e reuniões com agricultores ou grupo de agricultores interessados no fornecimento de alimentos; - Promover debates visando auxiliar na compreensão sobre a modalidade de compra.

\section{Realizar levantamento da demanda}

- Identificar a quantidade e a variedade dos alimentos adquiridos pelas instituições: O que consome? Quanto consome? Quando consome? Discutir a possibilidade de consumo de variedades produzidas na região;

- Discutir as exigências das especificações quanto as características de qualidade do produto (tamanho, variedade, aparência, dente outros);

- Considerar a demanda das instituições no planejamento da produção, respeitando a sazonalidade, o manejo sustentável, a cultura, os hábitos alimentares e as tradições do local.

Elaborar e/ou adequar os cardápios de acordo com a oferta de produtos da agricultura familiar, respeitando a sazonalidade, o manejo sustentável, a cultura, os hábitos alimentares e as tradições do local. 
Para garantir que um maior número de agricultores tenha acesso aos mercados institucionais torna-se relevante identificar as diferentes formas de organização dos agricultores (cooperativas, associações ou grupos informais) (etapa 1) de cada região. Mapear os produtores da região e estabelecer contato com os mesmos desde o início do processo de compra auxilia na efetivação, ampliação e continuidade da compra. Nesse processo, tanto organizações governamentais (assistência técnica), como não governamentais (sindicatos), podem representar importantes parceiros na identificação de produtores, principalmente de agricultores menos estruturados.

Além disso, sabe-se que o abastecimento institucional requer uma demanda contínua de grandes quantidades de alimentos que os pequenos agricultores podem ter dificuldade em atender (VIEIRA; DEL GROSSI, 2010). Por esse motivo, as cooperativas e associações possuem um papel fundamental (MULLER, 2007). O cooperativismo dos agricultores também pode auxiliar no fornecimento de demandas específicas, como de vegetais e frutas pré-processados - higienizados e picados - MARTINELLI et al., 2015) ou outros alimentos com algum grau de beneficiamento/processamento, na logística de entrega e no fornecimento de grandes quantidades de alimentos. Porém, algumas regiões podem não possuir um tecido social amplamente estruturado para atender a demanda institucional de alimentos. Nesse sentido, torna-se necessário incentivar os processos organizacionais, em que o poder público, associado a organizações não governamentais, representa atores-chave. Trata-se de uma etapa transversal a todas as demais, cujo objetivo é ampliar tanto o número de agricultores familiares envolvidos, como a diversidade de oferta de produtos, além de fortalecer o setor agrícola familiar por meio do auxílio para criação de agroindústrias familiares (incentivos técnicos e financeiros) e do desenvolvimento dos fornecedores.

Após a identificação dos agricultores familiares e suas organizações, torna-se necessário realizar o levantamento da oferta de produtos da AF e de suas potencialidades (etapa 2). Essa etapa permite conhecer a realidade do sistema produtivo da região, aproximando produtores e consumidores e favorecendo o estabelecimento de relação de confiança e parceria (TRICHES; SCHNEIDER, 2010). Com isso cria-se uma oportunidade para o planejamento da produção e para adaptações dos cardápios, a curto e médio prazo, às características produtivas da região. Nessa etapa do processo é possível conhecer a disponibilidade de alimentos nas diferentes épocas do ano (sazonalidade), o que possibilita a 
construção de um calendário agrícola que oriente o planejamento e a adaptação dos cardápios à variedade de alimentos regionais e à realidade produtiva local. Essa ação pode refletir em uma maior variabilidade dos cardápios das instituições (CAVALLI et al., 2012) com consequências positivas ao meio ambiente, dada a manutenção da biodiversidade local. Além disso, espera-se que essa etapa auxilie na redução de chamadas públicas "desertas", com pequena variedade de alimentos e/ou compostas por alimentos que não são produzidos na região

Por outro lado, para realizar a adequação entre a oferta e a demanda de alimentos também é importante realizar o levantamento da demanda de produtos (etapa 3). Assim, será possível não somente que o cardápio planejado corresponda à produção agrícola (etapa 2), como também que o produtor se organize para atender demandas específicas a médio e longo prazo, planejando a produção e ampliando a oferta de produtos. Essa etapa possibilita identificar, além das variedades consumidas, as quantidades necessárias de cada alimento. Essas informações devem ser contrastadas com a oferta de alimentos da AF, o que possibilitará definir os alimentos a serem comprados e, quando necessário, desenvolver estratégias para complementar a compra de uma parcela de produtos de outros agricultores e/ou fornecedores.

A distribuição dos produtos pelos agricultores aos diferentes equipamentos públicos de SAN apresenta-se como outra possível dificuldade para a integração da $\mathrm{AF}$ como fornecedora de alimentos. Isso porque muitas vezes eles não dispõem da infraestrutura necessária para o armazenamento e transporte dos produtos. Ainda que se reconheça a necessidade de apoio financeiro das administrações públicas para infraestrutura de distribuição dos produtos, a aproximação e o diálogo entre gestores e produtores podem auxiliar na busca de soluções viáveis para a execução do programa. Desse modo, é importante discutir a sistemática de entrega dos produtos (etapa 4). Nessa etapa, a frequência e a época de entrega devem ser consideradas e debatidas, assim como o local e o dia de entrega dos produtos. A frequência de entrega vai depender da estrutura de armazenamento das instituições e da disponibilidade de transporte. Trata-se de uma etapa chave para o sucesso da compra pública de alimentos da AF, dada a sua implicação na construção dos cardápios e na definição dos preços dos produtos (cobrir possíveis gastos de transportes). A definição da sistemática de distribuição deve ser construída por meio do diálogo entre os agentes envolvidos, analisando as possibilidades de parcerias para a entrega dos produtos. 
Como resultado dessa primeira fase (etapas de 1 a 4), espera-se a construção de cardápios adaptados às características produtivas da região e a oferta de alimentos da AF (quantidade, variedade e frequência de entrega).

\section{Fase 2: Efetivação da Compra Institucional}

A segunda fase está relacionada ao processo de efetivação da compra institucional (Figura 4). Os órgãos compradores, familiarizados com o processo licitatório, podem enfrentar dificuldades para a elaboração e compreensão do funcionamento da chamada pública. Isso porque, diferente da licitação, a chamada pública é dirigida a um grupo específico de fornecedores: os agricultores familiares. A realização de seminários/oficinas de sensibilização e instrumentalização dos responsáveis pela compra de alimentos pode auxiliar a construção dos editais. 
Figura 4. Etapas, operacionalização e atores envolvidos na fase de efetivação da compra institucional de alimentos da Agricultura Familiar

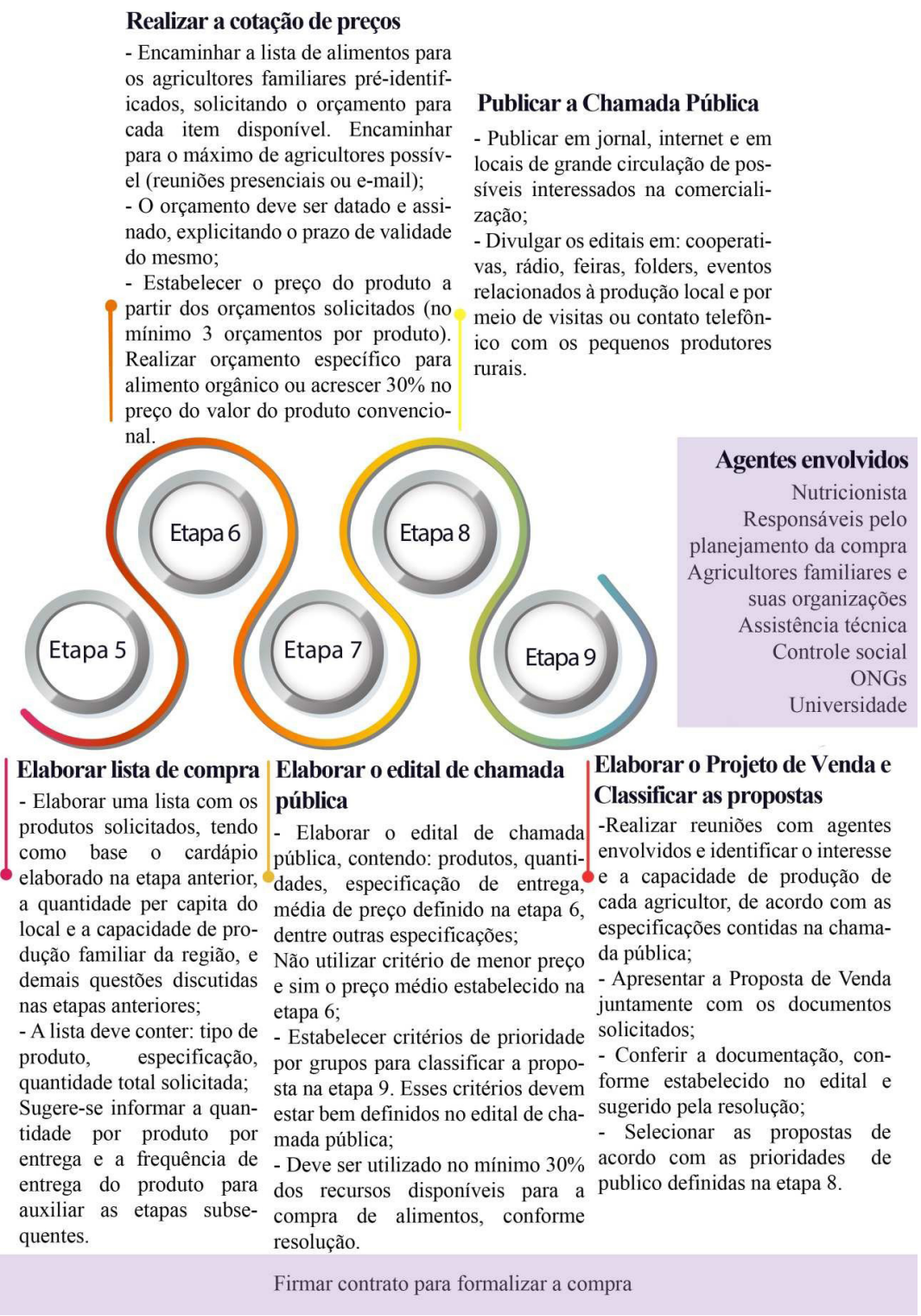


A etapa 5 consiste em elaborar a lista de compra de alimentos provenientes da agricultura familiar, ou seja, definir os produtos que comporão a chamada pública. É fundamental que essa etapa seja realizada a partir das informações discutidas nas etapas anteriores. A lista final de alimentos deve, portanto, ser resultado do processo de adequação dos cardápios para incorporar alimentos ofertados pela AF e também contemplar as demandas específicas do órgão comprador que podem ser atendidas pelo pequeno produtor. Deve conter especificações em termos de qualidade do produto, descritas o mais próximo possível da realidade produtiva da agricultura familiar, visando fomentar sistemas agrícolas sustentáveis, a exemplo da produção agroecológica, é importante evitar restrições quanto ao tamanho e ao formato do produto. Isso porque as especificidades desse sistema produtivo podem não adequar-se aos padrões hegemônicos de qualidade exigidos pelo mercado no que se refere às características físicas dos alimentos. Porém, o estímulo à aquisição de alimentos agroecológicos vai ao encontro da promoção da SAN, não somente pela oferta produtos sem adição de compostos químicos prejudiciais, como também pela superioridade nutricional de seu conteúdo (BARANKSI et al., 2014). Ao mesmo tempo, contribui para a conservação ambiental e manutenção da biodiversidade (TUOMISTO et al., 2012). A lista elaborada deverá ser encaminhada aos agricultores para realização da etapa seguinte.

O processo de compra via chamada pública surgiu com o intuito de facilitar a compra de alimentos de agricultores familiares, uma vez que eles não dispõem de condições em termos de estruturas e capacidade de produção para concorrer com grandes empresas no processo licitatório, cujo principal critério de compra é o menor preço. Nessa perspectiva, a elaboração do edital de chamada pública deve realizar a cotação de preços para os produtos (etapa 6) junto aos agricultores familiares pré-identificados nas etapas 1,2 e 3 . O preço estabelecido para cada produto deve ser determinado com base na realidade da $\mathrm{AF}$ e não com base em outros fornecedores. Para cada produto são necessários orçamentos de, pelo menos, três fornecedores familiares. O preço que constará no edital de chamada pública será a média de preço desses fornecedores. Na impossibilidade de realizar orçamento específico para os alimentos provenientes de produção orgânicos/ agroecológicos, deve-se acrescentar $30 \%$ ao valor dos produtos convencionais (BRASIL, 2012). Além disso, a definição final do preço deve considerar os gastos com a distribuição dos produtos, que vai variar segundo a sistemática definida em cada região, estabelecida pela execução da etapa 4 . 
De posse dessas informações é necessário elaborar o edital de chamada pública (etapa 7). As principais dificuldades podem estar relacionadas ao pouco conhecimento dos gestores em relação ao funcionamento da modalidade. Essa etapa deve ser realizada seguindo as normativas vigentes e utilizando como base as chamadas públicas já realizadas por outras instituições. Tendo em vista a inclusão dos grupos produtivos mais vulneráveis, e/ou de agricultores da região, destaca-se nesse processo a importância de estabelecer os grupos prioritários que devem ser considerados para a classificação das propostas ${ }^{5}$.

A etapa seguinte consiste em publicar a chamada pública (etapa 8) para possibilitar a participação de um maior número de agricultores. Para alcançar esse objetivo, recomenda-se a publicação em diversos meios de comunicação e em espaços com grande circulação de pessoas. Paralelamente, a chamada pública deve ser encaminhada ao Ministério de Desenvolvimento Agrário (MDA) ${ }^{6}$ para que seja publicada no site do governo. Essa é uma atividade de responsabilidade do departamento de compras da instituição, porém a participação de outros agentes, como os órgãos de assistência técnica e as organizações de agricultores, pode garantir uma maior difusão da informação.

A etapa 09 consiste em elaborar o projeto de venda e classificar as propostas, conforme os critérios de prioridade estabelecidos no edital de chamada pública. Os agricultores familiares interessados em participar da chamada pública necessitam, nesse momento, elaborar o projeto de venda de alimentos para as instituições. O projeto deve ser elaborado pelos agricultores, preferencialmente por meio de suas organizações e com apoio de órgãos de assistência técnica. Em reuniões com os agricultores interessados devem-se definir as quantidades e variedades que cada participante poderia produzir para um determinado período, considerando as especificações contidas na chamada pública, respeitando a capacidade produtiva de cada participante e a frequência de entrega. $\mathrm{O}$ documento deve conter ainda, a identificação dos participantes e os valores a serem cobrados pelos produtos. Junto à proposta de venda, devem ser apresentados os

\footnotetext{
5 Sugere-se a priorização de agricultores locais. Dentre esses, sugere-se a classificação das propostas respeitando a seguinte ordem de priorização: $1^{\circ}$ assentados de reforma agrária, comunidades tradicionais indígenas e comunidades quilombolas; $2^{\circ}$ fornecedores de gêneros alimentícios orgânicos ou agroecológicos, $3^{\circ}$ organizações com DAP Jurídica; $4^{\circ}$ Organizações formais que apresentarem maior porcentagem de agricultores familiares e/ou empreendedores familiares rurais locais, seguidos por maior número do território rural, estado e país. Grupo de mulheres deve ter prioridade sobre os demais critérios.

6 Encaminhar para paa@mda.gov.br
} 
documentos exigidos para participação na chamada pública, conforme legislação vigente (BRASIL, 2012a; b). Ressalta-se que o limite de venda por agricultor por ano é independente da participação em outras modalidades do PAA. A classificação da proposta se dará com base nos critérios de prioridade estabelecidos no edital de chamada pública.

\section{Fase 3: Qualificação da entrega de produtos}

Após a classificação dos fornecedores se iniciará a fase de organização para qualificação da entrega dos produtos (Figura 5). Nesse momento, é necessário adaptar o cronograma de entrega (etapa 10) e estabelecer o funcionamento da entrega (etapa 11). A adequação conjunta e periódica de um cronograma de entrega possibilita que toda a variedade e quantidade de produtos sejam entregues, reduzindo problemas como falta, sobras e substituição de produtos. Além disso, maximiza a eficiência do processo e garante a entrega em quantidade e variedade necessárias, a qualidade do produto pela redução do tempo de transporte e permite ainda a organização da produção por parte dos agricultores. 
Figura 5. Etapas, operacionalização e atores envolvidos na fase de qualificação da entrega de alimentos da agricultura familiar em restaurantes institucionais

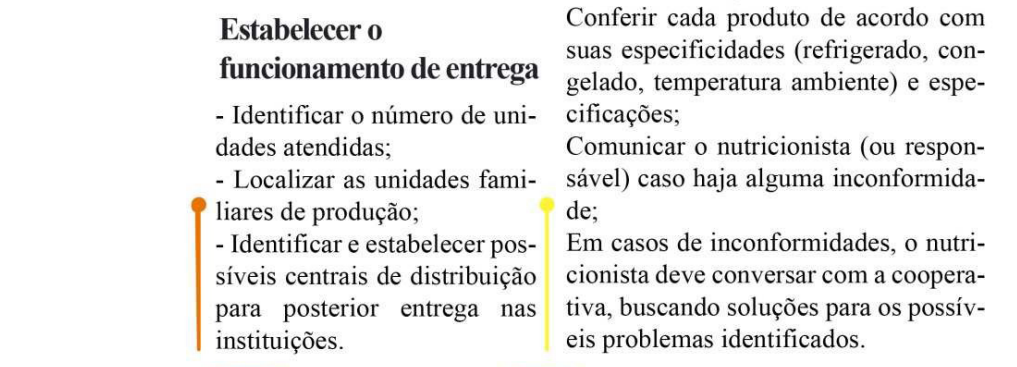

\section{Conferir os produtos no recebimento}

Conferir os produtos de acordo com o cronograma e com o termo de aceite; Utilizar lista de substituição previamente elaborada para avaliar a possibilidade de alterações;

Estabelecer o funcionamento de entrega

- Identificar o número de unidades atendidas;

- Localizar as unidades familiares de produção

entificar e estabelect para posterior entrega nas instituições
Conferir cada produto de acordo com specificidades (refrigerado, congelado, temperatura ambiente) e especificações de;

Em casos de inconformidades, o nutrieis problemas identificados.

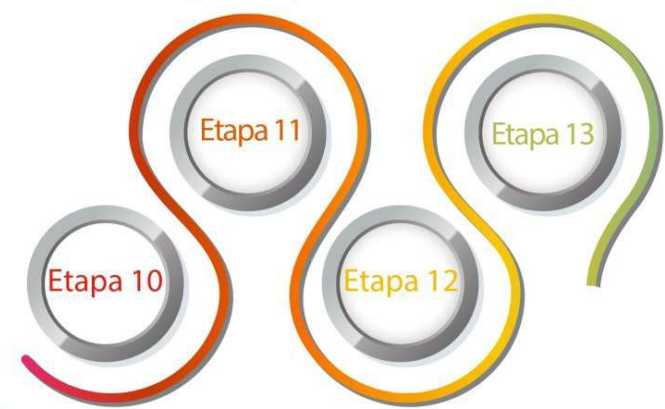

Agentes envolvidos

Nutricionista

Cozinheiros

Organizações de agricultores Assistência técnica

Controle social Estoquista

Entregadores Universidade

\section{Adaptar o cronograma de entrega}

- Realizar reuniões com os agricultores selecionados para o planejamento da entrega;

- Estabelecer datas para entrega dos produtos, considerando a capacidade de produção, a sazonalidade e a necessidade da instituição com base nos cardápios elaborados e o número de indivíduos atendidos pela instituição;

- Considerar questões discutidas na etapa 4.

\section{Estabelecer critérios de substituição de produtos e de preparações}

- Elaborar lista de substituição específica de acordos com os alimentos produzidos na região, levando em conta as características nutricionais dos alimentos e grupos de alimentos;

- Elaborar uma lista com regras de substituição para as preparações, levando em conta as características nutricionais e sensoriais de cada preparação. 
No entanto, a definição e constante adaptação do cronograma de entrega não evita possíveis substituições de produtos. Dessa forma, definir os critérios de substituição de produtos e de preparações (etapa 12) auxilia na manutenção das características nutricionais e sensoriais das refeições servidas, mesmo com a ocorrência de possíveis problemas relacionados à entrega de alimentos. Sabe-se que a produção agrícola pode sofrer com intempéries climáticas que levam a perda da produção. Essa etapa possibilitará aos produtores a continuidade na comercialização de seus produtos mesmo com a ocorrência de problemas na produção de determinado alimento. O nutricionista da instituição deve definir quais as possibilidades de modificações no cardápio sem prejuízos à qualidade da refeição. Isso pode vir a partir de critérios nutricionais e sensoriais como hortaliças folhosas por folhosas (alface por repolho, por exemplo ${ }^{7}$ ), evitando substituições que alterem amplamente o cardápio, como folhoso por tubérculo.

Por fim, a etapa 13 refere-se a conferir os produtos no momento da entrega. Essa etapa visa auxiliar na garantia da qualidade dos produtos entregues e na resolução de problemas a curto e médio prazo. Desse modo, é importante que seja elaborado um roteiro de recebimento que contenha as exigências definidas nas etapas anteriores, bem como as possibilidades de substituição. Em caso de dúvidas o responsável pelo recebimento deve contatar o responsável técnico da unidade. Por outra parte, nessa etapa os agricultores devem apresentar o termo de aceite de seus produtos, que deve ser conferido e assinado pelo responsável pelo recebimento, esse termo representará o comprovante do fornecimento para o agricultor.

\section{Considerações finais}

A instauração de políticas públicas de compra direta de alimentos da agricultura familiar para o abastecimento dos equipamentos públicos de segurança alimentar e nutricional não garante a sua implementação, mas representa um ponto de partida para a incorporação dos agricultores ao fornecimento de alimentos a esses equipamentos. Nesse sentido, ainda que o PAA institucional tenha um alcance limitado, auxiliou a incorporação da AF a uma parcela de RP (em

\footnotetext{
7 Sugere-se o uso da classificação proposta por Borjes et al. (2010) para estabelecer as possibilidades de substi-
} tuição dos produtos. 
que pese o curto período de sua implementação). No entanto, são necessárias outras estratégias que propiciem maior protagonismo à $\mathrm{AF}$ no abastecimento institucional de alimentos, como a desburocratização do processo.

Considerando a importância da compra pública de alimentos para a construção do sistema alimentar, a sistemática apresentada neste capítulo para a efetivação da compra de alimentos aos agricultores locais pode ajudar a sua implementação e, assim, contribuir para a transformação do sistema alimentar globalizado atual em um sistema localizado, sustentável e saudável. Salienta-se que as etapas apresentadas objetivam auxiliar o processo de implementação da compra de alimentos de agricultores locais, no entanto outras estratégias podem ser desenvolvidas e/ou adaptadas à realidade de cada região.

\section{REFERÊNCIAS}

BARAŃSKI, M. et al. Higher antioxidant and lower cadmium concentrations and lower incidence of pesticide residues in organically grown crops: a systematic literature review and meta-analyses. British Journal of Nutrition, v. 112, n. 5, p. 794-811, 2014.

BORJES, L.C.; CAVALLI, S. B.; PROENCA, R. P. C. Proposta de classificação de vegetais considerando características nutricionais, sensoriais e de técnicas de preparação. Revista de Nutrição, Campinas, v. 23, n. 4, p. 645-654, 2010.

BRASIL. Ministério do desenvolvimento e combate à fome. Manual Programa Restaurante Popular. Brasília: 2004.

BRASIL. Decreto ${ }^{\circ}$ 7.775, de 4 de julho de 2012. Regulamenta o art. 19 da Lei $n^{\circ}$ 10.696, de 2 de julho de 2003, que institui o Programa de Aquisição de Alimentos, e o Capítulo III da Lei no 12.512, de 14 de outubro de 2011, e dá outras providências. Diário Oficial da União: Brasília, 05 jul 2012a.

Resolução no 50, de 26 de setembro de 2012. Dispõe sobre a sistemática de funcionamento da modalidade de execução Compra Institucional, no âmbito do Programa de Aquisição de Alimentos da Agricultura Familiar (PAA). Diário Oficial da União: Brasília, 27 set 2012b.

Ministério do Desenvolvimento Agrário. Segurança Alimentar. Sistemas Agroalimentares Locais. 2013. Disponível em: <http://www.mds.gov.br/ segurancaalimentar/sistemas-publicos-agroalimentares $>$. Acesso em: 10 nov. 2013.

. Decreto $\mathrm{n}^{\circ}$ 8.473, de 22 de junho de 2015. Estabelece, no âmbito da Administração Pública federal, o percentual mínimo destinado à aquisição de gêneros alimentícios de agricultores familiares e suas organizações, empreendedores familiares 
rurais e demais beneficiários da Lei $\mathrm{n}^{\circ} 11.326$, de 24 de julho de 2006, e dá outras providências. Brasília: Diário Oficial da União, 23 jun 2015.

CAVALLI, S. B. Projeto aprovado: Qualidade da alimentação escolar a partir do fornecimento de alimentos da agricultura familiar: um estudo multicêntrico na região sul do Brasil. Florianópolis: Universal MCTI/CNPq No 14/2012. Processo $n^{\circ}$ 483184/2012-8 2012.

CAVALLI, S. B. et al. Planejamento e operacionalização do fornecimento de vegetais e frutas pelo Programa de Aquisição de Alimentos para a alimentação escolar. In: Ministério do Desenvolvimento Social e Combate à Fome (Org.). Avaliação de políticas públicas: reflexões acadêmicas sobre o desenvolvimento social e o combate à fome. Brasília: Ministério do Desenvolvimento Social e Combate à Fome, 2014. p. 186-207.

CAVALLI, S. B. et al. Abastecimento do Restaurante Universitário da UFSC com alimentos da agricultura familiar: instrumentalização dos agentes envolvidos. Projeto de Extensão - Departamento de Nutrição, Universidade Federal de Santa Catarina, Florianópolis, 2013-2017.

COLEY, D.; HOWARD, M.; WINTER, M. Local food, food miles and carbon emissions: A comparison of farm shop and mass distribution approaches. Food Policy, v. 34, n. 2, p. 150-5, 2009.

CERUTTI, A. K.; CONTU, S.; ARDENTE, F.; DONNO, D.; BECCARO, G. L. Carbon footprint in green public procurement: Policy evaluation from a case study in the food sector. Food Policy, v. 58, p. 82-93, 2016.

DAROLT, M. R.; LAMINE, C.; BRANDEMBURG, A. A diversidade dos circuitos curtos de alimentos ecológicos: ensinamentos do caso brasileiro e francês. Agriculturas, v. 10, n. 2, p. 5, 2013.

FABRI, R.K. Uso de alimentos regionais da agricultura familiar na alimentação escolar. Programa de Pós Graduação em Nutrição (Dissertação de Mestrado). Universidade Federal de Santa Catarina. 291p.

FAO. Organización de las Naciones Unidas para la alimentación y la agricultura (FAO). El estado de la inseguridad alimentaria en el mundo. Cumplimiento de los objetivos internacionales para 2015 en relación con el hambre: balance de los desiguales progresos. Roma: 2015.

FAO. Organização das Nações Unidas para a Alimentação e a Agricultura. Superação da fome e da pobreza rural - Iniciativas brasileiras. Brasília: Organização das Nações Unidas para a Alimentação e a Agricultura, 2016.

FORNAZIER, A.; BELIK, W. Produção e consumo local de alimentos: novas abordagens e perspectivas para as políticas públicas. Segurança Alimentar e Nutricional, v. 20, n. 2, p. 204-18, 2013. 
GLIESSMAN, S. R. Agroecologia: processos ecológicos em agricultura sustentável. Porto Alegre: UFRGS, 2001.

MARTINELLI, S. S.; SOARES, P.; FABRI, R. K.; CAMPANELLA, G. R. A.; ROVER, O. J.; CAVALLI, S. B. Potencialidades da compra institucional na promoção de sistemas agroalimentares locais e sustentáveis: o caso de um restaurante universitário. Segurança Alimentar e Nutricional, v. 22, n. 1, p. 558-73, 2015.

MÜLLER, A. L.; FIALHO, A. V.; SCHNEIDER, S. A inovação institucional e a atuação dos atores locais na implementação do Programa de Aquisição de Alimentos no Rio Grande do Sul. Sociedade e Desenvolvimento Rural, v. 1, n.1, p.1-21, 2007.

RAYNER, G. et al. Trade liberalization and the diet transition: a public health response. Health Promotion International, v 21 (suppl1), p. 67-74, 2006.

SARAIVA, E. B. et al. Panorama da compra de alimentos da agricultura familiar para o Programa Nacional de Alimentação Escolar. Ciência \& Saúde Coletiva, v. 18, n. 4, p. 927-935, 2013.

SOARES, P. Análise do Programa de Aquisição de Alimentos na alimentação escolar em um município de Santa Catarina. 2011. 240p. Dissertação (Mestrado) - Programa de Pósgraduação em Nutrição, Universidade Federal de Santa Catarina, Florianópolis, 2011.

SOARES, P. et al. Potencialidades e dificuldades para o abastecimento da alimentação escolar mediante a aquisição de alimentos da agricultura familiar em um município brasileiro. Ciência \& Saúde Coletiva, v. 20, p. 1891-900, 2015.

SONNINO, R.; TORRES, C. L.; SCHNEIDER, S. Reflexive governance for food security: The example of school feeding in Brazil. Journal of Rural Studies, v. 36, p. $1-12,2014$.

VIEIRA, D. F. A.; DEL GROSSI, M. E. Influência do programa de aquisição de alimentos na comercialização dos produtos da agricultura familiar: o caso do município de Paracatu em Minas Gerais. Sociedade e Desenvolvimento Rural, v. 4, n. 2, p. 21-48, 2010.

TRICHES, R. M.; SCHNEIDER, S. Alimentação escolar e agricultura familiar: reconectando o consumo à produção. Saúde sociedade, v. 19, n. 4, p. 933-945, 2010.

TUOMISTO, H. L. et al. Does organic farming reduce environmental impacts? - A meta-analysis of European research. Journa lof Environmental Management, v. 112, p. 309-20, 2012. 


\section{PARTE 3}

FORMAS ALTERNATIVAS DE ABASTECIMENTO 


\title{
Grupos de consumo responsável no Brasil: aproximando consumidores e produtores em redes agroecológicas e solidárias
}

\author{
Juliana Gonçalves \\ Thais Mascarenhas
}

\section{Introdução}

Este capítulo aborda os circuitos curtos agroalimentares sob a ótica dos grupos de consumo responsável (GCRs) no Brasil e se propõe a discutir a interdependência entre os elos da cadeia de abastecimento de alimentos, refletindo sobre as limitações do modelo convencional e possibilidades de ressignificá-lo, por meio de relações mais justas e solidárias, da produção ao consumo. Aponta os GCRs no Brasil como uma alternativa aos circuitos alongados de abastecimento, apresentando seu histórico, principais características e o fortalecimento de suas práticas por meio da articulação de redes no âmbito nacional e na região metropolitana de São Paulo.

No debate sobre os atuais sistemas alimentares e circuitos de comercialização, muitas iniciativas da sociedade civil, como os grupos de consumo responsável, vêm surgindo na perspectiva de aproximar consumidores e produtores. Nos grandes supermercados, o alimento é comercializado de maneira padronizada e os cidadãos pouco sabem sobre sua origem e modo de produção. Em contraponto, muitas pessoas vêm se questionando sobre o caminho do alimento até chegarem às suas mesas. Assim, os GCRs buscam encurtar as cadeias e atingir preços mais justos, em uma relação de confiança com os produtores e apoio mútuo. 
Ao refletir sobre as relações predominantes na cadeia de abastecimento de alimentos e a consequente crise agroalimentar mundial, percebe-se a necessidade de promover alternativas para transformar esse cenário. No entanto, na mesma medida em que se reconhece o potencial transformador dos GCRs, assim como tantas outras experiências na lógica dos circuitos curtos agroalimentares, é preciso ponderar suas limitações, pois há um conjunto de fatores que restringem a capacidade de fortalecimento e multiplicação dessas experiências. São dificuldades como: concentração de informação e poder na mão de poucos atores da cadeia; falta e descontinuidade de assistência técnica para transição agroecológica na produção e investimento tecnológico; promessa da reforma agrária; carência de massa crítica; mobilização da sociedade civil, entre outras. Nesse sentido, para fortalecer e multiplicar experiências como os grupos de consumo, a discussão sobre a cadeia de abastecimento de alimentos deve passar a ocupar um lugar de maior destaque nas relações comunitárias, no planejamento das políticas públicas, nas universidades, para que o Estado e o conjunto da sociedade tenham maior comprometimento com a segurança alimentar e nutricional estabelecendo relações mais saudáveis nos ambientes rural e urbano. No entanto, é preciso disposição para promover os enfrentamentos necessários.

\section{Da produção ao consumo, um olhar para além das relações comerciais}

Para um alimento chegar à mesa do consumidor são muitos os caminhos que precisa percorrer. Esse percurso envolve relações humanas, sua interação com o ambiente e as diferentes atitudes entre os envolvidos influenciarão os efeitos dessa trajetória. Olhando para a cadeia de abastecimento de alimentos, verificamos que a organização do trabalho pode ser mais hierárquica ou horizontal, o princípio de igualdade pode ou não ser considerado para remunerar homens e mulheres e a mão de obra infantil pode ou não estar envolvida. $O$ manejo dos recursos naturais pode respeitar a sazonalidade, a biodiversidade local, a conservação do solo e da água ou adotar outros parâmetros. A comercialização pode concentrar-se na mão de poucas grandes redes de supermercados ou ser organizada pelos produtores, por meio de uma relação mais horizontal e próxima 
do consumidor final. E o consumidor, quando decide o que comprar e onde comprar, pode apoiar cadeias mais ou menos solidárias.

É certo que tais lógicas são complexas, influenciadas por vários fatores, podendo assumir diferentes contornos. No entanto, sabe-se que o modelo convencional, baseado nas grandes escalas e na concentração de capital, é movido por um conjunto de práticas cujo resultado quase sempre remunera mal o agricultor familiar e oferece alimentos com alta quantidade de agrotóxicos ao consumidor final ou ainda produtos orgânicos a preços elevados. As multinacionais que controlam cada elo da cadeia agroalimentar predominante, fruto de um modelo liberalizado e desregulamentado, contam com apoio das elites políticas e instituições internacionais, colocando o lucro à frente da segurança alimentar e respeito ao ambiente (VIVAS \& MONTAGUT, 2011, p.38).

São muitas as relações envolvidas da produção ao consumo para promover o acesso à alimentação saudável e a valorização dos trabalhadores do campo. Por isso se faz necessário discutir produção, beneficiamento, distribuição, comercialização e consumo a partir de uma perspectiva mais ampliada de saúde humana, das questões sociais e do campo ambiental. Na produção, a agroecologia apresenta-se como alternativa, pois busca integrar a esfera econômica às esferas ambiental, cultural e social. A agricultura familiar de base agroecológica afirma em suas práticas a função social da terra, a proteção da biodiversidade, valorizando saberes ancestrais. Na comercialização, os canais de venda direta, como as feiras e os grupos de consumo, apresentam-se como espaços alternativos de venda para essa produção agroecológica, na medida em que reduzem intermediários, buscando uma remuneração mais justa aos produtores e preços mais acessíveis aos consumidores. E na outra ponta, consumidores bem informados, críticos e engajados podem apoiar essa produção por meio da compra e de uma relação de parceria junto aos produtores. Em síntese, a compra de alimentos agroecológicos locais, em espaços alternativos de comercialização, contribui para aproximar produtores e consumidores, ressignificando relações entre campo e cidade através das trocas materiais e simbólicas envolvidas. Nessas experiências, "nem tudo o que se produz é consumo, nem tudo o que troca é mercadoria, as pessoas comem comida e símbolos e trocam bens e sentidos de vida" (BRANDÃO, 2007, p. 55).

Discutir e problematizar o tema do consumo, reconhecendo a interdependência entre os elos da cadeia de abastecimento, estimula as pessoas a intervirem 
nesse contexto. E é a partir dessa intervenção crítica que o consumo responsável pode ser entendido como um ato político. Na reflexão sobre a escolha de compra, considerando a história por trás do produto, nota-se o transbordamento da esfera política para as ações cotidianas, revelando o exercício da cidadania também no ato do consumo. Assim, a mudança no nosso consumo encontra sentido transformador enquanto parte da nossa vontade coletiva e intervenção como cidadãos.

Diante da concentração dos grandes produtores e dos grandes distribuidores, iniciativas como os GCRs, embora pouco numerosos no Brasil, representam estratégias de resistência, reconstruindo relações de mercado, resgatando uma lógica de abastecimento usual no passado mas que foi perdendo força com o tempo. Os GCRs se articulam em âmbito nacional por meio da Rede Brasileira de Grupos de Consumo Responsável, com apoio do Instituto Kairós (organização da sociedade civil que, desde 2000, trabalha com a educação para o consumo responsável) ${ }^{1}$.

\section{Grupos de consumo responsável no Brasil, experiências de autogestão para o consumo coletivo}

Os Grupos de Consumo Responsável (GCRs) são iniciativas de pessoas que questionam a lógica predominante de abastecimento alimentar e se organizam coletivamente para exercer o ato da compra de forma criteriosa, representando uma alternativa aos principais canais de comercialização encontrados no mercado. Extrapolam a esfera individual da compra, considerando aspectos como tipo de produção (agricultura familiar de base agroecológica, economia solidária, local, reforma agrária, etc.), condições de trabalho, relação com a natureza, número de intermediários entre produtor e consumidor final, remuneração dos atores envolvidos, distância geográfica, entre outros. Tais características estão presentes

1 O Instituto Kairós fomenta o consumo responsável por meio do apoio e disseminação de estratégias que facilitam o acesso a produtos da agricultura familiar e da economia solidária na perspectiva dos circuitos curtos de comercialização. Trabalha com assistência técnica para transição agroecológica e viabilidade econômica de pequenos produtores; articulação de políticas públicas e redes; e produção de conhecimento. Por meio de suas articulações, no âmbito dos circuitos curtos, contribuiu para promover algumas conquistas como a consolidação da "Feira Agroecológica do Modelódromo do Ibirapuera" e mais recentemente a aprovação da Lei Municipal 16.140/2015, que trata da obrigatoriedade da inclusão progressiva dos alimentos orgânicos na alimentação escolar da rede municipal de ensino em São Paulo. Mais informações em: <www.institutokairos.net>. Acesso em: 20 mar. 2016. 
nos grupos membros da Rede Brasileira de Grupos de Consumo Responsável, como veremos mais adiante.

Existem diversas referências sobre experiências de consumidores organizados coletivamente para aquisição de alimentos e relação direta com produtores, no Brasil e no mundo. As primeiras relatadas na modernidade são os Teikeis ${ }^{2}$, que surgem no Japão nos anos 1970 já atentos aos perigos dos agrotóxicos. Nos diferentes continentes ao redor do mundo, há pessoas no campo e na cidade, que plantam e que se alimentam, formando comunidades voltadas para outro modo de produção e consumo. CSA (Community Supported Agriculture, ou Comunidade que Sustenta a Agricultura, em muitos países), Teikei (no Japão), GAS (Gruppi di Acquisto Solidari, ou Grupos de Compra Solidária, na Itália), AMAP (Associations pour le Maintien dùne Agriculture Paysanne, ou Associação para a Manutenção de uma Agricultura Camponesa, na França), GCR, entre outras - os nomes podem ser diferentes e as práticas variarem de acordo com suas especificidades culturais, geográficas, socioeconômicas e políticas, mas a essência é a mesma: cidadãos comprometidos a compartilhar riscos e benefícios, em diferentes graus e de diferentes formas, mas alinhados na perspectiva comum de contribuir para um novo paradigma nas relações entre campo e cidade.

Surgiram no Brasil, no final da década de 1970, as primeiras iniciativas de consumidores organizados em rede para a aquisição de produtos orgânicos ${ }^{3}$. Porém, com a expansão das lojas de produtos naturais e da venda dos orgânicos nos supermercados nos anos 1990, essas iniciativas foram encerradas (CARNEIRO, 2012 , p. 40-44). No entanto, sabe-se que ex-membros hoje participam de outros GCRs ativos. Recentemente, foram identificados cerca de 25 grupos de consumo responsável ativos no Brasil ${ }^{4}$.

A maioria dessas experiências nascem articuladas com movimentos sociais, principalmente da agroecologia e da economia solidária, ao mesmo tempo em que viabilizam necessidades de escoamento da produção dos produtores familiares e dos grupos produtivos de base solidária e agroecológica. O encontro entre a economia solidária e a agroecologia está presente nessas práticas por meio

2 Inspiradas por Teruo Ichiraku, filósofo e líder de cooperativas agrícolas.

3 A Cooperativa Ecológica (Coolmeia), em Porto Alegre (RS); e a Cooperativa de Consumidores de Produtos Naturais (Coonatura), no Rio de Janeiro (RJ).

4 Além dos GCRs, há ainda no país outras iniciativas de circuitos curtos de alimentos, semelhantes aos GCRs, que estão organizados na "Rede CSA Brasil". 
de sua organização autogestionária e de critérios para a escolha dos produtos, valorizando produtores que aliam cuidados com os seres humanos e a natureza.

De modo geral, o funcionamento dos GCRs pode ser sintetizado da seguinte forma:

Na prática muitos trabalham principalmente com hortaliças provenientes do cultivo de base agroecológica e organizam semanalmente os pedidos dos consumidores para transmiti-los aos produtores; estes, por sua vez, fazem a colheita das hortaliças de acordo com a demanda; os produtos são então transportados ao local indicado na data combinada; após, os produtos entregues são organizados para que os consumidores possam buscá-los. Os ciclos de pedidos podem ser realizados de formas diversas e, para isso, cada grupo combina diferentes acordos entre os consumidores e os produtores. (INSTITUTO KAIRÓS, 2013, p. 108).

É importante, contudo, deixar claro que não existe um sistema perfeito, comum a todos os grupos, pois cada um se adapta a partir dos recursos e ausências inerentes ao seu contexto local. Nota-se, portanto, dinâmicas e formatos de funcionamento diversos. Alguns grupos optam por estabelecer uma relação mais próxima com poucos produtores (que em geral fornecem hortaliças), realizando a compra de itens variados com frequência limitada. Outros, para garantir diversidade de produtos, relacionam-se com um vasto leque de produtores dos mais diversos tipos (alimentos frescos e secos, fitoterápicos, papelaria, produtos de limpeza, etc.), tornando a gestão de pedidos mais complexa. Há também os grupos que possuem apenas um núcleo para retirada de pedidos (redes singulares) e os que contam com mais de um ponto de distribuição (redes capilares) 5 .

A aproximação entre consumidores e produtores por meio das práticas dos GCRs trazem benefícios e pressupõem compromissos para ambos. O Quadro 1 apresenta esses benefícios e compromissos.

5 Para saber mais detalhes sobre os tipos de organização em redes singulares e capilares: <http://institutokairos.net/ portfolio-items/organizacao-de-grupos-de-consumo-responsavel/>. 
Quadro 1: Aproximação entre produtores e consumidores

\begin{tabular}{|c|c|c|c|}
\hline \multicolumn{4}{|c|}{$\begin{array}{l}\text { Grupos de Consumo Responsável: } \\
\text { Aproximação que traz benefícios e compromissos para as duas pontas }\end{array}$} \\
\hline \multicolumn{2}{|l|}{ Consumidores } & \multicolumn{2}{|l|}{ Produtores } \\
\hline Benefícios & Compromissos & Benefícios & Compromissos \\
\hline $\begin{array}{l}\text { - Relação direta com } \\
\text { o produtor possibili- } \\
\text { ta conhecer a origem } \\
\text { e o modo de produ- } \\
\text { ção, valorizando o } \\
\text { produto. } \\
\text { - Redução de interme- } \\
\text { diários possibilita pre- } \\
\text { ços melhores ao con- } \\
\text { sumidor final. } \\
\text { - Aspectos como sazo- } \\
\text { nalidade e biodiversi- } \\
\text { dade local, permitem } \\
\text { ao consumidor expe- } \\
\text { rimentar alimentos } \\
\text { não convencionais. } \\
\text { - Transbordamento da } \\
\text { noção de política para } \\
\text { a esfera da participa- } \\
\text { ção coletiva. }\end{array}$ & $\begin{array}{l}\text { - Planejar suas com- } \\
\text { pras antecipadamente. } \\
\text { - Ter disponibilidade } \\
\text { para retirar sua cesta } \\
\text { em dia, horário e local } \\
\text { específico. } \\
\text { - O consumidor não } \\
\text { será abastecido com } \\
\text { os mesmos alimentos } \\
\text { ao longo de todo o } \\
\text { ano como ocorre ha- } \\
\text { bitualmente nas } \\
\text { grandes redes. } \\
\text { - Em geral, as ativi- } \\
\text { dades de gestão do } \\
\text { grupo são assumidas } \\
\text { de maneira voluntária } \\
\text { por consumidores. } \\
\text { - Ter disponibilidade } \\
\text { para propor e se en- } \\
\text { volver nas atividades } \\
\text { educativas do grupo. }\end{array}$ & $\begin{array}{l}\text { - Com os pedidos an- } \\
\text { tecipados, a venda } \\
\text { é garantida e evita- } \\
\text {-se perda de produ- } \\
\text { tos e tempo de tra- } \\
\text { balho destinado à } \\
\text { comercialização. } \\
\text { - Redução de interme- } \\
\text { diários possibilita me- } \\
\text { lhor remuneração ao } \\
\text { produtor. } \\
\text { - Relação de confian- } \\
\text { ça que pode dispensar } \\
\text { certificação formal. } \\
\text { - Maior flexibilida- } \\
\text { de do consumidor } \\
\text { torna-se opção para } \\
\text { produtores que têm } \\
\text { pouca experiência em } \\
\text { comercialização, di- } \\
\text { ficuldade no planeja- } \\
\text { mento da produção, e/ } \\
\text { ou estão em transição } \\
\text { agroecológica. }\end{array}$ & $\begin{array}{l}\text { - Entregar o que foi } \\
\text { pedido (mesmo que } \\
\text { volume de compras } \\
\text { dos GCR seja peque- } \\
\text { no) na data e local } \\
\text { combinados. } \\
\text { - Cumprir crité- } \\
\text { rios de boas práticas } \\
\text { acordados. } \\
\text { - Ter disponibilidade } \\
\text { para receber visitas à } \\
\text { produção. } \\
\text { - Pode ser solicitada } \\
\text { disponibilidade do } \\
\text { produtor para partici- } \\
\text { par ativamente de ou- } \\
\text { tras atividades do gru- } \\
\text { po (reuniões cotidia- } \\
\text { nas, discussões para } \\
\text { tomada de decisões } \\
\text { no grupo, etc). }\end{array}$ \\
\hline
\end{tabular}

Em relação à identidade desses grupos, percebe-se um alinhamento, pois geralmente suas práticas são motivadas pela valorização do campo e de hábitos alimentares saudáveis, o conhecimento da cadeia que envolve desde a produção até o consumo e a possibilidade de interferir nessa cadeia. A maioria das experiências possui vínculo com organizações que atuam na esfera social, como Universidades e ONGs, o que indica um certo perfil desse consumidor para manter e investir nessa outra prática de consumo. A maior parte desses consumidores pertencem à classe média e possuem alto nível educacional, o que pode limitar a ruptura que esse consumo promove. Em linhas gerais, os grupos possuem um objetivo comum que é o de conquistar benefícios coletivos a partir da cooperação na produção, intermediação e consumo, atuando como redes solidárias (INSTITUTO KAIRÓS, 2013, p. 111). 
Dentre os diversos GCRs existentes, uma característica importante a ser notada é que cada um se organiza como quiser, a partir de seus acordos ou princípios. Não há um modelo a ser seguido e as iniciativas surgem conforme os acordos feitos entre seus integrantes. O que há em comum são os princípios da economia solidária (inclusive os GCRs são considerados "empreendimentos econômicos solidários" segundo os mapeamentos oficiais realizados de maneira articulada pelo movimento e pelo poder público). São iniciativas coletivas e autogestionárias, ou seja, são organizações horizontais, não há um "dono".

Em relação à comercialização, podemos dizer que as práticas dos GCRs buscam estar alinhadas com os princípios e critérios do Comércio Justo e Solidário (CJS). Os grupos buscam estabelecer suas práticas de maneira dialogada, baseados no fortalecimento da democracia, relacionando-se com produtores com condições justas de produção, empenhando-se na construção de processos transparentes de formação de preços, respeitando o meio ambiente e a diversidade, tecendo relações transparentes com os demais consumidores e demais integrantes da cadeia comercial e buscando integrá-los, ainda que para isso enfrentem inúmeros desafios (MASCARENHAS; GONÇALVES, 2016, p. 129-135).

Além das atividades operacionais que garantem o abastecimento de produtos, a experiência dos GCRs assume dimensões políticas e educativas, pois são espaços em que a prática e a reflexão caminham juntas. Muitos grupos desenvolvem atividades educativas, culturais e de comunicação junto aos consumidores e produtores, além de eventuais interações junto a um público mais amplo.

Um exemplo de atividade que transcendeu a esfera operacional e individual de alguns grupos foi a Pesquisa Comparativa de Preços ${ }^{6}$, realizada no âmbito da Rede Brasileira de GCRs. Nos debates sobre a agricultura orgânica, há uma percepção geral de que os alimentos orgânicos são muito mais caros e inacessíveis para grande parte da população. Essa pesquisa, lançada recentemente, contribui para desmistificar a ideia de que esse tipo de produto é sempre mais caro. As análises do estudo mostram que o preço varia significativamente em função do canal de venda. Os preços praticados nos GCRs são muito menores que nos supermercados, com produtos equivalentes variando entre $16 \%$ até

\footnotetext{
6 Pesquisa coordenada pelo Instituto Terra Mater, no âmbito de projeto executado pelo Instituto Kairós junto à Secretaria Nacional de Economia Solidária do Ministério do Trabalho e Emprego (SENAES/MTE). Contou com a participação voluntária de 5 GCRs em diferentes regiões do país, completando 1 ano de coleta de preços em 5 cidades para 22 tipos de frutas, hortaliças e ovos.
} 
280\%. Assim, quem está envolvido com o tema dos orgânicos e dos circuitos curtos alimentares constata que é principalmente nas grandes redes de supermercado que são praticados preços mais altos.

Dessa forma, as experiências dos GCRs no país provocam reflexões fundamentais sobre o envolvimento dos consumidores na discussão das cadeias produtivas, seu contexto e seus efeitos, convidando os consumidores para um exercício de reflexão cotidiana e também de mudança de hábitos, compartilhando riscos e benefícios com os produtores.

\section{Práticas de resistência na Rede Brasileira de Grupos de Consumo Responsável}

Se a articulação entre consumidores em cada GCR, no contexto local, é fundamental para a construção de soluções coletivas cotidianas para o acesso a gêneros alimentícios produzidos e comercializados de maneira justa e solidária, a articulação entre os diversos grupos traz novas perspectivas para essa atuação de resistência, indo contra a tendência hegemônica do alongamento das cadeias agroalimentares, da concentração dos setores de distribuição e da postura consumista.

Foi por meio do trabalho com educação para o consumo responsável e do contato com a diversidade de experiências de GCRs que surgiu a proposta de fazer um levantamento dos grupos em 2009, pelo Instituto Kairós, para entender suas variadas práticas, motivações, dinâmicas e sonhos compartilhados (INSTITUTO KAIROS, 2010).

Observou-se, então, o vasto potencial da troca de experiências e construções coletivas inter-GCRs. Essa integração foi ocorrendo na medida em que encontros presenciais foram viabilizados ${ }^{7}$, com representantes de todos os grupos mapeados convidados, e também de maneira virtual com o desenvolvimento de um software de gestão para GCRs, por exemplo. Baseando-se no princípio da

\footnotetext{
7 O I Encontro Nacional dos GCRs (em 2011) foi viabilizado por meio de projeto em parceria com o Ministério do Desenvolvimento Agrário. Os II e III Encontros Nacionais (2013 e 2015) bem como a Oficina de Comercialização (2014) foram viabilizados por meio de projeto em parceria com a Secretaria Nacional de Economia Solidária, do Ministério do Trabalho e Emprego. Mais informações em: <www.institutokairos.net>. Acesso em: 10 fev. 2017.
} 
autogestão para a construção da sua prática, foi constituída, então, a "Rede Brasileira de Grupos de Consumo Responsável”.

Presentes em diversos estados do país, cerca de 25 GCRs fazem parte da Rede Brasileira. Nesses grupos, mais de 3.000 consumidores compram produtos de mais de 300 fornecedores.

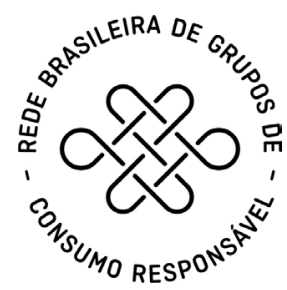

A Figura 1 mostra como estão distribuídos espacialmente. É importante ressaltar, entretanto, que o mapa reflete os GCRs integrantes da Rede Brasileira nesse momento e que chegaram até a Rede voluntariamente, pois não existe um trabalho de mapeamento ativo de novos grupos. Ou seja, certamente existem mais iniciativas como essa no país.

Figura 1: Mapa da Rede Brasileira de GCRs

\section{Rede de Grupos de Consumo Responsável}
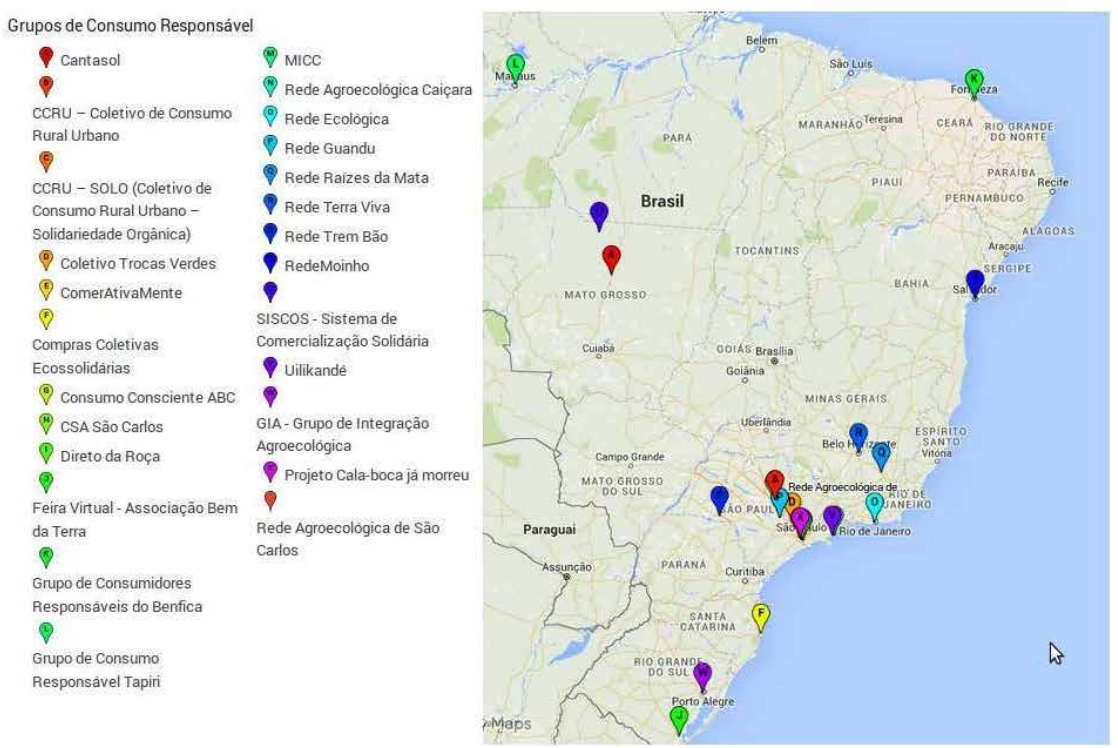

Fonte: Instituto Kairós. Disponível em: <http://goo.gl/ReCwc2>. Acesso em: 20 jul. 2016. 
São cerca de 3.500 consumidores participantes de GCRs. Mas esse número pode variar bastante tendo grupo com cerca de 10 consumidores e grupo com quase 1.000 consumidores. É importante ressaltar ainda que geralmente cada consumidor participante compartilha a cesta recebida com sua família. Considerando uma família de quatro integrantes na média, pode-se estimar que 14.000 pessoas consomem produtos adquiridos em GCRs.

Em relação aos fornecedores, há cerca de 370 fornecendo produtos para GCRs, sendo que há grupos com apenas um produtor e uma estreita ligação estabelecida e grupos com mais de 30 fornecedores. Estes últimos, em geral, mantêm relações de proximidade com os produtores de hortaliças e se preocupam também com a oferta de produtos complementares, como beneficiados, artesanais, papelaria, limpeza, etc ${ }^{8}$. Ainda que a maioria dos GCRs da Rede Brasileira mobilizem consumidores de classes mais favorecidas, a preocupação com a democratização do acesso a esse tipo de produto, possibilitando o consumo por consumidores de baixa renda, está presente em diversos grupos. Destaca-se aqui a atuação do Movimento de Integração Campo-Cidade (MICC), na zona leste da cidade de São Paulo, do Coletivo de Consumo Rural Urbano (CCRU), em Diadema/SP) e da Rede Tapiri, em Manaus/AM. O MICC, por exemplo, envolve mais de 1.000 consumidores de classes populares recebendo cestas quinzenais de hortaliças em transição agroecológica de agricultores familiares do interior de São Paulo em espaços articulados em parceria com a igreja.

A preocupação com a questão se faz presente de outra forma para outros GCRs. Ainda que o fornecimento das cestas da Rede Ecológica, no Rio de Janeiro/ RJ, ocorra principalmente para cerca de 200 consumidores de classe média-alta, o grupo decidiu que não quer crescer mais. Porém, com a preocupação de disseminar a experiência e a cultura do consumo responsável, realizaram um curso para fomentar novos grupos de consumo responsável, especialmente nas periferias.

\section{Articulações no território como potência nas relações}

Nos encontros nacionais realizados, ocorreram inúmeras e valiosas trocas de experiências, em que cada participante pode levar consigo e compartilhar no

8 Dados sobre consumidores e fornecedores obtidos a partir dos questionários respondidos para o III Encontro Nacional dos Grupos de Consumo Responsável, em agosto de 2015. 
seu grupo, possibilitando a criação de novas alternativas para enfrentar os desafios do dia a dia. Porém, no retorno ao cotidiano, a dificuldade de realizar ações conjuntas com outros GCRs é grande, ocorrendo mais entre os grupos mais próximos territorialmente. O próprio momento dos encontros nacionais possibilitou que articulações locais ocorressem posteriormente.

Assim, deu-se início, por exemplo, a aproximação entre o MICC e o CCRU, ambos na Região Metropolitana de São Paulo, que passaram a fazer compras regulares cruzando seus fornecedores. Isto é, a banana e o palmito pupunha vindos do Vale do Ribeira eram comprados pelo CCRU, acrescidos do pedido do MICC, e, de outro lado, o fornecedor de hortaliças do MICC passou a também entregar no CCRU.

A necessidade de integrações regionais entre os GCRs próximos surgiu como uma demanda real, já que a junção de um volume maior de pedido possibilita operacionalizar a logística de certos produtos. Na Região Metropolitana de São Paulo, a integração entre os GCRs avançou e outros grupos se aproximaram para concretizar uma compra coletiva de um produto não perecível. Decidiu-se que o primeiro produto a ser comprado seria o arroz, dada sua importância na alimentação cotidiana dos consumidores, e que este viria de uma cooperativa do MST (Movimento dos Trabalhadores Rurais Sem-Terra), no sul do país. A compra coletiva enfrentou diversos desafios para concretizar-se, desde a organização dos pedidos até a logística final de entrega ao consumidor e pagamentos. Por outro lado, mostrou que essa articulação não só é possível, mas é também catalisadora no processo de integração dos GCRs. Novos encontros presenciais foram articulados e novas possibilidades de contribuições entre esses grupos para um objetivo comum foram amadurecidas. Outras compras, então, têm sido articuladas, como a da farinha de mandioca de um assentamento do MST, parceiro de um GCR.

Além das compras coletivas, os consumidores dos GCRs buscam estabelecer uma nova relação de proximidade e parceria com os produtores, que vai além da relação puramente comercial. Isso é tema exaustivamente discutido nos encontros nacionais. Em um deles, chegou-se à proposta de visita de membros da Rede Brasileira a uma rede de agricultores ligados à agroecologia, a Rede Ecovida, no sul do país. A proposta concretizou-se e a visita estreitou as relações entre as duas redes, com maior desdobramento no campo das articulações para a incidência política. 
Outra visita ocorreu fruto da articulação entre os GCRs de São Paulo e uma cooperativa de agricultores do Vale do Ribeira, já parceira há certo tempo. A visita possibilitou que os consumidores e agricultores se conhecessem melhor e os consumidores aprendessem sobre agroflorestas e o cultivo da banana e da pupunha. A proximidade e estreitamento de vínculos facilitam depois os acordos da comercialização bem como traz uma outra dimensão para a compreensão da realidade do campo para os consumidores e da realidade da cidade para os agricultores.

Dessa forma, surgiu a Rede de Grupos de Consumo Responsável Sampa, derivada da Rede Brasileira. A Rede GCRs Sampa tem se reunido periodicamente para avançar nas articulações da logística compartilhada, aproximar-se de produtores parceiros, estreitar relações e trocar experiências, fortalecendo o consumo responsável na região.

A articulação dessa rede local ocorreu junto com a aproximação a parceiros da comercialização que compartilham valores dos GCRs, como a transparência na formação do preço e a importância da integração das cadeias produtivas. Esses parceiros da comercialização também atuam na lógica dos circuitos curtos e estão buscando viabilizar a logística de pequenos produtores, da agricultura familiar, da agroecologia e da economia solidária, e construir novas práticas de comercialização na cidade.

E por que não potencializar essas ações articulando-as coletivamente? Como ampliar essas ações buscando construir juntos um projeto agroalimentar territorial? Junto a esses parceiros, avaliou-se a necessidade de mapear e desenhar o "estado da arte" da logística, oferta e demanda na região. Levantar e organizar essas informações é um primeiro passo para costurar e acordar rotas compartilhadas, fomentar ações conjuntas e construir um projeto coletivo de logística solidária.

Nota-se que na Rede Brasileira de GCRs as trocas simbólicas são mais intensas, uma vez que a distância geográfica dificulta a realização de parcerias comerciais. Nesse cenário, a Rede de GCRs Sampa se apresenta como experiência a ser multiplicada em outros territórios, mostrando que a proximidade entre os grupos permite, além das trocas simbólicas, interações práticas como logística solidária e compras compartilhadas, promovendo maior diversidade de produtos nos grupos, divisão de custos com transporte, entre outros ganhos coletivos.

As interações em um GCR específico (que já é uma rede em si) promovem acesso a produtos de qualidade, remuneração mais justa aos produtores e 
transformações culturais a partir das relações sociais no grupo. Porém, quanto maior for a capacidade de articulação desses GCRs em redes regionais, nacionais e até internacionais, maior será sua capacidade de gerar impactos sociopolíticos e econômicos. E o diálogo das redes de GCRs com outras redes, no âmbito dos circuitos curtos pode contribuir para a promoção de uma mudança mais estrutural na produção, distribuição e consumo de alimentos.

\section{Considerações finais}

Frente ao contexto das cadeias alimentares submetidas, em todo o seu percurso, há uma concentração de poder na mão de poucos atores e a consequente distância e perda de vínculo entre produtores e consumidores, nos circuitos alongados de abastecimento, é urgente que os enfrentamentos necessários sejam levados a cabo.

Nesse sentido, os GCRs, junto a outros movimentos ligados à agroecologia e aos mercados locais, em todo o mundo, trazem novas propostas para o desenvolvimento de experiências alternativas em que o consumo é entendido como um ato político. São ações coletivas, baseadas na autogestão, que partem do incômodo de indivíduos frente ao sistema produtivista e consumista em que vivemos e se propõem como práticas de resistência. Constituem-se como espaços onde é possível não só partilhar ideias mas também construir algo novo. No entanto, participar de um GCR requer esforço contínuo para garantir sua sobrevivência, além de criatividade e disposição para encarar coletivamente os inúmeros desafios envolvidos em sua gestão operacional e estratégica.

Dispostos a se fortalecerem mutuamente por meio da articulação em rede, GCRs nas diversas regiões do país fazem parte da Rede Brasileira de Grupos de Consumo Responsável. Mais recentemente, essas articulações se desdobraram em interações também em âmbito territorial, como ocorreu com os GCRs da Região Metropolitana de São Paulo, constituindo-se a "Rede de Grupos de Consumo Responsável Sampa”. As articulações territoriais se potencializam com parceiros que estejam na mesma busca e estejam dispostos à construção coletiva de um projeto político comum. E se traduzem em ações concretas de logística solidária, criando potentes conexões entre o campo e a cidade e costurando parcerias múltiplas entre os diversos atores. 
Muitas experiências conectando campo e cidade já estão acontecendo. Não obstante, o atual contexto exige que avancemos na oferta de produtos da agricultura familiar de base agroecológica para as diferentes camadas sociais. O desafio, enquanto movimentos alternativos, é conseguir unidade para lutar conjuntamente também na esfera política.

O Estado deve se comprometer na promoção efetiva de maior equilíbrio entre o ramo empresarial da agricultura e a agricultura familiar, setores que estão em pontos de partida tão desiguais. Porém, a discussão sobre a cadeia de abastecimento de alimentos deve passar a ocupar um lugar de maior destaque não só nas políticas públicas, mas também nas relações comunitárias, nas universidades e outros espaços. Uma mudança de padrão da produção ao consumo necessita de um quadro ampliado de transformações políticas, econômicas e sociais.

Os grupos de consumo responsável se afirmam como práticas de resistência a partir da ação coletiva. Somados às experiências mapeadas ao redor do mundo, os GCRs e demais iniciativas no campo dos circuitos curtos revelam que não são um fenômeno isolado, mas sim uma espécie de contra-tendência, ainda frágil, mas que pode indicar novos caminhos para os sistemas de abastecimento agroalimentares, com mudanças estruturais profundas. Essa transformação precisa ser cultivada, coletivamente, nos campos e nas cidades, por agricultores e consumidores, exercendo ativamente sua cidadania e articulados em redes.

\section{REFERÊNCIAS}

BRANDÃO, C. R. Tempos e espaços nos mundos rurais do Brasil. In: Ruris, v. 1, n.1, mar 2007, pp. 37-64.

CARNEIRO, C. B. M. Compras Coletivas de produtos orgânicos e participação política: um estudo de caso da Rede Ecológica (RJ). Rio de Janeiro, 2012, 192 fls. Dissertação (mestrado) - Instituto de Ciências Humanas e Sociais, Universidade Federal Rural do Rio de Janeiro.

INSTITUTO KAIRÓS; CAPINA (Org.). Práticas de comercialização: uma proposta de formação para a economia solidária e a agricultura familiar. São Paulo, Instituto Kairós, 2013. Disponível em: <www.institut okairo s.net>. Acesso em: 5 ago. 2016.

INSTITUTO KAIRÓS. Levantamento do Perfil dos Grupos de Consumo no Brasil: Consumo como intervenção - Um olhar sobre as experiências de consumo coletivo 
no Brasil. Instituto Kairós, 2010. Disponível em: <www.in stitutokai ros.net> Acesso em: 10 ago. 2016.

INSTITUTO KAIRÓS; PISTELLI, R. S. S.; MASCARENHAS, T. S. Organização de Grupos de Consumo Responsável. Série: Caminhos para as práticas de consumo responsável. São Paulo, O Instituto, 2011. Disponível em: <www.institutokairos.net> Acesso em: 10 ago. 2016.

LAMINE, C. Settling Shared Uncertainties: Local Partnerships Between Producers and Consumers. Sociologia Ruralis. In: European Society for Rural Sociology. v.45, n.4, out/2005.

MASCARENHAS, T. S.; GONÇALVES, J.; BENSADON, L. S. A atuação dos grupos de consumo responsável no Brasil: expressões de práticas de resistência e intercâmbios em rede. In: ENCONTRO NACIONAL DE ESTUDOS DO CONSUMO, 7., 2014, Rio de Janeiro. Anais... Rio de Janeiro, Pontifícia Universidade Católica do Rio de Janeiro, 2014.

MASCARENHAS, T.; GONÇALVES, J. Grupos de Consumo Responsável: práticas de consumidores baseadas no comércio justo e solidário. In: STELZER, J.; GOMES, R. (Org.). Comércio justo e solidário no Brasil e na América Latina. Florianópolis, Departamento de Ciências da Administração / UFSC, 2016.

PISTELLI, R. S. S. Relações de consumo responsável em educação: um diálogo com a economia popular e solidária através da trajetória do Instituto Kairós. São Paulo, 2014, 123 fls. Dissertação (mestrado) - Faculdade de Educação, Universidade de São Paulo.

PREISS, P. V.; MARQUES, F. C. Tendências no movimento de re-localização alimentar brasileiro: uma análise de Iniciativas Colaborativas de Compras. In: Tessituras. Pelotas, v. 3, n. 2, jul./dez. 2015, p. 269-300.

RÊGO, D. F. de A. A Natureza da comercialização na economia solidária: a contribuição dos grupos de consumo responsável. 2014. 161 f. Dissertação (Mestrado) - Escola de Administração, Universidade Federal da Bahia, Salvador, 2014.

RETIÈRE, M. Produtos sem veneno são sempre mais caro? Uma pesquisa da Rede Brasileira de Grupos de Consumo Responsável. 2016. Disponível em: <www. institutokairos.net>. Acesso em: 5 ago. 2016.

SINGER, P. Introdução à economia solidária. São Paulo: Fundação Perseu Abramo, 2002.

VIVAS, E.; MONTAGUT, X. (Coord.). Do campo para a mesa: os circuitos de produção e de distribuição de alimentos. Portugal: Sururu Produções Culturais / CIDAC/ Mó de Vida, 2011. 


\title{
Rede Ecovida de Agroecologia: origens, princípios e sua concepção de comercialização
}

\author{
Julian Perez-Cassarino ${ }^{1}$ \\ Laércio Meirelles ${ }^{2}$
}

A agroecologia tem emergido na sociedade como um campo técnico em ascensão nas últimas décadas, porém é como um campo político e na disputa entre as diferentes propostas de desenvolvimento para o rural brasileiro que ela tem se afirmado. Sua proposta supera o desafio da construção de alternativas de produção em bases sustentáveis para, dentro de sua práxis, expor as fragilidades e os efeitos negativos do modelo da agricultura convencional (hoje denominada de agronegócio) para, então, propor o redesenho dos sistemas agroalimentares como um todo, repensando os modos de organização social, produção, industrialização, comercialização e certificação dos produtos ecológicos.

Neste campo de enfrentamentos de modelos e de construção de alternativas concretas para a produção e comercialização de alimentos amigáveis com a saúde do planeta e das pessoas, uma força política, técnica e econômica tem se consolidado no cenário nacional e internacional: A Rede Ecovida de Agroecologia.

Presente nos três estados do sul do Brasil, esta rede conta com quase 20 anos de existência e tem se constituído como espaço articulação social, mas também de proposição de formas técnicas, sociais e econômicas alternativas ao modelo de desenvolvimento que hegemoniza o campo brasileiro.

1 Engenheiro Florestal, Doutor em Meio Ambiente e Desenvolvimento (UFPR). Professor Adjunto da Universidade Federal da Fronteira Sul (UFFS-Campus Laranjeiras do Sul). Coordenador Núcleo de Estudos Avançados em Soberania e Segurança Alimentar e Nutricional "Karu Porã".

2 Engenheiro Agrônomo. Coordenador do Centro Ecológico Ipê-RS. 
A proposta deste capítulo é trazer, em sua primeira parte, o resultado de um longo processo de sistematização dos documentos e do histórico da Rede Ecovida, de forma a resgatar as motivações, o ideário e o processo de organização que geraram uma das principais organizações em âmbito nacional e internacional. Para isso, fez-se um resgate de documentos públicos e relatórios de reuniões e encontros, além do resgate da memória da organização com atores chave de sua construção, além dos próprios autores que integraram a coordenação da Rede em alguns momentos de sua história e acompanham e vivenciam sua dinâmica até o presente momento.

A segunda parte dedica-se a analisar uma das principais ações que a Rede tem desenvolvido: a construção de mecanismos alternativos de mercado, aspecto que caracteriza a organização e a tornou uma das referências neste campo, trazendo junto com este, a proposta de uma metodologia também alternativa de avaliação de conformidade, a certificação participativa. O capítulo analisa a concepção de comercialização da Rede Ecovida e traça um paralelo com os dados dos canais e volumes de comercialização dos núcleos que integram a Rede.

A reflexão aqui proposta procura trazer elementos históricos e analíticos da proposta de construção de mercados da Rede Ecovida, uma das grandes inovações e contribuições desta organização para o debate da agroecologia, de forma a contribuir para a análise e proposição de estratégias de abastecimento alimentar orientadas pela perspectiva da promoção da soberania e segurança alimentar e nutricional.

\section{A Rede Ecovida de Agroecologia: os nós que criaram a rede}

A Rede Ecovida de Agroecologia surgiu como resultado da necessidade de articulação sentida pelas organizações não governamentais e por grupos de agricultores ecologistas à medida que suas ações se ampliavam e ganhavam proporção. Essa necessidade se fez sentir por três razões principais: i) fortalecer as experiências através do intercâmbio e do reconhecimento mútuo; ii) aumentar a capacidade de diálogo com a sociedade, dando mais visibilidade às ações de promoção da agroecologia; iii) ter um canal de expressão que permitisse demandar políticas públicas de apoio à agroecologia. Essas três razões podem ser sintetizadas na necessidade de configurar um espaço coletivo que proporcione as condições 
para o estabelecimento de uma identidade comum entre diversas iniciativas que se multiplicavam no interior dos estados do Sul do Brasil.

Anteriormente à criação da Rede Ecovida já havia um espaço de articulação em torno da agroecologia no Sul do Brasil. A Rede Tecnologias Alternativas-Sul (Rede TA/Sul) agregava ONGs que atuavam neste campo e nesta área. Esta Rede se integrava com uma rede no Sudeste e outra no Nordeste do Brasil, formando a chamada Rede PTA (Projeto em Tecnologias Alternativas) em âmbito nacional. Trata-se de um espaço que agregava somente as organizações de assessoria, com o intuito de discutir suas estratégias e influência política. A Rede TA/Sul acabou sendo o espaço central de articulação das organizações em torno da agroecologia no Sul do Brasil, sendo a articulação na qual se agregavam os atores precursores da Rede Ecovida (REDE ECOVIDA, 2007a).

A ideia de tecnologias alternativas está na origem do debate da agroecologia, sendo que o foco inicial da proposta levada a campo junto às famílias agricultoras era o de propor alternativas tecnológicas aos padrões da "revolução verde". Souza (2003) destaca que o processo histórico que resultou no que se entende atualmente por agroecologia passou por diversas mudanças e que atualmente se verifica uma reaproximação de diversas "correntes do pensamento alternativo". Para o autor:

A década de 1980 foi um momento forte deste movimento, pois reunia
duas questões importantes: a monumental crise econômica Brasileira (ficou
conhecida pelos economistas como a década perdida) e o fortalecimento
dos movimentos sociais. Com o enfraquecimento do modelo da revolução
verde e a percepção de que aquele era o momento de fazer avançar um
projeto alternativo, inúmeras organizações uniram-se em torno do projeto
dos Encontros Brasileiros da Agricultura Alternativa (EBAAs), que reuni-
ram milhares de pessoas em várias regiões do Brasil (SOUZA, 2003, p. 22).

Em meados dos anos 90 a Rede TA Sul frequentemente abordava um tema com o qual os produtores da região vinham se deparando: a certificação do que era produzido sob o enfoque da Agroecologia - a bem da verdade, a expressão Agricultura Ecológica era mais frequente neste momento. As iniciativas de comercialização se multiplicavam, as vendas para outros Estados e regiões crescia e havia uma pressão, em um primeiro momento por parte das empresas certificadoras que atuavam no país e, posteriormente, por parte do Ministério da Agricultura, 
Pecuária e Abastecimento (MAPA), para normatizar o processo de produção e certificação de produtos orgânicos no Brasil. A partir de 1994 são publicadas, por parte do MAPA, vários dispositivos legais, portarias e instruções normativas, buscando regular este sistema de produção. Merece destaque a publicação da Instrução Normativa 07, em maio de 1999, que definia a produção orgânica e estabelecia os critérios para sua certificação (BRASIL, 1999).

O longo processo de debate em torno da legislação levou à desconsideração das portarias e instruções normativas do MAPA, pois elas seriam brevemente substituídas pela legislação nacional, fato ocorrido em dezembro de 2003. No ano de 2010, com a conclusão da regulamentação da Lei $n^{\circ}$ 10.831/03 (BRASIL, 2003) e o consequente reconhecimento da certificação participativa, reativa-se a Associação Ecovida de Certificação Participativa (AECP), criada em 2001 mas que não chegou a ser utilizada pela Rede até o ano de 2010. No segundo semestre de 2010 a associação foi credenciada no MAPA como Organismo Participativo de Avaliação de Conformidade Orgânica (OPAC), estando autorizada e realizar processo de certificação formalmente (MEIRELLES, 2010).

Voltando um pouco no tempo, em 1989 a Cooperativa Ecológica Coolméia convida os agricultores ecologistas - assim considerados por ela - a participar de uma feira na cidade de Porto Alegre. A primeira edição da Feira de Agricultores Ecologistas (FAE) ocorreu no dia 16 de outubro de 1989. Com uma proposta inicial de ocorrer a cada mês, em dois anos a FAE passa a ser semanal. No âmbito da FAE, gera-se a proposta de promover a certificação participativa, definida neste momento como a geração de credibilidade a partir do encontro entre agricultores e consumidores. Algumas das entidades e associações precursoras da Rede Ecovida participavam desta feira, ajudando a construir esse processo e difundindo seus princípios e suas ideias para outras organizações dos três estados do Sul e mesmo para outros espaços.

A certificação tornava-se importante ponto de inflexão no que se refere à viabilidade das iniciativas com enfoque agroecológico. A pressão da normatização estabelecida pelo MAPA, bem como das próprias certificadoras nacionais e internacionais estabelecidas no país, cria uma reação no âmbito das organizações do campo agroecológico por buscar mecanismos de não obrigatoriedade da certificação. Ao mesmo tempo, como dito, alternativas à certificação "convencional", por auditagem, eram experimentadas, com o intuito de garantir a autonomia dos agricultores e suas organizações nesse processo. Algumas organizações acabavam 
optando por selos próprios, que buscavam comunicar à sociedade as qualidades socioecológicas da produção.

Um fato em particular impulsiona a ação em rede. A proposição de um projeto de normatização e certificação da agricultura orgânica no Estado de Santa Catarina, elaborado sem o devido diálogo com as organizações do campo agroecológico, estimula uma reação em uma das regiões do Estado (Planalto Norte). Em um seminário realizado para debater o projeto em questão, decide-se pela criação de um processo de articulação que fizesse frente à proposta, criando uma Rede Regional de Agroecologia, fato ocorrido no primeiro semestre de 1998 (REDE ECOVIDA, 2007a).

A proposta ganhou proporção, e o diálogo entre as ONGs que compunham a Rede TA/Sul em Santa Catarina estimulou a realização de um seminário estadual a fim de ampliar e fortalecer sua composição. Assim, criava-se, em novembro de 1998, a Rede Ecovida de Certificação Participativa. Durante o primeiro semestre de 1999 foram sendo realizadas atividades de discussão e formação para estruturação da Rede Ecovida. A proposta foi sendo divulgada e, mediante a articulação preexistente entre as ONGs da Rede TA/Sul, organizações do Rio Grande do Sul e Paraná se interessam pelo debate em andamento em Santa Catarina. Em seminários próprios, RS e PR definem por integrar-se à Rede Ecovida.

No ano de 1999, realiza-se no município de Lages o $1^{\circ}$ Encontro Ampliado da Rede Ecovida de Agroecologia, que reúne representantes de grupos de agricultores ecologistas e das ONGs de assessoria, quando se consolida a ampliação da Rede Ecovida para os três estados do Sul do Brasil. Nesse momento, a estrutura organizativa da Rede estava centralizada, havendo uma coordenação formada por um membro por Estado mais um coordenador geral, sendo o encontro ampliado o principal espaço de articulação entre as organizações.

O ano de 1998 pode então ser considerado como o momento de "fundação" da Rede Ecovida, ano em que se definiram o nome e o perfil inicial da articulação. No entanto, conforme destacado, o processo gerado pela reação à iniciativa do Estado catarinense aglutinou demandas políticas, técnicas e de mercado represadas naquele momento histórico e que puderam se manifestar por meio do processo de criação da Rede Ecovida (MARQUES et al., 2001; REDE ECOVIDA, 2007a). Conforme pode-se observar em Rede Ecovida (2007a, p. 11, grifos do autor): 


\begin{abstract}
A Rede Ecovida se concretiza basicamente a partir de uma identidade e reconhecimento histórico entre as iniciativas de Ong's e organizações de agricultores construídos na região sul. Assim, imediatamente passa se tornar uma Rede da Região Sul.

Diante dessa história conclui-se que a Rede não nasce em 98. Nesta data inicia-se um novo formato organizacional de um movimento agroecológico no Sul do Brasil: a Rede Ecovida de Agroecologia.
\end{abstract}

$\mathrm{O}$ ano de 2000 marca a realização do $2^{\circ}$ Encontro da Rede Ecovida, também em Lages-SC, quando se define pela ampliação de sua perspectiva, ou seja, não restringir o processo de articulação somente ao campo da certificação, mas sim caracterizar-se como espaço de articulação da agroecologia no Sul do Brasil. Assim, a Rede passa a denominar-se Rede Ecovida de Agroecologia, sendo a certificação participativa como um dos seus cinco grandes objetivos. O $2^{\circ}$ encontro ampliado representa importante momento de afirmação da Rede Ecovida, não somente pela ampliação da perspectiva pra além da certificação participativa, mas também pela definição de uma série de conceitos e pressupostos que orientariam sua ação nos anos seguintes. Da mesma forma, esse encontro dá continuidade e afirma um perfil metodológico centrado numa perspectiva de horizontalidade, o que significa dizer que as definições de perfil político, técnico e os espaços de tomada de decisão são exaustivamente debatidos nos encontros ampliados, que contam com a presença de agricultores e técnicos em permanente processo de diálogo.

O encontro do ano 2000 concentrou seus esforços em estabelecer as definições sobre os princípios e objetivos da Rede, perfil dos participantes, forma de inserção, atribuições, bem como a definição conceitual de agroecologia e outras questões que compuseram o documento "Organização e Funcionamento da Rede Ecovida de Agroecologia” (REDE ECOVIDA, 2000, 2003), que se pode caracterizar como o regimento interno da Rede Ecovida. Segundo o documento:

A Rede Ecovida de Agroecologia é um espaço de articulação entre agricultores familiares e suas organizações, organizações de assessoria e pessoas envolvidas e simpatizantes com a produção, processamento, comercialização e consumo de alimentos ecológicos. A Rede trabalha com princípios e objetivos bem definidos e tem como metas fortalecer a agroecologia nos seus mais amplos aspectos, disponibilizar informações entre os envolvidos e criar mecanismos legítimos de geração de credibilidade e de garantia dos processos desenvolvidos pelos seus membros (REDE ECOVIDA, 2000, p. 4). 
O encontro define que para integrar-se à Rede Ecovida é necessário estar inserido em alguma forma de organização. Notadamente no caso das famílias agricultoras, que só podem filiar-se à Rede caso estejam organizados em grupos, formais ou informais. À exceção da figura do colaborador, os demais membros devem estar inseridos em alguma forma de organização local. Além dos grupos de agricultores, define-se que podem integrar a Rede Ecovida as ONGs de assessoria, organizações de consumidores (cooperativas, associações de bairro, etc.), comercializadoras e agroindústrias, desde que sejam microempresas e empreendimentos familiares (REDE ECOVIDA, 2000, 2007a). Portanto, a Rede Ecovida caracteriza-se como uma rede de organizações orientadas pelos princípios e objetivos destacados no Quadro 1.

Quadro 1. Princípios e Objetivos da Rede Ecovida de Agroecologia

\begin{tabular}{|l|l|}
\hline Princípios & Objetivos \\
\hline $\begin{array}{l}\text { Ter a Agroecologia como base para o desen- } \\
\text { volvimento sustentável }\end{array}$ & $\begin{array}{l}\text { Desenvolver e multiplicar as iniciativas } \\
\text { agroecológicas. }\end{array}$ \\
\hline $\begin{array}{l}\text { Garantir a qualidade do processo através da } \\
\text { Certificação Participativa }\end{array}$ & $\begin{array}{l}\text { Incentivar o trabalho associativo na produção } \\
\text { e no consumo de alimentos ecológicos. }\end{array}$ \\
\hline $\begin{array}{l}\text { Trabalhar com agricultores e agricultoras fa- } \\
\text { miliares e suas organizações }\end{array}$ & $\begin{array}{l}\text { Articular e disponibilizar informações entre as } \\
\text { organizações e pessoas }\end{array}$ \\
\hline $\begin{array}{l}\text { Ser regida por normativa própria de funciona- } \\
\text { mento e de produção }\end{array}$ & $\begin{array}{l}\text { Aproximar, de forma solidária, agricultores e } \\
\text { consumidores }\end{array}$ \\
\hline $\begin{array}{l}\text { Trabalhar na construção do comércio justo e } \\
\text { solidário }\end{array}$ & $\begin{array}{l}\text { Ter uma marca-selo que expresse o processo, o } \\
\text { compromisso e a qualidade }\end{array}$ \\
\hline & $\begin{array}{l}\text { Fomentar o intercâmbio, o resgate e a valori- } \\
\text { zação do saber popular }\end{array}$ \\
\hline
\end{tabular}

Fonte: Rede Ecovida, 2000, p. 3.

Nesse mesmo ano de 2000 os integrantes da Rede Ecovida decidem por um formato descentralizado de organização, mesmo porque a amplitude da Rede inviabilizava o processo de articulação realizado de forma centralizada como até o momento, principalmente por meio dos encontros ampliados e de reuniões de coordenação. Define-se, então, por uma organização estruturada em "núcleos regionais", que reproduzem nas microrregiões a estrutura da Rede Ecovida, contando com coordenação, secretaria, tesouraria, além da formação de um conselho de ética próprio (REDE ECOVIDA, 2000, 2007a).

Os núcleos regionais são a unidade funcional da Rede Ecovida, onde se efetiva o processo de certificação participativa. A Figura 1 ilustra a forma como a 
Rede se organiza, demonstrando as diversas etapas, desde as famílias até a Rede como um todo, usando como referência o Núcleo Litoral Solidário do Rio Grande do Sul. A melhor interpretação da imagem pode ser feita se lida da direita para a esquerda. Ou seja, os grupos de agricultore(a)s configuram um primeiro nível de articulação em rede, espaço fundamental de estruturação da Rede Ecovida como um todo. A articulação entre eles e deles com ONGs, grupos de consumidore(a)s e outras organizações em determinada região, configuram um Núcleo Regional, um segundo nível de articulação em rede. A soma dos diferentes Núcleos Regionais configuram a Rede Ecovida de Agroecologia como um todo, sendo este o terceiro nível de articulação da Rede.

Figura 1 - Exemplo de estruturação de um núcleo dentro da rede

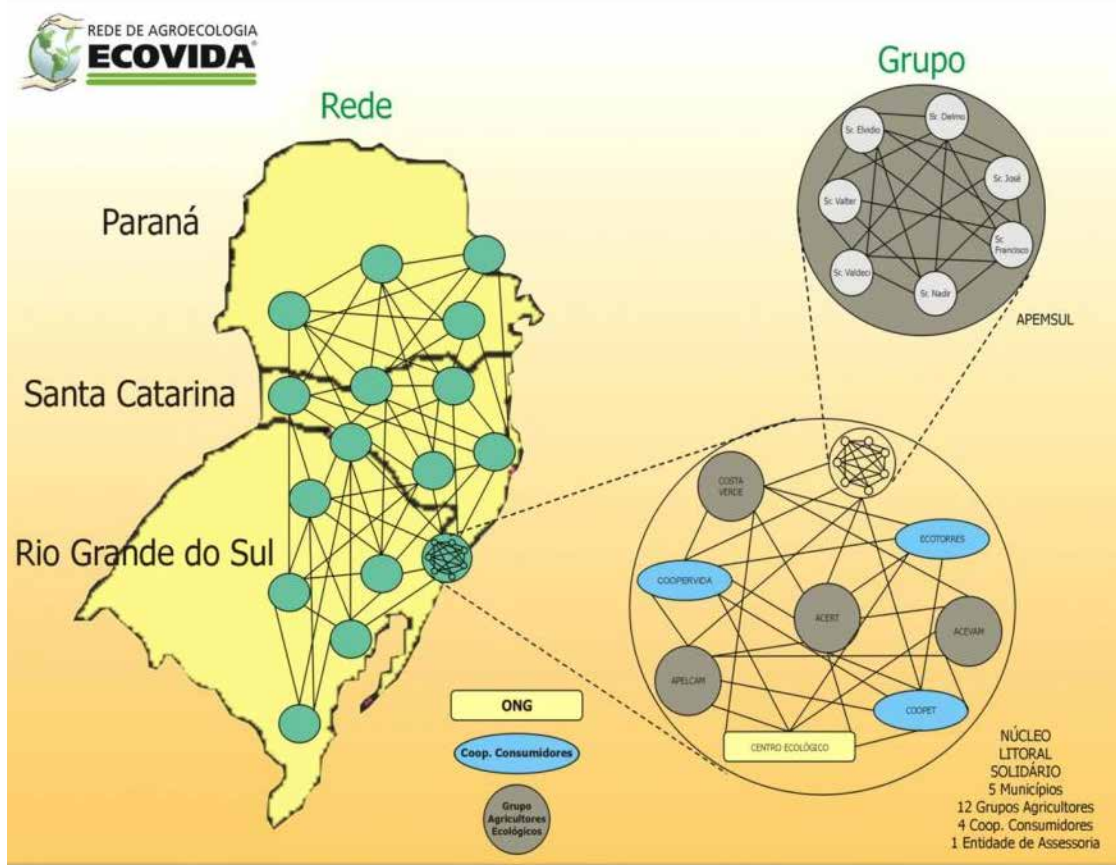

Fonte: Rede Ecovida (2007a, p. 16)

Ainda em perspectiva histórica, no ano de 2001, um novo Encontro (o terceiro), realizado em Francisco Beltrão no Paraná, discute as normas internas para a transição agroecológica. Realizou-se um profundo debate entre agricultores, técnicos e a presença de algumas representações de consumidores em torno das 
normas e dos procedimentos de certificação (REDE ECOVIDA, 2003). Esse debate culminou na produção do documento denominado "Normas Simplificadas da Rede Ecovida de Agroecologia" (REDE ECOVIDA, 2001) e no formulário de certificação das famílias agricultoras. Ambos documentos, com os princípios da certificação participativa, orientações de uso do selo e outras orientações, resultaram na publicação no ano de 2004 do "Caderno de Formação: Certificação Participativa de Produtos Ecológicos” (REDE ECOVIDA, 2004), conforme observado na Figura 2.

A ampliação no campo de ação da Rede Ecovida, para além da certificação participativa, refletiu de forma clara o momento histórico em que se encontravam as organizações de agricultores e de assessoria do campo agroecológico no Sul do Brasil. No entanto, há que destacar que a metodologia de certificação participativa em rede é um importante aspecto de unicidade e inovação dentro da Rede, dando originalidade à sua proposta, principalmente quando articulada à construção de mecanismos alternativos de mercado.

Nesse sentido, as normas simplificadas construídas no $3^{\circ}$ Encontro Ampliado resultaram em importante momento de consenso dentro da Rede Ecovida, no que se refere aos critérios e a metodologia da certificação participativa. Esse procedimento possibilitou não só maior unicidade no processo de certificação, como acabou por lhe conferir maior respaldo. Esse aspecto se tornou importante ferramenta no momento da negociação política em torno da aceitação da certificação participativa no marco legal brasileiro de agricultura orgânica. A construção de uma nova metodologia e, consequentemente, de um novo processo social em torno da geração de credibilidade para garantia da qualidade de produtos orgânicos/ecológicos, pode ser resumida da seguinte forma:

A certificação participativa é um sistema solidário de geração de credibilidade. O selo de certificação da Rede Ecovida expressa que o produto foi gerado com respeito ao meio ambiente e que é fruto de relações sociais justas. A aplicação dos princípios e a verificação das normas de produção ecológica são realizadas com a participação efetiva dos agricultores e consumidores envolvidos no processo, garantindo o aperfeiçoamento constante e o respeito às características de cada região. O selo ECOVIDA é o resultado de um processo participativo, que envolve uma série de procedimentos desenvolvidos dentro de cada núcleo regional, onde ocorre a filiação à Rede, a convivência e a verificação do Conselho de Ética, concedendo o selo se for o caso e quando solicitado pelo grupo (REDE ECOVIDA, [200-], s/p). 
A sistematização realizada pela Rede Ecovida em torno das normas e dos procedimentos de certificação tornou-se também importante referência para a difusão da certificação participativa em outros países. A Figura 2 exibe traduções do caderno de normas da Rede Ecovida para o espanhol e inglês feita por ONGs estrangeiras com objetivo de promover a certificação participativa em seus países.

Figura 2 - Caderno de formação da Rede Ecovida e suas respectivas traduções ao inglês e espanhol

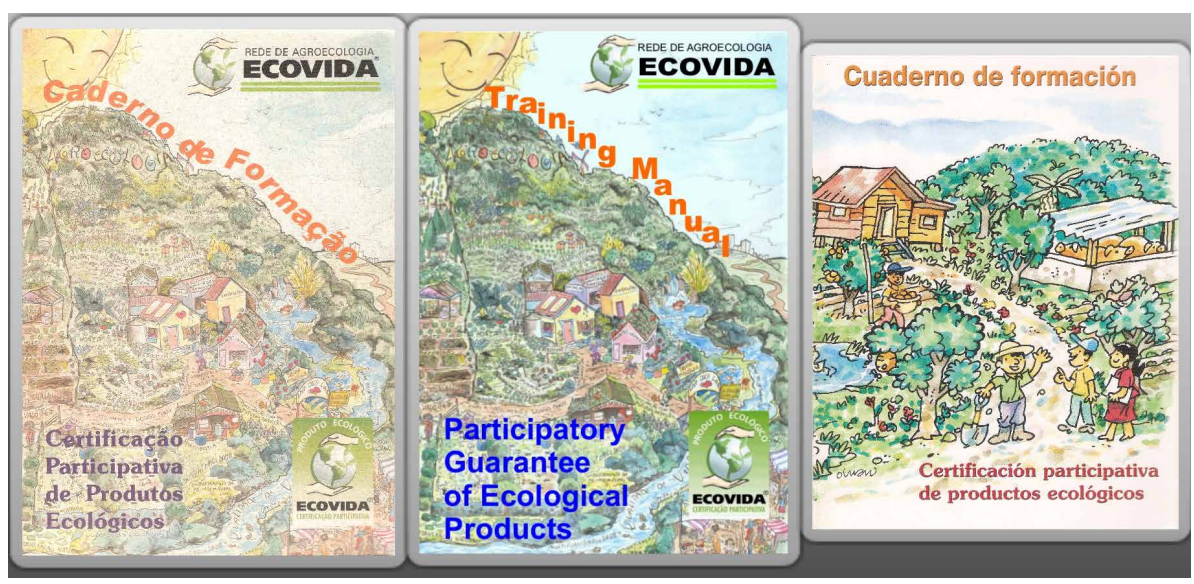

Fonte: Rede Ecovida (2004, [200-], [2005?]).

A partir do $3^{\circ}$ Encontro ampliado foram detalhadas as estruturas de organização e articulação da Rede Ecovida, uma vez que ficou decidido pela realização de encontros ampliados somente a cada dois anos. Criou-se, então, como principal instância de decisão no âmbito da Rede, à exceção dos encontros ampliados, a realização de "plenárias de núcleos", que reuniriam no mínimo dois representantes de cada núcleo e seriam realizadas duas a três vezes ao ano (REDE ECOVIDA, 2007a).

Assim, a Rede Ecovida passa a estruturar-se a partir dos núcleos regionais, plenárias de núcleos, coordenação geral e encontro ampliado; complementa esta estrutura a formação temporária ou permanente de "Grupos de Trabalho" por demanda. As comissões de ética se fazem presentes em três instâncias (grupos, núcleos e Rede). O organograma organizacional da Rede Ecovida, que reflete esta estrutura, pode ser observado na Figura 3. 
Figura 3 - Organograma da Rede Ecovida de Agroecologia

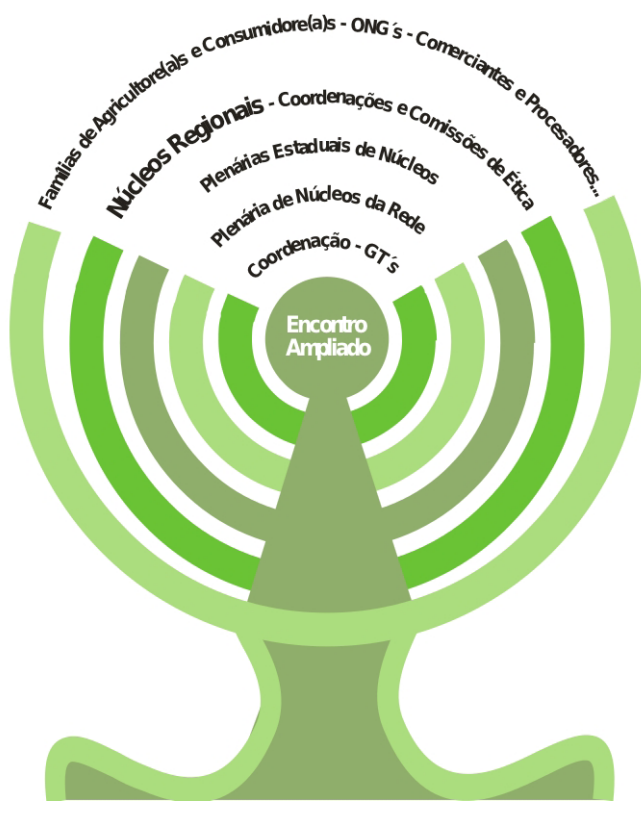

Fonte: Rede Ecovida (2007a, p. 18).

Esta dinâmica organizativa possibilitou um reconhecimento maior entre os membros da Rede Ecovida e, por outro lado, exercitava o processo de certificação participativa nas regiões. Na perspectiva de fortalecer a imagem da Rede Ecovida, uma plenária de núcleos realizada no ano de 2002 optou pela divisão da imagem da Rede em dois modelos. O primeiro é o selo a ser utilizado nos produtos certificados; o segundo é a logomarca da Rede, a fim de utilizar em materiais didáticos e de divulgação. Uma das preocupações centrais era o de evitar a confusão entre os consumidores, uma vez que o uso do selo de qualidade orgânica em outros espaços, que não o rótulo dos produtos, poderia gerar dificuldades de compreensão sobre o que era ou não um produto orgânico. Da mesma forma, a criação de uma logomarca separada de um selo ampliava suas possibilidades de uso como material de identificação entre os membros da rede (REDE ECOVIDA, 2002). Ambos os materiais possuem orientações claras e definidas sobre as formas e condições para o uso de cada imagem (REDE ECOVIDA 2004, 2007a). A Figura 4 expressa a mudança e a evolução gráfica do selo e da logomarca da Rede Ecovida. Da esquerda para a direita mostra-se inicialmente o selo/marca 
original da Rede Ecovida (quando não havia separação); o selo e logomarca com o dito "ecovida" em preto representam o momento da divisão entre selo e logomarca, e por fim a logomarca e selo atuais da Rede Ecovida.

A partir do encontro realizado em Francisco Beltrão em 2001, a dinâmica organizativa da Rede foi se consolidando; a coordenação passou a ser colegiada, com, pelo menos, três representantes de cada Estado e as plenárias possibilitavam maior celeridade na tomada de decisões. Dessa forma, os encontros ampliados se tornaram cada vez mais espaços de intercâmbio, formação, celebração e mobilização política, deixando seu caráter deliberativo de lado. As decisões fundamentais que passam pelos Encontros Ampliados são a eleição da coordenação e a aprovação da formação de novos Núcleos Regionais.

Figura 4 - Selos e logomarcas da Rede Ecovida

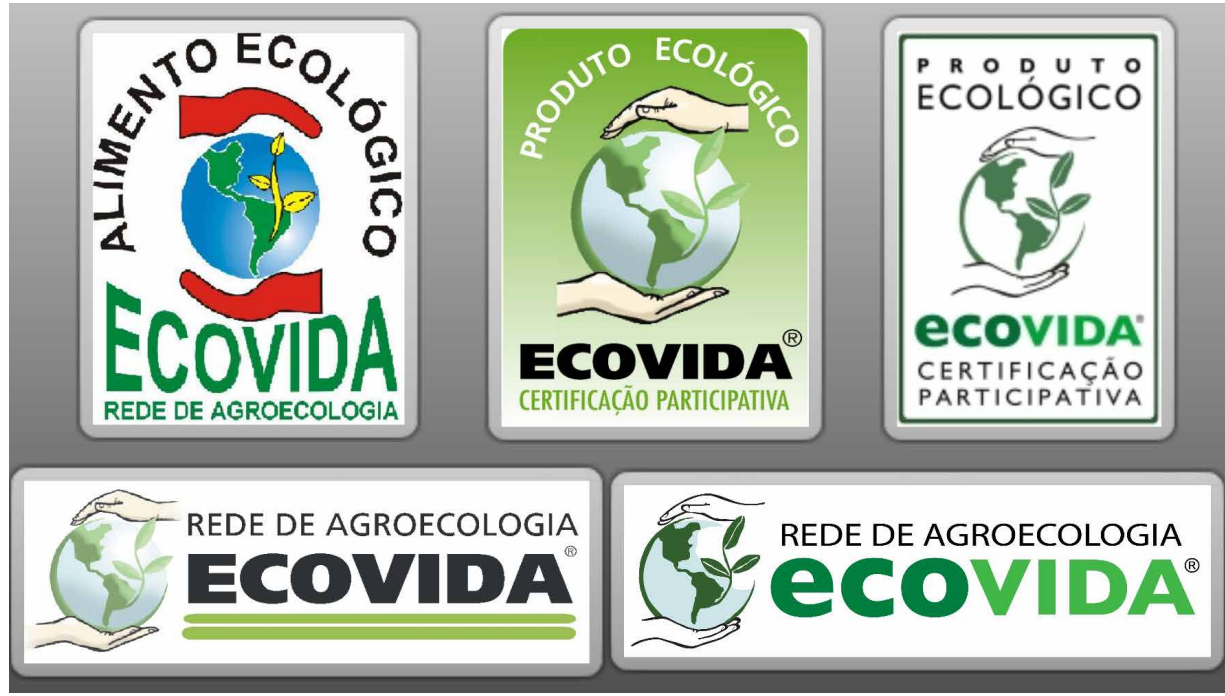

Fonte: Rede Ecovida (2007a) e site da Rede Ecovida.

Os encontros ampliados, porém, podem ser considerados como os marcos que expressam o momento político da Rede Ecovida. Assim, a partir de 2003, os encontros passam a ter lemas que simbolizavam esses momentos e pautavam a dinâmica de discussões e formação no âmbito da Rede. No Quadro 2, um breve resumo dos encontros ampliados realizados pela Rede Ecovida de Agroecologia. 
Quadro 2. Encontros ampliados da Rede Ecovida de Agroecologia

\begin{tabular}{|c|c|c|c|c|c|}
\hline $\begin{array}{l}\text { Encontro } \\
\text { Ampliado }\end{array}$ & Ano & Local & Lema & Participantes & Temática \\
\hline $1^{\mathrm{o*}}$ & $\begin{array}{l}\text { maio/ } \\
1999\end{array}$ & Lages-SC & $* *$ & 120 & $\begin{array}{l}\text { Discussão das formas de } \\
\text { organização e alcance da } \\
\text { Rede }\end{array}$ \\
\hline $2^{\text {o* }}$ & $\begin{array}{l}29-30 \\
\text { maio/ } \\
2000\end{array}$ & Lages-SC & $* *$ & 150 & $\begin{array}{l}\text { Construção das Normas } \\
\text { de organização e fun- } \\
\text { cionamento, princípios, } \\
\text { objetivos e formas de } \\
\text { adesão }\end{array}$ \\
\hline $3^{0 *}$ & $\begin{array}{l}\text { maio/ } \\
2001\end{array}$ & \begin{tabular}{|l|} 
Francisco \\
Beltrão-PR \\
\end{tabular} & $* *$ & 200 & $\begin{array}{l}\text { Discussão das normas de } \\
\text { certificação participativa }\end{array}$ \\
\hline $4^{\circ}$ & $\begin{array}{l}13-15 \\
\text { maio/ } \\
2003\end{array}$ & \begin{tabular}{|l} 
Passo \\
Fundo-RS
\end{tabular} & $\begin{array}{l}\text { Cultivando a éti- } \\
\text { ca, reproduzin- } \\
\text { do a vida }\end{array}$ & 350 & $\begin{array}{l}\text { Foco no fortalecimen- } \\
\text { to dos mecanismos de } \\
\text { geração de credibilida- } \\
\text { de e controle social no } \\
\text { processo de certificação } \\
\text { participativa }\end{array}$ \\
\hline $5^{\circ}$ & $\begin{array}{l}26-28 \\
\text { julho/ } \\
2005\end{array}$ & $\begin{array}{l}\text { Praia } \\
\text { Grande-SC }\end{array}$ & $\begin{array}{l}\text { Agricultura eco- } \\
\text { lógica, alimen- } \\
\text { tando a sobera- } \\
\text { nia de um povo }\end{array}$ & 800 & $\begin{array}{l}\text { Debater a relação entre } \\
\text { agroecologia e soberania } \\
\text { alimentar }\end{array}$ \\
\hline $6^{\circ}$ & $\begin{array}{l}17-19 \\
\text { julho/ } \\
2007\end{array}$ & Lapa-PR & $\begin{array}{l}\text { Nossa identida- } \\
\text { de se constrói } \\
\text { em rede }\end{array}$ & 1000 & $\begin{array}{l}\text { Fortalecer a identidade } \\
\text { entre os integrantes e os } \\
\text { processos organizativos e } \\
\text { políticos dentro da Rede } \\
\text { Ecovida }^{76}\end{array}$ \\
\hline $7^{\circ}$ & \begin{tabular}{|l|}
$5-7$ \\
setem- \\
bro/ \\
2009
\end{tabular} & Ipê-RS & $\begin{array}{l}\text { Agricultura fa- } \\
\text { miliar ecológica: } \\
\text { produzindo ali- } \\
\text { mentos, alimen- } \\
\text { tando sonhos }\end{array}$ & 1200 & $\begin{array}{l}\text { Os circuitos de comer- } \\
\text { cialização dentro da } \\
\text { Rede e o papel das polí- } \\
\text { ticas públicas para a pro- } \\
\text { moção da Agroecologia }\end{array}$ \\
\hline $8^{\circ}$ & $\begin{array}{l}28-30 \\
\text { maio/ } \\
2012\end{array}$ & \begin{tabular}{|l} 
Florianó- \\
polis-SC
\end{tabular} & $\begin{array}{l}\text { Construindo So- } \\
\text { nhos, dando Eco } \\
\text { à Vida }\end{array}$ & 1200 & $\begin{array}{l}\text { Relação OPAC - Rede, } \\
\text { políticas públicas de } \\
\text { apoio à agroecologia } \\
\text { e novas estratégias de } \\
\text { comercialização }\end{array}$ \\
\hline
\end{tabular}

3 Nesse encontro é lançado o "Caderno de Formação no 1: uma identidade que se constrói em rede", com o objetivo de orientar novos grupos e fortalecer o processo organizativo daqueles que já a compõem (REDE ECOVIDA, 2007a). Esse caderno e o caderno sobre certificação participativa constituem os principais materiais de formação da Rede Ecovida.

4 Destaque para a Feira de Saberes e Sabores, a mais significativa dentre todas que ocorreram nos encontros. 


\begin{tabular}{|l|l|l|l|l|l|}
\hline $9^{\circ}$ & $\begin{array}{l}20-22 \\
\text { abril/ } \\
2015\end{array}$ & $\begin{array}{l}\text { Marechal } \\
\text { Cândido } \\
\text { Rondon-PR }\end{array}$ & $\begin{array}{l}\text { Agroecologia } \\
\text { em Rede - Cul- } \\
\text { tivando a Vida }\end{array}$ & 1500 & $\begin{array}{l}\text { Atualidade e futuro da } \\
\text { Agroecologia; Gênero, } \\
\text { Juventude e Agroecolo- } \\
\text { gia. Gestão e melhora do } \\
\text { SPG da Rede }\end{array}$ \\
\hline $10^{\circ}$ & $\begin{array}{l}21-23 \\
\text { abril/ } \\
2017\end{array}$ & Erechim-RS & $\begin{array}{l}\text { Cuidado, Cultu- } \\
\text { ra e Bem Viver: } \\
\text { Construindo } \\
\text { Caminhos }\end{array}$ & 1500 & $\begin{array}{l}\text { Concepção de Agroeco- } \\
\text { logia para além da pro- } \\
\text { dução orgânica, repre- } \\
\text { sentando também uma } \\
\text { alternativa para ter mais } \\
\text { qualidade de vida no } \\
\text { campo e na cidade, com } \\
\text { segurança e soberania } \\
\text { alimentar e respeito às } \\
\text { diversidades de gênero e } \\
\text { de gerações. }\end{array}$ \\
\hline
\end{tabular}

Fonte: Rede ECOVIDA (2007); Informantes-chave; www.ecovida.org.br; vivência dos autores.

* Estes primeiros três encontros eram nominados somente de encontros; a partir do quarto se utilizou a expressão encontro ampliado. Cabe ressaltar que houve outras reuniões e encontros prévios a estes, desde o ano de 1998, mas é a partir de 1999 que se contabilizam como Encontros Ampliados.

** Não havia proposição de lema para estes primeiros encontros.

Vale destacar que entre os anos de 2009 a 2011 concentraram grande parte dos esforços das organizações da Rede em torno do processo de regulamentação da agricultura orgânica e, consequentemente, da legalização da certificação participativa. Tal processo demandou um esforço burocrático e de coleta e organização de informações em vários níveis, desde as unidades produtivas, passando pelos mecanismos de comercialização e organização (REDE ECOVIDA, 2010).

Apesar da motivação para formação da Rede ter se dado por uma reação à imposição de um modelo de certificação e regulamentação dos produtos ecológicos, sua criação reflete um momento de amadurecimento do campo agroecológico, que passa a perceber a necessidade de fortalecimento dos processos de articulação entre as diversas experiências em andamento (REDE ECOVIDA, 2007a). A definição de agroecologia por ela adotada exemplifica sua perspectiva holística e multidimensional dos processos rurais; nela questões técnico-produtivas se articulam com dimensões sociais, econômicas, culturais e, obviamente, ambientais. Para a Rede Ecovida, a agroecologia pode ser definida como:

[...] processo de produção de alimentos e produtos em conjunto com a natureza, onde os agricultores (as) possam desenvolver suas atividades sem agredir o meio ambiente, tornando independentes dos "pacotes 
tecnológicos" com seus caros e degradantes insumos industriais, visando não somente as sobras financeiras, mas principalmente qualidade de vida. É a base para o desenvolvimento sustentável nos aspectos sociais, ambientais e econômicos, envolvendo as dimensões políticas, técnicas e culturais, em processos educativos e metodologicamente adequados, onde (os) trabalhadores (as) assumem o protagonismo maior e aumentam seu poder de intervenção na sociedade de forma organizada. (CEPAGRI, 1998 apud REDE ECOVIDA, 2007a, p. 25).

A Rede Ecovida configura-se como um espaço fundamentalmente voltado para a articulação e o fortalecimento de seus membros e a promoção da agroecologia em suas diversas dimensões. Nesse sentido, cabe ressaltar a frequente preocupação de seus integrantes pela garantia da horizontalidade em seu funcionamento. Mais do que falar em uma ação da Rede Ecovida em si, o que se pode afirmar é que a Rede Ecovida é a expressão articulada das ações desenvolvidas por cada uma das organizações que a integra. É evidente que esse processo é carregado de limites e contradições, como em todo processo de organização social, porém, também é evidente que a forma de agir e pensar dentro da Rede Ecovida tem fortalecido esta perspectiva horizontal de funcionamento.

Atualmente, segundo informes da coordenação e da Associação Ecovida de Certificação Participativa (AECP), a Rede Ecovida conta com aproximadamente 5000 famílias de agricultore(a)s que a integram, organizadas em cerca de 500 grupos. Dessas, cerca de 3200 estão certificadas. Integram ainda a Rede mais de 20 organizações de consumidores, 80 organizações de assessoria, 120 agroindústrias, 40 comercializadoras, organizadas em 28 núcleos regionais, distribuídos por cerca de 350 municípios do Sul do Brasil, conforme pode ser observado nas Figuras 5, 6, 7 e 8 (MEIRELLES, 2017; PEREZ-CASSARINO, 2012). 
Figura 5. Mapa de ocorrência da Rede Ecovida no Estado do Paraná

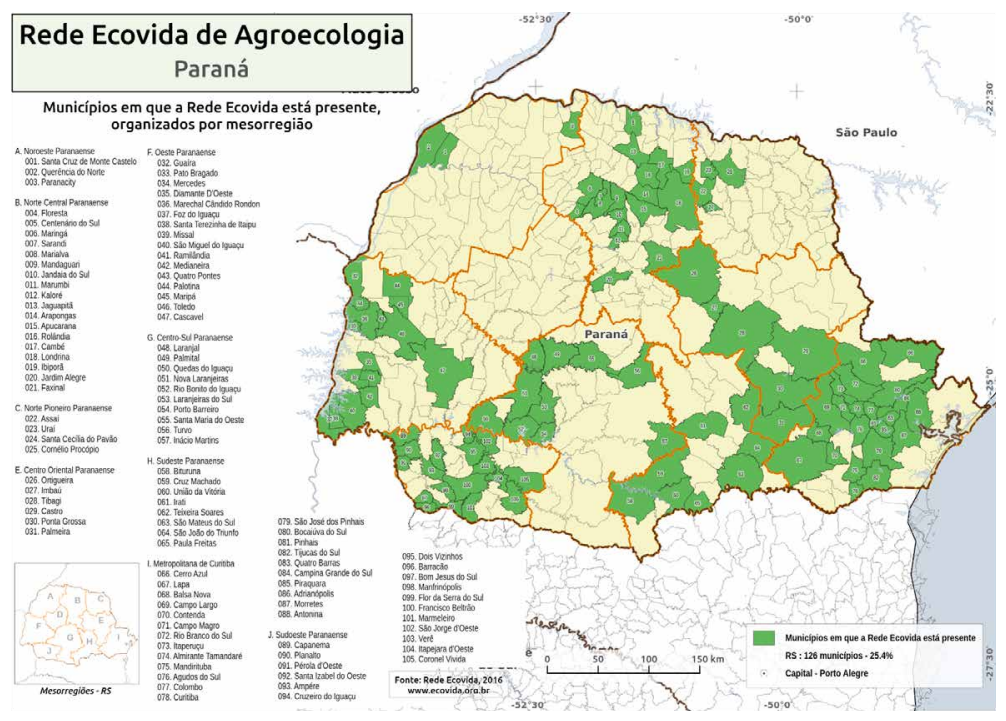

Fonte: Rede Ecovida, 2016.

Figura 6. Mapa de ocorrência da Rede Ecovida no Estado de Santa Catarina

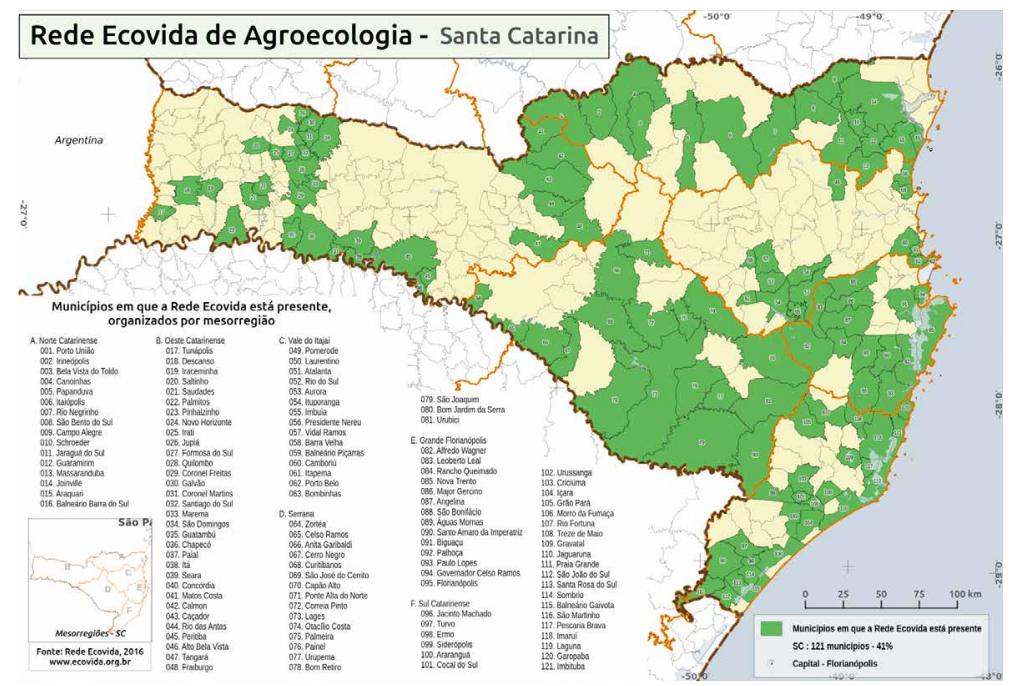

Fonte: Rede Ecovida, 2016. 
Figura 7. Mapa de ocorrência da Rede Ecovida no Estado do Rio Grande do Sul

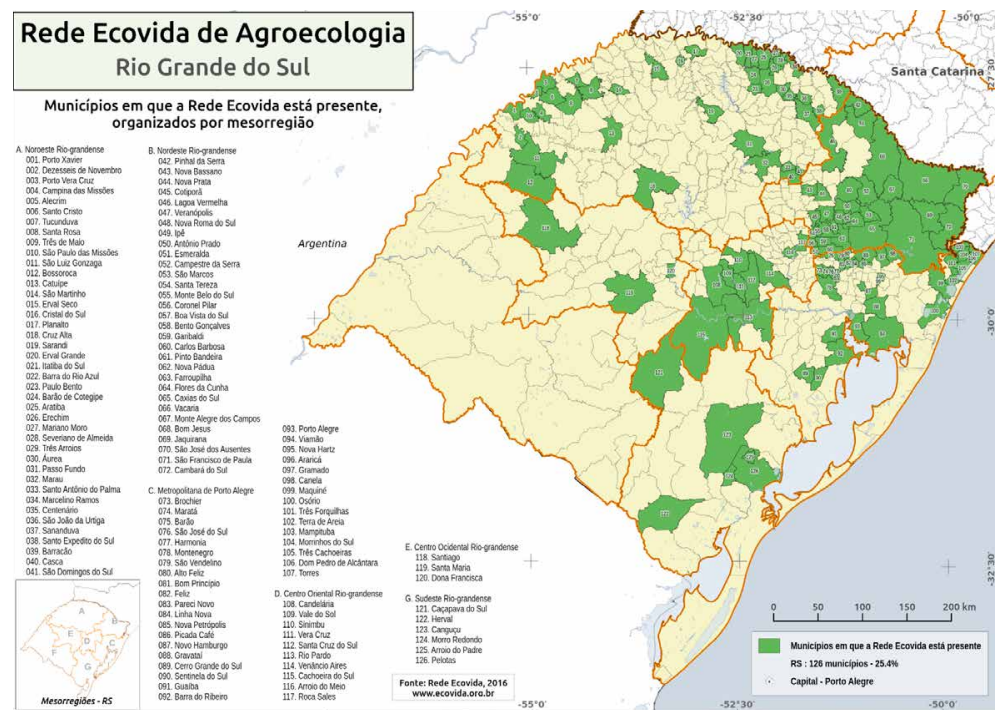

Fonte: Rede Ecovida, 2016.

Figura 8. Mapa de ocorrência da Rede Ecovida no Sul do Brasil

\section{REDE ECOVIDA DE AGROECOLOGIA}

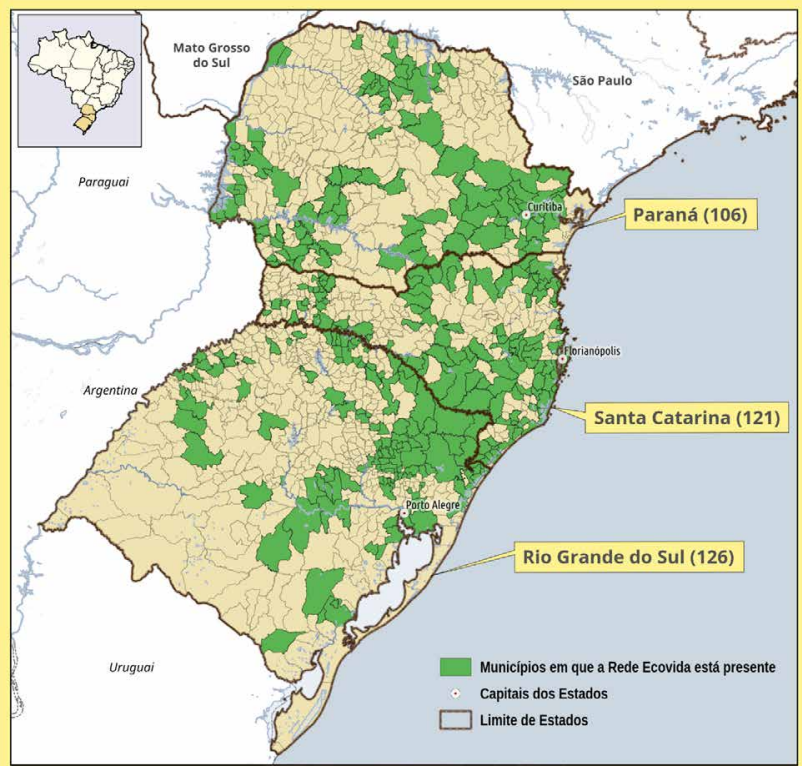

Fonte: Rede Ecovida, 2016 
Vale lembrar que esta presença tem sido crescente no decorrer dos anos. Dados iniciais, do final dos anos 1990 e início dos anos 2000, davam conta da presença de algo em torno de 350 famílias de agricultore(a)s integrando a Rede Ecovida. A ação articulada das organizações de agricultore(a)s, ONGs, grupos de consumidore(a)s em forma de rede indica que há uma reconhecida efetividade na metodologia, opção política e proposta técnico-produtiva e socioeconômica assumida em torno da agroecologia por estas organizações. Muito há de aprimorar-se ainda neste processo, mas o próprio avanço desenfreado do agronegócio neste mesmo período, impôs limites significativos ao avanço da agroecologia, tais como a deriva de agrotóxicos, a contaminação transgênica, a monopolização dos canais de comunicação, estabelecendo um ambiente desfavorável, principalmente no meio rural à proposição de modelos alternativos ao hegemonicamente estabelecido.

Esse avanço esteve fortemente apoiado em políticas de governo, mas é preciso reconhecer que a partir do ano de 2003, com a ascenção do governo Lula, para além do apoio declarado ao agronegócio, também foi possível construir um conjunto de políticas que deram impulso à iniciativas no campo da agroecologia.

Neste contexto de limites e avanços, apoios e enfrentamentos, um dos importantes espaços de crescimento da agroecologia foi a abertura dos mercados institucionais, por meio do Programa de Aquisição de Alimentos (PAA) e das aquisições da agricultura familiar na alimentação escolar. Essas políticas vieram a qualificar uma estratégia há muito adotada pelos grupos que integram a Rede, de diversificar seus canais de comercialização, visando, prioritariamente, abastecer os mercados locais. Essa perspectiva de comercialização construída pelo coletivo de organizações que integram a Rede Ecovida será tratada na próxima seção.

\section{A Rede Ecovida e seu ideário de comercialização}

Em todo esse processo de constituição, fortalecimento e consolidação da Rede Ecovida de Agroecologia esteve presente a formulação e prática de uma etapa importante da produção agrícola: a comercialização. Nos primórdios da Rede, mesmo antes de seu surgimento como tal, a busca do que então se chamava comercialização direta era uma preocupação constante. O desiderato de diminuir os elos que separam produção e consumo sempre foi buscado. 
Nos documentos gerados ao longo dos anos pela Rede Ecovida ela expressa seus princípios e objetivos de trabalho. Nestes documentos é evidente a orientação aos seus membros para buscarem estratégias de mercado baseadas no comércio justo e solidário e, consequentemente, a priorização dos mercados locais. Esse enfoque de mercados, conforme apontado na seção anterior, mais do que uma proposição política, representa a prática e o pensamento das organizações no momento de criação e estabelecimento da Rede Ecovida, que procurou agregar os objetivos e ideais de seus integrantes em um espaço político comum. O caderno de formação $\mathrm{n}^{\circ} 1$ descreve de forma mais detalhada seus princípios e nele se destacam os seguintes princípios em relação à comercialização:

- Fortalecimento das relações de economia popular solidária na Rede e a articulação junto a outros espaços e formas de mercado justo e solidário.

- Priorização da relação direta com os consumidores(as), o abastecimento local e regional, com perspectivas à segurança e soberania alimentar.

- Oposição a qualquer forma de exploração ou opressão seja econômica, política, social, de gênero ou geração (REDE ECOVIDA, 2007a, p. 15).

A perspectiva de uma relação diferenciada com os mercados encontra-se integrada à própria dinâmica de organização e funcionamento da Rede Ecovida. Em seus critérios de certificação, descritos no caderno de formação sobre certificação participativa, observam-se orientações bastante claras no que se refere ao perfil de mercados e ao tipo de relação que se pretende estabelecer. A proposição de formas alternativas de mercado compreende-se como critério para inserção e certificação no âmbito da Rede Ecovida. No que se refere às "normas de produção ecológica", no campo das "regras gerais", destaca-se um item que trata da comercialização, no qual se propõe como objetivos para os grupos de agricultores que pretendem ser certificados:

- O acesso de toda população aos produtos ecológicos, independente do nível de renda. Para isto os produtos devem ser ofertados a preços que sejam justos ao produtor e acessíveis aos consumidores;

- O estabelecimento de relações mais próximas entre agricultores e consumidores através de formas de comercialização que priorizem a venda direta e/ou que reduzam ao máximo as intermediações;

- A valorização e priorização no atendimento ao mercado interno (REDE ECOVIDA, 2004, p. 16). 
Os dados objetivos sobre volumes e canais de comercialização dentro da Rede são escassos. Podemos afirmar que a Rede Ecovida não conhece em detalhes a Rede Ecovida. A estrutura descentralizada, a falta de uma maior institucionalidade e a pouca cultura de sistematização de dados são algumas das razões.

Os dados da pesquisa de campo realizada nos anos de 2010-2011 na tese de doutoramento de PEREZ-CASSARINO (2012) são um esforço importante no sentido de consolidar informações sobre os diferentes canais de comercialização construídos pelos grupos da Rede e seu volume de comercialização. Mas o dinamismo natural dos processos de comercialização nos impede considerar que os dados de cinco anos atrás são válidos do ponto de vista quantitativo.

No entanto, o conhecimento da realidade da Rede Ecovida por parte dos autores e o acompanhamento às dinâmicas de comercialização que nela ocorrem permitem afirmar que o perfil e o peso de cada iniciativa de comercialização em relação às demais têm se mantido no decorrer dos anos. Dessa forma, os dados serão apresentados no sentido de estabelecer comparativos entre as diferentes formas de comercialização da Rede, que possibilitam a análise entre os pressupostos propostos pela Rede em seus documentos e a prática de comercialização das organizações que a integram.

Um dos aspectos a destacar na estratégia de comercialização construída pelas organizações que integram a Rede Ecovida é que na quase totalidade dos núcleos regionais, as feiras ecológicas são as protagonistas do processo de comercialização. Estima-se que hoje ocorram mais de 250 feiras ecológicas em mais de 200 municípios do Sul do Brasil (em 2011 eram 165 feiras), em municípios de pequeno, médio e grande porte. Em 2011, as feiras representavam mais de $40 \%$ do volume mensal total comercializado pelos grupos que integram a Rede Ecovida.

As feiras são vistas dentro da Rede como a expressão mais genuína do que ela busca como estratégia de comercialização. São um instrumento fundamental para popularizar e democratizar o acesso a produtos ecológicos. Promovem o consumo de produtos locais. Os preços são convenientes para quem produz e para quem consome. E ainda podemos dizer que existe uma forte tendência que as bancas de uma feira expressem integralmente a biodiversidade que caracteriza uma propriedade manejada com o enfoque agroecológico.

É importante notar que as feiras têm se caracterizado como o "ponto de partida" para a comercialização nos grupos da Rede, construindo uma cultura, desde o início da construção dos mercados por parte dos grupos, de que a relação direta com os 
consumidores, a sociabilidade nos espaços de comercialização, a valorização do papel do agricultor, a diversificação da produção, o atendimento aos mercados locais - valores intrínsecos às feiras - configuram-se como pressupostos da estratégia de comercialização construída pelas famílias que integram a Rede Ecovida.

O segundo equipamento de comercialização mais relevante entre os grupos da Rede Ecovida são os mercados institucionais. Com o declínio do Programa de Aquisição de Alimentos (PAA) como política pública acessível aos agricultores familiares, o mercado institucional hoje está centrado basicamente no Programa Nacional de Alimentação Escolar (PNAE).

Em 2010-11, pouco mais de $20 \%$ do volume comercializado pela Rede Ecovida envolvia os mercados institucionais, porém os dados refletiam fundamentalmente a execução do PAA. É a partir de 2011-12 que as compras no PNAE se expandem e boa parte das prefeituras e governos de Estado passam a realizar chamadas públicas para as compras da agricultura familiar de forma mais estruturada. De forma a exemplificar, os dados de 2010-11 indicavam um número próximo a R 1 milhão/mês em produtos ecológicos comercializados no âmbito da Rede nestes mercados. Em 2015, somente o Núcleo Mauricio Burmeister do Amaral, da região metropolitana de Curitiba-PR, comercializou cerca de R $\$ 400$ mil/mês nas chamadas públicas municipais e estadual na região.

Apesar do estímulo aos mercados locais e a prioridade às relações diretas entre agricultor e consumidor - conforme se observa nas feiras e mercado institucional -, os grupos de agricultore(a)s também têm realizado esforços em diversificar suas estratégias de comercialização, o que significa acessar também os canais estabelecidos de produtos orgânicos. As vendas no varejo "convencional" (supermercados, lojas especializadas, distribuidoras de produtos orgânicos, restaurantes, empresas, etc) representava em 2011 pouco mais de $20 \%$ do volume comercializado pelos grupos pesquisados. Essa tendência tem sido mantida na Rede.

Essa comercialização extrapola em muitos casos o mercado local, deslocando produtos para outros Estados e regiões. De uma forma geral, gestores dos processos de comercialização tem afirmado que a demanda é maior do que a oferta de produtos e que, apesar de serem mercados de nicho, ainda encontram-se em franca expansão.

Isso tem permitido melhores condições de negociação por parte dos grupos, não tendo que enfrentar, na maioria dos casos, as condições características que estes mercados impõe aos seus fornecedores, tais como rígidas exigências de 
padronização dos produtos, devolução de sobras, extensão dos prazos de pagamento, entrega de "enxovais", exigência de repositores, entre outros fatores, que encarecem os custos e exigem uma logística e gestão mais elaborada.

Não se observa, porém, uma preocupação ou reflexão mais aprofundada dos grupos e núcleos da Rede sobre os riscos de uma mudança no processo de negociação com a possível imposição de algumas ou todas as condições impostas aos fornecedores "convencionais" desses canais, notadamente grandes redes supermercadistas.

Ainda como uma proposta de construção alternativa de mercados, um dos mecanismos que têm sido estimulada no âmbito da Rede Ecovida nos últimos anos, com a entrada no mercado institucional, é a abertura de pontos fixos, ou seja, lojas de comercialização de produtos ecológicos gestionadas por membros da Rede. Seus desenhos variam de acordo com as regiões, há pontos fixos mantidos por associações de agricultores e outros por empreendedores individuais familiares, consumidores e/ou agricultores filiados à Rede. No entanto, os pontos que mais têm chamado a atenção são aqueles abertos por organizações de consumidores, geralmente cooperativas que articulam consumidores de um bairro ou município e se organizam no intuito de manter um espaço que permita a comercialização permanente de produtos ecológicos no decorrer da semana.

Apesar de ainda serem poucos os pontos (31 mapeados em 2011), é uma estratégia que se encontra em expansão e muito valorizada pelos grupos da Rede e consumidores, uma vez que permitem o abastecimento mais regular e não somente em alguns dias da semana, tal qual as feiras ecológicas. Em 2010-11 representava pouco mais de $5 \%$ do volume mensal total comercializado pelos grupos. Porém, seu processo de gestão e os custos de manutenção de um espaço regular (locação, funcionários, custos de manutenção etc.) dificultam a difusão desta estratégia de forma mais ampla, sendo que o apoio do poder público cumpre um papel relevante no estímulo e expansão destas iniciativas, tais quais pode se observar em alguns municípios com os Centros de Comercialização Permanentes da Agricultura Familiar (CCPAF), espaços muitas vezes apoiados pelo Poder Público para viabilizar a comercialização da agricultura familiar em seus municípios. Somente no Paraná são mais de 40 em funcionamento, com diferentes dinâmicas e formas de gestão (BISCHOF, 2016), mas que servem como referência para implementar ações públicas voltadas à especificidade dos produtos ecológicos. 
276

No estudo realizado em 2010-11, as demais estratégias de comercialização foram agrupadas em um item chamado "outras iniciativas", que incluía entregas residenciais, cestas e exportação, as quais representam um volume reduzido no âmbito da Rede Ecovida. No total, essas iniciativas somam um volume financeiro inferior a 5\% do volume total comercializado pelos grupos da Rede Ecovida.

\section{A inovação proposta pelo Circuito Sul de Circulação de Alimentos Ecológicos}

Uma análise à parte merece ser realizada para o caso do Circuito Sul de Circulação de Alimentos Ecológicos. O Circuito Sul começou a estruturar-se em meados de 2006, visando ao intercâmbio de produtos entre alguns núcleos da Rede Ecovida de Agroecologia, a fim de garantir maior oferta de produtos nas feiras e demais canais de comercialização, bem como superar a sazonalidade da produção em cada região. Da mesma forma, o Circuito visa aumentar a oferta de alimentos ecológicos para as próprias famílias agricultoras. A comercialização se dá basicamente por meio da troca de produtos entre as associações de cada região. As rotas estabelecidas comunicam os núcleos entre si, recolhendo produtos das associações que se situam no âmbito da rota. Como norma geral, cada associação, por meio de seus canais de comercialização, demanda volumes de produtos próximos aos que ofertam. As rotas principais funcionam semanalmente e hoje têm cumprido um importante papel no aumento da diversidade de oferta nas feiras e para o mercado institucional, principalmente no atendimento aos editais do PNAE (MARFIL, 2009).

O Circuito se organiza em "estações", que correspondem às organizações envolvidas em cada Núcleo Regional com o intercâmbio de produtos. A articulação entre pedidos e oferta se dá por comunicações telefônicas e via internet, feitas entre os agricultores interessados, havendo pouco envolvimento das organizações de assessoria. O intercâmbio de produtos conta com quase nenhuma estrutura física de suporte, de fato, os caminhões se encontram nas estações e vão realizando a troca de produtos entre um caminhão e outro, seguindo viagem de retorno para suas estações. Apesar de ainda ter muitos desafios a superar, principalmente em termos de facilidade de comunicação e de logística para a comercialização, o Circuito tem se caracterizado como uma das principais inovações 
em termos de comercialização no âmbito da Rede. Seu funcionamento, apesar de ainda demandar, em alguns casos, a realização de grandes distâncias, representa importante fator de garantia de regularidade e aumento da oferta de produtos, portanto de garantia de abastecimento.

A seguir tem-se o mapa de rotas do Circuito. O funcionamento delas não é fixo, ou seja, algumas funcionam em determinados períodos do ano somente. Da mesma forma, pequenos ramais se formam em torno dessas rotas, que ligam os grupos próximos às rotas principais. A rota mais frequente e com maiores volumes até o momento no Circuito é a que corresponde ao trecho "Erechim/ RS-Curitiba/PR", que funciona semanalmente (Figura 9). Segundo Marfil (2014), o Circuito Sul tem incrementado seus volumes de comercialização ano a ano. Em 2014, foram mais de 3.500 toneladas de alimentos circulando entre as rotas do Circuito, envolvendo cerca de 1500 famílias em seu funcionamento.

Figura 9 - Mapa das rotas do Circuito Sul de comercialização da Rede Ecovida

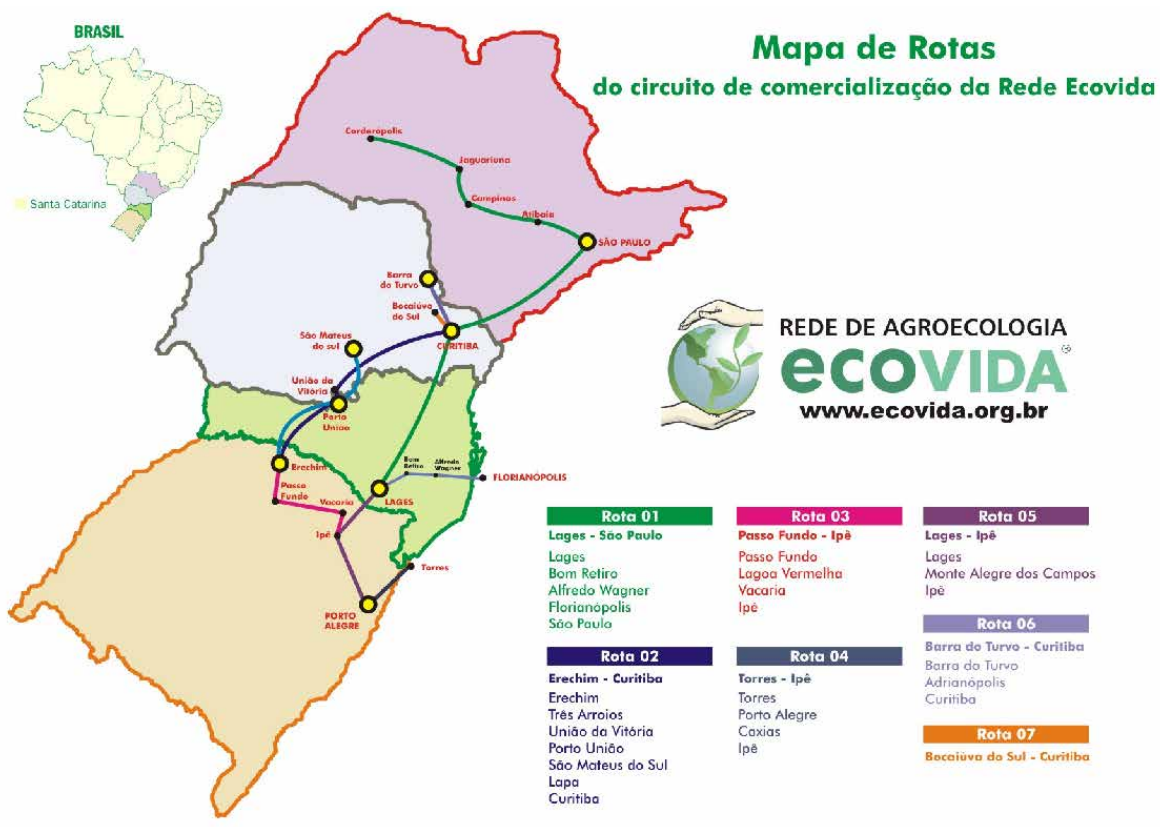

Fonte: DAROLT et al. (2016). 
Segundo Darolt et al. (2016), as seguintes rotas se encontram em funcionamento no ano de 2016, vinculando as mais diferentes estações, sendo que umas funcionam permanentemente e outras podem funcionar somente em períodos de safra ou demanda de produtos:

a) Estações-núcleo: são dez e estão localizadas nos Estados do RS, SC, PR, SP, MG e BA;

b) Conexões e subestações: são dezessete no Estado do RS, quatorze no Estado de SC, vinte seis no Estado do PR, quatro no Estado de SP uma no estado de MG e três no Estado da BA;

c) Número de municípios: 73 municípios;

d) Quantidade de Rotas Longas (mais de $300 \mathrm{Km}$ ): 09 rotas;

e) Quantidade de Rotas Médias (de $50 \mathrm{Km}$ a $300 \mathrm{Km}$ ): 11 rotas;

f) Quantidade de Rotas Curtas (Local até $50 \mathrm{Km}$ ): 24 rotas.

Como síntese do levantamento até aqui realizado sobre a dinâmica e iniciativas de comercialização na Rede Ecovida, foram elaborados mapas da incidência da Rede nos três estados do Sul do Brasil, destacando quais as iniciativas de comercialização presentes em cada município. A Figura 10 apresenta a distribuição das iniciativas de comercialização e grupos da Rede Ecovida em cada estado, considerando os 17 núcleos regionais (de uma total de 26, mas que em termos de volume representam cerca de $80 \%$ da comercialização da Rede) que enviaram as informações que compõem o levantamento de 2010-11 (PEREZ-CASSARINO, 2012). 
Figura 10 - presença da Rede Ecovida e seus canais de comercialização
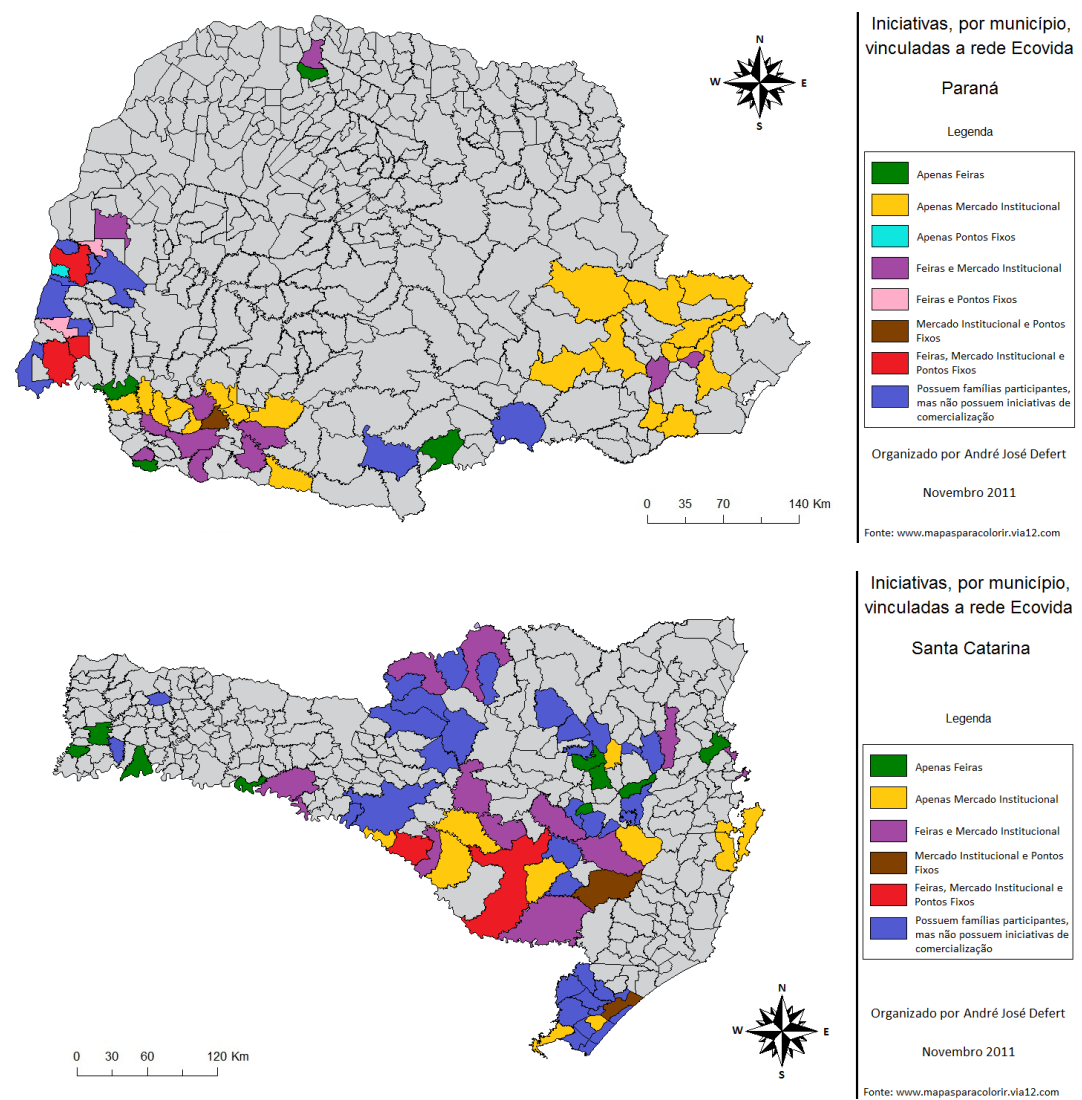

Iniciativas, por municipio vinculadas a rede Ecovida Santa Catarina
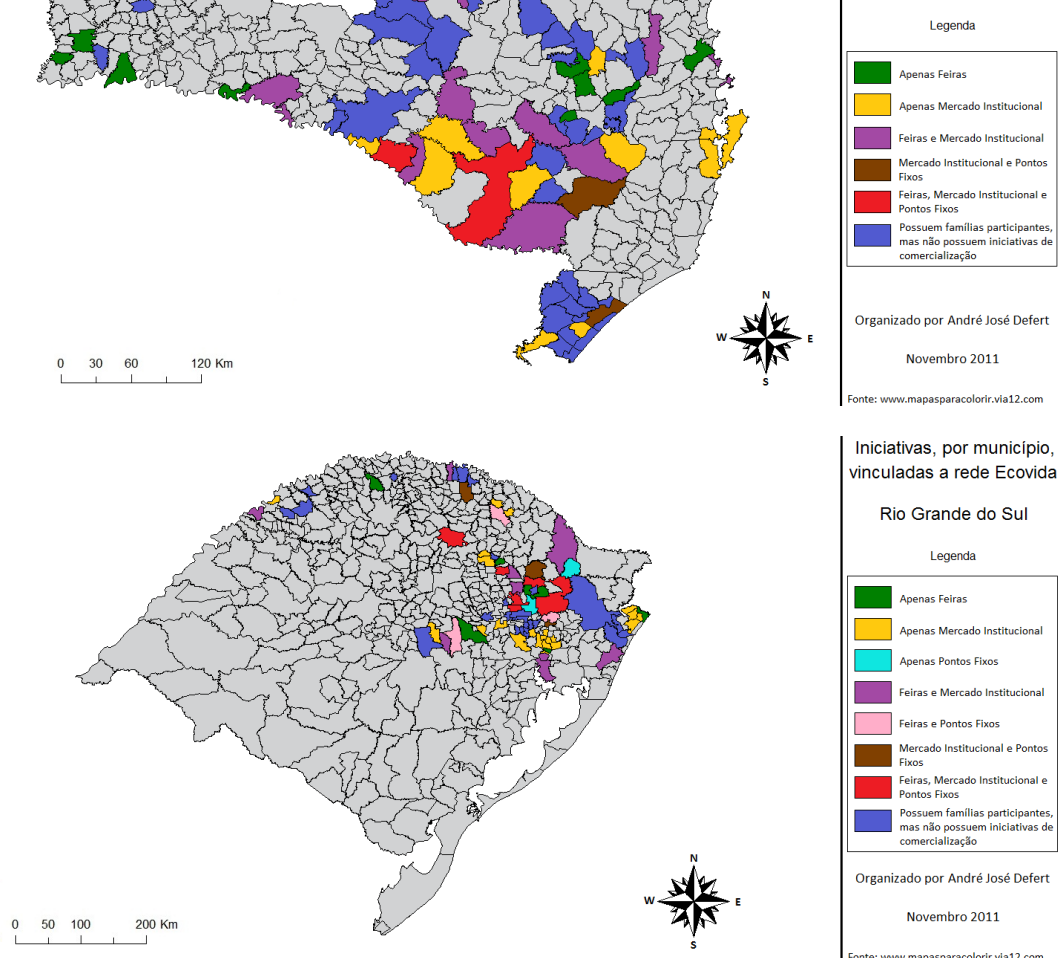

Iniciativas, por municipio, vinculadas a rede Ecovida Rio Grande do Sul

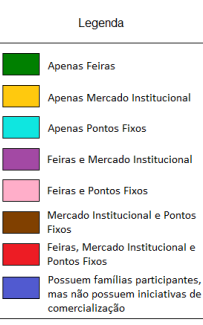

Organizado por André José Defert Novembro 2011

Fonte: Perez-Cassarino, 2012. 
Apesar da ausência de vários municípios neste levantamento, os dados revelam a presença e a diversidade de formas de comercialização dentro da Rede Ecovida de Agroecologia. Este aspecto configura-se como um dos elementos centrais da estratégia de comercialização constituída pelos grupos que compõe a Rede, pautado não somente pela busca da aproximação entre produtores e consumidores e o fortalecimento dos mercados locais, mas também pela diversificação de canais de comercialização como forma de garantir a autonomia das famílias e suas organizações (PEREZ-CASSARINO, 2012).

\section{Considerações finais}

A Rede Ecovida de Agroecologia tem se consolidado como uma articulação de organizações que se tornou uma das referências no debate em torno da comercialização e certificação alternativas. Até o presente momento, no entanto, apesar dos vários estudos em torno da Rede, poucas eram as informações que tornavam visível o discurso e proposta de trabalho a que a Rede se propõe.

Os dados coletados e a análise realizada nos permitem afirmar que as organizações que integram a Rede Ecovida têm se orientado pela perspectiva da construção social dos mercados (MALUF, 2004; WILKINSON, 2008), que busca construir formas de abastecimento alimentar que estejam socialmente enraizadas - tendo a aproximação agricultor-consumidor como pressuposto - e ambientalmente situadas.

A análise aqui realizada se coloca como uma sistematização da colaboração que a Rede Ecovida tem proporcionado no redesenho dos sistemas agroalimentares e, neste caso, na proposição de referências apara a construção de uma estratégia de abastecimento alimentar orientada pela promoção da Soberania e Segurança Alimentar e Nutricional (MALUF, 2009, SEVILLA-GUZMÁN; SOLER, 2010).

A partir da leitura do perfil da comercialização no âmbito da Rede Ecovida de Agroecologia, pôde-se observar que os grupos que a integram têm procurado estabelecer uma prioridade no que se refere ao atendimento dos mercados locais. Da mesma forma, observa-se que prevalecem as estratégias focadas na aproximação agricultor-consumidor e os esforços por construir mecanismos de mercado que evitem intermediações. Esse esforço da Rede em estabelecer canais de comercialização mais populares, pode ser interpretado como um sinal de coerência com seus objetivos, que pressupõe uma massificação dos processos 
agroecológicos bem como uma leitura da agroecologia que vai para além do produtivo, engloba dimensões sociais e políticas e apontam para a construção de uma sociedade orientada pelos princípios da solidariedade, da preservação ambiental e da justiça em seu mais amplo sentido.

\section{REFERÊNCIAS}

BISCHOF, Maristela. A construção social de mercados nos Centros de Comercialização Permanentes da Agricultura Familiar. Dissertação (Mestrado em Meio Ambiente e Desenvolvimento) - Universidade Federal do Paraná, Curitiba, 2016.

BRASIL. Ministério da Agricultura, Pecuária e Abastecimento. Instrução Normativa 07 de 17 de maio de 1999. Disponível em: <www.planetaorganico.com.br/instnorm.htm>. Acesso em: 18 jan. 2012.

Presidência da República. Lei 10.831, de 23 de dezembro de 2003. Disponível em: <http://www.planalto.gov.br/ccivil_03/leis/2003/L10.831.htm>. Acesso em: 7 jan. 2012.

DAROLT, Moacir Roberto; GRANDO, Gustavo H Ceccon; ALMEIDA, Fabíola R. R. Membros de Circuito. Cartilha - Circuito Sul de Circulação e Comercialização de Alimentos Ecológicos da Rede Ecovida de Agroecologia. Curitiba: 2016 (mimeo).

MALUF, Renato. Mercados Agroalimentares e a agricultura familiar no Brasil: agregação de valor, cadeias integradas e circuitos regionais. In: Ensaios FEE, Porto Alegre: FEE/UFRGS, v. 25, nº 1, p. 299-33, 2004.

. Segurança Alimentar e Nutricional. Petrópolis: Vozes, 2009.

MARFIL, José Antonio da Silva. Circuito de Comercialização da Rede Ecovida de Agroecologia. Palestra proferida no VII Encontro Ampliado da Rede Ecovida de Agroecologia, Ipê, 13 a 15 de novembro de 2009.

. Circuito de Comercialização da Rede Ecovida de Agroecologia. Palestra proferida no IX Encontro Ampliado da Rede Ecovida de Agroecologia, Marechal Cândido Rondon, 20 a 22 de abril de 2015.

MARQUES, Claudio Luiz Guimarâes et al. Formación y consolidación de la Red Ecovida de Agroecología. In: Encuentro latinoamericano de comercialización y certificación orgánica y mercado justo. Quito: MAELA, 23 al 26 de octubre del 2001.

MEIRELLES, Laércio. Credenciamento OPAC Ecovida. [Mensagem de trabalho]. Mensagem recebida por: <rede-ecovida@googlegroups.com>. Em: 02 dez. 2010.

PEREZ-CASSARINO, J. A construção de mecanismos alternativos de mercados no âmbito da Rede Ecovida de Agroecologia. Tese (Doutorado em Meio Ambiente e Desenvolvimento) - Universidade Federal do Paraná, Curitiba, 2012. 
REDE ECOVIDA DE AGROECOLOGIA. Normas de Organização e Funcionamento. Lages: Rede Ecovida, 2000 (mimeo).

. Normas Simplificadas da Rede Ecovida. Ipê: Rede Ecovida de Agroecologia, 2001(mimeo).

. Rede Ecovida de Agroecologia. Passo Fundo, [200-]. 1 fôlder.

. Planejamento da Rede Ecovida de Agroecologia. Lages: Rede Ecovida de Agroecologia, 2002. Relatório de Plenária de Núcleos da Rede Ecovida.

. $4^{\mathrm{O}}$ Encontro Ampliado: cultivando a ética e reproduzindo a vida. Jornal da Programação. Passo Fundo, 13 maio 2003.

. Certificação participativa de produtos ecológicos. Caderno de Formação. Florianópolis: Rede Ecovida de Agroecologia, 2004.

. Certificación participativa de productos ecológicos. Cuaderno de Formación. Trad. Maria Perez-Cassarino. San José: CEDECO, [2005?].

. Training manual of participatory guarantee of ecological products. Trad. Margareth Carneiro. Florianópolis: Rede Ecovida de Agroecologia: [200-].

. Uma identidade que se constrói em Rede. Caderno de Formação no 1 . Curitiba: Rede Ecovida de Agroecologia, 2007a.

. $6^{\circ}$ Encontro Ampliado da Rede Ecovida: nossa identidade se constrói em rede. Jornal do(a) Participante. Lapa, 17 jul. 2007.

. $7^{\circ}$ Encontro Ampliado da Rede Ecovida: agricultura familiar ecológica: produzindo alimentos, alimentando sonhos. Jornal do Encontro. Ipê, 13 nov. 2009.

Plenária da Rede Ecovida de Agroecologia. Lages, agosto 2010. Gravação digital, debate sobre regulamentação da certificação participativa na Rede Ecovida.

. Apresentação sobre distribuição da Rede Ecovida nos Estados. Apresentação realizada em reunião de coordenação. Março de 2016

SEVILLA GUZMAN, Eduardo; SOLER, Marta. Agroecología y soberanía alimentaria: alternativas a la globalización agroalimentaria. In: Patrimonio cultural en la nueva ruralidad andaluza. PH Cuadernos. Vol. 26. Sevilla: Consejería de Cultura/Junta de Andalucía, 2010.

SOUZA, Marcelo Santos. A Agroecologia no Brasil e o caso da Rede Ecovida. In: Seminário: modelos de desenvolvimento da agricultura familiar e políticas agrícolas nacionais e internacionais: comparação França/ Europa/ Brasil. Paris, 10 de novembro de 2003.

WILKINSON, John. Mercados, redes e valores: o novo mundo da agricultura familiar. Porto Alegre: UFRGS, Programa de Pós-Graduação em Desenvolvimento Rural, 2008. 


\title{
Comercialización y agroecología en Uruguay
}

\author{
Alberto Gómez Perazzoli \\ Inés Gazzano \\ Analía Cartelle \\ Federico Bizzozero
}

\section{Introducción}

Asistimos en Uruguay a un proceso de intensificación agraria, impulsado por el crecimiento económico de la producción exportable con impactos sobre la sustentabilidad en aspectos económicos, sociales y ambientales. En una situación mundial de mayor inestabilidad debido a la globalización del sistema alimentario, el agotamiento y/o degradación de los recursos naturales y el cambio climático. Es fundamental promover la transición hacia nuevas formas de organizar la producción, distribución y consumo de alimentos integrando un enfoque agroecológico.

Existe experiencia acumulada en Uruguay en producción ecológica, estrategias comerciales diversas y organizacionales entre productores/as y consumidores/ as; sistemas de certificación participativa y algunos esfuerzos de fomentar el desarrollo de la agricultura familiar en general. Diversos actores están impulsando actualmente un Plan Nacional de Agroecología promoviendo agriculturas más biodiversas, resilientes y socialmente justas. Se parte de fortalecer el desarrollo del potencial endógeno; restaurar y potenciar el funcionamiento ecosistémico, donde los insumos externos son reemplazados por procesos naturales, para desarrollar agroecosistemas sustentables.

La conservación de los bienes naturales es un aspecto central vinculado al objetivo de producir y abastecer de alimentos sanos a la población, las estrategias 
productivas y comerciales de los productores agroecológicos integran estos fundamentos y se relacionan también a formas de mejorar los ingresos y medios de sustento de la población rural, aumentando la resiliencia de los sistemas productivos y disminuyendo el riesgo frente a condiciones ambientales y de mercado.

El trabajo analiza la producción, comercialización y certificación de la producción ecológica en Uruguay, centrado en los aportes de un taller sobre comercialización de productos ecológicos, realizado con la participación de agricultores/as y personas vinculadas a la comercialización, procesamiento, consumidores y técnicos/as de la Red de agroecología, a partir del cual se plantea un primer diagnóstico y se desarrollan algunas propuestas, desde la visión de los actores. Dentro de esta concepción dentro de la transformación del sistema agroalimentario, la comercialización pasa a ser un elemento clave para el rediseño agroecológico en escalas amplias.

\section{Contexto: producción agropecuaria en Uruguay}

Uruguay es uno de los países de menor densidad de población de

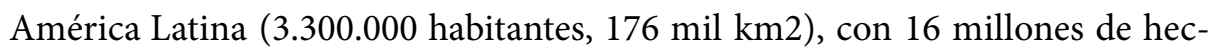
táreas destinadas a la producción agropecuaria. De acuerdo al tipo de producción $78 \%$ de la tierra se dedica a ganadería, $10 \%$ a agricultura, $7 \%$ a forestación y $6 \%$ a otros usos. El producto bruto interno (PBI) agroindustrial es del $12 \%$ del total y el sector agropecuario es muy relevante por su participación en el comercio exterior: las exportaciones del sector agropecuario/agroindustrial representan una fracción creciente de las exportaciones de bienes y servicios, pasan de 55-60\% en 1985 para más del 75\% en 2011. (PAOLINO Y MONDELLI, 2013; DIEA-MGAP, 2016).

El país ha crecido económicamente, con tasas altas en relación a su historia: entre 2003 y 2013, el PBI nacional aumenta el 73\%, gran parte de este crecimiento se explica por el aumento de la agricultura de granos (principalmente soja) que crece $120 \%$.

Uruguay ha tenido históricamente dos formas de producción agropecuarias: por un lado las estancias ganaderas, basadas en el pastoreo extensivo de pasturas naturales y empresas agrícolas dedicadas a la exportación y por otro la 
agricultura familiar, orientada hacia el mercado interno o vinculada en forma subordinada a cadenas de exportación.

En los últimos años se observa un proceso de intensificación agrícola, caracterizada por el crecimiento de la agricultura (principalmente soja) y la forestación, impulsadas por la rentabilidad asociada a un ciclo de precios altos de los comodities. Esto trajo como consecuencia aumento del precio, concentración y extranjerización de la tierra. Actualmente las familias agricultoras representan el 61,1 \% del total y ocupan el 13,8 \% del área agropecuaria, el 55\% de las explotaciones (entre 1 y 99 ha) reúnen el 4,5\% de la superficie, mientras el 9,3\% de las explotaciones superior a 1000 ha acumulan más de $61,3 \%$ de la superficie, lo que muestra la enorme concentración de la propiedad de la tierra que existe en Uruguay (DIEA, 2011).

La profundización del modelo industrial de agricultura se fundamenta en la ampliación de escala, en base a la tecnología de cultivos genéticamente modificados (soja y maíz) y su paquete asociado de alto uso de insumos: entre 2002 y 2014 las importaciones en $\mathrm{Kg}$ de principio activo, aumentaron en herbicidas $874 \%$; insecticidas $175 \%$ y funguicidas $195 \%$ (MGAP, 2016). Para el pe ríodo 2000 a 2014 , la importación de fertilizantes aumentó 340 \% (DIEA, 2016). La producción de cultivos cerealeros e industriales, aumentó 390\% entre 2000 y 2014 y el área $370 \%$. El rendimiento, para el caso de la soja, aumenta un $36 \%$ entre 2000 y 2014, por lo que el aumento de producción se explica fundamentalmente por un crecimiento del área. En el caso de los plaguicidas las cifras indican un aumento de la cantidad por hectárea y por unidad de producto (DIEA, 2016).

A la agricultura convencional y al cambio de uso del suelo; se asocia la degradación ambiental, involucrando procesos como degradación y desertificación de suelos; disminución y pérdida de biodiversidad; transformación del paisaje, pérdida y degradación de ecosistemas y su funcionalidad, deforestación eutrofización, sedimentación y contaminación de aguas, acumulación de residuos de pesticidas en los productos alimenticios, junto con problemas sociales y económicos tales como desplazamiento productivo, creciente inseguridad acerca de la productividad y rentabilidad futura de los establecimientos agrícolas y marginación de los productores de menos recursos (BIDEGAIN, et al. 2010; 
TISCORNIA, et al. 2014; MVOTMA, 2014; BRAZEIRO, et al. 2015; CHIAPPE Y PIÑEIRO, 2010).

Se constatan problemas de eutrofización en cursos de agua, varios de ellos son fuente de agua para el abastecimiento de los principales centros urbanos como el Río Santa Lucía, Laguna del Cisne, Laguna del Sauce (KRUK, et al, 2013; BONILLA, et al., 2015).

\section{Situación de la Producción, comercialización y certificación de la agricultura orgánica ${ }^{1}$ en Uruguay.}

En el país se registran 1.207.000 hectáreas orgánicas certificadas de ganadería de carne, con fines de exportación, se trata de 400 predios extensivos con superficies promedio de 2900 hectáreas cada uno. Por otro lado existen unos 120 agricultores certificados, asociados a la Red de Agroecología del Uruguay, que comercializan en el mercado interno hortalizas, frutas, lácteos, que trabajan predios de 7 ha en promedio. (DINAMA, 2015, Red de Agroecología del Uruguay, 2016). Este sector está constituido principalmente por agricultores familiares.

La superficie orgánica representa el 7\% del total agropecuario, es una superficie relevante; de acuerdo al total de hectáreas Uruguay es el séptimo país en el mundo y el segundo luego de Argentina en América Latina. Estas cifras toman en cuenta sólo agricultores certificados. Existe un sector no cuantificado, de agricultores rurales y urbanos, miembros de redes de conservación de semillas criollas, escuelas y otros centros educativos o terapéuticos que desarrollan prácticas agroecológicas. El consumo de productos orgánicos en el mercado interno es creciente y se vincula fundamentalmente a Montevideo y área metropolitana donde reside aproximadamente el 70\% de la población del país. (SORIANO FRAGA, 2012). A partir de 1999 se inicia la exportación de productos orgánicos, hoy centrada en carne y miel (GAZZANO y GÓMEZ PERAZZOLI, 2017).

\footnotetext{
1 En el texto se usa indistintamente orgánico y ecológico para referirse a "todo método de producción sustentable en el tiempo, que mediante manejo racional, preserve los recursos naturales, la diversidad biológica y el medio ambiente, sin la utilización de productos de síntesis química ni organismos genéticamente modificados (OGM) o derivados de estos" (Decreto MGAP 233. 17/11/2008).
} 
Desde las organizaciones sociales se viene impulsando un marco legal que implemente un Plan Nacional de Agroecología en un marco de soberanía alimentaria. Se propone crear una Comisión Honoraria para el Fomento de la Agroecología, con participación de representantes del Estado: varios ministerios del Poder Ejecutivo (de Ganadería y Agricultura, Medio Ambiente, Salud, Desarrollo Social y Oficina de Planeamiento y Presupuesto), instituciones públicas vinculadas a la investigación, innovación, extensión y educación y de miembros de la sociedad civil. Esta comisión dispondrá de un tiempo de 180 días para elaborar el plan definitivo y luego actuará en su monitoreo y evaluación. Entre otros puntos plantea promover un aumento en el número de productores y/o productoras bajo sistemas de producción, distribución y consumo de productos alimentarios con enfoque agroecológico y fomentar mercados locales y de cercanía para productos con enfoque agroecológico, favoreciendo la interacción entre productores/as y consumidores/as y fortaleciendo una cultura de consumo responsable (GAZZANO et al., 2016).

\section{Canales comerciales: mercado interno}

Los canales comerciales utilizados en el mercado interno, de acuerdo a su importancia, son los supermercados, puntos fijos de venta gestionados por los agricultores, ferias, reparto de canastas a domicilio, venta a agroindustrias y venta en los predios (Cuadro 1). Los/as agricultores/as han desarrollado estrategias diversificadas para abastecer el mercado interno. Por lo general se articulan en asociaciones, siendo las más comunes las cooperativas agrarias. En algunos casos existen organizaciones de consumidores que participan activamente en la gestión del abastecimiento. Mientras que la venta de productos frescos está gestionada por las organizaciones de productores/as, los productos procesados en su mayoría son producidos por empresas que compran la materia prima a productores/as ecológicos, la elaboran en agroindustrias locales y las comercializan en el conjunto de los canales. Algunas cooperativas de productores/as han comenzado a seguir esta misma estrategia, asociándose a agroindustrias locales para procesar hortalizas ecológicas, como por ejemplo salsa de tomate, kétchup o encurtidos. Crecientemente se encuentran en el mercado productos importados, en su mayor parte con algún grado de procesamiento, comercializados por 
empresas importadoras nacionales. Incluye productos de origen tropical que no pueden ser producidos en el país y de consumo importante como la banana, la yerba mate, el té y café.

Cuadro 1 - Evolución de la venta de productos ecológicos según canal comercial

\begin{tabular}{|l|l|l|l|l|}
\hline & 2012 (dólares/año) & $2012(\%)$ & 2007 & 1999 \\
\hline Supermercados & 1.200 .000 & 60 & 56 & 59 \\
\hline Ecotienda & 270.000 & 13 & 10 & - \\
\hline Ferias & 110.000 & 5 & 10 & 9 \\
\hline Canastas & 87.000 & 4 & 7 & 25 \\
\hline Otros & 341.000 & 17 & 17 & 9 \\
\hline TOTAL & $2: 008.000$ & 100 & 100 & 100 \\
\hline
\end{tabular}

Fuente: Soriano Fraga, G. 2012.

Los/as agricultores/as ecológicos tienen como estrategia el desarrollar circuitos cortos de comercialización, buscando un contacto más directo con la población consumidora y una mayor autonomía y control del proceso. El primer espacio de venta de alimentos ecológicos fue una feria que comenzó a funcionar en 1995, en Montevideo y continúa funcionando hasta la fecha (GÓMEZ PERAZZOLI, 2003). Hoy el número de ferias ha crecido, en la capital y en el interior del país. Existen dos experiencias de puestos fijos de venta, gestionados por cooperativas de agricultores/as en Montevideo (Ecotienda, creada en el 2005 y Ecomercado inaugurado en 2015). Tanto las ferias como los puntos fijos gestionados por productores/as llevan adelante actividades de promoción y difusión de alimentos ecológicos y son espacios de formación práctica en comercialización para agricultores y agricultoras. Diversas tiendas especializadas en alimentos naturales ofrecen alimentos ecológicos. El sector vinculado a la gastronomía presenta algunas experiencias de abastecimiento directo con agricultores/as, lo que les permite acceder a productos orgánicos y especialidades que no son comunes en el mercado convencional. Movimientos como Slow Food promueven la producción ecológica y la biodiversidad local, incorporando por ejemplo frutos nativos a las propuestas gastronómicas (ROSANO, 2012).

En los últimos años surgen espacios de comercialización en eventos que se realizan una vez por año, vinculados a alimentación saludable, gastronomía, ecología, productos artesanales o espacios culturales que ofrecen espacios de comercialización y difusión a los agricultores/as ecológicos. 


\section{Certificación}

La certificación de productos orgánicos se encuentra regulada en un "Sistema Nacional de Certificación de la Producción Orgánica” (Uruguay, 2008). El sistema reconoce la posibilidad de registrar certificadoras públicas o privadas de tercera parte y certificadoras participativas, que implementen Sistemas Participativos de Garantía. Permite la venta directa desde las personas productoras a las consumidoras, sin certificar, aunque agricultores/as deben seguir las normas de producción orgánica. La única certificadora habilitada por la autoridad competente, (Ministerio de Ganadería, Agricultura y Pesca, MGAP), es la Red de Agroecología del Uruguay, que evalúa la conformidad mediante un Sistema Participativo de Garantía integrado por agricultores/as, consumidores/as y técnicos/as. Funciona en forma descentralizada a nivel nacional y desarrolla otras áreas como el desarrollo de mercados locales, la capacitación, promueve la organización y el intercambio entre las personas dedicadas a la producción, procesamiento de alimentos, consumo y organizaciones de apoyo técnico y social.

El sector exportador es auditado por certificadoras internacionales de tercera parte, reconocidas en los mercados de destino pero no registradas ante la normativa nacional.

El reconocimiento legal de los sistemas participativos de garantía fue una conquista de organizaciones de agricultores y agricultoras ecológicos y organizaciones no gubernamentales de apoyo que señalaban que los sistemas de tercera parte, no resultaban apropiados para los agricultores familiares por la complejidad de los procedimientos y sus costos, que están determinados por las necesidades de un mercado global.

\section{La demanda y consumidores/as}

Las personas consumidoras de alimentos ecológicos los prefieren por atributos vinculados a la salud, ambiente y frescura. En la figura 1 se analizan los atributos valorados por consumidores/as de la Ecotienda (punto de venta de productos orgánicos gestionado por una cooperativa de productores/as), datos que confirman otras investigaciones. 
Figura 1 - Atributos valorados por personas consumidoras de Ecotienda

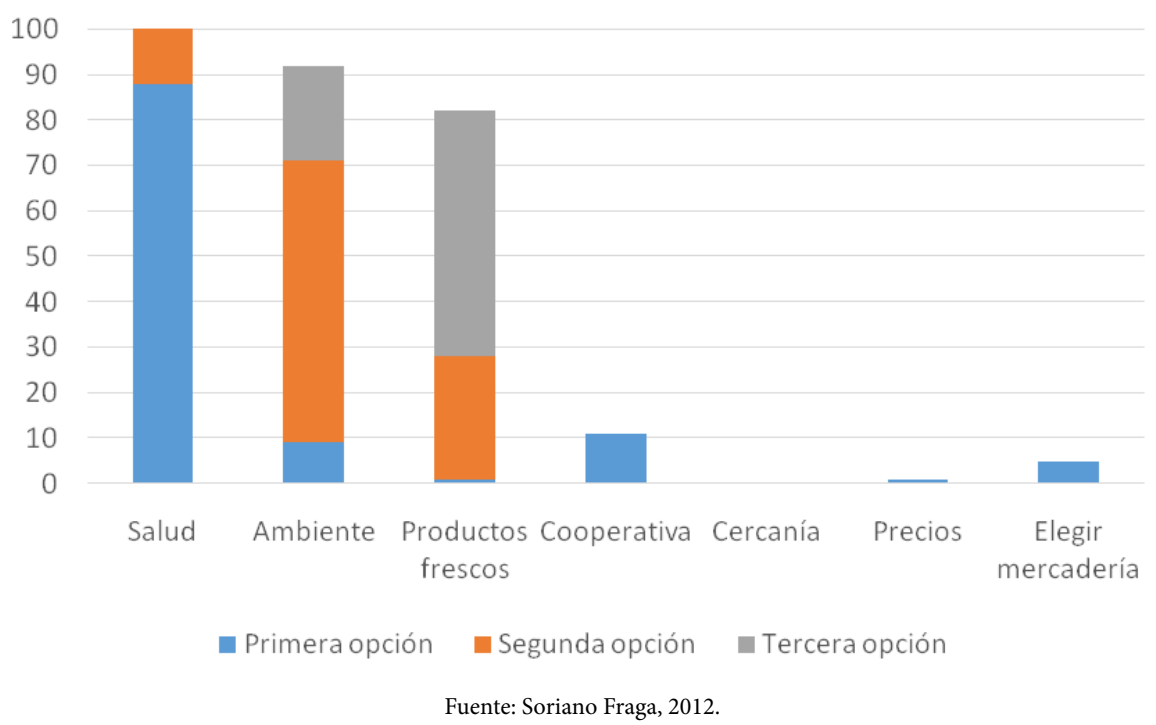

* Espontáneo, tres primeras menciones. Encuesta personal aplicada a 50 clientes de Ecotienda en forma coincidental, dentro del local de Ecotienda, en el momento de la compra en el año 2008.

En forma coincidente, dentro de los habitantes de Montevideo que conocen los productos orgánicos (aunque no los consuman), los principales atributos valorados son: salud (39\%), cuidado del ambiente $25 \%$, mejor sabor $20 \%$, más frescos 18\%. (INTERCONSULT, 2009)

\section{Acceso a los productos}

Dentro de las personas consumidoras que manifiestan conocer los productos orgánicos en Montevideo, la principal limitante es encontrarlos en los lugares a donde ellos concurren, factor incluso más importante que el precio (Figura 2). 
Figura 2 - Limitantes para adquirir productos orgánicos. (Total de menciones). Encuesta telefónica sobre hogares particulares de Montevideo

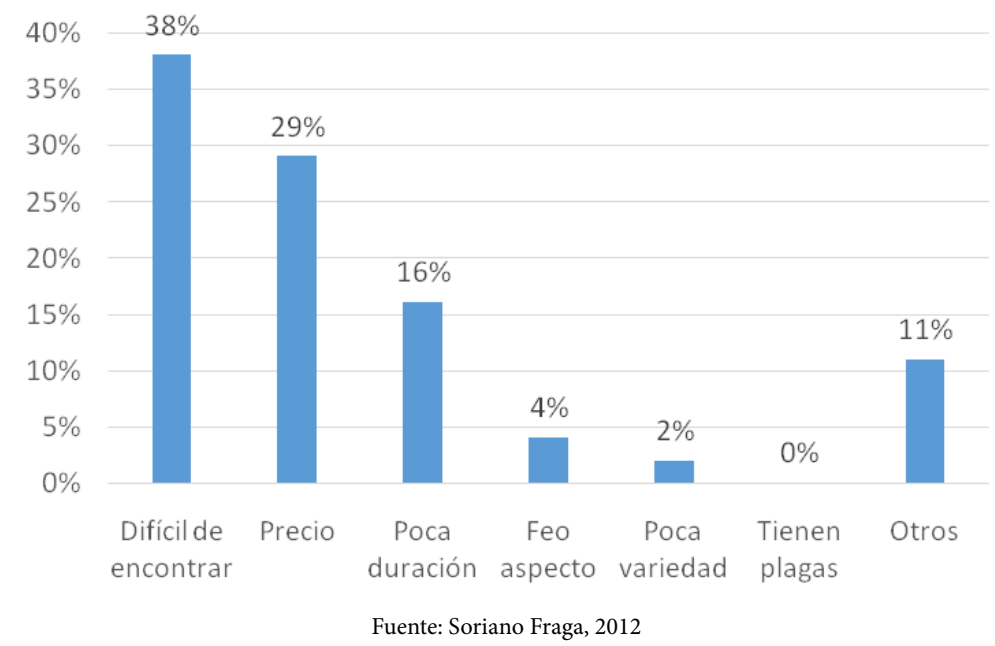

\section{Precios}

Los precios de productos orgánicos en supermercados son en promedio un $20 \%$ mayor que los convencionales. Sin embargo, la mayor parte de las personas consumidoras percibe que los productos orgánicos tienen un precio $40 \%$ mayor a los convencionales. El 38\% de consumidores/as declaran que estarían dispuestos a consumir productos orgánicos si el sobreprecio fuera del 20\%. Si el sobreprecio se ubica en el $40 \%$ aún un 15\% de personas consumidoras elegirían productos orgánicos sobre los convencionales (Figura 3). Este 15\% de consumo representa una demanda potencial cuatro veces mayor a la oferta actual de alimentos orgánicos (SORIANO FRAGA, 2012). 
Figura 3 - Elasticidad de la demanda al precio

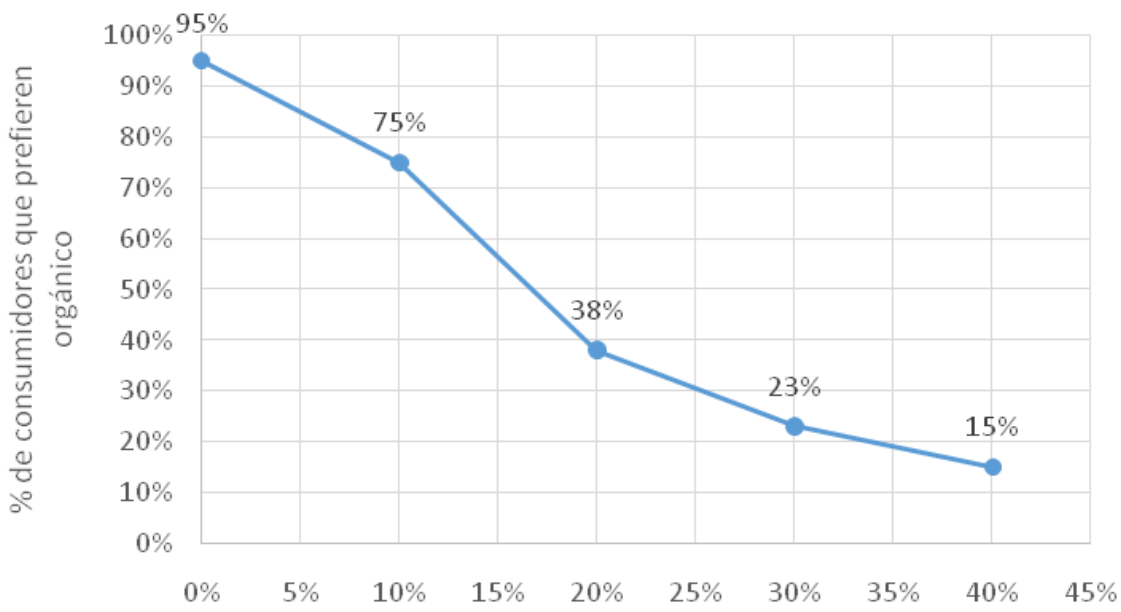

Sobreprecio orgánico vs convencional

Fuente: Soriano Fraga (2012)

* Declarada, en relación a los productos convencionales. Encuesta telefónica sobre hogares particulares de Montevideo.

Se puede afirmar que existe un amplio campo de crecimiendo del sector, existe una demanda potencial elevada, con consumidores/as que valoran los alimentos orgánicos porque lo asocian con la salud y el ambiente. Se plantea el desafío de ampliar los canales de distribución para mejorar el acceso a los productos.

\section{La visión de los actores en la Red de Agroecología}

La Red de Agroecología del Uruguay articula agricultores y agricultoras ecológicos, consumidoras/os, personas dedicadas al procesamiento y distribución de alimentos y diversas organizaciones sociales, instituciones y personas que comparten una visión positiva e integral sobre los impactos sociales, económicos y ambientales de la agroecología y acuerdan contribuir a su desarrollo. Esta red desarrolla un Programa de certificación participativa, promueve los mercados locales, la capacitación, encuentros y trabaja en incidencia en políticas públicas (Red de Agroecología, 2006).

Como producto de un taller sobre comercialización de productos ecológicos, con la participación de agricultores/as y personas vinculadas a la comercialización, 
procesamiento, consumidores/as y técnicos/as, es posible derivar un diagnóstico del sector y propuestas, desde la visión de los actores (Red de Agroecología, 2016).

\section{Debilidades}

Hay consenso en que la falta de oferta es un problema para el desarrollo de canales comerciales, dado que provoca que no se logre continuidad en la oferta y frena el crecimiento o la apertura de nuevos canales. Hay pocos productores/ as, muchas veces dispersos y poca escala de producción.

Se señalan también problemas de calidad, sobre todo con los supermercados, que son más exigentes.

Aparecen otros problemas como la competencia de productos no certificados, la demora de los pagos en supermercados, la dificultad de establecer vínculos más directos con la población consumidora en los supermercados. También se analiza que productores y productoras están bastante involucrados con la comercialización, lo que tiene aspectos positivos pero es difícil mantener un equilibrio entre esta actividad y los requerimientos de trabajo en los predios.

La alienación dentro del sistema capitalista, vista tanto desde el punto de vista de las personas consumidoras, como productoras se señala como una debilidad interna por la "incapacidad" de cambiarlo y a la vez como una amenaza externa que determina qué y cómo producir ; qué y cómo consumir, dado que las personas desde esa situación, no reconocen los procesos y personas involucradas en la producción de alimentos así como tampoco se vinculan entre sí para desarrollar experiencias de cooperación o estrategias de cambio.

\section{Fortalezas}

El aumento de la demanda se vizualiza también como una fortaleza, por las oportunidades que genera. También el vínculo más directo con la población consumidora y las relaciones de confianza que se establecen. La diversidad de productos y de canales, la capacidad de fijar precios con cierta estabilidad, los avances en la calidad y otros aspectos como el agregado de valor con mano de 
obra familiar en los packing o el compromiso de productores / as y de algunos sectores de consumidores y consumidoras, se ven también como aspectos positivos

\section{Propuestas}

Se proponen iniciativas diversas en las siguientes áreas: mejorar el vínculo entre productores/as y consumidores/as, aumentar la oferta, desarrollar políticas públicas, aumentar y mejorar los canales comerciales, trabajar en calidad, planificación y precios y fortalecer los mecanismos de cooperación internos que brinda la Red. En el marco de fortalecer las iniciativas dentro de la red se plantea promover la creación de nuevos grupos de agricultores y agricultoras, coordinar mejor la comercialización entre grupos y entre regionales, fijar criterios comunes de calidad, envases, hacer una guía de experiencias de comercialización, mejorar la comunicación y la visibilidad. Se identifica la necesidad de abrir nuevos canales y se prioriza y reafirma la importancia de las ferias. Se plantea la necesidad de que los nuevos canales estén adaptados a las posibilidades locales, en particular a la capacidad productiva.

\section{Desafíos}

La agroecología en una de sus definiciones más amplias, ha sido definida como la disciplina que estudia la ecología de los sistemas alimentarios (FRANCIS et al., 2003), ampliando el enfoque desde las interacciones cultivo y ambiente a nivel de una parcela, o del estudio y diseño de agroecosistemas sustentables a nivel predial hasta los paisajes, comunidades y biorregiones sustentables. Dentro de esta concepción la comercialización pasa a ser un elemento clave para el rediseño agroecológico en escalas más amplias, articulando parcela-predio-región y también productores/as- consumidores/as desde el concepto de cercanía, jerarquizando lo local, el relacionamiento directo, la identidad de lo producido y de quien lo produce, posibilitando el conocimiento y control social de la formas de producir, el cuidado del ambiente, entre otros.

La práctica de agricultoras/es ecológicos y sus organizaciones señala que el control de la comercialización es una estrategia compartida y jerarquizada, 
que se mantiene a pesar que compite con los tiempos necesarios para las tareas agropecuarias, que en los establecimientos principalmente familiares muchas veces implica una sobrecarga de trabajo. Incluso el vínculo con los supermercados está bajo el control directo de cooperativas de productores/as que en general han logrado mantener sus marcas en las góndolas. Mientras la oferta sea menor a la demanda, como es la situación actual, aquellos productores y productoras que venden en supermercados pueden esperar mantener estabilidad en el canal, sin embargo, productores/as que no comercializan en forma exclusiva en este canal; es percibido como el riesgo de depender demasiado de las grandes superficies.

En un escenario de demanda potencial elevada en relación a la oferta actual será necesario pensar nuevas estrategias comerciales y productivas, que acompañen un necesario crecimiento de la producción. Las ferias, puntos fijos de venta gestionados por productores/as y otros canales de venta directa o circuitos cortos son priorizados por todas las personas pero están limitados por los tiempos requeridos para su gestión. Una mejor articulación y organización entre productores/as puede ser una opción para desarrollar nuevos canales asignando a aquellas personas con mayor tiempo disponible a dedicarse a la actividad comercial. La profundización de formas de comercialización donde participan activamente la población consumidora puede ser otra vía a explorar.

Varios gobiernos locales están apoyando el desarrollo de la Agroecología, en especial en las zonas más urbanizadas del país. Esto abre posibilidades interesantes de ampliar puntos de venta en espacios públicos, que dependen de las decisiones de las autoridades locales.

El país ha aprobado recientemente una legislación sobre compras públicas que reserva el 30\% del mercado en compras centralizadas y $100 \%$ en compras descentralizadas para las familias agricultoras (LEY 19292, 2014). Si bien no establece diferencias entre producción ecológica y convencional es una oportunidad para grupos de productores/as ecológicos, por ejemplo para promover la descentralización de la producción en el país, en aquellos grupos más alejados del principal mercado consumidor, en el área metropolitana del sur del país.

La existencia de un sello de calidad de certificación participativa, reconocido por las autoridades competentes, legitimado por productores/as y comercializadoras y reconocido por consumidores/as, gestionado por organizaciones sociales, es un recurso valioso que puede ser mejor aprovechado para la difusión y promoción de los alimentos ecológicos. 
Finalmente la propuesta de un Plan Nacional de Agroecología que articule las políticas públicas para el sector con participación de las organizaciones sociales, hoy en discusión en el Parlamento y con buenas posibilidades para que sea aprobado, puede generar mejores condiciones para el desarrollo del sector.

\section{REFERÊNCIAS}

BIDEGAIN, M; GARCÍA PRÉCHAC, F , HILL, M; CLÉRICI, C. La erosión de suelos en sistemas agrícolas. En: GARCÍA PRÉCHAC F, ERNST O, ARBELECHE P, PÉREZ BIDEGAIN M, PRISTCH C, FERENCZI A, RIVAS M. 2010. Intensificación agrícola: oportunidades y amenazas para un país productivo y natural. UDELAR. Montevideo, Uruguay. Disponible en: <http://www.csic.edu.uy/renderResource/index/ resourceId/8589/siteId/3>. Acceso em: 1 jul. 2016.

BONILLA S, SIGNE H, SOMMA A, GRAVIER A, BRITOS A, VIDAL L, DE LEÓN L, BRENA B, PÍREZ M, PICCINI C, MARTÍNEZ DE LA ESCALERA G, CHALAR G, GONZÁLEZ PIANA M, MARTIGANI M, AUBRIOT L. 2015. Cianobacterias y cianotoxinas en ecosistemas límnicos de Uruguay. Revista del Laboratorio Tecnológico del Uruguay. INNOTEC 2015, 10 (9-12).

BRAZEIRO A, ACHKAR M, TORANZA C, BARTHESAGUI L. Potenciales impactos del cambio de uso del suelo sobre la biodiversidad terrestre en Uruguay. En: FERNÁNDEZ-REYES L, RIAL A Y VOLPEDO A (Eds). Efectos de los cambios globales sobre la biodiversidad. CYTED-Conservation International, 2008.

CHIAPPE, M Y PIÑEIRO, D. La agricultura uruguaya en el marco de la integración regional y su impacto sobre la sustentabilidad, 1998. Disponible en: <https:// www.academia.edu/454578/La_Agricultura_Uruguaya_En_El_Marco_De_La_I ntegraci\%C3\%B3n_Regional_Y_Su_Impacto_Sobre_La_Sustentabilidad $>$.

DIEA - MGAP. Censo General Agropecuario. Montevideo. Uruguay, 2011. DIEAMGAP. Anuario estadístico agropecuario 2015.

FRANCIS, C.; LIEBLEIN, G.; GLIESSMAN, S.; BRELAND, T.; CREAMER, N.; HARWOOD, R., y otros. Agroecology: theecology of foodsystems. J. Sustainable Agriculture, 22(3): 99-118, 2003.

GAZZANO I, GÓMEZ PERAZZOLI A, NANSEN K. Plan Nacional de Agroecología: hacia la construcción de una política pública. III Congreso de Ciencias Sociales Agrarias. Facultad de Agronomía, UdelaR, Uruguay, 2016.

GAZZANO, I; GÓMEZ PERAZZOLI, A. Agroecology in Uruguay. Agroecology and Sustainable Food Systems, 2017, vol. 41, no 3-4, p. 380-400. 
GÓMEZ PERAZZOLI, A. Feria de productos orgánicos del Parque Rodó, Montevideo, Uruguay. CEUTA, 2003. Acceso en: 29 set. 2016. Disponible en: <http://www.ceuta. org.uy/files/La_Feria_Organica_del_Parque_Rodo.pdf > .

INTERCONSULT. Estudio de mercado de hortalizas. Requerimientos de consumidores y comercios minoristas de Montevideo, Colonia, Rivera y Santana de Livramento. 2009.

KRUK C, SUÁREZ C, RÍOS M, ZALDÚA N, MARTINO D. Ficha: Análisis Calidad de Agua en Uruguay. Asesoramiento Ambiental Estratégico, Vida Silvestre, IUCN. Montevideo, Uruguay. 2013.

MGAP, Servicios Agrícolas Datos estadísticos de productos fitosanitarios. Disponible en: <http://www.mgap.gub.uy/portal/page.aspx?2,dgsa,dgsa-serviciosdatos-estadisticos-de- importaciones, $\mathrm{O}$,es, $0>$. Consultado en: 15 maio 2016.

PAOLINO, C., MONDELLI, M.Especialización agrícola yagroindustrial en Uruguay: ¿maldición o bendición? ANUARIO 2012 - OPYPA, 2013.

Poder Legislativo del Uruguay. Ley 19291. Producción familiar agropecuaria y pesca artesanal, 2014.

RED DE AGROECOLOGÍA. Manual operativo y guía para la formación. 2006. Disponible em: <http://redagroecologia.uy/wp-content/uploads/2014/12/manualoperativo.pdf $>$. Acceso en: 29 de setiembre 2016.

RED DE AGROECOLOGÍA. Informe de Taller de Comercialización, 2016.

ROSANO, L. Recetario de frutos nativos del Uruguay. 2012. Disponible en: <http:// www.verdeoliva.org/documento/recetario4.pdf>. Acceso en: 29 set. 2016.

SORIANO FRAGA, G. Productos orgánicos: análisis del mercado montevideano y oportunidades para el sector. Unidad de Montevideo Rural. Intendencia de Montevideo, 2012. Disponible en: <http://www.montevideo.gub.uy/sites/default/files/ produccion_agroecologica.pdf.>. Acceso en: 29 set. 2016.

TISCORNIA G, ACHKAR M, BRAZEIRO, A. Efectos de la intensificación agrícola sobre la estructura y diversidad del paisaje en la región sojera de Uruguay Ecología Austral 212-219, Agosto de 2014 Asociación Argentina de Ecología Uruguay. 2014. Decreto 557-2008: 17/11/2008: Creación del sistema nacional de certificación de la producción orgánica. Disponible en: <www.impo.com.uy/bases/decretos/557-2008>. Acceso en: 1 jul. 2016. 


\section{AUTORES}

Adriana Machado es ingeniera agrónoma por la Universidad de la República (UdelaR). Uruguay. Becaria de la Agencia Nacional de Investigación e Innovación (ANII) para la Maestría en Ciencias Agrarias opción Ciencias Sociales. Coordina el área de Facilitación de Comercio, en el Departamento de Ruralidad del Ministerio de Desarrollo Social (MIDES). adrianapmt@gmail.com

Alberto Gómez Perazzoli es ingeniero agrónomo, magíster en Desarrollo Rural Sustentable. Núcleo interdisciplinario Colectivo TA, Impactos de la intensificación de los sistemas agroalimentarios y Agroecología. Universidad de la República, Uruguay. Integrante de la Red de Agroecología del Uruguay y del Centro Uruguayo de Tecnologías Apropiadas (CEUTA). a.gomezperazzoli@gmail.com

Alejandro Pizzolon es ingeniero agrónomo, actualmente cursando maestría en Desarrollo Rural Sustentable en la Facultad de Agronomía de Uruguay. Es docente del area de gestión de empresas en el departamento de ciencias sociales de la misma universidad. Trabaja además como consultor en comercialización y gestión de empresas asociativas en organizaciones de productores y proyectos en instituciones públicas.apizzolon@gmail.com

Aline Luiza Führ é nutricionista, graduada pela Universidade Federal da Fronteira Sul (UFFS); residente em Saúde da Família pela Universidade Federal da Integração Latino-Americana (UNILA). alineluizafuhr@gmail.com

Altivo Roberto Andrade de Almeida Cunha é engenheiro agrônomo, doutor em Economia pela Universidade Estadual de Campinas; Pesquisador visitante do Centro de Desenvolvimento e planejamento regional da Universidade Federal de Minas Gerais (UFMG) e Consultor da Food And Agriculture Organization (FAO).

altivo.cunha@gmail.com

Analia Cartele es ingeniería agronomica y tecnicatura agropecuaria de Produccion Familiar en curso. Trabaja en la Red de Agroecologia del Uruguay, especializada en certificación con sistemas participativos de garantias. Docente de facultad de agronomia (UdelaR) e integrante de colectivos vinculados al desarrollo rural y Agroecologia. analiacartelle@hotmail.com 
André Michelato Ghizelini é sociólogo, doutor em Sociologia pela Universidade Federal do Paraná. Professor do Curso de Ciências Sociais da Universidade Federal do Espírito Santo. andremichelato@gmail.com

Camila Elizandra Rossi é graduada, mestra e doutoranda em Nutricão (Doutorado previsto para término em julho de 2018), pela Universidade Federal de Santa Catarina. Atua na área de Nutrição em Saúde Coletiva, especialmente com as temáticas de epidemiologia do excesso de peso corporal e Políticas Públicas em Alimentação em Nutrição.camilarossi@uffs.edu.br

Carla Rosane Paz Arruda Teo é nutricionista, doutora em Ciências de Alimentos pela Universidade Estadual de Londrina, com pós-doutorado em Nutrição em Saúde Pública pela Universidade de São Paulo. Docente Permanente do Programa de Pósgraduação em Ciências da Saúde da Universidade Comunitária da Região de Chapecó. Desenvolve estudos sobre políticas e programas de alimentação e nutrição, segurança alimentar e nutricional, agricultura familiar. carlateo@unochapeco.edu.br

Carmine Piano dos Santos é nutricionista pela Universidade Federal da Fronteira Sul (2016). Atua como nutricionista no município de Cruzeiro do Iguaçu-PR como coordenadora do Núcleo de Apoio Saúde da Família (NASF) e responsável técnica (RT) da alimentação escolar. carminepiano@gmail.com.

Cassiani Gotâma Tasca é doutoranda no Programa de Pós-Graduação em Nutrição (PPGN/UFSC) desde 2015. Mestre em Nutrição (UFSC, 2007), especialista em Docência para o Ensino Superior pela Universidade do Sul de Santa Catarina (UNISUL, 2009), graduada em Nutrição pela Universidade do Vale do Itajaí (UNIVALI, 2003). Atualmente é professor assistente I da Universidade Federal da Fronteira Sul (UFFS) Campus Realeza-PR. Atua na área de Alimentação Coletiva, com ênfase nas dimensões sensorial, higiênico-sanitária, regulamentar e sustentável.

cassianigotama@yahoo.com.br

Cecilia Rocha é doutora em Economia pela York University, Canadá; professora e diretora da Escola de Nutrição da Ryerson University, Toronto, Canadá, e membro do IEPS-Food. crocha@ryerson.ca

Cimone Rozendo é socióloga, doutora em Meio Ambiente e Desenvolvimento pela Universidade Federal do Paraná, professora dos Programas de Pós-Graduação em Desenvolvimento e Meio ambiente e Ciências Sociais da Universidade Federal do Rio Grande do Norte. cimone.rozendo@gmail.com

Claire Lamine é Socióloga, PhD, Pesquisadora do Institut National de la Recherche Agronomique (INRA) Ecodévéloppement, Avignon - França. claire.lamine@inra.fr

Denise Boito Pereira da Silva é engenheira agrônoma, doutoranda em Administração de Organizações pela Faculdade de Economia, Administração e Contabilidade de Ribeirão Preto (FEA-RP). denise_bps@hotmail.com 
Dienifer Heckler é engenheira florestal pela Universidade Federal de Santa Maria (2016) e atua nas áreas de gestão ambiental, extensão e desenvolvimento rural. dieniferheckler@gmail.com

Elsa Barbosa Simões é licenciada em Agronomia pela Universidade Estadual da Louisiana nos Estados Unidos, mestre em Gestão da Qualidade e Marketing Agroalimentar pela Universidade de Évora em Portugal, candidata ao Doutorado em Ciências Agrárias e Ambientais na mesma universidade, é docente na Escola de Ciências Agrárias e Ambientais da Universidade de Cabo Verde. simoeselsa@hotmail.com

Federico Bizzozero es ingeniero agrónomo por la Universidad de la Republica (UdelaR). Coordina el programa de Agroecología del Centro uruguayo de Tecnologías Alternativas (CEUTA), integrado por un equipo de profesionales en la materia. El área de Cursos contiene un programa de 20 cursos clave en los ejes de Agroecología y Energía. fbizzozero@gmail.com

Gilles Maréchal é economista e consultor da Terralim e Pesquisador Associado do Centre National de la Recherche Scientifique (CNRS), Rennes - França. gilles. marechal@terralim.fr

Ines Gazzano es ingeniera agrónoma Universidad de la República Uruguay (UdelaR). MSc en Agroecología y Desarrollo Rural Sostenible - Universidad Internacional de Andalucía - España. Dra en Recursos Naturales y Sostenibilidad. Universidad de Córdoba - España. Profesora Agregada Grupo Agroecología del Departamento de Sistemas Ambientales de la UdelaR. Integrante de la Sociedad Científica Latinoamericana de Agroecología (SOCLA). igazzano@gmail.com

Jorge Vaz Tourem es licenciado en Ciencias Sociales, aspirante a Magister en Demografía y Estudios de Población por la Facultad de Ciencias Sociales de la Universidad de la República (UdelaR). Responsable del Departamento de Ruralidad del Ministerio de Desarrollo Social (MIDES) de Uruguay. jorvaztourem@gmail.com

José Giacomo Baccarin é livre docente em Desenvolvimento Agroindustrial e Política Agrícola pela Universidade Estadual Paulista (UNESP), campus de Jaboticabal; doutor em Engenharia de Produção pela Universidade Federal de São Carlos (2005); mestre em Economia Agrária pela Universidade de São Paulo (1985), campus de Piracicaba. Graduado em Agronomia pela Universidade Estadual Paulista Júlio de Mesquita Filho (UNESP), campus de Jaboticabal (1979). baccarin@fcav.unesp.br

Julian Perez-Cassarino é engenheiro florestal, doutor em Meio Ambiente e Desenvolvimento pela Universidade Federal do Paraná (UFPR). Professor do Campus Laranjeiras do Sul, da Universidade Federal da Fronteira Sul (UFFS), e dos Programas de Pós-Graduação em Agroecologia e Desenvolvimento Rural Sustentável (UFFS) e Meio Ambiente e Desenvolvimento (UFPR). julian.cassarino@uffs.edu.br 
Juliana Gonçalves é graduada em Administração de Empresas pelo Mackenzie e pós-graduada em Política e Relações Internacionais pela FESPSP; foi coordenadora de projetos no Instituto Kairós, atuando em temáticas como economia solidária, agroecologia e consumo responsável. Atualmente é gestora no Programa Jovens Urbanos do CENPEC. julianagoncallves@yahoo.com.br

Laércio Meirelles é engenheiro agrônomo pela Universidade Federal de Viçosa (UFV/1987). Há trinta anos desenvolve trabalhos de assessoria e formação em Agricutura Ecologica através do Centro Ecológico, ONG com atuação local na serra gaúcha e no litoral norte do RS e Sul de SC. laerciomeirelles@gmail.com

Marcia Pozzagnol é nutricionista, mestre em Ciências da saúde pela Universidade Comunitária da Região de Chapecó (Unochpaecó). Atua como nutricionista. marciapozzagnol@unochapeco.

Moacir Roberto Darolt é agrônomo, doutor em Meio Ambiente e Desenvolvimento Rural pela Universidade Federal do Paraná e Université Paris VII, pesquisador do Instituto Agronômico do Paraná (IAPAR) e professor da Universidade Federal do Paraná - UFPR. darolt@iapar.br

Nilson Maciel de Paula é graduado em Economia pela Universidade Federal do Paraná (UFPR/1976), Mestrado em Desenvolvimento, Agricultura e Sociedade pela Universidade Federal Rural do Rio de Janeiro (1983), Doutorado em Economia University College London (1991) e Pós Doutorado na University of Reading, UK (1999). Atualmente é professor sênior do Programa de Pós-Graduação em Políticas Públicas da UFPR. nilson@ufpr.br

Oscar Agustín Torres Figueredo é engenheiro florestal, doutor em Desenvolvimento Rural pela Universidade Federal do Rio Grande do Sul; professor associado do Departamento de Engenharia Florestal da Universidade Federal de Santa Maria, Campus Frederico Westphalen (UFSM/FW). ostorres28@yahoo.com

Panmela Soares é doutora em Ciências da Saúde pela Universidade de Alicante, Espanha. Integrante do Núcleo de Pesquisa de Nutrição em Produção de Refeições (NUPPRE) da Universidade Federal de Santa Catariana e do grupo de pesquisa de Saúde Pública da Universidade de Alicante. Professora Associada da Universidade de Alicante, departamento de "Enfermería comunitaria, medicina preventiva y salud pública e historia de la ciencia”. panmela.soares@ua.es

Rafaela Karen Fabri é graduada em Nutrição pela Universidade Federal do Paraná, mestre e doutoranda em Nutrição pelo Programa de Pós-Graduação em Nutrição da Universidade Federal de Santa Catarina. rafaela.kfabri@gmail.com

Rozane Marcia Triches é nutricionista, doutora em Desenvolvimento Rural pela Universidade Federal do Rio Grande do Sul; professora do Programa de Pós-Graduação em Agroecologia e Desenvolvimento Rural Sustentável da Universidade Federal da Fronteira Sul (UFFS).rozane.triches@uffs.edu.br 
Suélen Regina Lothermann é nutricionista, graduada pela Universidade Federal da Fronteira Sul (UFFS). suh_rl@hotmail.com

Suellen Secchi Martinelli possui graduação em Nutrição e Matemática - Licenciatura Plena pela Universidade Estadual do Centro-Oeste. Mestre e Doutora em Nutrição pelo Programa de Pós-Graduação em Nutrição da Universidade Federal de Santa Catarina. Professora no Departamento de Nutrição da Universidade Federal de Santa Catarina (UFSC). suellen.martinelli@ufsc.br

Suzi Barletto Cavalli é nutricionista, Mestre em Extensão Rural (UFSM) e Doutora em Alimentos e Nutrição (UNICAMP). Pós-Doutorado em Nutrição (Universidade de Buenos Aires - UBA, Argentina). Professora Associada do Departamento de Nutrição da Universidade Federal de Santa Catarina (UFSC), atuando na Graduação, no Mestrado e Doutorado em Nutrição. suzi.cavalli@ufsc.br

Thais Mascarenhas é mestre em Educação pela Universidade de São Paulo e bacharel em Ciências Econômicas pela mesma universidade; é coordenadora de Projetos no Instituto Kairós, atuando com os temas da economia solidária, autogestão, agroecologia, agricultura familiar, comércio justo e solidário e consumo responsável.

thaismas@yahoo.com

Vanessa Ramos Kirsten é nutricionista, doutora em Saúde da Criança e do Adolescente pela Universidade Federal de Santa Maria; professora do Departamento de Alimentos e Nutrição da Universidade Federal de Santa Maria (UFSM) e do Programa de PósGraduação em Gerontologia da UFSM. kirsten.vr@gmail.com

Vitória Uliana Bianchini é nutricionista pela Universidade Federal de Santa Catarina. Mestre em Nutrição pelo Programa de Pós-Graduação em Nutrição da Universidade Federal de Santa Catarina (UFSC). vitoriabianchini_@hotmail.com

Vladmir Silves Ferreira é doutor em Ciências Sociais pela Universidade de Cabo Verde, em parceria com a Universidade Federal do Rio Grande do Sul, Brasil. Vogal do Conselho Directivo, docente e pesquisador na Escola Superior de Ciências Agrárias e Ambientais. Actua na área de Sociologia com ênfase em Sociologia Rural e do Desenvolvimento.vladmir.ferreira@adm.unicv.edu.cv

Walter Belik é professor titular aposentado de Economia Agrícola do Instituto de Economia da Unicamp. Doutor em Economia com estágio de Pós-Doutorado no IILAS, University College, Inglaterra e no Departamento de Agricultura \& Economia dos Recursos Naturais da UC, Berkeley. Foi membro do CONSEA e coordenador da Iniciativa América Latina e Caribe sem Fome da FAO. Na Unicamp, atuou como coordenador do Núcleo de Estudos e Pesquisas em Alimentação (NEPA) da UNICAMP por cinco anos.belik@unicamp.br 
(...) cabe aos estudiosos da questão alimentar e representantes dos movimentos sociais não apenas identificar criticamente os determinantes da insegurança alimentar e as estratégias de usurpação, pelos agentes dominantes, de bandeiras e proposições alternativas. Mais do que isso é preciso desvendar perspectivas que emergem da sociedade civil e de instituições envolvidas na construção de uma via alternativa que se materialize numa agenda sólida de segurança alimentar desafiadora e capaz de mitigar os efeitos nocivos da ordem alimentar atual. A organização deste livro é uma iniciativa de grande relevância nessa perspectiva, por colocar o tema do abastecimento alimentar sob uma ótica que difere das abordagens convencionais voltadas para a organização dos mercados, posição dos agentes comerciais, e para a conexão mercantil entre produtores e consumidores. Ou seja, não se trata de uma discussão sobre as possibilidades de disciplinar ou dar maior eficiência à estrutura atacadista e varejista, mas sobre estratégias e políticas formuladas para atender as populações mais vulneráveis através de redes alternativas, com base nas quais é possível passar ao largo da centralidade dos mercados estruturados sob o comando das grandes corporações.

(Excerto do Prefácio)

Nilson Maciel de Paula

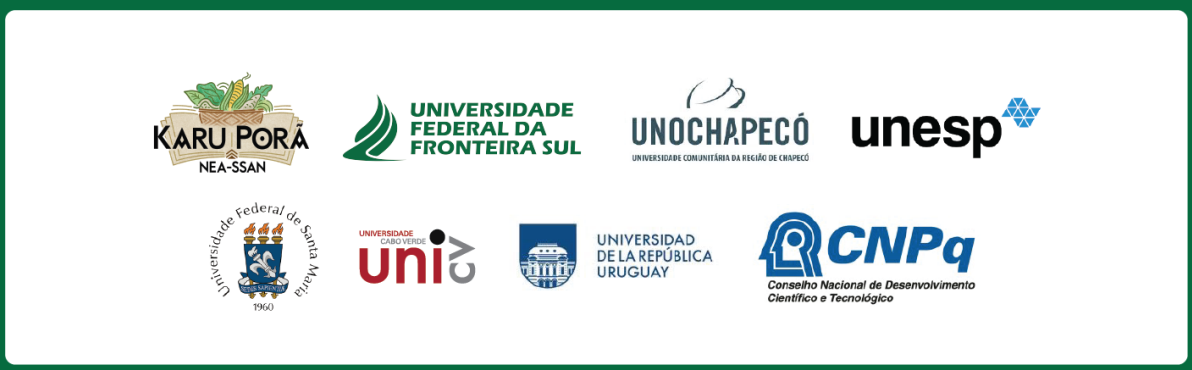

